\title{
Legal Issues for Implementing the Clean Development Mechanism in China
}

\author{
Xiaoyi Jiang \\ A thesis submitted in fulfillment of the degree of \\ Doctor of Philosophy
}

School of Law

University of Western Sydney

Principal Supervisor: Professor Michael Jeffery QC 



\section{Table of Contents}

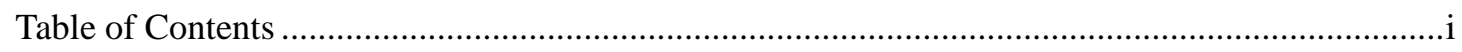

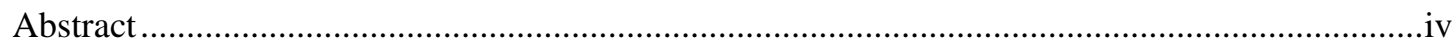

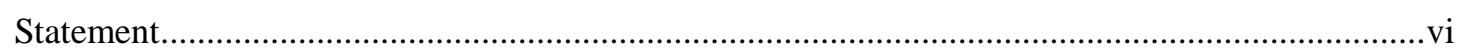

List of Selected Acronyms ...................................................................................................... vii

List of Charts, Tables and Figures....................................................................................... viii

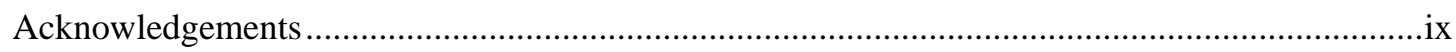

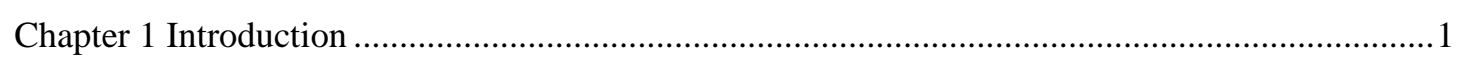

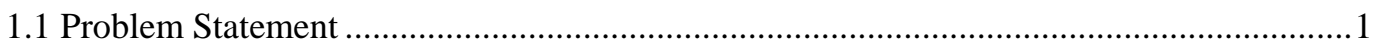

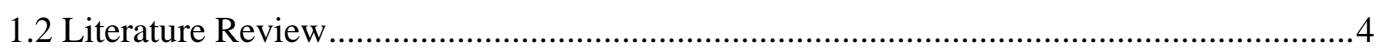

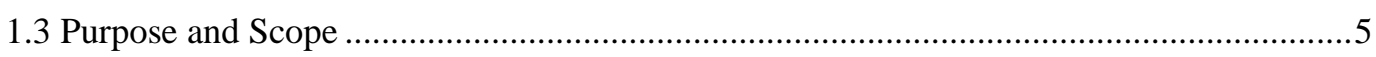

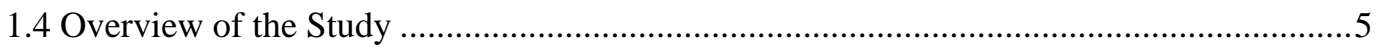

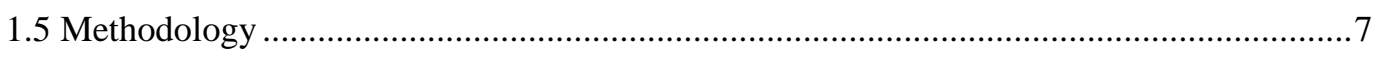

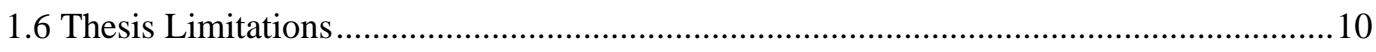

Chapter 2 What the CDM Is and How It Operates: The CDM in an International Context............12

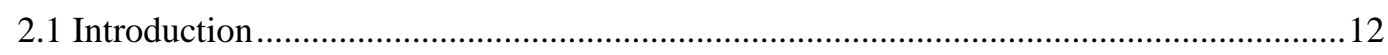

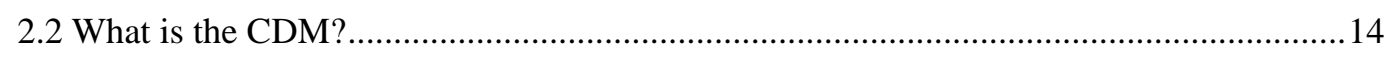

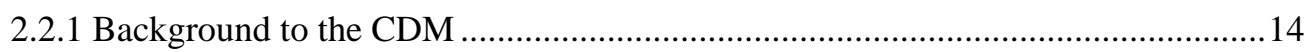

2.2.2 The CDM and Other Two Kyoto Protocol Mechanisms ......................................27

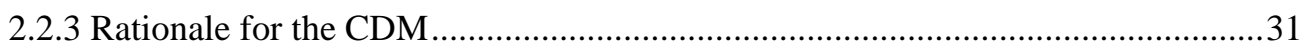

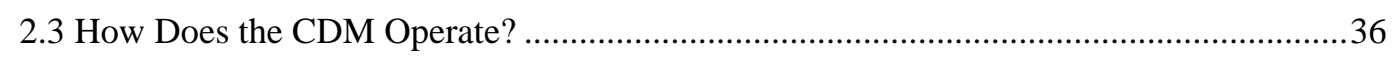

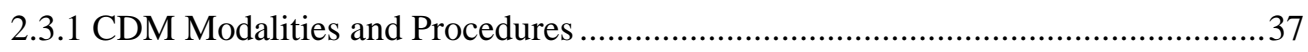

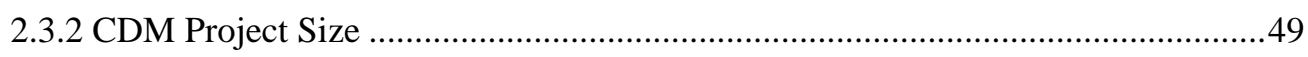

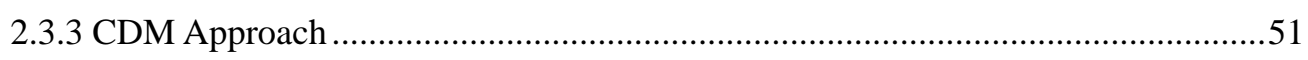

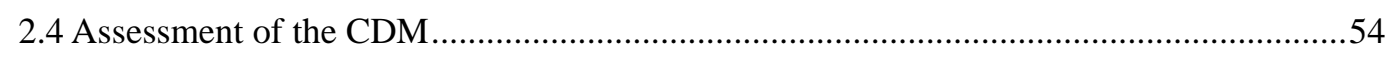

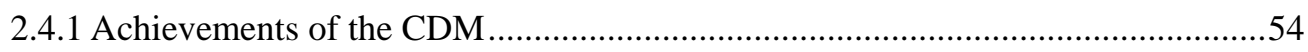

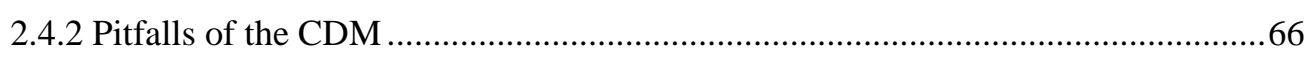

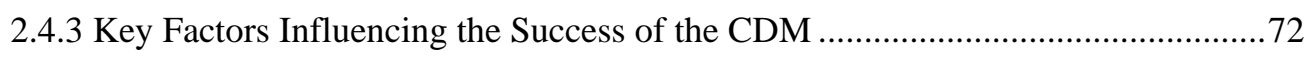

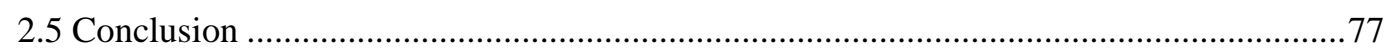

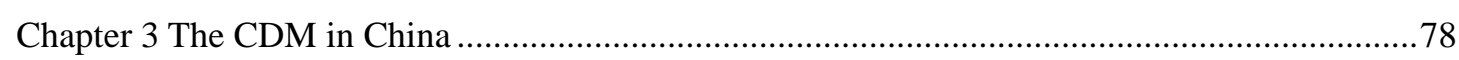

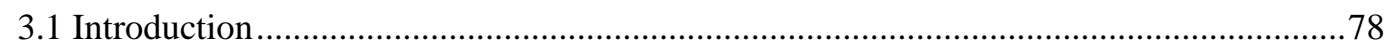

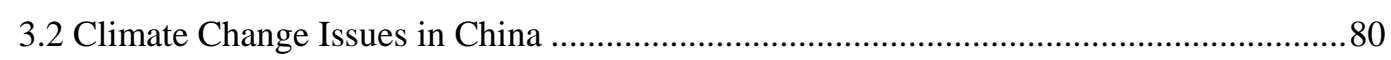

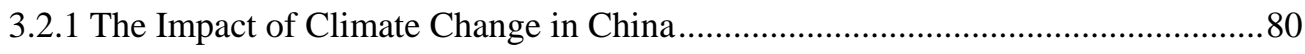

3.2.2 China's Capacity for Addressing Global Warming in a Domestic Context............91

3.2.3 China's Position on Climate Change Issues in an International Context ..............107

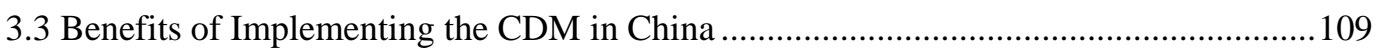

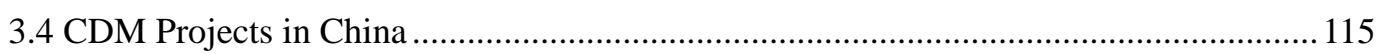

3.4.1 The Development of CDM Projects in China ....................................................116

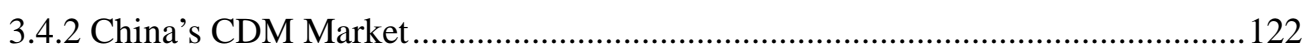

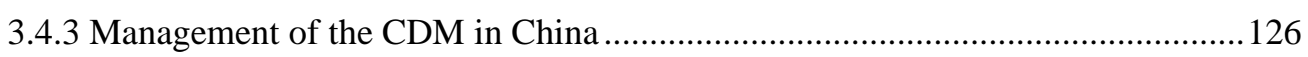

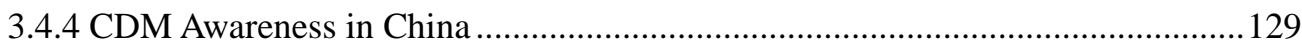

3.4.5 Assessment of the CDM Performance in China ...................................................131 


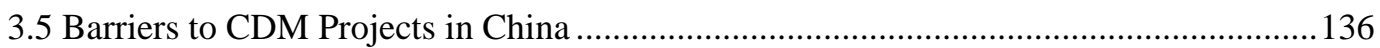

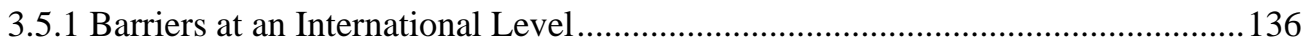

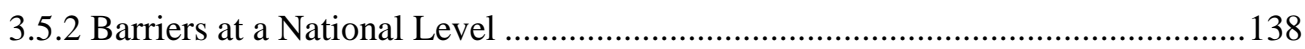

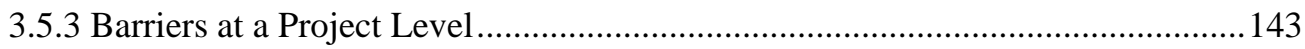

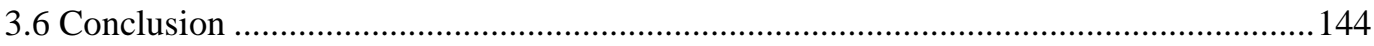

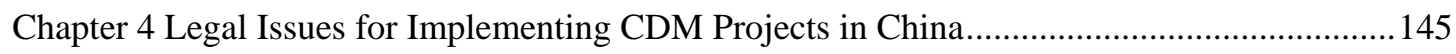

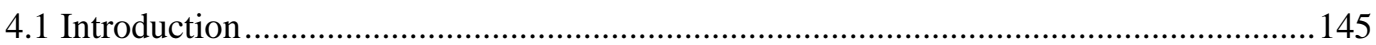

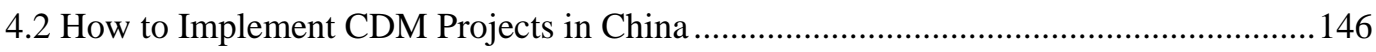

4.2.1 Legal Requirements for CDM Projects in China ..................................................147

4.2.2 Key Legal Entities Involved in CDM Projects in China .......................................148

4.2.3 Legal Steps in Developing CDM Projects in China...........................................151

4.2.4 Regulation Concerning the Proceeds of CDM Projects in China...........................154

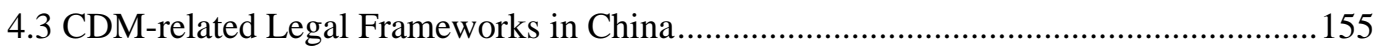

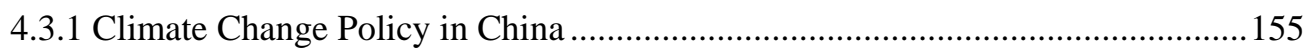

4.3.2 Existing Legislative Framework Supporting the CDM.......................................164

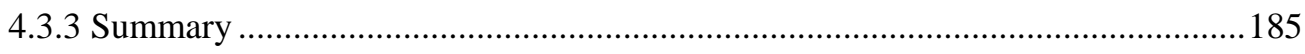

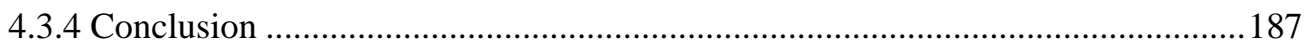

4.4 Enforcement of the CDM-related Laws and Regulations in China.................................188

4.4.1 Institutional Framework of Enforcing the CDM-related Laws and Regulations in

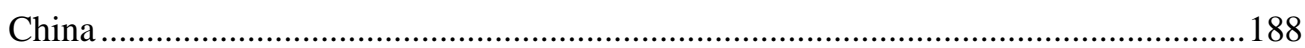

4.4.2 Enforcement Measures of the CDM-related Laws and Regulations ....................200

4.4.3 Analysis of the Enforcement of the CDM-related Laws and Regulations in China

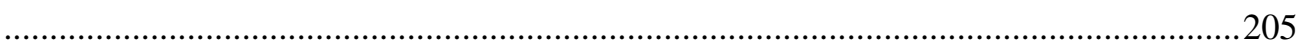

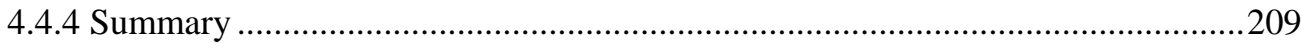

4.5 Research on Legal Issues for Implementing CDM Projects in China...........................210

4.5.1 Legal Relationships Involved in Implementing CDM Projects in China ..............211

4.5.2 CDM-related Contracts ...........................................................................221

4.5.3 Assessing Key Legal Issues for Implementing CDM Projects in China ...............234

4.6 Exploring Potential Risks arising from Implementing CDM Projects under the Legal

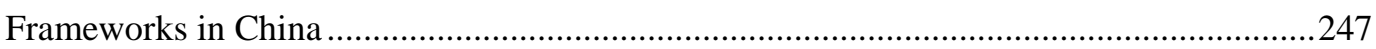

4.6.1 Potential Risks at Different CDM Project Development Stages ..........................248

4.6.2 General Risks in CDM Development in China .................................................257

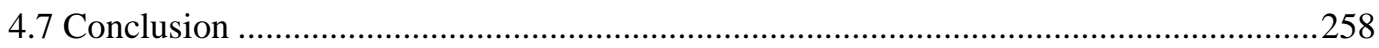

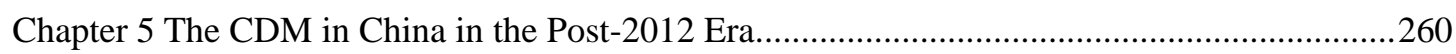

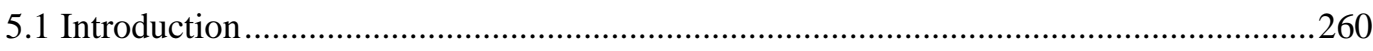

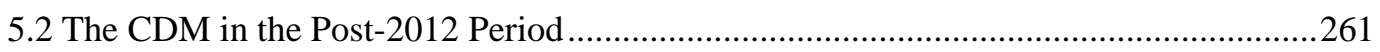

5.2.1 The Proposal under the UN for the Post-2012 Period...........................................261

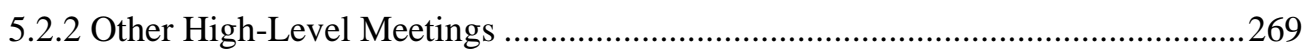

5.2.3 The Tendencies of an International Climate Policy for the Post-2012 Era ..........273

5.2.4 The Fate of the CDM in the Post-2012 Regime ...............................................2278

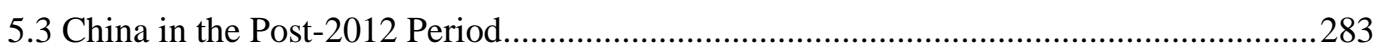

5.3.1 China's Position on the Post-2012 Regime ………............................................2.283

5.3.2 Other Major Countries' Positions on the Post-2012 Regime ................................284

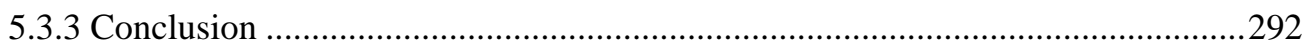


5.3.4 What will the Post-2012 Regime Bring for China?.............................................294

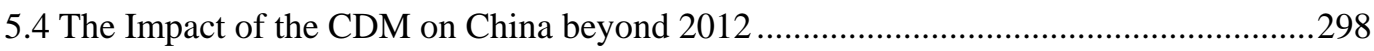

5.4.1 Implications of implementing the CDM beyond 2012 for China.........................298

5.4.2 Limitations of the CDM in Promoting Sustainable Development in China beyond

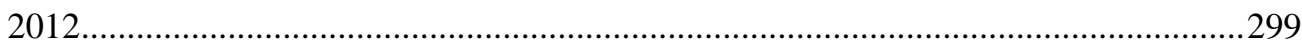

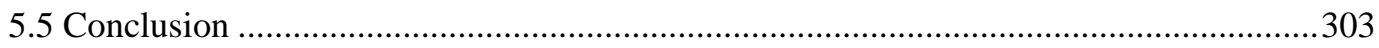

Chapter 6 A Comparative Study on the Implementation of CDM Projects in India.......................304

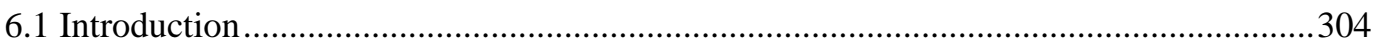

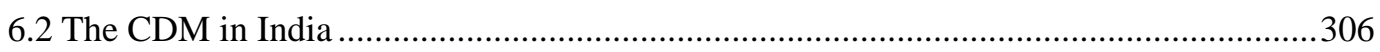

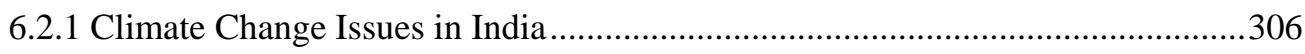

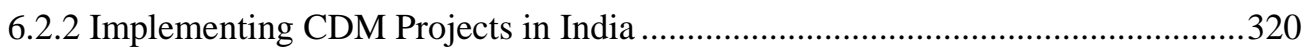

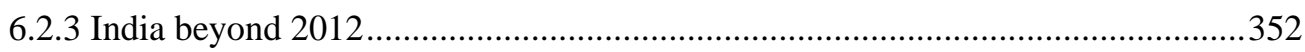

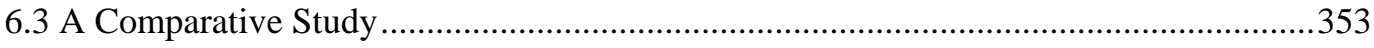

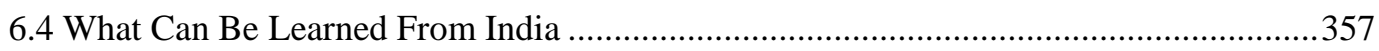

Chapter 7 Conclusion and Recommendations: How Provide for Better Implementation of the

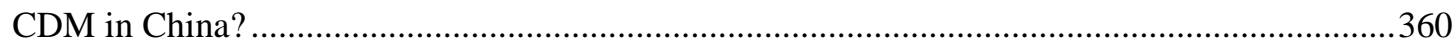

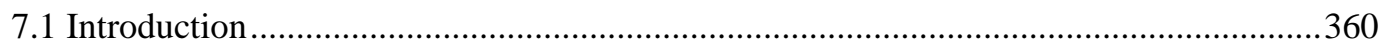

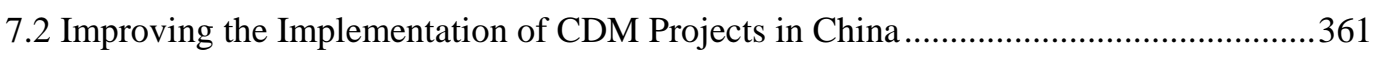

7.2.1 General Requirements for Improving CDM Projects in China .............................362

7.2.2 Managing Risks throughout the Implementation of CDM Projects in China .......365

7.2.3 Overcoming Barriers to the Implementation of CDM Projects in China ..............370

7.3 Dealing with the Limitations of the CDM in Promoting Sustainable Development in

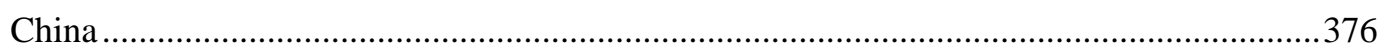

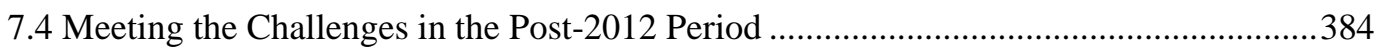

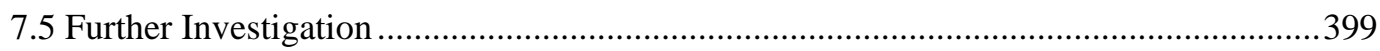

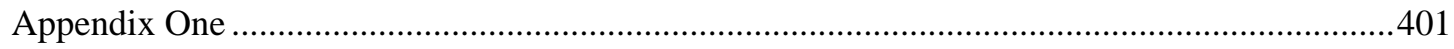

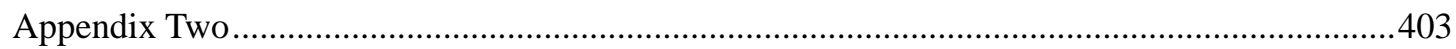

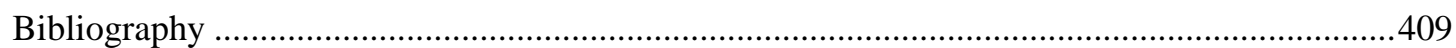




\begin{abstract}
Today, climate change is among the most hotly-debated topics worldwide. The Clean Development Mechanism (CDM), one of the three financial mechanisms under the Kyoto Protocol open to developing and developed countries, was devised to assist in mitigation of global warming. Since it was initiated, thousands of CDM projects have been carried out. China, in particular, with its large carbon emission potential and favourable investment environment, has dominated the global carbon market through participating in CDM projects and has become the largest beneficiary.
\end{abstract}

However, despite the significant benefits the CDM has brought to China, many barriers and problems are still encountered in the practical implementation of CDM projects. Moreover, as the first Kyoto period is set to expire in 2012, China, as a major emitter and developing country, will play a crucial role in combating global warming in the post-2012 period. Therefore, it will be under considerable pressure to reduce carbon emissions without undermining its economic development.

The central aim of this thesis is to discuss what China should do to make full use of the CDM to promote sustainable development and meet the challenge of climate change from a legal perspective. First, how the CDM contributes to sustainable development in China is explored on the basis of the current situation of CDM projects. Following this, the existing barriers and problems encountered in the practical implementation of CDM projects are indentified, based on a field work study. 
Finally, how the CDM would contribute to assisting China in dealing with climate change beyond 2012 is analysed.

Based on this analysis, the thesis comes to a conclusion that the CDM has limitations in promoting sustainable development in China and thus should be regarded only as a complementary instrument in combating climate change. Legal strategies for improving the implementation of CDM projects under the legal framework in China are thus put forward and some proposals for China to meet the challenge of climate change in the post-2012 era are made. 


\section{Statement}

I certify that the work in this thesis entitled Legal Issues for Implementing the Clean Development Mechanism in China has not been submitted for a higher degree to any other university or institution. To the best of my knowledge and belief, this thesis is original and all my own work and contains no copy of work previously published by another person except where otherwise duly acknowledged in the text.

The interview and written survey presented in this thesis were approved by Macquarie University Ethics Review Committee, reference number: HE26SEP2008-D06093 on 26 September 2008.

Xiaoyi Jiang

25 March 2010 


\section{List of Selected Acronyms}

AAU

APEC

APP

AR4

$\mathrm{CO}_{2}$

$\mathrm{CDM}$

CDM EB

CER

CFCs

COP/MOP

DNA

DOE

ERPA

ERU

EU

FDI

GDP

GHG

G77

MEP

MoEF

$\mathrm{NCB}$

NCCCC

NCDMA

NDRC

NGO

NPC

IPCC

JI

ODA

PDD

RMU

SEPA

TRIPS

UN

UNEP

UNFCCC

VER

UNGA

US

WMO

WHO
Assigned Amounts Unit

Asia-Pacific Economic Cooperation

Asia-Pacific Partnership on Clean Development and Climate

IPCC Fourth Assessment Report

Carbon dioxide

Clean Development Mechanism

CDM Executive Board

Certified Emission Reduction

chlorofluorocarbons

Conference/Meeting of Parties

Designated National Authority

Designated Operational Entity

Emission Reduction Purchase Agreement

Emission Reduction Unit

European Union

Foreign Direct Investment

Gross Domestic Product

Greenhouse Gas

Group of 77

Ministry of Environmental Protection (China)

Ministry of Environment and Forests (India)

National CDM Board (China)

National Climate Change Coordinate Committee (China)

National Clean Development Mechanism Authority (India)

National Development and Reform Commission (China)

Non-Government Organization

National People's Congress (China)

Intergovernmental Panel on Climate Change

Joint Implementation

Official Development Assistance

Project Design Document

Removal Unit

State Environmental Protection Administration (China)

Agreement on Trade-related Aspects of Intellectual Property Rights

United Nations

United Nations Environmental Programme

United Nations Framework Convention on Climate Change

Voluntary Emission Credits/Verified Emission Reduction

UN General Assembly

The United States of America

World Meteorological Organization

World Health Organization 


\section{List of Charts, Tables and Figures}

Figure 2.1 An Idealised Model of the Natural Greenhouse Effect 18

Table 2.1 Article 12 of the Kyoto Protocol 30

Chart 2.1 Registered Project Activities by Host Party 55

Chart 2.2 Registered Projects by Region 55

Chart 2.3 Registered Projects by Al and NAI Investor Parties 56

Chart 2.4 CERs Issued by Host Party 56

Chart 2.5 Expected Average Annual CERs from Registered Projects by 57 Host Party

Chart 3.1 Share of Total Primary Energy Supply in 2005 (China) 94

Chart 3.2 China - Electricity Generation by Fuel 2005

Chart 3.3 China's Primary Energy Demand 96

Chart 3.4 China's Energy-related $\mathrm{CO}_{2}$ Emissions 98

Chart 3.5 $\mathrm{CO}_{2}$ Emissions in China 99

Table 3.1 Major CDM Capacity Building Projects in China 117

Table 3.2 CDM-related Management Institutions in China 127

Table 4.1 Legal Steps in Developing CDM Projects in China 151

Chart 6.1 Share of Total Primary Energy Supply in 2005 (India) 318

Chart 6.2 Procedures for Applying for CDM Projects in India 330 


\section{Acknowledgements}

My sincere gratitude goes to my principal supervisor Professor Michael Jeffery QC who provided guidance, advice and insight throughout this project. Professor Michael Jeffery QC is an experienced, responsible and respected supervisor. The successful completion of this project would not have been possible without his invaluable support. The support and encouragement of my associate supervisor, Professor Donna Craig, is also gratefully acknowledged.

I would also like to thank those people who assisted me in conducting fieldwork in China. I thank them for helping me organize the fieldwork and taking time to participate in interviews and written surveys. For confidentiality reasons, I am unable to list their names here, but their cooperation and help are acknowledged.

This work is the result of lasting commitment, continuous encouragement, and patience of my family especially the support of my boyfriend Chunxu Wang and the unconditional dedication of my parents. It was only through their understanding and sacrifice that I have been able to complete this challenging project. They are the most important people in my life. This work is dedicated to them.

Finally, special mention and appreciation goes to those who came into my life during my study in Australia. I am deeply appreciative of them for enriching my life and dispelling my fears and loneliness for being abroad alone. With their company, I can have courage to face the difficulties and challenges in my thesis and life. Just because 
of them, doing a $\mathrm{PhD}$ in Australia has become an experience that can never be forgotten. They are irreplaceable. 


\section{Chapter 1 Introduction}

\subsection{Problem Statement}

The Clean Development Mechanism (CDM) is a 'market-based' mechanism defined in the Kyoto Protocol ${ }^{1}$ to the United Nations Framework Convention on Climate Change (UNFCCC) ${ }^{2}$ as part of the Kyoto response towards mitigation of global warming. Global warming has been described as one of the greatest challenges for the twenty-first century. ${ }^{3}$ For decades scientists have understood the processes by which emissions of carbon dioxide $\left(\mathrm{CO}_{2}\right)$ and other gases might warm the planet through the so-called 'greenhouse effect', nevertheless it was not until the 1980s that international concern about anthropogenic impacts on the atmosphere through such emissions came to a head, and it was only in the last two decades of the twentieth century that the UN took the first steps towards recognizing and addressing the issue. ${ }^{4}$ These first steps led to the conclusion of the 1992 UNFCCC, followed by its innovative 1997 Kyoto Protocol that refines and quantifies the rights and obligations regarding greenhouse gas (GHG) emissions reductions under the UNFCCC. According to the Kyoto Protocol, industrialized countries (Annex I Parties) are assigned legal binding

\footnotetext{
${ }^{1}$ Kyoto Protocol, opened for signature 11 December 1997 (entered into force 16 February 2005). Text of the Kyoto Protocol is available at <http://unfccc.int/resource/docs/convkp/kpeng.pdf > at 9 October 2009.

${ }^{2}$ United Nations Framework Convention on Climate Change, opened for signature 12 June 1992 (entered into force 21 March 1994).

${ }^{3}$ A consensus has been reached from a scientific, political, economic or legal perspective. See, eg, Kevin Watkins et al, Human Development Report of 2007/08: Fighting climate change: Human solidarity in a divided world, United Nations Development Programme (UNDP) Report (2007)

<http://hdr.undp.org/en/reports/global/hdr2007-2008/> at 9 October 2009, and Carolyn Fry, The Impact of Climate Change: The World's Greatest Challenge in the Twenty-first Century (2009).

${ }^{4}$ See David Freestone, 'Introduction: The UN Framework Convention on Climate Change, the Kyoto Protocol and the Kyoto Mechanisms' in David Freestone and Charlotte Streck (ed), Legal Aspects of Implementing the Kyoto Protocol Mechanisms: Making Kyoto Work (2005) 3, 3.
} 
reduction targets for GHG emissions by an average of 5.2 per cent during the first commitment period 2008-2012 below 1990 levels whilst developing countries (non-Annex I Parties) whose paramount task at present stage is the economic development and to get rid of poverty are free of emission obligations during this period.

In order to assist with the massive reductions of GHG emissions necessary to arrest the processes of climate change, three 'financial mechanisms' - Joint Implementation $(\mathrm{JI})^{5}$, Emissions Trading $^{6}$ and the CDM - have been devised under the Kyoto Protocol. With the dual aim of fostering sustainable development in developing countries and helping industrialized countries meet their mandated GHG emission reduction targets cost-effectively, the $\mathrm{CDM}$ is the only mechanism within the Kyoto Protocol open to Contracting Parties classified as industrialized countries and developing countries. In brief, it works in the following way: industrialized countries invest in emission reduction projects undertaken in developing countries through providing financial assistance or clean technology transfer to buy Certified Emission Reduction $(\mathrm{CER})^{7}$ credits. These CERs can be traded and sold, and used by industrialized countries to a meet a part of their emission reduction targets under the Kyoto Protocol. In the meantime, developing countries may obtain economic, environmental and technological benefits from undertaking the CDM projects. Since the CDM was initiated, more than 2,000 projects have been registered worldwide and

\footnotetext{
${ }^{5}$ Joint Implementation is defined in Article 6 of the Kyoto Protocol. For details, see below 28.

${ }^{6}$ Emissions Trading is set out in Article 17 of the Kyoto Protocol. For details, see below 28.

${ }^{7}$ CERs, each equal to one tonne of $\mathrm{CO}_{2}$ and generated from CDM project activities, can be transferred under the rules of the Kyoto Protocol.
} 
it is estimated to produce CERs amounting to more than 2.7 billion tonnes of $\mathrm{CO}_{2}$ equivalent in the first commitment period of the Kyoto Protocol. ${ }^{8}$

As a non-Annex I Party of the Kyoto Protocol, China is eligible to participate in CDM projects. In recent years, China with its large carbon emission potential and favorable investment and legal environments has become the global CDM project centre and has then dominated the global carbon market. Already today, CDM projects launched in China have been responsible for approximately 60 per cent of the total CERs produced under the scheme. ${ }^{9}$ Hence, China has benefited greatly from the CDM. In spite of these benefits, many barriers and problems are still encountered in the practical implementation of CDM projects in China as a result of the complex, time-consuming and technical CDM project operational rules and procedures. On the other hand, although the CDM has brought significant benefits to China, its impact on sustainable development in China in the long term is still uncertain.

In addition, as the first phase of the Kyoto Protocol is set to expire in 2012, the international climate change regime and the CDM will likely be changed in the post-2012 period. China, as a major GHG emitter and developing country, will play an important role in combating global warming in the post-2012 period. It is expected to take on more reduction responsibilities and thus will be under considerable pressure to reduce carbon emissions without undermining its economic development.

\footnotetext{
${ }^{8}$ See UNFCCC <http://cdm.unfccc.int/about/index.html> at 9 October 2009.

${ }^{9}$ See CDM Statistics: CERs Issued by Host Party, UNFCCC

<http://cdm.unfccc.int/Statistics/Issuance/CERsIssuedByHostPartyPieChart.html> at 9 October 2009.
} 
Against this background, it is important to analyse how the CDM contributes to promoting sustainable development in China and to formulate recommendations as to what China should do to make full use of the CDM to promote sustainable development and to meet the challenges of global warming and emission reductions.

\subsection{Literature Review}

An extensive literature has developed covering more than 200 studies on economic, political, methodological, sustainable development and legal aspects of how the CDM has been implemented since 1997. However, there is a dearth of literature that seriously or thoroughly explores the legal issues surrounding the CDM in China. Most earlier overseas studies only apply the 'common but differentiated responsibilities' principle $^{10}$ and cost-effectiveness analysis ${ }^{11}$ to discuss the prospects and pitfalls of the CDM in a global context or from a developing country's perspective. The research on the CDM develops rapidly. Most recent studies analyse the implementation of the $\mathrm{CDM}$ and point out various existing problems from a global perspective rather than in the context of China. In addition, most research on this topic in China does not deal with the topic directly. It still treats these issues in a cautious manner, giving only a general introduction to the background, content, operation and management rules of the CDM and with respect to its implementation in China. Although there are several lawyers with access to the climate change cases who attach great importance to the

\footnotetext{
${ }^{10}$ This principle has been recognized by international community as one of the basic principles in international environmental law. For details, see below 33.

${ }^{11}$ Cost-effectiveness analysis (CEA) is a form of economic analysis that compares the relative costs and outcomes (effects) of two or more courses of action.
} 
concrete legal issues and contractual risks in the CDM in China, they have just identified the existing legal problems without having set forth corresponding solutions in a systematic and comprehensive way. Accordingly, this thesis contributes to addressing this gap.

\subsection{Purpose and Scope}

Based on the above introduction, my thesis will explore how the CDM could be used by China to its benefit from a legal perspective. It should be noted that this study focuses on the legal aspect of implementing the CDM in China in spite of the importance of other aspects that may influence the success of the CDM.

\subsection{Overview of the Study}

In order to logically achieve this purpose, my thesis is divided into seven chapters and several critical issues are identified and addressed in each chapter. Chapter one is an introduction giving an overview of the whole thesis. This chapter introduces a general background to the $\mathrm{CDM}$ and its implementation in China, and then, reviews the relevant literature and states the purpose and scope of the research. The methodology used in the thesis as well as the limitations of the study are also set out.

Chapter two describes what the CDM is and how it operates. It presents the basic background to the CDM and critically analyses the new mechanism in the global context. 
Chapter three discusses the CDM in the context of China. The current situation of the CDM implemented in China is explored and its performance is assessed in accordance with China's national circumstances. In addition, barriers to the CDM development in China are identified.

Chapter four investigates the legal aspects of implementing the CDM in China. Many critical legal issues involved in the implementation of the CDM in China are examined under the current international regulatory framework and Chinese domestic laws and regulations. Following that, the potential project risks under the legal frameworks in China are explored.

Chapter five discusses the CDM in China in the post-2012 period. The challenges of climate change to be faced by China beyond 2012 and the role of the CDM in assisting China in meeting these challenges in the post-2012 period are discussed based on the prospect for climate change regime beyond 2012.

Chapter six conducts a comparative study of the CDM in India as there are many similarities between both India and China with regard to the CDM implementation and its impact and approach to climate change issues due to the fact that India is another major developing country with a large population and a potential source of GHG emissions rivaling China in the near future.

Chapter seven contains the conclusion and recommendations. This chapter starts with a summary of what has been discussed and analysed in the previous chapters, and 
then discusses how to increase the benefits from CDM projects and also to identify ways to improve its implementation and meet the challenges in the post-2012 period in a proactive manner. The stage for further study on the development of CDM on a primarily innovative basis for cooperation between developed and developing countries is also discussed.

\subsection{Methodology}

With a view to successfully completing the thesis, interdisciplinary research methods covering many subjects like legal research, ethical approach, empirical research, statistical analysis and economic perspective, are applied. The causes leading to the emergence of environmental issues are diversified. Conversely, any environmental problems cannot be solved by one method only. For this reason, analysing and settling environmental issues must apply interdisciplinary research methods. Here below are the methods used in thesis.

Historical Study: In the second chapter of thesis, background to and origin of the CDM are reviewed. The historical study enables the author to analyse and discuss the necessity of the CDM from a historical perspective.

Case Study: The CDM is a practical scheme. Hence, it is impossible to gain a comprehensive idea of the real situation surrounding CDM projects in China without case study and field work. In this circumstance, through contacting the people involved in implementation of CDM projects in practice in China, the first-hand 
information, which is essential to accurately identifying the real problems in and barriers to the implementation of CDM projects in practice, may be obtained.

Comparative Study: A comparative study on the implementation of CDM projects in India is conducted. Through this comparative study, the India's experience and lessons in managing and operating CDM projects as well as addressing climate change issues through viable environmental laws and policies could be critically reviewed in order to consider how China could solve its own problems concerning the CDM and climate change.

Statistical Study: Statistical study is an indispensable part of the thesis. A lot of information and data concerning CDM projects are collected. Through statistical study, the underlying regularities, which are essential to developing the thesis, could be obtained from this information and data. Based on these regularities, the problems of the implementation of CDM projects may be identified and solutions may be put forward.

Legal and Economic Study: Knowledge from the disciplines of both Law and Economics are utilised to analyse the nature of the CDM and discuss the possible solutions to the problems of the implementation of CDM projects in China. Cost-effectiveness analysis and cost-benefit analysis are applied to discuss the underlying rationale for the CDM and legal analysis is used to explore the legal nature of the CDM. Only by fully understanding its nature, can it be possible to put forward the corresponding suggestions on addressing the existing problems concerning the 
CDM implementation in China.

In addition, the following approaches are used in the thesis:

Pragmatic Approach: When assessing the performance of the CDM in China, a pragmatic approach is applied. One of the objectives of the CDM is to assist developing countries in achieving sustainable development. Operationally in the methodological literature there seems to be a consensus that sustainable development encompass at least three dimensions: the social, the economic and the environmental. ${ }^{12}$ However, when it comes to practical and concrete assessments of sustainability impacts of $\mathrm{CDM}$ projects, there is no single, authoritative and universally accepted approach or methodology applicable to any CDM project regardless of project type and location. ${ }^{13}$ This is because the actual definitions of what constitutes sustainable development vary according to different countries' national circumstances. Accordingly, the pragmatic approach should be applied to assess the CDM's contribution to sustainable development in the context of China.

Market-based Approach and Interventionist Approach: Both market-based and interventionist approaches are applied to discuss the CDM in this thesis. As for the CDM, both approaches stress the need for a system capable of generating emission reductions, but differ on the best means of achieving this. A market-based approach, based on private sector activities, relies upon healthy competition in a transparent

\footnotetext{
${ }^{12}$ Karen Holm Oslen, 'The Clean Development Mechanism's Contribution to Sustainable Development: A review of the literature' (Publication, Capacity Development for the Clean Development Mechanism, 2006) 6.

13 Ibid 8.
} 
market place to provide the most efficient and effective means of encouraging hosts and investors to conduct CDM project activities. However, an interventionist approach, which is based on traditional public sector development assistance, challenges the private sector's ability to fulfill the CDM's stated purpose of assisting developing countries in achieving sustainable development under the market-based approach. Such an approach emphasizes the need for the active involvement of public sector institutions, including home and host governments and international development institutions in promoting the design of projects driven by broad-based policy concerns rather than market disciplines. ${ }^{14}$ In this thesis, both market-based approach and interventionist approach are used to analyse the development of the CDM in China.

\subsection{Thesis Limitations}

First of all, the limitation of my thesis lies in keeping track of the rapidly evolving international policies on climate change and following the rapid CDM project progress and relevant regulations updates. They are essential but challenging, especially within a limited time and the resources available.

Second, the deficiencies in availability of reliable and updated data concerning the CDM to a limited extent affect the in-depth analysis in the thesis. Although most of the CDM-related data could be gained through the CDM official websites, some of them, especially those concerning the pricing and trading information on specific

\footnotetext{
14 Jacob Werksman, 'The Clean Development Mechanism: Unwrapping the "Kyoto Surprise"', (1998) 7(2) Review of European Community and International Environmental Law 147153.
} 
CDM projects, are confidential. Also, it is difficult to find an authoritative source of statistics about China. Some of the key statistics are not complete or identical and it is difficult to verify the reliability of some available data.

Third, in spite of extensive fieldwork conducted during the studies, it is still a difficult task to obtain a comprehensive picture of the real situation surrounding the implementation of CDM projects in China.

Finally, difficulties are encountered in the field work as any climate change issue is extremely sensitive in China. Most CDM projects involve trade secrets and often the national confidential information concerning energy security and energy resources. Thus, CDM developers and related officials tend to be reluctant to take part in any field study in order to keep the information from being disclosed. Moreover, it is difficult for the author, a full-time $\mathrm{PhD}$ candidate, to contact the actual CDM participants in China. As a result, during the interviews, the respondents were cautious about their comments on any climate change-related issues in China and had discreet replies to the interview questions. 


\section{Chapter 2 What the CDM Is and How It Operates: The CDM in an International Context}

\subsection{Introduction}

The economic development worldwide has brought advanced material progress but has also been responsible for ecological imbalance and environmental pollution. Climate change is considered as one of the most challenging environmental problems in the twenty-first century.

In light of the urgency of addressing climate change issues, the Intergovernmental Panel on Climate Change (IPCC) was established in 1988 with a view to improving the understanding of the extent of anthropogenic causes of climate change and its implications. The IPCC concluded, in its 1990 report, that it is 'certain' that 'emissions (of GHGs) resulting from human activities are substantially increasing the atmospheric concentrations of the greenhouse gases carbon dioxide, methane, chlorofluorocarbons (CFCs) and nitrous oxide,' and that 'these increases will enhance the (naturally occurring) greenhouse effect, resulting on average in an additional warming of the Earth's surface' ${ }^{1}$. Based on the first IPCC assessment report and other scientific studies, the international response to climate change took shape in 1992 with the adoption of the UN Framework Convention on Climate Change (UNFCCC). It sets out a framework for action aimed at stabilising atmospheric concentrations of

\footnotetext{
${ }^{1}$ IPCC 1990 Report, Summary for Policymakers, xi.
} 
GHGs to avoid 'dangerous anthropogenic interference' ${ }^{2}$ with the climate system. In order to ultimately achieve the objective under the UNFCCC, the Kyoto Protocol to the UNFCCC was concluded in 1997. It sets GHGs quantified reduction goals for industrialized countries in the first commitment period 2008-2012 and eventually entered into force in 2005.

The CDM is one of the financial mechanisms incorporated in the Kyoto Protocol, under which advanced countries that invest in GHG reduction projects in developing countries are able to utilise credits for reduced GHG emissions to help achieve their own reduction targets. As an emerging market-based mechanism, the CDM has been implemented worldwide amid considerable criticism about its contribution to reducing GHGs emissions and promoting sustainable development in developing countries.

Against this background, this chapter provides a comprehensive introduction to the $\mathrm{CDM}$ in an international legal context. This chapter is divided into five parts and many soft law documents concerning climate change are examined. Part two focuses on explaining what the CDM is. First, the background to the CDM is introduced in order to provide an overview of the circumstances leading to the inclusion of the $\mathrm{CDM}$ as one of the three financial mechanisms under the Kyoto Protocol. Based on the above introduction, the definition and purpose of the CDM are introduced and the rationale for the CDM is analysed. Part three illustrates how the CDM operates in a

\footnotetext{
${ }^{2}$ See United Nations Framework Convention on Climate Change, opened for signature 12 June 1992, art 2, (entered into force 21 March 1994).
} 
global context. This part elaborates the CDM's international operational rules and procedures and classifications. Part four critically assesses the success of the CDM in a global context. The achievements as well as pitfalls of the CDM are explored. Based on the above, the key factors influencing the success of the CDM are identified.

\subsection{What is the CDM?}

\subsubsection{Background to the CDM}

Climate change has always been a complex and challenging issue. Environmental policy must be based on sound science. Therefore, it is necessary to fully explain objective scientific knowledge about climate change and its impact in order to better understand the plausibility and effectiveness of international policy initiative to address climate change.

\subsubsection{Global Climate Change and Impact}

After recognising the problem of potential global climate change, the IPCC was set up under the auspices of the United Nations Environmental Program (UNEP) and the World Meteorological Organization (WMO) in 1988 to provide an authoritative international statement of scientific understanding of climate change. A main activity of the IPCC is to provide in regular intervals an assessment of the state of knowledge on climate change mainly through peer reviewed and published scientific and technical literature instead of carrying out research or doing it monitor climate related data or other relevant parameters. The IPCC's periodic assessments of the cause, impacts and possible response strategies to climate change are the most 
comprehensive and up-to-date reports available on the subject, and form the standard reference for all concerned with academia, government and industry worldwide. ${ }^{3}$ The IPCC Fourth Assessment Report (AR4), which includes Working Group I ${ }^{4}$ Report ‘The Physical Science Basis', Working Group II Report 'Impacts, Adaptation and Vulnerability' and Working Group III Report 'Mitigation of Climate Change', was released in 2007. By that reason, the scientific conclusions on climate change in this part are mainly introduced according to the latest AR4. ${ }^{5}$

The climate system is a complex, interactive system consisting of the atmosphere, land surface, snow and ice, oceans and other bodies of water, and living things. ${ }^{6}$ The atmospheric component of the climate system most obviously characterises climate. Climate is often defined as 'average weather' and is usually described in terms of the mean and variability of temperature, precipitation and wind over a period of time

\footnotetext{
${ }^{3}$ Susan Solomon et al (ed), Climate Change 2007: The Physical Science Basis (2007), 1.

${ }^{4}$ The IPCC has three Working Groups and a Task Force:

Working Group I assesses the scientific aspects of the climate system and climate change.

Working Group II assesses the vulnerability of socio-economic and natural systems to climate change, negative and positive consequences of climate change, and options for adapting to it.

Working Group III assesses options for limiting greenhouse gas emissions and otherwise mitigating climate change.

The Task Force on National Greenhouse Gas Inventories is responsible for the IPCC National Greenhouse Gas Inventories Program.

${ }^{5}$ It should be noted that although the IPCC report is supposed to be the world's most authoritative scientific account of the scale of global warming, it has been recently subjected to the criticism that the 2007 report overstates the dangers of climate change as a result of use of unreliable evidence. For example, the panel had based claims about disappearing mountain ice on anecdotal evidence in a student's dissertation and an article in a mountaineering magazine. Consequently, the panel was forced to issue a retraction after it emerged statements about the melting of Himalayan glaciers were inaccurate.

<http://www.telegraph.co.uk/earth/environment/climatechange/7177230/New-errors-in-IPCC-climate-change-repo rt.html> at 5 February 2010.

${ }^{6}$ Le Treut, H., R. Somerville, U. Cubasch, Y. Ding, C. Mauritzen, A. Mokssit, T. Peterson and M. Prather, 2007: Historical Overview of Climate Change. In: Climate Change 2007: The Physical Science Basis. Contribution of Working Group I to the Fourth Assessment Report of the Intergovernmental Panel on Climate Change [Solomon, S., D. Qin, M. Manning, Z. Chen, M. Marquis, K.B. Averyt, M. Tignor and H.L. Miller (eds.)]. Cambridge University Press, Cambridge, United Kingdom and New York, NY, USA, 94, 96.
} 
ranging from months to thousands or millions of years (the classical period is 30 years, as defined by the WMO). ${ }^{7}$

Climate change in IPCC refers to a statically significant variation in either the mean state of the climate or in its variability, persisting for an extended period (typically decades or longer). ${ }^{8}$ Over historic time spans there are a number of factors that determine earth's climate. These factors may include the internal dynamics like latitude, altitude, proportion of land to water, and proximity to oceans and mountains. Also, the external factors affecting climate include natural phenomena such as volcanic eruptions and solar variations, as well as human-induced changes in atmospheric composition.

The realisation that Earth's climate change might be sensitive to the atmospheric concentrations of gases that create a greenhouse effect is more than a century old. It was discovered by Joseph Fourier in 1824 and was first calculated by Svante Arrhenius in 1896 that emissions from human industry might someday bring a global warming. However, other scientists dismissed this idea as faulty. In 1939, G.S. Callendar argued that the level of both carbon dioxide and temperature had been rising, but most scientists found his arguments implausible. Until the early 1960s, C.D. Keeling measured the level of carbon dioxide in the atmosphere: it was rising fast. Researchers began to take an interest, struggling to understand how the level of carbon dioxide had changed in the past, and how the level was influenced by chemical

\footnotetext{
${ }^{7}$ Ibid.

${ }^{8}$ Ibid 95 .
} 
and biological forces. Gradually, they found that the GHG plays a crucial role in climate change, so that the rising level could gravely affect our future. ${ }^{9}$

The greenhouse effect is like a partial blanket for the longwave radiation coming from the Earth's surface (See fig 2.1 below). ${ }^{10}$ The Sun powers Earth's climate, radiating energy at very short wavelengths, predominately in the visible or near-visible (e.g., ultraviolet) part of the spectrum. Roughly one third of the solar energy that reaches the top of Earth's atmosphere is reflected directly back to space. The remaining two-thirds is absorbed by the surface and, to a lesser extent, by the atmosphere. To balance the absorbed incoming energy, the Earth must, on average, radiate the same amount of energy back to space. Because the Earth is much colder than the Sun, it radiates at much longer wavelengths, primarily in the infrared part of the spectrum. Much of this thermal radiation emitted by the land and ocean is absorbed by the atmosphere, including clouds, and reradiated back to Earth. The glass walls in a greenhouse reduce airflow and increase the temperature of the air inside. Analogously, the Earth greenhouse effect warms the surface of the planet. Earth's natural greenhouse effect makes life possible as without the natural greenhouse effect, the average temperature at Earth's surface would be below the freezing point of water. However, if the concentration of GHGs ${ }^{11}$ increases, they will absorb more of the outgoing infrared radiation, leading to an enhanced global warming effect.

\footnotetext{
${ }^{9}$ See Spence Weart, The discovery of Global Warming (2009) American Institute of Physics <http://www.aip.org/history/climate/co2.htm> at 10 October 2009.

${ }^{10}$ See Le Treut, above n 6, 115.

11 Water vapour is the most important greenhouse gas, and carbon dioxide is the second most important one. Methane, nitrous oxide, ozone and several other gases present in the atmosphere in small amounts also contribute
} 
Figure 2.1 An Idealised Model of the Natural Greenhouse Effect

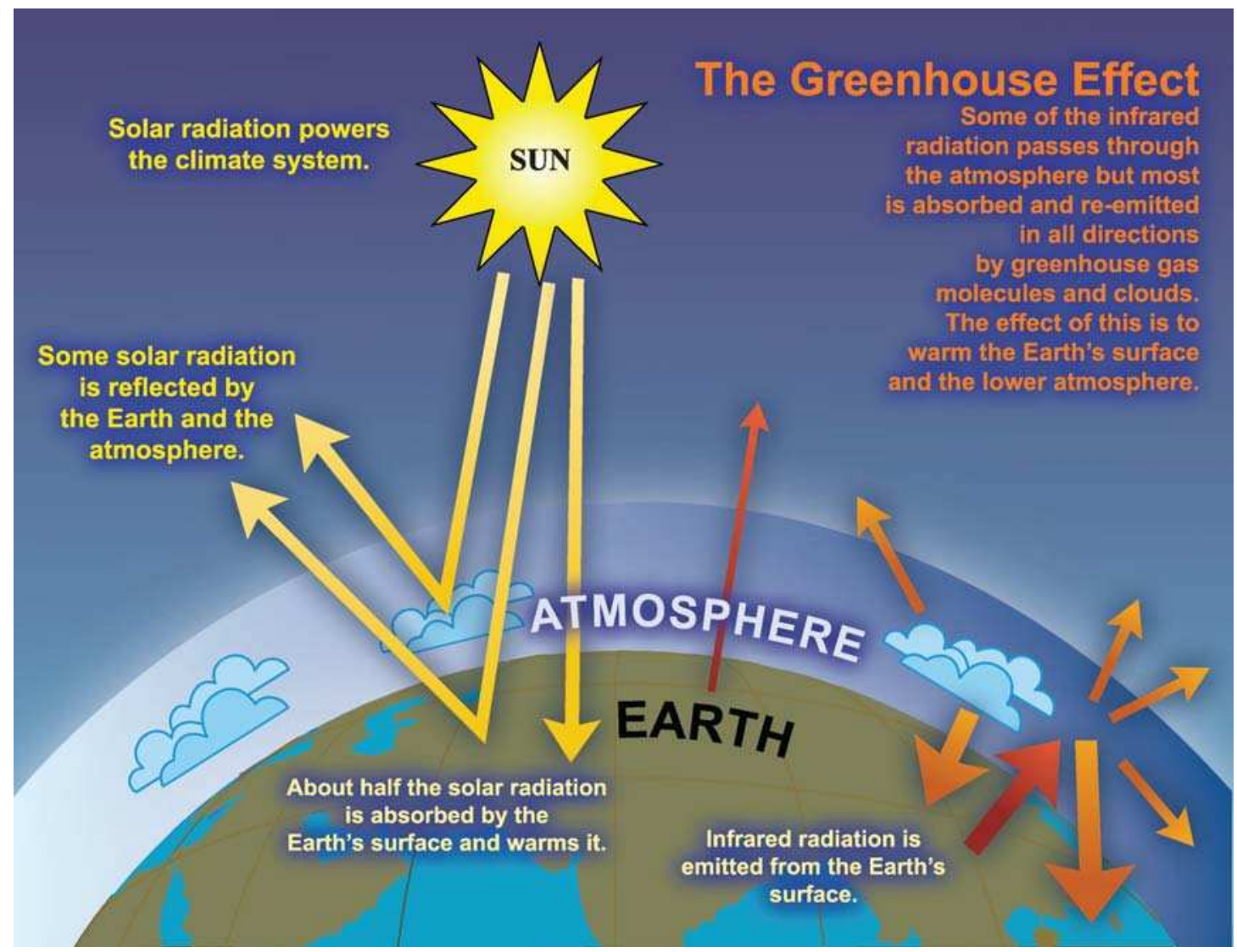

Source of the picture: 2007: Historical Overview of Climate Change. In: Climate Change 2007: The Physical Science Basis.

The term 'global warming' is a specific example of the broader term climate change,

which can also refer to global cooling. The key conclusions of the IPCC AR4 include that:

Warming of the climate system is unequivocal, as is now evident from observations of increases in global average air and ocean temperatures, widespread melting of snow and ice, and rising global average sea level. ${ }^{12}$

For the next two decades, a warming of about $0.2^{\circ} \mathrm{C}$ per decade is projected for a range of SRES ${ }^{13}$ emission scenarios. Even if the concentrations of all greenhouse gases and

to the greenhouse effect.

12 IPCC, 2007: Summary for Policymakers. In: Climate Change 2007: The Physical Science Basis. Contribution of Working Group I to the Fourth Assessment Report of the Intergovernmental Panel on Climate Change [Solomon, S., D. Qin, M. Manning, Z. Chen, M. Marquis, K.B. Averyt, M.Tignor and H.L. Miller (eds.)]. Cambridge University Press, Cambridge, United Kingdom and New York, NY, USA, 5.

${ }^{13}$ It is short for Special Report on Emissions Scenarios. The Special Report on Emissions Scenarios (SRES) was a 
aerosols had been kept constant at year 2000 levels, a further warming of about $0.1^{\circ} \mathrm{C}$ per decade would be expected. ${ }^{14}$

World temperatures could rise by between 1.1 and $6.4^{\circ} \mathrm{C}$ during the 21 st century. ${ }^{15}$

Continued greenhouse gas emission at or above current rates would cause further warming and induce many changes in the global climate system during the 21 st century that would very likely (confidence level $>90 \%$ ) be larger than those observed during the 20th century. ${ }^{16}$

In summary, it is obvious that the global warming is an indisputable phenomenon according to the AR4.

With respect to the causes of global warming, the key conclusions of the IPCC AR4 are as follows:

Global atmospheric concentrations of carbon dioxide, methane and nitrous oxide have increased markedly as a result of human activities since 1750 and now far exceed pre-industrial values determined from ice cores 17 spanning many thousands of years. The global increases in carbon dioxide concentration are due primarily to fossil fuel use and land use change, while those of methane and nitrous oxide are primarily due to agriculture. $^{18}$

Carbon dioxide is the most important anthropogenic greenhouse gas... Most of ( $>50 \%)$ of the observed increase in globally averaged temperatures since the mid-20th century is very likely (confidence level $>90 \%$ ) due to the observed increase in anthropogenic greenhouse gas concentrations. ${ }^{19}$

Discernible human influences now extend to other aspects of climate, including ocean warming, continental-average temperatures, temperature extremes and wind patterns. ${ }^{20}$

Anthropogenic warming and sea level rise would continue for centuries due to the time scales associated with climate processes and feedbacks, even if greenhouse gas

report prepared by the Intergovernmental Panel on Climate Change (IPCC) for the Third Assessment Report, on future emission scenarios to be used for driving global circulation models to develop climate change scenarios, The SRES Scenarios were also used for the Fourth Assessment Report.

14 Above n 12, 12.

15 Ibid 13.

16 Ibid.

${ }^{17}$ Ice core is a cylinder of ice drilled out of a glacier or ice sheet.

18 Above n 12, 2.

19 Ibid.

${ }^{20}$ Ibid 10. 
concentrations were to be stabilised. ${ }^{21}$

Therefore, it can be concluded that global warming is occurring now. The increase of $\mathrm{CO}_{2}$ amounts in the atmosphere as a result of human activities, primarily the burning of fossil fuels and clearing of forests, has greatly intensified the natural greenhouse effect and has caused global warming.

Global warming is confirmed to have had a severe impact on the environment showing in the following three basic physical changes.

First, the most direct consequence of global warming is the higher temperatures. In fact, eleven of the last twelve years (1995-2006) rank among the 12 warmest years in the instrumental record of global surface temperature (since 1850). ${ }^{22}$

Second, global warming also leads to sea level rise. As the earth heats up, sea level rises because warmer water takes up more room than colder water, a process known as thermal expansion. Melting glaciers compound the problem by dumping even more fresh water into the oceans. ${ }^{23}$ The actual facts are demonstrated in the IPCC conclusions that 'there is high confidence $(>80 \%)$ that the rate of observed sea level rise increased from 19th to 20th century, and global average sea level rose at an average rate of $1.8(1.3$ to 2.3$) \mathrm{mm}$ per year over 1961 to $2003{ }^{2}{ }^{24}$

\footnotetext{
${ }^{21}$ Ibid 16.

${ }^{22}$ Ibid 5.

${ }^{23}$ See, eg, The Nature Conservancy, Climate Change Impacts: Rising Seas <http://www.nature.org/initiatives/climatechange/issues/art19621.html> at 10 October 2009.

${ }^{24}$ Above n 12, 6-7.
} 
Third, changes in rainfall patterns are occurring due to the increased evaporation. Global warming is intensifying the circulation of water on, above and below the surface of the Earth, leading to drought in many areas. More intense and longer droughts have been observed over wider areas since the 1970, particular in the tropics and subtropics. ${ }^{25}$ At the same time, lands affected by drought are more vulnerable to flooding once rain falls. The frequency of heavy precipitation events has increased over most land areas, consistent with warming and observed increases of atmospheric water vapour. $^{26}$

In addition, the IPCC AR4 projects the future impact of global warming on the environment and human life.

First, freshwater resources will be influenced. The patterns of river run-off and water availability will vary by different regions, posing a greater threat to water-stressed areas. Moreover, drought-affected and flood-affected areas are likely to increase in the future.

Second, for increases in global average temperature exceeding 1.5-2.5 degrees Celsius and in concomitant atmospheric carbon dioxide concentrations, there are projected to be major changes in ecosystem structure and function, species' ecological interaction, and species' geographical ranges, with predominantly negative consequences for biodiversity, and ecosystem goods and services e.g., water and food supply. ${ }^{27}$

\footnotetext{
25 Ibid 8.

26 Ibid 7.

${ }^{27}$ IPCC, 2007: Summary for Policymakers. In: Climate Change 2007: Impacts, Adaptation and Vulnerability.
} 
Third, globally, the potential for food production is projected to increase with increases in local average temperature over a range of 1-3 degrees Celsius in spite of the fact that the increases in the frequency of droughts and floods are projected to affect local crop production negatively. ${ }^{28}$

Fourth, coasts are projected to be exposed to increasing risks, including coastal erosion, due to climate change and sea-level rise. Many millions more people are projected to be flooded every year due to sea level rise by the $2080 \mathrm{~s}^{29}$

Fifth, in the aggregate, net effects of costs and benefits of climate change for industry, settlement and society tend to be more negative with the greater the change in climate. Where extreme weather events become more intense and more frequent, the economic and social costs of those events will increase, and these increases will be substantial in the areas most directly affected.

Finally, projected climate change-related exposures are likely to affect the health status of millions of people, particularly those with low adaptive capacity, through heat-related illness and disease.

In conclusion, although the implications of the significant changes in the delicate climate system which human depends upon for survival might vary from one region to another, it is certain that global warming is real and mostly human-induced. Under

Contribution of Working Group II to the Fourth Assessment Report of the Intergovernmental Panel on Climate Change, M.L. Parry, O.F. Canziani, J.P. Palutikof, P.J. van der Linden and C.E. Hanson, Eds., Cambridge University Press, Cambridge, UK, 7-22, 11.

${ }^{28}$ Ibid.

${ }^{29}$ Ibid. 
this scenario, irreversible adverse consequences are set to be incurred by global warming, unless a solution is found to effectively address this problem. Presently, humanity already possesses the fundamental scientific, technical, and industrial know-how to solve the carbon and climate problem. ${ }^{30}$ Therefore, it is possible to combat global warming and what much needed is an immediate action.

\subsubsection{International Responses to Climate Change}

The international community has been working together to minimise the risks which would be brought about by climate change through the 1992 convention and its innovative 1997 Kyoto Protocol due to the fact that climate change is universal and all human beings are in some way implicated. The next section provides an overview of the climate regime established by the convention and the key process leading to the adoption of Kyoto Protocol so as to introduce the circumstances leading to the inclusion of the CDM under the Kyoto Protocol.

The international community began to take GHGs and global warming into account in the 1980s. By the late 1980s climate change was already firmly on the international agenda and in 1988 the UN General Assembly (UNGA) passed Resolution 43/53 on the protection of the Global Climate for Present and Future Generations of Mankind. ${ }^{31}$ It declared the issue to be one of 'common concern to mankind' and

\footnotetext{
${ }^{30}$ See especially Stephen Pacala and Robert Socolow, 'Stabilization Wedges: Solving the Climate Problem for the Next 50 Years with Current Technologies' (2004) 13 Science, 968.

${ }^{31}$ Protection of the Global Climate for Present and Future Generations of Mankind, GA Res 43/53, 70 ${ }^{\text {th }}$ plen mtg, UN Doc A/Re/42/53 (1988).
} 
endorsed the establishment of IPCC. ${ }^{32}$ Two years later, in 1990, UNGA Resolution 45/212 established an intergovernmental Negotiating Committee to develop a legal instrument on climate change. ${ }^{33}$ The outcome of a further two years of strenuous negotiations was the 1992 UNFCCC.

The text of the Convention was adopted at the United Nations Headquarters, New York on 9 May 1992; it was open for signature at the Rio de Janeiro from 4 to 14 June 1992, and thereafter at the United Nations Headquarters, New York, from 20 June 1992 to 19 June 1993. By that date the Convention had received 166 signatures. The Convention entered into force on 21 March $1994 .^{34}$ It now enjoys a near universal membership, with 194 countries having ratified.

With an ultimate objective of stabilising GHG concentrations at a level that would prevent dangerous anthropogenic interference with the climate system ${ }^{35}$ and based on common but different responsibilities principle, precautionary principle, cooperation principle and sustainable development principle, both developed and developing countries under the convention accepted a number of general commitments in accordance with their common but different responsibilities, respective capacities and their social and economic conditions.

\footnotetext{
${ }^{32}$ See Protection of the Global Climate for Present and Future Generations of Mankind, GA Res 43/53, 70 ${ }^{\text {th }}$ plen mtg, UN Doc A/Re/42/53 (1988).

${ }^{33}$ David Freestone, 'Introduction: The UN Framework Convention on Climate Change, the Kyoto Protocol and the Kyoto Mechanisms' in David Freestone and Charlotte Streck (ed), Legal Aspects of Implementing the Kyoto Protocol Mechanisms: Making Kyoto work (2005), 3, 3.

${ }^{34}$ See United Nations Framework on Climate Change,

<http://unfccc.int/essential_background/convention/status_of_ratification/items/2631.php> at 10 October, 2009.

35 Ibid.
} 
Under the UNFCCC, all convention parties are required to develop national inventories of anthropogenic emissions by sources and removals by sink of all GHGs and launch national strategies for climate change mitigation and adaptation to expected impact. They would also take climate change into account in their relevant social, economic, and environmental policies; cooperate in scientific, technical, and educational matters; and promote technology transfer, sustainable management, education, public awareness, and the exchange of information related to climate change. ${ }^{36}$

In addition, Annex I countries, which essentially comprise developed countries and economies in transition, committed themselves to adopting policies and measures with the aim of returning their GHG emissions to 1990 levels by the year 2000 and the richest countries shall provide new and additional financial resources and facilitate technology transfer. ${ }^{37}$

The Conference of Parties (COP), which is the supreme body of the Convention, held continued sessions in order to promote and review the implementation of these obligations under the convention.

A major accomplishment of the Convention is that it sets an overall framework for intergovernmental efforts to tackle the challenge posed by climate change. It recognises the fact that the climate system is a shared resource whose stability can be affected by industrial and other emissions of $\mathrm{CO}_{2}$ and other GHGs.

\footnotetext{
36 Ibid.

37 Ibid.
} 
When the Convention was adopted, governments knew that its commitments would not be sufficient enough to seriously tackle climate change. At COP 1 (Berlin, March/April 1995), conference parties therefore launched a new round of talks to address the vagueness of the commitments in the UNFCCC itself and to develop more concrete obligations and a more precise time frame for reducing GHGs emissions produced by the industrialized countries in Annex I. They adopted the 'Berlin Mandate $^{, 38}$ and established a new subsidiary body, the Ad hoc Group on the Berlin Mandate, to draft 'a protocol or another legal instrument' for adoption. After two and a half years' intense negotiations, the Kyoto Protocol was adopted at COP 3 in Kyoto, Japan, on 11 December 1997.

The Kyoto Protocol shares the Convention's objective, principles and institutions, and significantly strengthens the Convention by committing Annex I Parties to individual, legally-binding targets to limit or reduce their GHG emissions within a specific time frame. The individual targets for Annex I Parties are listed in the Kyoto Protocol's Annex B, which add up to a total cut in collective emissions of six $\mathrm{GHGs}^{39}$ by 5.2 per cent from 1990 levels in the commitment period 2008-2012. However, as the legitimate priority needs of developing countries at the current phase are the achievement of sustainable economic growth and the eradication of poverty, they are free of reduction obligations during this period.

\footnotetext{
${ }^{38}$ Report of the Conference of the Parties on its First Session, FCCC/CP/1995/7/Add.1(1995) <http://www.inecc.net/policy-issues/international/Berlin\%20Mandate.pdf> at 7 July 2007.

39 The six gases are to be combined in a 'basket', with reductions in individual gases translated in to ' $\mathrm{CO} 2$ equivalents' that are then added up to produce a single figure.
} 
To assist the Annex I countries in achieving their emission reduction targets, the Protocol incorporated three mechanisms - Joint Implementation, the CDM and Emissions Trading. However, the Protocol only sketched out the basic features of its mechanisms and compliance system due to the complexity of trade-off. A new round of negotiations was therefore launched to flesh out the Kyoto Protocol's rulebook and this round finally culminated at COP 7 in October/November 2001 with the adoption of the Marrakesh Accords, providing a much needed framework of 'guideline, modalities and rules' ${ }^{40}$ for moving forward with implementation of the protocol. Marrakesh Accords, in particular, establish detailed operational guidelines for the CDM, which need to be elaborated through the workings of the CDM Executive Board and the COPs. After strenuous negotiations, the Kyoto Protocol eventually entered into force on 16 February 2005 with 141 countries ratifying it, including the most major industrialized countries - except the United States, Australia and Monaco. ${ }^{41}$ To date, the US is the only industrialized country that has not ratified the Kyoto Protocol.

\subsubsection{The CDM and Other Two Kyoto Protocol Mechanisms}

The Kyoto Protocol, for the first time, sets binding Quantified Emissions Limitation

\footnotetext{
40 The Marrakesh Accords and the Marrakesh Declaration, <unfccc.int/cop7/documents/accords_draft.pdf> at 9 November 2008.

${ }^{41}$ The Article 25 of Kyoto Protocol stipulates that 'This Protocol shall enter into force on the ninetieth day after the date on which not less than 55 Parties to the Convention, incorporating Parties included in Annex I which accounted in total for at least 55 per cent of the total carbon dioxide emissions for 1990 of the Parties in Annex I.' The US which is responsible for about a quarter of the emissions that have been blamed for global warming formally withdrew from the protocol in 2001, claiming it would damage the U.S. economy, and major developing nations like China and India are exempt. After the strenuous negotiations, the Russian Federation eventually ratified the protocol and the Kyoto Protocol went into effect.
} 
and Reduction Objectives (QELROs) for industrial countries' anthropogenic emission by source, and removal by sinks ${ }^{42}$, of GHGs. However, the most innovative aspect of the Protocol may in fact not be these strict commitments but the introduction of the three market-based mechanisms.

Joint Implementation (JI) is defined in Article 6 of the Kyoto Protocol. Under JI, an Annex I Party may implement an emission reduction project or a project that enhances removals by sinks in the territory of another Annex I Party and count the resulting Emission Reduction Units (ERUs) towards meeting its own Kyoto target. The sponsoring governments receive credits that may be applied to their emissions targets; the recipient nations gain foreign investment and advanced technology. Usually, it is cheaper to carry out energy efficiency work in the transition countries, and to realise greater cuts in emissions by doing so.

Emissions Trading, as set out in Article 17 of the Kyoto Protocol, establishes a system of emission rights trading whereby one Annex I country might directly purchase from another Annex I country some of its rights to emit GHGs. The emissions units which can be traded and sold under the Kyoto Protocol's emissions trading scheme may be in the form of: Assigned Amounts Units (AAUs) ${ }^{43}$, or ERUs, CERs and Removal Units (RMUs) ${ }^{44}$.

\footnotetext{
${ }^{42}$ Removal by sinks means removing carbon dioxide from the atmosphere, which could include the sequestering of carbon by land use, land-use change or forestry (LULUCF).

43 AAUs refer to the quantity of GHGs that a Party to the Kyoto Protocol is allowed to release in the global atmosphere as calculated on a yearly basis in Annex B of the proposal.

${ }^{44}$ RMUs are generated by land use, land-use change, and forestry activities such as afforestation or reforestation that sequestrate $\mathrm{CO}_{2}$.
} 
The CDM, which is defined in Article 12 of the Kyoto Protocol (See table 2.1 below), is the only mechanism open to Contracting Parties classified as industrialized countries and developing countries. Deemed as the 'Kyoto Surprise ${ }^{45}$, proposal of the CDM emerged late in the COP 3 negotiations and consensus on the final text developed with unprecedented speed. The CDM is very much a creation of combination of Brazilian proposals concerning the Clean Development Fund (CDF) and various proposals concerning JI. The CDF was a compliance mechanism proposed by Brazil in a meeting of the Ad hoc Group on Berlin Mandate. Under the CDF proposal, Parties who failed to comply with their assigned emissions commitments in a given budget period (2001-2020) were penalised through a requirement to contribute to the $\mathrm{CDF}$. The penalty was to be contributed to a 'non-Annex I clean development fund' for use in funding climate change projects in developing countries to foster sustainable development. The negotiation in Kyoto could be characterized as a struggle that merged the US-backed proposals for projects-based Joint Implementation, and the proposals for CDF, which stress that 'each party included in Annex I to the Convention shall meet its QELROs through domestic actions. ${ }^{46}$ Eventually, the CDM evolved into a mechanism for Annex I countries to gain emissions offsets to achieve their QELROs. Developing countries, however, highlight the CDM's function to assist them in promoting sustainable

\footnotetext{
${ }^{45}$ Raúl Estrada-Oyuela, 'Remarks on From Kyoto to Buenos Aires: Technology Transfer and Emissions Trading' (Speech delivered at a conference held at Columbia University, New York, 24 April 1998). See also Jacob Werkman, 'Unwrapping the Kyoto Surprise' (1998) 7(2) Review of European Community and International Environmental Law 147, 151.

${ }^{46}$ See the negotiating text by the Chairman (NTC) (FCCC/AGBM/1997/3/Add.1 and Corr.1), dated 21 April 1997, prepared by the Chairman, with assistance from the Secretariat, is a comprehensive document reflecting all submissions made by Parties to date and structured in the form of a protocol, and without attribution to the Parties. Para.121.4.
} 
development, and see it as a new channel for financial assistance, investments, technology transfer, and promotion of equity.

Besides the ultimate objective - stabilisation of greenhouse gas concentrations in the atmosphere at a level that would prevent dangerous anthropogenic interference with the climate system - of the Convention, the CDM has two basic aims. The purposes of the CDM shall be to assist Parties not included in Annex I in achieving sustainable development and to assist Parties included in Annex I in achieving compliance with their quantified emission limitation and reduction commitments under Article $3 .{ }^{47}$ In brief, it works in the following way: industrialized countries pay for projects that cut or avoid emissions in developing countries and are awarded credits that can be used to meet their own emissions targets; the developing countries benefit from free infusions of advanced technology and introduction of foreign investment which are essential to sustainable development through implementing eligible CDM projects in their countries.

Table 2.1 Article 12 of the Kyoto Protocol

\begin{tabular}{|l|l|}
\hline Article & Provisions \\
\hline 12.1 & Definition \\
\hline 12.2 & Objectives \\
\hline 12.3 & Transaction between non-Annex I and Annex I countries \\
\hline 12.4 & Governance \\
\hline 12.5 & Basis of the certification of emissions reductions \\
\hline 12.6 & Project finance \\
\hline 12.7 & Auditing and verification \\
\hline
\end{tabular}

\footnotetext{
${ }^{47}$ United Nations Framework Convention on Climate Change, opened for signature 12 June, 1992, art 2, entered into force 21 March, 1994.
} 


\begin{tabular}{|l|l|}
\hline Article & Provisions \\
\hline 12.8 & Administration expenses and adaptation costs \\
\hline 12.9 & Involvement of private and/or public entities \\
\hline 12.10 & Banking of CERs \\
\hline
\end{tabular}

\subsubsection{Rationale for the CDM}

The rationale for the new law must be expressed in terms of its compatibility and continuity with established cultural and legal principles. ${ }^{48}$ The creation of the CDM was also a result of the thought of responsibilities shouldering and benefit sharing among different countries in the international regime. Besides, it is based on established legal principles and embodies economics theory.

(1) Responsibilities shouldering and benefits sharing under the CDM

National interest is the priority in the international regime. Climate change has always been a sensitive issue due to the fact that the emission rights always link to the national interest. As economic development proceeds, it is necessary to generate more electricity, bolster industry and participate in activities seen as adding to emit GHGs. For this reason, some countries are not willing to accept the constrained emission targets as these targets may damage their national economies to a certain extent. However, all the nations around world must work together and make their due efforts to reduce emissions facing the irreversible impacts caused by global warming. In this scenario, how to reasonably allocate responsibilities regarding emission reductions and balance the benefits concerning investment and technology among different countries is a paramount task in climate regime.

\footnotetext{
${ }^{48}$ Roger Cotterrell, Law as an Instrument of Social Change ( $2^{\text {nd }}$ ed, 1992) 59.
} 
Leading from this premise, the most important consideration for developed countries, which mainly account for the current situation of global warming, is to establish a system to achieve GHG emission abatement targets at the lowest cost. In spite of the conclusion of IPCC's report that any changes in global climate patterns will have the most severe impacts on the poorest and most vulnerable sections of society, ${ }^{49}$ developing countries still advocate their responsibilities on climate change issues in terms of the accumulative contribution to global warming and per capita GHG emission levels and wish to seize every opportunity to develop their national economy and advance clean technologies.

The negotiation of the CDM is considered to be a process seeking a win-win strategy to countries' benefits. The Kyoto Protocol recognises the differentiated responsibilities of combating climate change based on historical contributions to emissions and provides legally binding commitments for industrialized countries to reducing their GHG emissions. As the only flexible financial mechanism involving developing countries, the CDM provides an opportunity to share benefits from implementing emission-abatement projects between industrialised countries and developing countries. By developing the CDM, flows of finance and green technologies would enable poorer countries to leapfrog to cleaner and sustainable development and in the meantime, the CDM are aimed to assist developed countries in partially meeting their individual targets in an acceptable and workable way.

\footnotetext{
49 Above n 27, 8.
} 
(2) Underlying legal principles of the CDM

The principle of 'common but differentiated responsibility' evolved from the notion of the 'common heritage of mankind' dating to $1950 \mathrm{~s} .{ }^{50}$ Bearing in mind that humans depend on a healthy climate for their survival, the UN General Assembly went further by recognizing the earth's climate as a 'common concern' of humankind. ${ }^{51}$ The principle recognises historical differences in the contributions of developed nations and developing nations to global environmental problems, and differences in their respective economic and technical capacities to tackle these problems. It includes two fundamental elements. The first one concerns the common responsibility of nations for the protection of the environment, or parts of it, at the national, regional and global levels. The second one concerns the need to take into account the different circumstances, particularly each nation's contribution to the evolution of a particular problem and its ability to prevent, reduce and control the threat. ${ }^{52}$

The principle was therefore suggested by Principle 23 of the 1972 Stockholm Declaration, described succinctly in Principle 7 of the Rio Declaration on Environment and Development, clearly stated by Article 3(1) of UNFCCC as the first basic principle and has been recognized in other important international undertakings.

The precondition of establishing the CDM is based on different emissions reductions targets between developed countries and developing countries according to their

\footnotetext{
${ }^{50}$ See especially Frank Biermann, "Common Concern of Humankind": The Emergence of a New Concept of International Environmental Law' (1996) 34 Archiv des Völkerrechts 426.

${ }^{51}$ Ibid 431.

52 Ibid.
} 
historical contributions to climate change, financial and technological capacities, national circumstances and current per capita emissions. The developed countries' legally binding commitments in the first Kyoto period reflect differentiated responsibilities while the developing countries' involvement under the CDM demonstrates the common responsibilities to tackle climate change issues.

In addition, the CDM reflects sustainable development principle. 'Sustainable development' originally came from the World Commission on Environment and Development 1987 Bruntland Report: Our Common Future, which addresses the problem of conflicts between environment and development goals. The most frequently quoted definition of sustainable development is the development which meets the needs of the present without compromising the ability of future generations to meet their own needs. ${ }^{53}$

Sustainable development has been established as a significant principle in International Environmental Law. Article 3 (4) of UNFCCC clearly set out that 'The Parties have a right to, and should promote sustainable development'. Based on that, one of the objectives of the CDM is to assist Parties not included in Annex I in achieving sustainable development, which manifests the sustainable development principle.

${ }^{53}$ Report of the World Commission on Environment and Development: Our Common Future (1987). 
(3) Underlying economics rationale for the CDM

The economics rationale for the CDM has two dimensions. The first one is that the global climate system as a whole benefits from emission reductions wherever these reductions are made. Abatement is abatement, regardless of where it happens. The second one is the cost of financing an emission reduction will usually be quite different in different countries and regions. Accordingly, the most effective way to curb global warming with the least hurt to a national economy is trying to reduce emissions in amount at the possible lowest cost regardless of where they come from. The theory behind this approach is the 'marginal abatement cost' ${ }^{54}$

CDM is a good example of applying the theory of marginal abatement cost. Under the $\mathrm{CDM}$, abatement costs are the costs of reducing the quantity of GHGs emitted into the environment. In general, the greater the abatement is, the greater the costs are. Marginal abatement cost shows the added costs of achieving a one unit decrease in GHGs emission level, or alternative the costs saved if GHGs emissions are increased by a unit. ${ }^{55}$ The most important factor affecting the marginal abatement cost is the technology of the production process. Technology change may result in lowering the marginal abatement cost for a given GHG emissions. ${ }^{56}$ The developed countries have already adopted relatively more advanced technology and more reasonable managerial mean to GHGs emission reduction than developing countries. Thus, the

\footnotetext{
${ }^{54}$ For explanation, see below paragraph.

${ }^{55}$ Barry C. Field, Environmental Economics: An Introduction (2nd ed, 1997) 90.

${ }^{56}$ Ibid 91.
} 
marginal abatement cost would be much lower if developed countries choose to reduce their emissions in developing countries.

In terms of the above theory, the CDM may provide an opportunity for developed countries to earn emission credits partly fulfilling their binding targets at lower costs by investing in abatement projects in developing countries and for developing countries to introduce efficient fuel-use technologies.

\subsection{How Does the CDM Operate?}

Establishment of the CDM is the first step to unite developed countries and developing countries to address climate change through financial mechanism. The official acceptance of the CDM, however, is not a guarantee of effective implementation. The CDM needs transparency and clearly defined rules to ensure its continuing acceptance and workability. Only with explicit and reasonable requirements and operation rules, can make it possible for ratified countries to be proactive in participating in CDM projects. Hence, due to the fact that the CDM is an emerging market-based legal cooperation mechanism, its rules and requirements are extremely complex and detailed, requiring a broad understanding of the international climate change framework and its interaction with domestic legal system. ${ }^{57}$

Based on the above, this part deals with how the CDM operates in an international context. The CDM modalities and procedures, and various classifications are

\footnotetext{
57 See Unep Ris $\varnothing$ Centre on Energy, Climate and Sustainable Development and Risø National Laboratory, 'Legal Issues Guidebook to the Clean Development Mechanism' (The UNEP project CD4CDM, 2004) 40.
} 
introduced according to Article 12 of Kyoto Protocol, the Marrakech Accords and other decisions of the COP/MOP.

\subsubsection{CDM Modalities and Procedures}

\subsubsection{The CDM-related Bodies}

The implementation of $\mathrm{CDM}$ projects may involve a range of entities and bodies. Each of them has various responsibilities and functions, although their exact roles depend on the circumstances of a particular project and the host country in which it is being implemented. ${ }^{58}$

(1) CDM project participants

CDM Project Participants are the legal entities (both public and private entities) that develop and implement $\mathrm{CDM}$ project activities. ${ }^{59}$ In some cases, the project participants may include CER purchasers, which differ in accordance with the different models of implementing CDM projects. In order to develop a CDM project, project participants should develop Project Design Document (PDD), including description of the project, project monitoring plan and environmental impacts of the project, implement $\mathrm{CDM}$ project and monitor emission reductions as planned, and finally deliver CERs.

(2) The Conference of the Parties serving as the meeting of the Parties to the Kyoto Protocol (COP/MOP)

\footnotetext{
58 Ibid 22.

${ }^{59}$ Ibid 11.
} 
COP/MOP, as the supreme body of meeting/conference, has the power to make policy on climate change. With regard to the CDM, the COP/MOP has the following functions: ${ }^{60}$

- It has authority over and provides guidance to the CDM.

- It makes decides on the recommendations made by the CDM Executive Board (EB) on its rules of procedure.

- It makes decides on the designation of operational entities accredited by the EB.

- $\quad$ It reviews annual reports of the EB.

- It reviews the regional and subregional distribution of designated operational entities (DOEs) and CDM project activities.

- $\quad$ It assists in arranging funding of CDM project activities, as necessary.

(3) The CDM Executive Board (CDM EB)

The CDM EB is a formal government body established under Article 12 of Kyoto Protocol to oversee the implementation and administration of the CDM. It is under the authority and guidance of the COP/MOP, and is fully accountable to the COP/MOP. The main functions of the CDM EB are as follows: ${ }^{61}$

- $\quad$ to develop rules and procedures for CDM operation;

- $\quad$ to approve new methodologies related to baselines and monitoring

\footnotetext{
${ }^{60}$ See Report of the Conference of the Parties serving as the meeting of the Parties to the Kyoto Protocol, $1^{\text {st }}$ sess, 7-8, UN Doc FCCC/KP/CMP/2005/8/Add.1 (2005). It is available at <http://cdm.unfccc.int/Reference/COPMOP/08a01.pdf\#page=15> at 10 October, 2009.

${ }^{61}$ Refer to UNFCCC <http://cdm.unfccc.int/EB/background.html> at 4 March 2010. See also Decision 3/CMP.1, FCCC/KP/CMP/2005/8/Add.1.
} 
plan;

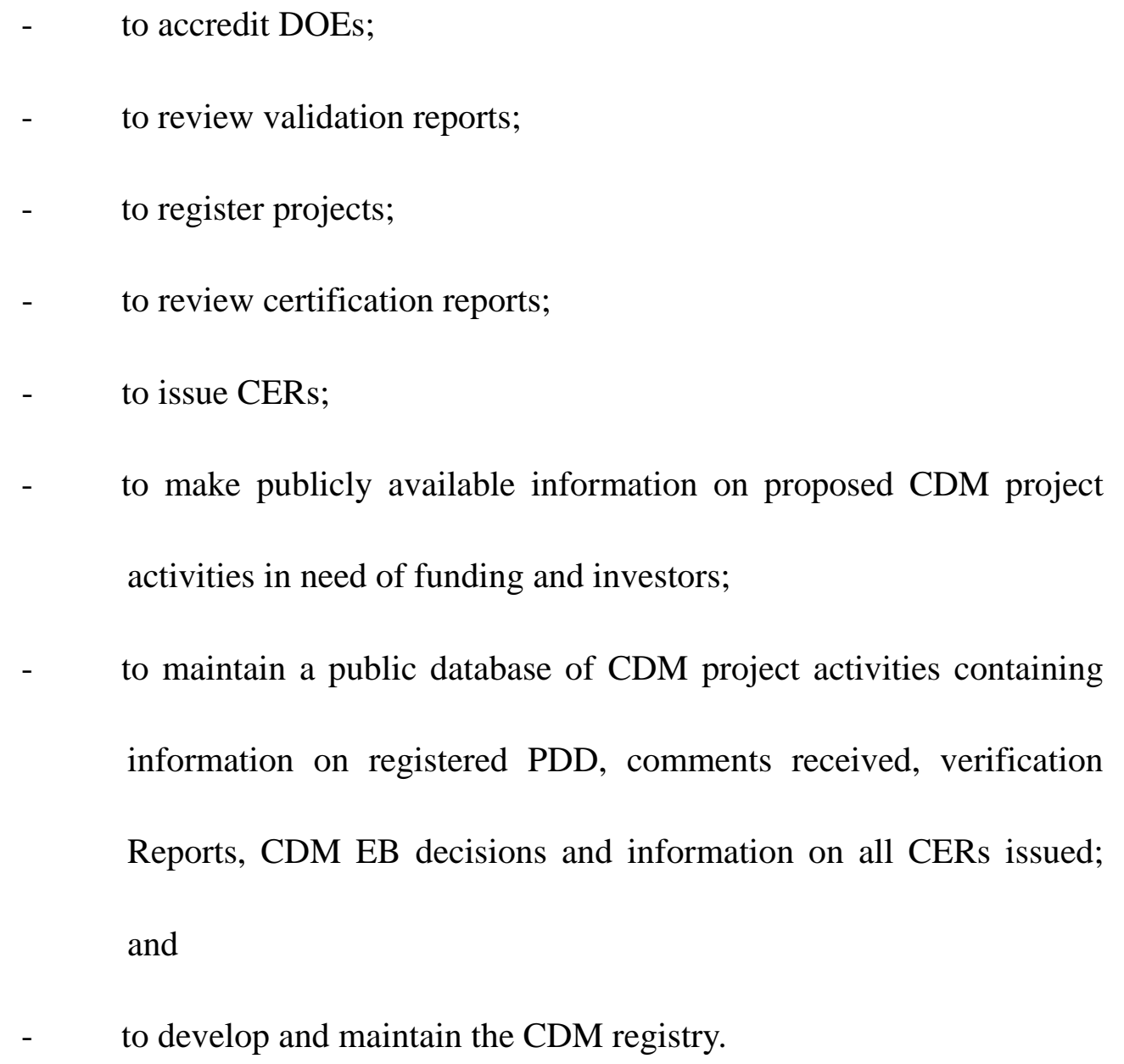

(4) Designated National Authority (DNA)

The EB is responsible for monitoring the CDM on behalf of the UNFCCC at an international level while the implementation of CDM projects must also be approved and should be monitored at a domestic level by the individual Party governments of countries undertaking CDM projects. ${ }^{62}$ DNA, a national authority for CDM, is designated by Party to the Protocol. Each Party to the Kyoto Protocol must designate an authority which is granted responsibility for authorizing and approving participation in CDM projects. The principal functions of a DNA are to:

${ }^{62}$ Above n 57, 24. 
- decide respective sustainable development criteria according to their national circumstances;

- confirm that project will contribute to sustainable development in the host country and thereby issue Letter of Approval to proceed with validation and registration under the CDM;

- assist potential investors to understand and navigate the CDM implementation related host country rules, such as energy sector, foreign investment and taxation; and

- $\quad$ report on national CDM programmes, develop a portfolio of priority CDM projects and networking information that can be used for marketing CDM project activities.

(5) Designated Operational Entity (DOE)

The DOE under the CDM is either a domestic legal entity or an international organization accredited and designated, on a provisional basis until confirmed by the $\mathrm{COP} / \mathrm{MOP}$, by the $\mathrm{EB}$ to validate proposed $\mathrm{CDM}$ projects and verify the reductions. Its two key functions are as follows: ${ }^{63}$

- $\quad$ It validates a proposed CDM project activity and subsequently requests registration to $\mathrm{CDM} \mathrm{EB}$.

- $\quad$ It verifies emission reductions of a registered CDM project, certifies as appropriate and requests the CDM EB to issue CERs accordingly.

${ }^{63}$ Refer to UNFCCC <http://cdm.unfccc.int/DOE/index.html> at 9 October 2009. 
In addition, the DOE must comply with applicable laws of the Parties hosting CDM project activities when carrying its functions.

\subsubsection{Key Requirements for CDM Project Approval}

The Kyoto Protocol and Marrakesh Accords set out specific legal requirements for individual CDM project to guide who and which projects can participate in the CDM.

Generally speaking, participation in the CDM is limited to Parties who have ratified the Kyoto Protocol and entities authorized by those Parties. In addition, the concrete eligibility requirements are varied to different developed countries, developing countries and the entities. ${ }^{64}$

The developing country participating in CDM projects should:

- $\quad$ be voluntary;

- $\quad$ have ratified the Kyoto Protocol; and

- $\quad$ have designated a national authority for the CDM.

Developed countries participating in CDM projects need to meet more requirements than developing countries, including:

- $\quad$ to be voluntary;

- $\quad$ to have ratified the Kyoto Protocol;

- $\quad$ to have designated a national authority for the CDM;

- to have calculated and recorded its assigned amount pursuant to the

\footnotetext{
${ }^{64}$ See 17/CP.7. Marrakesh Accords, 31-33, UN Doc FCCC/CP/2001/13/Add.2 (2002). It is available <http://unfccc.int/resource/docs/cop7/13a02.pdf\#page=20> at 10 October, 2009.
} 


\section{Protocol;}

- $\quad$ to have in place a national system for the estimation of anthropogenic emissions by sources and anthropogenic removals by sinks of all GHGs;

- $\quad$ to have in place a national registry;

- $\quad$ to have submitted annually the most recent required inventory; and

- $\quad$ to submit the supplementary information on assigned amount and make any adjustments to the amount pursuant to the Protocol.

The private and/or public entities participating in CDM project activities should be:

- $\quad$ to voluntary; and

- $\quad$ to be authorized by the eligible Party.

There are also primary criteria for potential CDM projects under the Kyoto Protocol, which are as follows: ${ }^{65}$

- The project shall assist the Host Country in achieving sustainable development. ${ }^{66}$

- The project shall provide real, measurable, and long-term benefits related to the mitigation of climate change. ${ }^{67}$

- $\quad$ The project shall generate reductions in emissions that are additional to

\footnotetext{
${ }^{65}$ See United Nations Framework Convention on Climate Change, opened for signature 12 June, 1992, art 2, entered into force 21 March, 1994.

${ }^{66}$ There are no detailed sustainable development criteria globally due to the fact that different countries have quite different national circumstances. Thus, Marrakesh Accords state that it is the Host Party's prerogative to confirm whether a CDM project activity could achieve this goal.

${ }^{67}$ The DOE may determine this requirement in the process of validation based on the PDD provided by the project participants.
} 
any that would occur in the absence of the certified project activity. ${ }^{68}$

There is no regulation under the Kyoto Protocol or the Marrakech Accords clearly demonstrating which kinds of the projects are qualified for CDM projects. Any project meeting the above requirements are eligible to apply for the CDM projects. However, based on the data released by official website of the UNFCCC with regards to the CDM projects ${ }^{69}$, certain types of eligible projects under the CDM can be identified and classified.

Renewable Energy Project

For example: biomass; geothermal/ hot dry rocks; hydro; solar; tidal; wind; wave; landfill gas.

- $\quad$ Energy Efficiency Project

For example: altering power station infrastructure to reduce distribution losses; modifying processes at the demand side to reduce the amount of electricity required.

- $\quad$ Power Project

\footnotetext{
${ }^{68}$ A CDM project activity is additional if anthropogenic emissions of GHGs by sources are reduced below those that would have occurred in the absence of the registered CDM Project activity. However, the additionality assessment process is complex and technical. In order to explain how and why the project activity is additional, it is necessary for project participants to identify baseline scenarios in accordance with the selected baseline methodology. The baseline for a CDM project activity is the scenario that reasonably represents the anthropogenic emissions by sources of GHGs that would occur in the absence of the proposed project activity. The difference between the baseline emissions and project emissions (GHG emissions after implementing the CDM project activity) is emission reductions. The Marrakesh Accords set out some guidance on how to calculate baseline emissions. A baseline shall be calculated by project participants in accordance with approved methodologies, which are publicly available on the UNFCCC CDM website or new methodologies, which need the approval by EB prior to a submission for registration of this project activity. Besides, project participants should take into account their national policies and circumstances when establishing a baseline and choosing a baseline methodology.

${ }^{69}$ The website address is $\langle$ http://cdm.unfccc.int/Statistics/index.html〉.
} 
For example: fuel switching a coal powered plant to natural gas; capturing land-fill methane gas to generate electricity.

Methane Recovery Project

For example: coal-mine methane; coal-bed methane.

- $\quad$ Transport Project

For example: implementation of cleaner engine technologies; fuel cell and battery vehicles upgrading existing fleet; traffic flow controls; mass transit substitution for private transport.

Architecture Project

For example: using cleaner architectural material.

- $\quad$ Forestry Project

For example: planting forests (Afforestation and Reforestation ${ }^{70}$ )

- $\quad$ Other Projects

For example: geological sequestration; geological sequestration for enhanced oil recovery.

On the contrary, in spite of their contributions to carbon emission reductions, the two types of the projects below are currently excluded from the CDM projects:

- $\quad$ Nuclear Project

The Marrakech Accords states that Parties included in Annex I are to

\footnotetext{
${ }^{70}$ Afforestation is the direct human-induced conversion of land that has not been forested for a period of at least 50years to forested land through planting, seeding and/or the human-induced promotion of natural seed sources. Reforestation is the direct human-induced conversion of non-forested land to forested land through planting, seeding and/or the human-induced promotion of natural seed sources, on land that was forested but that has been converted to non-forested land. For the first commitment period, reforestation occurring on those lands that did not contain forest on 31 December 1989.
} 
refrain from using CER generated from nuclear facilities to meet their commitments.

Deforestation Project

The COP6 decided in Bonn in 2001 to limit the eligibility of land-use activities in the CDM to afforestation and reforestation. The Deforestation Project, which prevents carbon dioxide from being emitted back into the atmosphere, is distinguished from afforestation and reforestation. Thus, it has been excluded from eligibility under the CDM for at least the first commitment period of the Kyoto Protocol.

\subsubsection{CDM Project Cycle}

The Marrakech Accords and later COPs to the UNFCCC stipulate the procedures and rules to implement a CDM project. This part describes the legal steps from designing a CDM project to issuing CERs. Set out below is a summary of the CDM project cycle.

Phase

Project Design

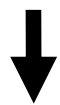

Project Validation

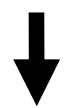

Project Registration

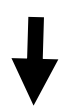

Project Monitoring
Actor Project developer

DOE

EB

Project developer
General Activities

Complete a PDD which includes

necessary project related

information

Review the PDD to confirm that

the requirements are met

Automatically register the

proposed CDM project

if there is no objection

Implement the monitoring plan contained in the registered PDD
Period

Within 30 days

Within 8 weeks

Specified in

the PDD 


\begin{tabular}{|c|c|c|c|}
\hline $\boldsymbol{\nabla}$ & & $\begin{array}{l}\text { to monitor and report emission } \\
\text { reductions }\end{array}$ & \\
\hline Project Operation & & & \\
\hline Reduction Verification & DOE & $\begin{array}{l}\text { Periodically review the monitored } \\
\text { enhanced reductions in GHGs } \\
\text { emissions as a result of a CDM } \\
\text { project }\end{array}$ & $\begin{array}{c}\text { During the } \\
\text { verification } \\
\text { period }\end{array}$ \\
\hline Reduction Certification & DOE & $\begin{array}{l}\text { Complete a Certification Report } \\
\text { writing that during the specified } \\
\text { time period, the project achieved } \\
\text { the enhanced reductions of GHGs } \\
\text { as verified }\end{array}$ & \\
\hline CERs Issuance & EB & $\begin{array}{c}\text { Automatically issue the CERs if } \\
\text { there is no objection }\end{array}$ & Within 15 days \\
\hline
\end{tabular}

\section{(1) Project Design}

The first step of undertaking a CDM project is to design a project. The Project developer should complete a PDD in accordance with the requirements set up by the CDM EB. The PDD shall include descriptions of the project activity itself and the application and justification of a proposal baseline methodology, a statement of the estimated operational lifetime of the project and the selected crediting period $^{71}$, stakeholder comments and an analysis of environmental impacts, a demonstration of sources of public funding for the project and an explanation of how the additionality requirements will be met, how the emission reductions will be monitored by drawing

\footnotetext{
${ }^{71}$ The crediting period for all CDM projects, except afforestation and reforestation projects, can be either:

- Seven years with the option of up to two renewals of seven years each if the project baseline is still valid or has been updated with new data; or

- 10 years with no renewal option.

For afforestation and reforestation projects, the choice is between:

- 20 years with up to two renewal periods of 20 years each; or

- 30 years with no renewal.
} 
up monitoring plan and how to calculate the reduced emissions and project leakage. Besides, project developer shall obtain written approval of voluntary participation from the DNA of each Party involved, including confirmation by the host Party that the project activity assists it in achieving sustainable development.

After completing a PDD as required, project developers should select and enter into a contractual arrangement with a DOE to review the PDD and any other supporting documentation.

(2) Project Validation

Validation is the process of independent evaluation of a project activity by a DOE against the requirements of the CDM on the basis of PDD. The DOE shall make publicly available the PDD in order to receive comments on the key requirements for the proposed project within 30 days. After deadline for receipt of comments, DOE shall make a determination as to whether, on the basis of the information provided and taking into account the comments received, the project activity should be validated. If the proposed project activity is determined to be valid, the DOE shall submit a request for registration in the form of a validation report including the PDD, the written approval of the host Party, and an explanation of how it has taken due account of comments received to the EB.

\section{(3) Project Registration}

Registration is the formal acceptance by the EB of a validated project as a CDM project. Registration is the prerequisite for the verification, certification and issuance 
of CERs related to that project activity. The registration shall be deemed final eight weeks after the date of receipt by the EB of the request for registration, unless a Party involved in the project activity or at least three members of the EB request a review of the proposed CDM project activity.

\section{(4) Project Operation}

After the project is validated and registered, it could be put into operation. During the operation, the following three steps need to be done in order to obtain CERs.

\section{(5) Project Monitoring}

The project developer shall monitor the operation of CDM project and emission reductions in accordance with the monitoring plan contained in the registered PDD. Any revisions to a monitoring plan require justification by the project developer and need to be validated by a DOE and approved by the CDM EB.

\section{(6) Reduction Verification}

Verification is the periodic independent review and ex post determination by the designated $\mathrm{DOE}^{72}$ of the monitored reductions in emissions of GHGs as a result of a registered CDM project activity during the verification period. As a first step, the project developer designates and contracts with a DOE, which shall perform the verification. Then, the DOE conducts on-site inspections, examines the performance of project activity and reviews monitoring results. If satisfactory, the DOE will make a verification report verifying that the monitoring methodologies for the estimation of

\footnotetext{
${ }^{72}$ The project developer may suggest the CDM EB design the same DOE that has validated the project to verify and certify emission reductions.
} 
reduction in anthropogenic emissions by sources have been applied correctly and their documentation is complete and transparent and thus confirming the GHGs reductions achieved.

\section{(7) Reduction Certification}

Certification is the written assurance by the DOE based on its verification report. The designated DOE shall complete a certification report certifying that, during the specified time period, the project activity achieved the amount of enhanced GHGs reductions as verified.

\section{(8) CERs Issuance}

Based on the certification report, the issuance shall be considered final 15 days after the date of receipt of the request for issuance to the EB of CERs equal to the amount of enhanced GHGs reductions as verified, unless a Party involved in the project activity or at least three members of the EB request a review of the proposed issuance of CERs.

\subsubsection{CDM Project Size}

Based on the output capacity or the volume of emission reductions, CDM projects can be divided into small-scale CDM project and large-scale project. The small scale CDM project activities include: ${ }^{73}$

- $\quad$ Renewable energy project activities with a maximum output capacity equivalent of up to 15 megawatts (or an appropriate equivalent).

\footnotetext{
${ }^{73}$ Decision 17/CP.7, Modalities and Procedures for a Clean Development Mechanism as defined in Article 12 of the Kyoto Protocol, para 6(c), 2, <151.1.187.213/Assets/8/20040506100129_10-3-36-111.pdf> at 8 July 2008.
} 
- $\quad$ Energy efficiency improvement project activities which reduce energy consumption, on the supply and/or demand side, by up to the equivalent of 15 gigawatt/hours per year.

Other project activities that both reduce anthropogenic emissions by sources and directly emit less than 15 kilotonnes of carbon dioxide equivalent annually.

The Marrakech Accords also set out small-scale CDM project activities may apply simplified modalities and procedures. The objective of this fast track mechanism is to enable small scale projects to be pursed without the need for going through the rigorous and expensive approval and assessment processes as required for larger scale projects. ${ }^{74}$ Accordingly, small-scale projects can take the following advantages: ${ }^{75}$

- a simple PDD;

- $\quad$ simplified methodologies for determining a baseline and creating a monitoring plan;

- the ability to bundle project activities for the PDD, registration and verification to reduce administration costs;

- $\quad$ simplified provisions for environmental impact analysis;

- $\quad$ lower registration fee; and

- $\quad$ an automatic ability to have the same DOE verify and certify emission reductions for a specific small scale CDM Project activity.

\footnotetext{
${ }^{74}$ Above n 57, 43.

${ }^{75}$ Ibid.
} 


\subsubsection{CDM Approach}

The CDM is a project-based GHG offset mechanism under the Kyoto Protocol. Hence, most CDM projects are currently limited to project by project approach. However, with the improvement of the CDM operational rules and development of emission abatement project, the scope of the $\mathrm{CDM}$ is expected to be broadened within the existing regulatory framework. As a result, policy CDM approach, sectoral CDM approach and programmatic CDM approach have been proposed.

Policy-based CDM is an approach where activities are implemented by the hosting government through adopting government policies. Since many types of government policies can affect GHG emissions, a broad definition of policy-based CDM would allow a single policy that reduces emissions in a range of sectors and actors to be eligible as a CDM activity. For example, a government policy to adopt a fuel tax that impacts fuel consumption in transportation and electricity generation would be considered a 'Policy-based CDM'. In this case, the policy becomes the project and the CERs would flow directly to the hosting government. However, a policy-based CDM approach may raise concerns regarding the assessment of additionality, as there are several motivations for the adoption of policies, and GHG mitigation may only be one of them. ${ }^{76}$ Therefore, the policies and measures could be credited indirectly through sectoral approaches. ${ }^{77}$

\footnotetext{
${ }^{76}$ Lambert Schneider, 'Is the CDM fulfilling its environmental and sustainable development objectives? An evaluation of the CDM and options for improvement' (Report prepared for WWF, Öko-Institut, 2007) 63. 77 Ibid.
} 
Where only policies that impact upon one sector would likely be able to meet the requirements of CDM and thus eligible under a policy-CDM approach, such approach has also been termed a 'Sectoral CDM'. Sectoral CDM is an approach where emissions reduction credits are generated from public and private actions in a single sector or sub-sector that reduce emissions below the level that would have occurred without the project. Hence, the project boundary would be a particular carbon-intensive sector and the eligible activity would be a government policy that directly is aimed at reducing emissions in that sector. Under the sectoral approach, a baseline is established for the whole sector and emissions below the baseline are credited. Thus, emissions and reductions are not based on the policies and measures taken by the government, but on the actual observed emissions trend in a particular sector. The sectoral CDM is a top-down approach that would provide a real incentive for developing countries to enact policies that make relevant sectors (energy, industrial, forestry, etc.) less carbon intensive over time, thus successfully mainstreaming climate considerations into the economic growth model. ${ }^{78}$

Besides policy CDM approach and sectoral CDM approach, there is a programmatic CDM approach. The programmatic CDM, which is often called Programme of Activity (PoA) has its origins in a decision of the COP/MOP that 'local/regional/national policies or standards cannot be considered as CDM project activities, but project activities under a PoA can be registered as a single CDM project

\footnotetext{
${ }^{78}$ Christiana Figueres, 'Sectoral CDM: Opening the CDM to the yet Unrealized Goal of Sustainable Development' (2006) 2 (1) International Journal of Sustainable Development Law \& Policy 512.
} 
activity. ${ }^{79}$ The concept of a PoA is described in EB 32, Annex 38, paragraph 1 as follows:

A programme of activities (PoA) is a voluntary coordinated action by a private or public entity which coordinates and implements any policy/measure or stated goal (i.e. incentive schemes and voluntary programmes), which leads to anthropogenic GHG emission reductions or net anthropogenic GHG removals by sinks that are additional to any that would occur in the absence of the PoA, via an unlimited number of CDM Programme Activities (CPAs) ${ }^{80}$.

Therefore, in programmatic $\mathrm{CDM}$, the program is the project and the program enacting agent, which may include government, NGO, financial intermediary and industrial federation, is the project participant. Based on that, a PoA has the key characteristics that first, it results in a multitude of dispersed actions. It enables carbon credits to be generated for activities that cut emissions over many locations and among a variety of actors. Second, the type, size, and timing of the actions induced by the program may not be known at the time of project registration. Third, the project is submitted using one single PDD.

Accordingly, the programmatic CDM is able to have more flexibility and reduce transaction costs per project. Therefore, developing programmatic CDM is beneficial to promote sustainable development in developing countries as it may enormously enhance the chances of small and poor countries accessing to the CDM. In such countries, single projects are often too small to be commercially attractive. As a consequence, many small and poor countries are not benefiting from the CDM at the

\footnotetext{
${ }^{79}$ Decision 7/CMP.1, Further Guidance Relating to the Clean Development Mechanism, para 20, 97, UN Doc FCCC/KP/CMP/2005/8/Add.1 (2005).

${ }^{80} \mathrm{~A} \mathrm{CPA}$ is defined as a project activity under a programme of activities. A CPA is a single, or a set of interrelated measure(s), to reduce GHG emissions or result in net anthropogenic greenhouse gas removals by sinks, applied within a designated area defined in the baseline methodology (EB 32, Annex 38, page 1).
} 
moment. The programmatic approach could dramatically change this by bringing together several CDM projects under a program.

\subsection{Assessment of the CDM}

Since it was initiated in 1997, the CDM has attracted worldwide attention and more than two thousand CDM projects have been registered. Against this background, it is necessary to review the performance of the CDM during these more than ten years. Based on that, this part assesses the achievements as well as pitfalls of the CDM. Following assessment, key factors influencing the successful implementation of the CDM are figured out.

\subsubsection{Achievements of the CDM}

\subsubsection{Current Situation of the CDM Implementation in an International}

\section{Context}

Operational Since the beginning of 2006, the CDM has been implemented worldwide. To present day, over 2,000 CDM projects have been registered and CERs amounting to more than 2.7 billion tonnes of $\mathrm{CO}_{2}$ equivalent are anticipated to be produced in the first commitment period of the Kyoto Protocol, 2008-2012. ${ }^{81}$ The five charts below demonstrate the overall situation of the CDM projects development from registered project activities by host party, registered projects by region, registered projects by investor parties, expected average annual CERs from registered projects by host party

\footnotetext{
${ }^{81}$ See the information released on the UNFCCC website <http://cdm.unfccc.int/about/index.html > at 10 October, 2009.
} 
and CERs issued by host party respectively.

\section{Chart 2.1 Registered Project Activities by Host Party}

\section{Registered project activities by host party. Total: 1,836}

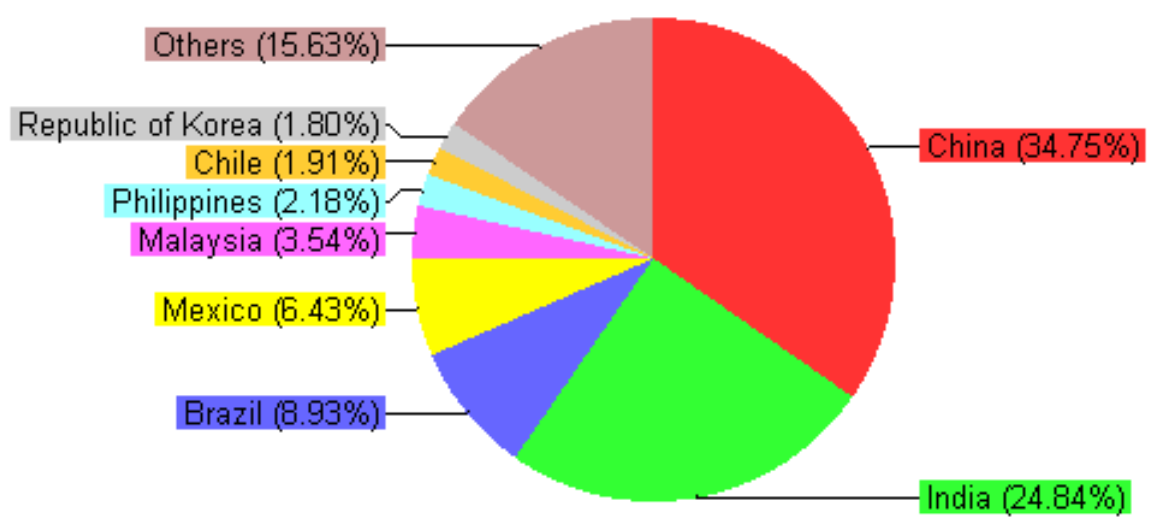

http:/icdm.unfccc.int (c) 02.10 .200914 .52

\section{Chart 2.2 Registered Projects by Region}

Registered projects by region. Total 1836

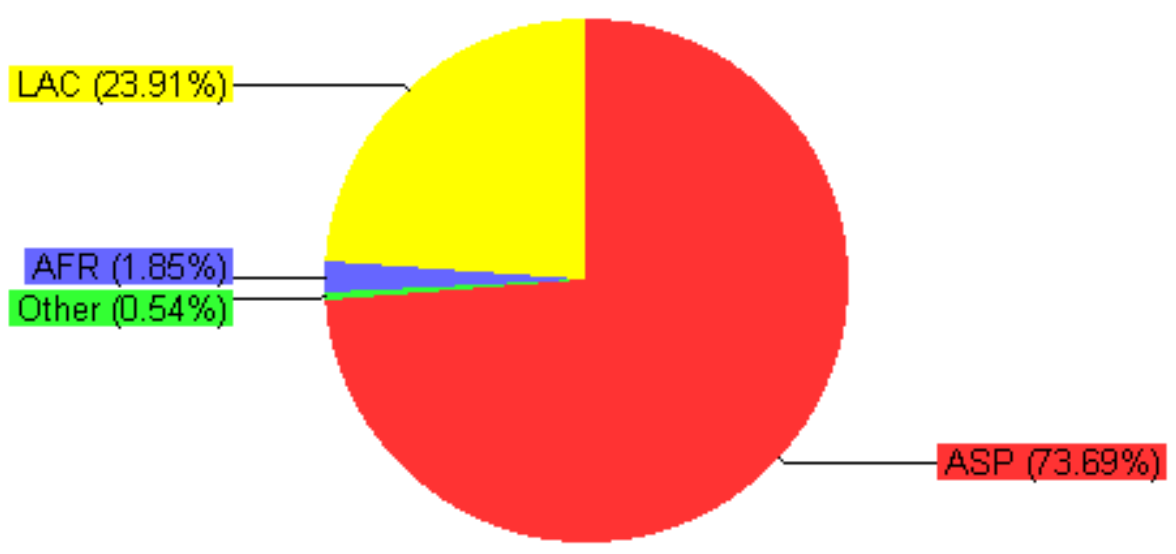

http:/icdm.unfccc.int (c) 02.10.2009 14:53

ASP: Asia and the Pacific, LAC: Latin American and the Caribbean, AFR: Africa 


\section{Chart 2.3 Registered Projects by Al and NAI Investor Parties}

Registered projects by $\mathrm{Al}$ and $\mathrm{NAl}$ investor parties

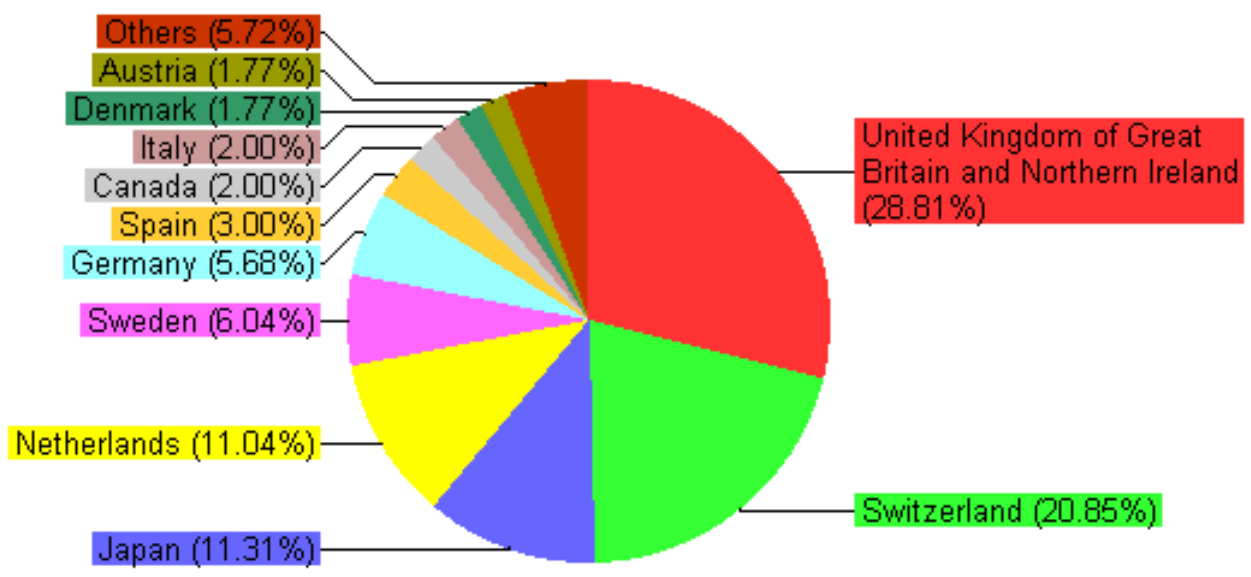

http:ilcdm.unfccc.int (c) 02.10.2009 $14: 53$

\section{Chart 2.4 CERs Issued by Host Party}

\section{CERs issued by host party. Total $333,215,472$}

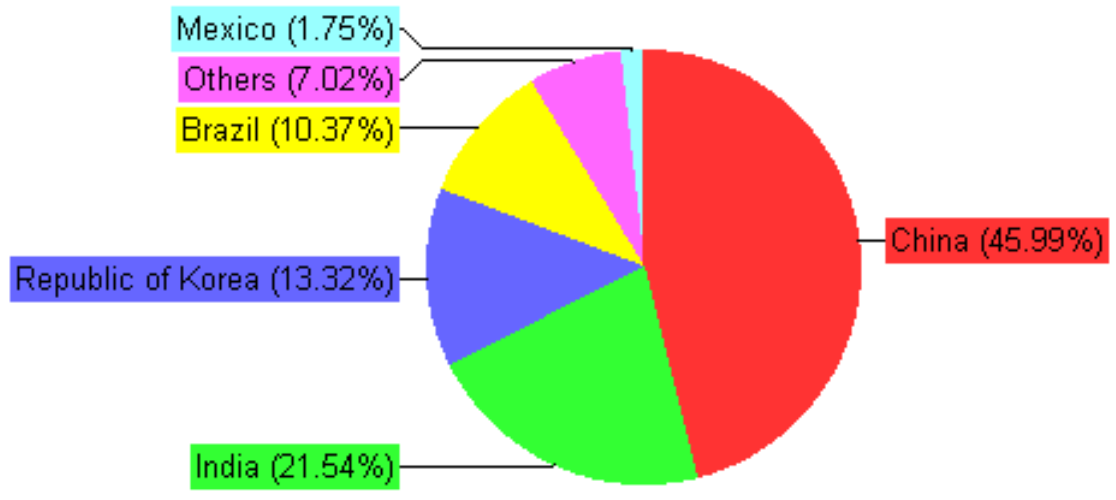

http:i/cdm.unfccc.int (c) 02.10 .200914 .53 
Chart 2.5 Expected Average Annual CERs from Registered Projects by Host Party

Expected average annual CERs from registered projects by host party. Total: $319,016,479$

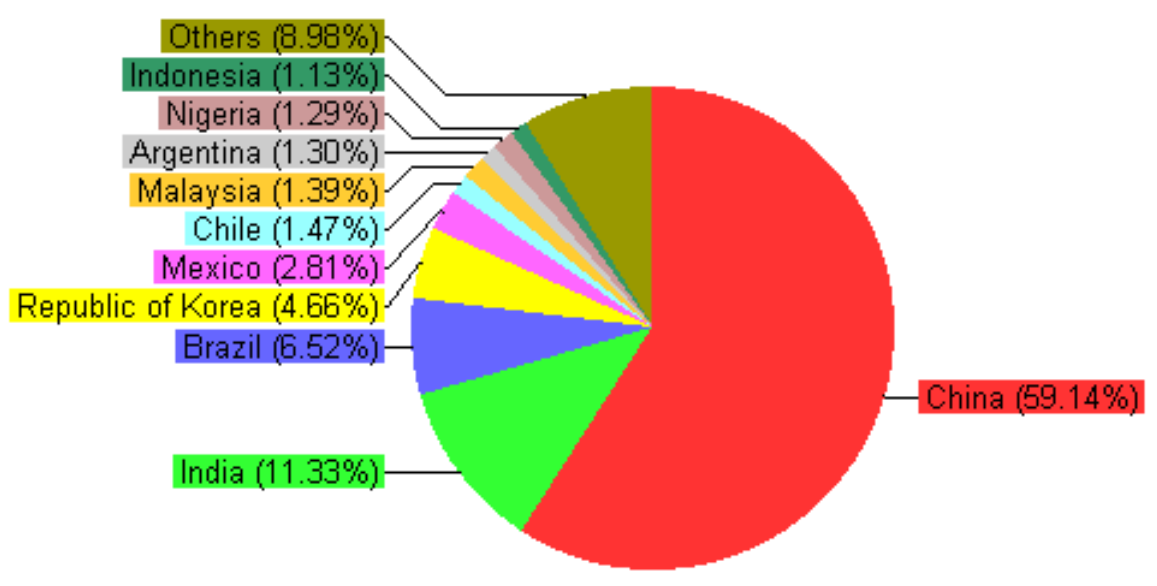

http:ilcdm.unfccc.int (c) 02.10 .200914 .52

Several conclusions can be obtained in accordance with the above statistics. First, the CDM have been developing rapidly. Up to October 2009, there has been 1836 CDM projects registered and 333,215,472 tons CERs issued. Furthermore, the volume of CERs is expected to increase to $1,190,000,000$ tons until end of 2012.

Second, China, India, Brazil, Mexico and Republic of Korea are the main host parties of CDM activities. China and India overwhelmingly lead other developing countries regarding the registered projects and issued and expected CERs. China, in particular, besides having had the most registered CDM projects and largest amount of issued CERs, is expected to generate more than half amount of the expected CERs. Accordingly, it can be said that China has dominated CDM regime and is expected to have greater influence on the CDM in the future. 
Third, in spite of rapid development, huge project geographical disproportion is observed. Asia and the pacific as a whole leads CDM project activities with 1,353 registered projects, accounting for 73.69 per cent of the total amount. However, Africa lags behind. There are only 34 projects in Africa registered, accounting for 1.85 per cent of 1,836 registered projects.

Finally, as to investor parties, the main sources of investment derive from European countries. Within Europe, the United Kingdom of Great Britain and Northern Ireland have invested in 49.66 per cent of the registered projects, and there are 11.04 per cent of the projects invested by Netherland. Besides, Japan takes part in 11.31 per cent projects.

\subsubsection{The CDM and the Carbon Market}

The global carbon market has grown as a response to the Kyoto Protocol and the $\mathrm{CDM}$ in particular. Carbon trading, sometimes called emission trading, is a market-based tool to limit GHG. It is defined as:

purchase contracts whereby one party pays another party in return for GHG emissions reductions or for the right to release a given amount of GHG emissions, that the buyer can use to meet its compliance - or corporate citizenship - objectives vis-à-vis climate change mitigation. ${ }^{82}$

Based on whether the involvement of an emission abatement project, carbon trading can be categorized into allowance-based transactions (or cap-and-trade schemes) and project-based transactions (or credit schemes). In the allowance-based transactions, the governing body begins by setting a total cap on emission allowances, which are

\footnotetext{
${ }^{82}$ Karan Capoor and Philippe Ambrosi, 'State and Trends of the Carbon Market 2007' (The World Bank 2007) 8.
} 
then allocated or auctioned off to individual regions, countries, or even firms. Members that do not have enough allowances to their emission must either make reductions or buy another member's spare allowances. Members with extra allowances can sell them or bank them for future use. AAUs under the Kyoto Protocol or EUAs under the EU ETS are the examples of such schemes. These transactions may facilitate mandated participants to meet compliance requirements at the lowest possible cost. A project-based transaction may allow the buyer purchases emission credits from a project that can verifiably demonstrate GHG emission reductions compared with what would have happened otherwise by funding pre-approved emissions reduction projects in other countries. ${ }^{83}$ The CDM and the JI mechanisms of the Kyoto Protocol, generating CERs and ERUs respectively are the most notable examples.

Also, the carbon markets can be categorized into compliance or non compliance, and mandatory or voluntary markets. Most carbon markets are mandatory because buyers largely participate in carbon trading due to carbon constraints at international, national or sub-national levels. On the other hand, some voluntary carbon markets, namely the Chicago Climate Exchange in the USA and the New South Wales Greenhouse Gas Abatement Scheme in Australia were set up to help facilitate carbon offset transactions.

The CDM is a compliance and mandatory project-based market mechanism. Through

\footnotetext{
83 Ibid.
} 
providing an opportunity for developing countries without emission caps under the Kyoto Protocol to participate in emission trading, it plays an influential part in carbon market. According to the World Bank's reports, a strong majority (about 91 per cent) of primary transactions for project-based credits come from CDM activities. ${ }^{84}$

Owing to unique characteristics of the CDM, the carbon trading under which may has its own buyers, sellers and commodities. The ultimate carbon credit buyers under the CDM market are most likely to be those companies and industrialized countries which ratified the Kyoto Protocol but could not meet their own emissions reduction targets in the first commitment period 2008-2012 under the Kyoto Protocol or have relatively high costs to reduce emission domestically. Among these buyers, European buyers totally dominate the CDM market with over 80 per cent of volumes transacted for the three consecutive years from 2006 to $2008 .^{85}$ Among them, the United Kingdom has the largest market share consolidating its leadership position as the carbon finance hub for the world. In addition, private sector companies have been the most active buyers.

The credit sellers in the CDM market are those companies or developing countries which may supply emission reductions with relatively lower costs. Asia as a whole leads the CDM market. Among the Asian countries, China accounts for the lion's share of transactions in the CDM market. Over the period 2002-08, China accounted

\footnotetext{
${ }^{84}$ See Karan Capoor and Philippe Ambrosi, 'State and Trends of the Carbon Market 2009' (The World Bank 2009) 31. See also Capoor and Ambrosi, above n 82, 20.

${ }^{85}$ Ibid 33.
} 
for 66 per cent of all contracted CDM supply. ${ }^{86}$ With 4 per cent and 3 per cent market share each, India and Brazil ranked second and third, respectively, on the list of sellers in terms of volumes transacted in 2008. On a cumulative basis, Brazil accounts for about 8 per cent of primary CERs contracted cumulatively over 2002-2008. India, on the other hand, accounts for 9 per cent of CERs contracted cumulatively over $2002-2008 .^{87}$

The commodity in the CDM market is carbon credit. Currently, most carbon credits in the CDM market are CERs. But there are also voluntary emission credits, or Verified Emission Reductions (VERs), which are also called carbon offsets. Their purchaser typically a commercial firm - buys an emissions allowance to offset the carbon produced. This happens mainly for reputational purposes, and to contribute voluntarily in the fight against climate change. Although there is no formal market for VERs, the voluntary market is growing. The major difference between the VER market and the CER market lies in whether it is influenced by political circumstances. The CER market is exposed to political decisions, while the voluntary market does not stop in 2012 and on the voluntary market emission reductions can be transacted for as long as the participants want.

Currently, most carbon credits are generated from projects in renewable energy, fuel switching and energy efficiency. Transacted volumes in these three broad project

\footnotetext{
${ }^{86}$ Ibid 34.

${ }^{87}$ Ibid 35.
} 
categories alone accounted for 82 per cent of volumes contracted in $2008 .^{88}$ In the meantime, transactions of HFC destruction projects ${ }^{89}$ are now virtually absent from the CDM market, with the exception of a handful of spot sales of un-contracted issued CERs from previously registered projects. In spite of the current dominance of the renewable energy, carbon credits derived from it was at 16 per cent in 2006 compared to 10 per cent in 2005 , buoyed mainly by China's decision to identify these alternative sources of energy as a priority. ${ }^{90}$ By contrast, HFC-23 destruction projects peaked in 2005 when it had a 67 per cent CDM market share and dominated the market by 34 per cent CDM market share in 2006.

In spite of economic downturn in 2008 , the prices of CER have risen steadily since 2005. A major factor in this stability is the market power of China, which maintained an informal pricing policy by raising the minimum price floor in the US\$10.40-11.70 (€ 8-9) range in 2007. ${ }^{91}$ According to the Nord Pool exchange in Lysaker, Norway, the price of CERs for 2008 increased to15.90 euros or \$23.58 a ton in March.

Based on the current situation of the CDM market, it has the following three characteristics:

First, as an emerging commodity market, the CDM market develops and improves

\footnotetext{
${ }^{88}$ Ibid, 40.

${ }^{89}$ HFC-23 (trifluoromethane) is generated as a waste gas in the manufacturing process of HCFC-22 which is a gas used as refrigerant and as feedstock, a raw material for other products. It has a global warming potential 11700 times greater than CO2. The UNFCCC and the Kyoto Protocol list the HFC-23 as a major potential GHG and one of the first types of projects established under CDM was the investment in the destruction of the compound HFC-23.

${ }^{90}$ Capoor and Ambrosi, above n 76, 27.

${ }^{91}$ Ibid 21.
} 
rapidly. However, the current CDM market is not only driven by fundamentals but also by political decisions, and that makes it unique from other commodity markets.

Second, the CDM market embodies the dichotomy between promoting sustainable development and searching for least-cost carbon credits. The CDM is structured as a project-based market mechanism under which searching for the least-cost carbon credits is the paramount consideration. Projects generate revenues through the CDM by reducing or storing a quantity of GHG emissions which are commodified as carbon credits and sold. ${ }^{92}$ Buyers and investors favour projects that require the least investment, least technology transfer and that provide the least sustainable development co-benefits as these produce the cheapest credits ${ }^{93}$ Although promoting sustainable development is one of the objectives of implementing CDM project, actually, it is only the byproduct of carbon trading due to the nature of a market-based mechanism - discover and direct funding to projects that will produce the maximum volume of carbon credits for every dollar invested. ${ }^{94}$ Therefore, the international or domestic policies and guides are needed to balance promoting sustainable development and reducing GHGs at the least cost. Owing to the appropriate policies adopted, the volume of investments in the renewable energy projects has enormously risen in these consecutive years.

Third, CDM market reflects China's influence on the global carbon market. China,

\footnotetext{
92 Ben Pearson, 'Market Failure: Why the Clean Development Mechanism Won't Promote Clean Development' (2007) 15(2) Journal of Cleaner Production 247, 249.

93 Ibid 251.

94 Ibid 249.
} 
one of the largest $\mathrm{CO}_{2}$ emitters in the near future, has dominated the CDM market. It influences the overall market price through its informal policy of requiring a minimum acceptable price before providing DNA approval to the projects. ${ }^{95}$ Given that, China's CDM related laws and regulations may in a large degree decide the performance of the CDM carbon market and thereby its achievements on reducing GHGs also influences the successful combat of global warming.

\subsubsection{Significance of the CDM in Addressing Climate Change}

The CDM has obtained great achievements since it was initiated. The historical significance of the CDM in addressing climate change has four aspects.

First, the emergence and development of the CDM represent a fact and a trend that developed countries and developing countries should cooperate together to tackle global warming issues. Even though different countries make their respective contributions to climate change, all the countries around world must take part in global warming mitigation and make unremitting efforts to reduce GHG emissions according to their differentiated responsibilities.

Second, the CDM combines emission reductions with market measures. It has raised unprecedented environmental awareness in the business sector, leading to a reduction in emissions. Moreover, it completes the global carbon market and provides an incentive for entrepreneurs to reduce GHG emissions in the most possible cost-effective way.

\footnotetext{
95 Capoor and Ambrosi, above n 82, 32.
} 
Third, the CDM promotes the development of emerging carbon trading related industries. It opens a new regime for developing countries and developed countries working together with a view to reducing emissions worldwide, and organically combines GHGs mitigation with operational incentives for business. As a result, carbon brokers, carbon trading exchanges, and carbon futures are on the rise. Also, subsidiary industries have flourished. Accountants are needed to audit carbon inventories, while lawyers have to be on hand to resolve carbon contracts and other complex legal issues relating to the unusual trade in a commodity that does not physically exist.

Finally, the CDM gives rise to many new legal issues. First, there are new legal issues as the CERs emerge. A CER - a valuable commodity created by the CDM - is the product of implementing a CDM project. Therefore, the rights and benefits associated with generation of emission reductions by a CDM project are of great significance for CDM project participants. However, as the CER is a relatively new concept, no universal recognition has been reached about the legal nature of CERs and who will be legally entitled to any benefits from GHG reductions so far. In addition, implementing a CDM project may involve various contracts. In this case, protecting both parties' interests and rights by legal measures is of vital importance. Furthermore, as a result of the CDM, many new carbon trading related industries emerge and develop. Regulating the new industries and setting up industries standards are also essential. 


\subsubsection{Pitfalls of the CDM}

In spite of rapid development of the CDM, this is not to say that it is a panacea for efficient global warming combat. As a man-made mechanism, CDM has its own limits to fulfill its expected purpose under the current rules design. Thus, this section discusses the pitfalls of the CDM from a global perspective.

\subsubsection{Pitfall in Realising Its Dual Objectives}

The dual aims of the CDM, elaborated in the Kyoto Protocol, shall be to help industrialized countries achieve their emission targets and assist developing countries in achieving sustainable development. Ultimately, low carbon economy and the mitigation of global warming would be realised. In the meantime, the CDM is structured to be a project-based market mechanism, and thereby possessing a commercial attribute. In this scenario, there would be a confliction between its objectives and commercial attribute. Therefore, the CDM's performance on realising its objectives is questioned.

First of all, the CDM is pointed to be 'a zero-sum-game' regarding its effect on GHG emission reduction. According to Lambert Schneider, an expert in international climate policy, CDM does not lead to a reduction of emissions; it only brings a trade-off between potential emissions avoided in developing countries and a real reduction in emissions in industrialized countries. ${ }^{96}$ Although the developed

\footnotetext{
${ }^{96}$ See Julio Godoy, A Development Mechanism: That Cleans Little (2009) Inter Press Service <http://www.climateark.org/shared/reader/welcome.aspx?linkid=121783\&keybold=Kyoto> at 4 June 2009.
} 
countries can take part in global emissions reduction movement and carbon market through the CDM, it does not make them accept any substantial emission restrictions. Rather, the developing countries are compensated for avoiding the emission reductions. Actually, $\mathrm{CO}_{2}$ emissions of the major developing countries, like China, India and Brazil, have surpassed the half of the world's emissions. Hence, the global carbon emission reduction would be futile without the participation of these major developing countries. Furthermore, the CDM provides an opportunity for developed countries to avoid taking practical actions to reduce emissions at the cost of money.

Second, from the perspective of promoting the sustainable development in all developing countries, the CDM has a pitfall. The CDM provides an opportunity for developed countries to invest in emission reduction projects in developing countries. In this scenario, the investment condition in these countries is the paramount consideration of intended industries. Paradoxically, many countries, especially the less developed ones, which are prone to suffer the severest environmental problems, have less competitive environment to attract investment and lack the institutional and technological capabilities to regularly and precisely monitor quotas and actual emissions. This pitfall of design of the CDM has brought about geographical disproportion of CDM projects. The less developed countries, which should foremost be expected to accept the assistance to avert the influence caused by climate change, on the contrary, cannot fully participate in the CDM and global carbon market. Still, the global warming issues cannot be completely solved without the inclusion of these most environment vulnerable countries. 
Moreover, the CDM provides an opportunity for industrialized countries to delay making costly, structural changes towards low-carbon technologies. A company in industrialized country has two ways to reduce emissions. One, it can reduce the GHGs by adopting new technology or improving upon the existing technology to attain the new norms for emission of gases domestically. Or it can help developing countries set up new technology that is eco-friendly through a CDM project, thereby helping it earn carbon credits. The industry chooses to invest in potentially CDM projects with commercial advantage. ${ }^{97}$ Obviously, it is much cheaper for industry to purchase cheap carbon credits under the CDM to offset their over used emissions than to implement the costly technologies that would actually bring about real emissions reductions at source. Hence, $\mathrm{CDM}$, in some degree, may become an impediment to create a low-carbon economy and to arrest global warming.

\subsubsection{Shortcomings of Complex CDM Procedures}

As mentioned earlier, it is not an easy task to implement CDM projects as there is an intricate regulatory system that ensures the project quality. Hence, CDM developers have to undergo a complex and time-consuming procedure to develop a CDM project. Consequently, many potential problems may be incurred by the operational rules of the CDM.

First, the essential deficiencies of the CDM are as follows: the additionality standard

\footnotetext{
${ }^{97}$ See the sentence written by the economist John Lay in the Financial Times: 'When a market is created through political action rather than emerging spontaneously from the needs of buyers and sellers, business will seek to influence market design for commercial advantage.' Why the Key to Carbon Trading is to Keep it Simple (2006) Financial Times <http://www.johnkay.com/in_action/441> at 10 October, 2009.
} 
is not objective and hard to be validated. Hence, numerous projects, which would have been implemented without the CDM, anyway, have become beneficiaries of the system. Take Chinese case for example: in China, coal-fired power plants generate approximately 80 per cent of all electric power. $^{98}$ In order to support the rapid economic development, China is building new power plants at an astonishing rate. In order to reduce the country's dependence on coal, the Chinese Government has implemented a series of policies and laws to promote the development of renewable energy. China's current five-year plan ${ }^{99}$ calls for major investments in hydro, wind, nuclear, and natural gas-fired power. The Renewable Energy Law ${ }^{100}$ also provides strong financial incentives and takes other measures for development of wind sector. Even with such favourable legal and financial environments, each new dam, wind farm, or natural gas power plant applies individually under the rules of the CDM and makes the argument that it would not be growing at all without help from CDM. Based on the above, many scholars express their question about authenticity of the additionality of projects. ${ }^{101}$

In addition, the CDM project verification process carried out by the third party DOE has problems. With the increase of CDM projects, the problems of under-staffed situation and asymmetrical information are compounded in the CDM EB. As a result, CDM system relies on verifiers to verify the claim of the project developers. In

\footnotetext{
${ }^{98}$ Michael W. Wara and David G. Victor, 'A Realistic Policy on International Carbon Offset' (Program on Energy and Sustainable Development Working Paper No 74, Stanford University, 2008), 12.

99 See China's Eleventh-Five Year Plan (2006-2010), ch 6 <http://en.ndrc.gov.cn/hot/t20060529_71334.htm> at 3 March 2010.

${ }^{100}$ See Renewable Energy Law 2005 (People's Republic of China) ch 6

<http://www.ccchina.gov.cn/en/NewsInfo.asp?NewsId=5371> at 3 March 2010.

101 See especially Wara and Victor, above 98, 12-4.
} 
practice, the verifiers, who are paid by the project developers, have strong incentives to approve the projects they check. ${ }^{102}$ Further, there is scant oversight on the integrity of the verification process and no record of punishing verifiers for misconduct. ${ }^{103}$ In this case, the verification of the CDM project lacks objectivity and equality.

Second, the investors and financiers may suffer the high transaction costs as a result of the CDM's time-consuming approval process and its ongoing reduction emissions monitoring. These costs needed do not only include the fees to implement the project, but also to go through the long process of accreditation and certification, with all the attendant expenses of carbon consultants, third-party verifiers and so forth. Thus, this factor would deter businesses from taking part in CDM projects. Yet this problem is even worse for the potential small-scale companies in developing countries as transaction cost is generally similar regardless of project size. Large high carbon credits volume projects can pay off their investment costs quickly while the ones with smaller credit volumes would be more vulnerable. By this reason, many smaller but still environmentally beneficial projects would be excluded from entering the scheme.

Third, delays and inefficiencies along the project cycle exist as a result of long term and detailed regulatory process, leading to a higher transaction cost, loss in CER volumes and lower market value. Besides, as more and more eligible projects begin to undertake CDM projects, overload of EB is another reason. Consequently, there are a large number of potential projects in the pipeline are wasting their time awaiting the

\footnotetext{
${ }^{102}$ Ibid 14 .

103 Ibid.
} 
registration and issuance.

Finally, the bureaucratic procedure of managing CDM projects may produce corruption. Implementation of the CDM involves both international and domestic processes. While under the international process, the EB is given a regulatory and supervisory role, the domestic governments have the responsibility of approving CDM projects in their countries by applying their own sustainable development standards. In this scenario, even if the CDM has rigid supervisory rules, there is also a possibility that the corruption might occur. In the meantime, possible fraud by companies in the developing countries may turn up under the current CDM application and operation system. Despite the complex regulatory framework, there are both the incentive and the opportunity for project developers to distort key information, so as to make a project appear more effective and generate higher carbon emissions to get more CDM credit to trade with industrialized countries looking to meet their Kyoto Protocol emission targets. And there is no way you can figure out which projects are genuine reductions and which are not genuine reductions. ${ }^{104}$

\subsubsection{Uncertainty surrounding the CDM in the Post-2012 Period}

The first short-term commitment period for CDM is a limited timeframe, primarily up to 2012 and therefore the future of CDM in the post-2012 period is still uncertain. As the expiration of the first Kyoto period is looming, the various negotiations on the post-2012 international climate change agreement are underway. The international

\footnotetext{
104 David Victor, 'Life after Kyoto' (Speech delivered at the UCLA International Institute, Los Angeles, 1 February 2001).
} 
climate regime and concomitant mechanisms are most likely to be changed. In this connection, the development of the CDM is unstable.

Against this background, the uncertainty surrounding the CDM may influence the operation of CDM market. This is because any changes in the CDM and international regulations on climate change would make the demand and supply for GHG credits after the first Kyoto commitment period unstable. This post-2012 uncertainty will render less attractive those CDM projects with a long lead time (e.g. hydro electricity systems), or with low level of credit generation in early years (e.g. forestry projects). ${ }^{105}$ Hence, the uncertainty post-2012 may hinder the development of CDM projects.

In conclusion, the pitfalls of the CDM limit its potential to assist in shifting to a lower-carbon economy and more effective actions to reduce emissions need to be further encouraged. The bottlenecks facing today's CDM should be removed and new approaches should be developed.

\subsubsection{Key Factors Influencing the Success of the CDM}

After introducing and assessing the CDM, the key factors influencing the successful implementation of the CDM could be identified. Based on the above, this section gives an overview of the key factors influencing the success of the CDM. Pinpointing these factors could help avoid the pitfalls of CDM and thereby make effective use of

\footnotetext{
105 Jane Ellis and Sami Kamel, 'Overcoming Barriers to Clean Development Mechanism Projects' (Organization for Economic Cooperation and Development and UNEP Risø Centre, 2007) 41.
} 
Before analysing the critical issues influencing implementation of the CDM, it is necessary to make clear how to define the success of the CDM. As an emerging mechanism, the CDM is a response to climate change, which is widely believed that it may have its irreversible aftermath to different nations, regional areas and even the world as a whole. However, this aftermath and performance of the CDM on global warming mitigation are different from nations to nations and regions to regions. Therefore, there are no universal criteria for the success of the CDM. In spite of the differences, the general criteria for the success of the CDM are as follows:

First, viewed globally, the success of the CDM is associated with the ultimate objective of the UNFCCC, which is stabilising GHG concentrations at a level that would prevent dangerous anthropogenic interference with the climate system. Thus, investigating the contributions of the CDM to emission reduction and global warming mitigation is a significant way to evaluate its utilities and performance.

Second, the paramount consideration of a developed country on emission reduction is how to realise its legally-binding GHG emission reduction target under the Kyoto Protocol at the possibly least cost. In this scenario, from a developed country's perspective, if implementation of the CDM renders it an opportunity to assist in achieving its commitment in the most cost-effective way, it will take part in the CDM projects without hesitation. Hence, a focal point of attracting developed countries to invest in CDM projects is how the CDM assists them in alleviating financial burden 
of emission reduction.

Third, as stipulated in the Kyoto Protocol, one of the purposes of the CDM shall be to assist developing countries in achieving sustainable development. Also, it is a developing country's prerogative to decide the sustainable development criteria according to its national circumstances. For the reason that the main task for developing countries at this stage is economy development and getting rid off poverty, the potential economic, environmental and social benefits accrued under the CDM are decisive factors for them to apply for CDM projects. Whether the CDM could bring about clean technologies that are anticipated to improve the environmental problems existing in developing countries or not and whether it could provide a new kind of prosperity instead of a brake on profits and employment or not are the essential ways to criticize the performance of the CDM.

Based on the above criteria, the following four factors which include transaction costs, potential risks, low carbon technology transfer and domestic investment environment may influence the success of the CDM.

(1) Transaction costs

As the CDM functions as a project-based market mechanism, the paramount consideration of CDM developers and investors must be how much they would spend on undertaking CDM projects. However, from project design to issuance of CERs, developing a CDM project is a costly endeavor due to the time-consuming approval process and complex monitoring procedure. In addition, transaction costs are 
generally similar regardless of project size. ${ }^{106}$ Therefore, transaction cost would be a barrier faced by project developers, especially for small-scale projects in poorer developing countries. Under such a circumstance, the amount of transaction costs on developing the $\mathrm{CDM}$ project is an essential factor for project developers to decide whether to participate in it or not and which project would provide them the maximum carbon credits and thus they should take part in.

(2) Potential risks

Undertaking any type of project entails a multitude of risks, such as political and exchange rate, time overrun and capital overrun risks. Especially, by their nature, CDM projects involve a higher degree of various risks than other general projects as they involve a range of national or international CDM-related entities, a new and developing area of law and cross-jurisdictional transaction of rights. Rather, the risks can be minimised or fairly shared between the entities involved in a CDM project through careful contract drafting according to the international CDM operational rules and its interaction with domestic regulations. Therefore, risk mitigation is seen as an influential factor to ensure that CDM projects could advance in a smooth manner and in a way where the benefits are maximized.

\section{(3) Low carbon technology transfer}

The question of whether the $\mathrm{CDM}$ is promoting sustainable development can be framed primarily in terms of whether it is promoting renewable in developing

\footnotetext{
106 Pearson, above n 92, 250.
} 
countries and thus assisting in the transition away from fossil fuel. ${ }^{107}$ Nowadays, the priority of most developing countries focuses on the economic advancement by developing industries. Based on that, the emission space is of utmost importance for them in the process of economic development. Yet most of these countries are lack of low carbon technologies or the capacities or capital to promote the appropriate technologies. In this scenario, the CDM provides an opportunity to facilitate technology transfer. Only when the low carbon technology is wide spread in developing countries, can they be possible to shift to low carbon economy. In other words, unless the issue of transfer of technology and resources to developing countries is adequately addressed, the CDM regime will not function. ${ }^{108}$

(4) Domestic investment environment

While the primary rules governing CDM projects and the transaction of CERs are set out in the Kyoto Protocol, ultimately these rules are implemented within host country existing legal and commercial regimes. In this circumstance, the host country's domestic investment environment will definitely influence the development of CDM projects. The country with a favorable regulatory and commercial environment for CDM projects may have crucial advantages, and thereby maximise the possibility of attracting potential developers to invest in CDM projects. Accordingly, the domestic CDM-related legal and economic structures could be considered by potential project

\footnotetext{
107 Ibid.

108 Agus P. Sari and Stephen Meyers, Clean Development Mechanism: Perspective from Developing Countries (1999) 14.

See also Stephen Humphreys, Youba Sokona and Jean Philippe Thomas, Equity in the CDM (1998) Linkages Journal <http://www.iisd.ca/journal/enda.html> at 10 October 2009.
} 
participants and furthermore affect their decisions on investment in developing CDM projects in that host county.

\subsection{Conclusion}

It has been more than a decade since the CDM was proposed at COP 3 in 1997.

During these years, great changes have taken place in international climate regime. The scientific conclusion regarding the existence of global warming has changed from a possibility to an unequivocal fact, according the IPCC assessment report; the major countries with carbon emissions, including both developed countries and developing countries, have changed their attitudes towards emission reduction from protecting their own national economic interests to working together and taking their individual responsibilities to address global warming; the CDM has developed from a proposal to an instrument with detailed and integrated operational rules, which may bring $327,137,986$ tons annual emission reductions today; the GHGs emission, which was viewed as industry waste, has become a commodity to attract investment.

After introducing the CDM in an international context, next chapters will discuss it in the context of China. 


\section{Chapter 3 The CDM in China}

\subsection{Introduction}

In the previous chapter, basic information on the $\mathrm{CDM}$ in an international context was introduced. For the reason that the CDM is an emerging mechanism which involves both international and domestic processes and must be implemented in the host country, this chapter focuses on implementation of the CDM in the context of China.

According to the IPCC Report, global warning may have different influences on different countries and regions. ${ }^{1}$ In China's case, on the one hand, climate in China has experienced noticeable changes over the past 100 years as well $;^{2}$ on the other hand, global warming may have a different impact on China due to its own national circumstances. Facing this situation, it is essential for China to minimize adverse impact of global warming as well as reduce GHG emissions without undermining economic development in accordance with its capacity of addressing climate change in a domestic context. Besides, China plays an influential role in global warming mitigation in the international regime in that it is the largest developing country and has become one of the greatest GHG emitters in the world. ${ }^{3}$ Therefore, China's position on climate change issues and cooperation with other countries may decide its international status, and, to some extent, influence the progress of global warming mitigation.

\footnotetext{
${ }^{1}$ For details, see Chapter two 20-3.

${ }^{2}$ National Development and Reform Commission, People's Republic of China, China's National Climate Change Programme (2007) 4.

${ }^{3}$ For details, see below $97-8$.
} 
Based on the above, implementation of CDM projects in China is of great significance. It may not only provide an opportunity for China to attract foreign investment and environmentally clean technologies, but could also assist in reducing global carbon emissions. CDM projects have been conducted in China since its first CDM project, Huitengxile Windfarm Project of Inner Mongolia, was registered by the CDM EB on 26 June 2005. During these four years, China has formed its own standards, rules, management and other supporting services for the CDM, and thus considerable benefits have been brought from the CDM to China. In spite of the achievements, various barriers to implementing CDM projects in China still exist.

Against this background, this chapter aims to explore the significance, current achievements of as well as barriers to implementing CDM projects in China. In order to achieve this objective, Part two investigates climate change issues in China through examining the impact of climate change on China, China's capacities for addressing climate change in the domestic context and China's position on climate change issues in the international regime. Based on the research findings of Part two, Part three discusses the opportunities that the CDM would bring to China on economic, social, environmental and international status aspects respectively. Part four explores the current situation of CDM projects in China through examining the CDM practice and assessing its performance. Part five identifies various barriers to the implementation of CDM projects in China. 


\subsection{Climate Change Issues in China}

\subsubsection{The Impact of Climate Change in China}

Climate change has a different impact on different countries dues to their different national circumstances. China has the following basic national circumstances:

(1) Physical features and administrative divisions of China

China, located in Eastern Asia on the western shores of the Pacific Ocean, is the third largest country in the world by area after Russia and Canada, with 9.6 million square kilometers in total. China's coasts are on the East China Sea, Korea Bay, Yellow Sea, and South China Sea. Besides, it has a continental coastline extending over 18,000 kilometers and an adjacent sea area of 4.73 million square kilometers. ${ }^{4}$

The terrain of China contains a large variety of landscapes. In the east, there are extensive and densely populated alluvial plains, while in the north, grasslands can be seen. China's grassland area for 2005 was 400 million hectares, most of which are high-cold prairie and desert steppe while the temperate grasslands in Northern China are on the verge of degradation and desertification because of drought and environmental deterioration. ${ }^{5}$ Southern China is dominated by hill countries and low mountain ranges. The central-east possesses the deltas of China's two major rivers, the Yellow River and Yangtze River (Chang Jiang). Also, western part of China mostly consists of mountains, notably the Himalayas, high plateaus, deserts. China's total

\footnotetext{
${ }^{4}$ Above n 2, 15.

${ }^{5}$ Ibid.
} 
area of desertification for 2005 was 2.63 million square kilometers, accounting for 27.4 per cent of the country's territory; ${ }^{6}$ arable land in China, however, only accounts for 14.86 per cent. $^{7}$ In addition, the national forest area for 2005 was 175 million hectares and the coverage rate was just 18.21 per cent. $^{8}$

China has administrative control over twenty-three provinces, including Taiwan province. There are also five autonomous regions, which have traditionally been referred to as 'Outer China' because they are located beyond the Great Wall of China, four municipalities, including Beijing (Capital of China), Shanghai, Chongqing and Tianjin; and two Special Administrative Regions that enjoy considerable autonomy. The twenty-two provinces, five autonomous regions and four municipalities can be collectively referred to as 'mainland China', a term which usually excludes Taiwan, Hong Kong and Macau.

\section{(2) Population in China}

China has the largest population in the world. In 2005, the population of China's mainland was 1.31 billion, accounting for 20.4 per cent of the world population. ${ }^{9}$ In spite of the large population, excessive population growth trend has been under effective control since the 'One Child Policy' was made by Chinese government in 1982 as a basic national policy.

\footnotetext{
6 Ibid.

${ }^{7}$ See The World Factbook (2008) Central Intelligence Agency

<https://www.cia.gov/library/publications/the-world-factbook/geos/ch.html> at 10 August 2008.

${ }^{8}$ Above n 2, 15.

${ }^{9}$ Ibid.
} 
Along with industrialization, a movement of urbanization is taking place in China: the urban population accounted for only 26.4 per cent in 1990 and increased to 43 per cent in $2005 .^{10}$ However, China is still at a low level of urbanization, with 750 million people living in rural areas and urban population accounting for 43 per cent of the national population, which is lower than the world average. ${ }^{11}$

Consequently, huge population and urbanization movement bring about huge employment pressure for China, with annually more than 10 million new labor forces in the urban areas and about 10 million new rural labor forces moving to the urban areas as a result of the urbanization process. ${ }^{12}$

\section{(3) Economic development in China}

China's economy has been developing rapidly since the 'Reform and Opening up Policy ${ }^{13}$, which was proposed by Xiaoping Deng in 1978. The economy has changed from a centrally planned system that is under a rigid political control to a more market-oriented economy that has a rapidly growing private sector and is a major player in the global economy. As a consequence, living standard in China has been improved dramatically. Although great economic changes have taken place, China is currently at a relatively low level of economic development. In 2005, the per capita Gross Domestic Product (GDP) of China was about US\$1,714 (based on exchange

\footnotetext{
10 Ibid.

${ }^{11}$ The data was issued in 2001. See Chinese Cities and Provinces Information and Links, A China Information Base <http://www.chinatoday.com/city/a.htm> at 10 August 2008.

12 Above n 2, 15.

${ }^{13}$ For explanation, see below.
} 
rate of the same year, the same below), only about one fourth of the world average level. $^{14}$

Remarkable disparity in economic development exists among different regions of China. In 2005, the per capita GDP of the eastern areas of China was US\$2,877, while that of the western areas was US\$ 1,136 , only 39.5 per cent of the former. Especially, Shanghai in the eastern areas is experiencing fast economic development. According to international standards on statistics, the per capita GDP in Shanghai in 2006 was over US\$7,000. ${ }^{15}$

The income disparity between rural and urban residents is also great. In 2005, the per capita disposable income of the urban residents was US\$1,281, while that of the rural residents was only US\$397, equivalent to 31.0 per cent of the former. ${ }^{16}$ Furthermore, poverty eradication is still a huge challenge for China. By the end of 2005, the poverty-stricken people in China's rural areas numbered 23.65 million, with the per capita annual pure income less than 683 Chinese Yuan(less than US\$ 100). ${ }^{17}$

\section{(4) Climatic conditions in China}

The climate of China is extremely diverse with tropical in the south to subarctic in the north owing to China's extensive territory and complex topography. The northern zone (containing Beijing) has summer daytime temperature of more than 30 degrees

\footnotetext{
14 Ibid 16.

15 This is according to the news conference held by the Information Office of Shanghai Municipal Government on February 72007.

16 Above n 2, 16.

${ }^{16}$ Ibid.
} 
Celsius and winters of arctic severity with the lowest temperature of minus 30 degrees Celsius in northernmost province Heilongjiang. The central zone (containing Shanghai) has a temperate continental climate with very hot summer and cold winter. There are also the famous 'Three Ovens' cities along the Yangtze River in summer: Chongqing, Wuhan, and Nanjing. The summer temperature in these cities may reach up to 40 degrees Celsius. The southern zone (containing Guangzhou) has a subtropical climate with very hot summer and mild winter.

Moreover, most parts of China have a continental monsoon climate with more drastic seasonal temperature variations. As a result, the temperature in China in the winter is 5 to 18 degrees Celsius lower than that in other areas on the same latitude such as North America and West Europe. ${ }^{18}$

Precipitation in China varies regionally even more than temperature. Annual precipitation gradually declines from the southeastern coastal areas with as high as 1,500 millimeters to the northwestern inland areas with less than 50 millimeters. ${ }^{19}$ Viewed seasonally, most of the precipitation occurs in summer, mainly from May to September. Hence, the unevenly seasonal and spatial distribution of precipitation in China may cause floods in South China and droughts in North China. Besides, China experiences frequent meteorological disasters, such as typhoons, monsoons and tsunamis etc., which are unusual worldwide in terms of the gravity of disaster, the scope of affected areas, and the mass of affected population.

\footnotetext{
${ }^{18}$ See General Information of the People's Republic of China (PRC), A China Information Base <http://www.chinatoday.com/general/a.htm> at 10 August 2008.

${ }^{19}$ Ibid.
} 
(5) Air quality in China

Although the trend of air pollution in China has lowed down, the overall pollution level is still high. ${ }^{20}$ According to 2006 China Environmental Quality Communique, 62.4 per cent of the monitored cities have met the national air quality standard of Grade II and 37.6 per cent worse than Grade II. 51 cities had air quality worse than Grade III, accounting for 9.1 per cent of the total monitored cities. ${ }^{21}$

The main pollutants in the air are TSP and PM10 $22, \mathrm{SO}_{2}$ and NOx. The cities of which the average annual value of TSP and PM10 has exceeded the limit value of the national standard of Grade II accounted for 37.2 per cent of the total cities included in the statistics released in $2007 .{ }^{23} 18.3$ per cent of the cities had higher average annual concentration of $\mathrm{SO}_{2}$ than the limit value of the national standard of Grade II. ${ }^{24}$ The pollution of NOx was relatively serious in the super big cities where there was a high population density and a big number of vehicles. ${ }^{25}$

Air pollution brings about acid rain. China is one of the countries in the world suffering from severe acid rain contamination, which brings many hazards to the environment, affects the standard of living and is even harmful to human health. The acid rain is caused mainly by $\mathrm{SO}_{2}$ and NOx from burning coal and oil. ${ }^{26}$ In 2006 ,

\footnotetext{
${ }^{20}$ This is according to China Environmental Quality Communiques 1996-2008 released by Ministry of Environmental Protection of the People's Republic of China <http://jcs.mep.gov.cn/hjzl/zkgb/>at 8 July 2008.

${ }^{21}$ China Environmental Quality Communiques - Air Quality 2006 <http://jcs.mep.gov.cn/hjzl/zkgb/06hjzkgb/200706/t20070619_105423.htm> at 8 July 2008.

${ }^{22}$ TSP and PM10 are kinds of particulates in the air, which most influence the quality of air.

${ }^{23}$ China Environmental Quality Communiques - Air Quality 2007 <http://jcs.mep.gov.cn/hjzl/zkgb/2007zkgb/200811/t20081117_131297.htm> at 8 July 2008.

24 Ibid.

25 Ibid.

${ }^{26} \mathrm{SO} 2$ or NOx comes into atmosphere and reacts with the tiny droplets of water in clouds to form sulphuric and
} 
among 524 monitored cities, acid rain occurred in 283 cities, accounting for 54.0 per cent. ${ }^{27}$ Central, South, Southwest and East China are the regions with serious acid rain impacts.

In conclusion, it can be clearly seen from the above introductions to China's national circumstances that: first of all, China is vulnerable to the impact of sea level rise because China has a long continental coastline and most of the relatively developed cities in China, including Shanghai, are along the continental coastline. Second, despite the huge territory, China is still has a vulnerable ecosystem due to the lack of arable land and forest and the expansion of deserts. Third, China is facing a great challenge of reducing employment pressure caused by huge population. Fourth, the priority for China at this stage is to get ride off poverty and develop economy, which could demand more energy and emission space. Fifth, China has relatively harsh climatic conditions, and thus more energy is needed to maintain a relatively comfortable room temperature. Finally, air pollution in China is serious and more efforts are needed to improve the air quality.

As mentioned earlier, global warming has been confirmed to be real. ${ }^{28}$ In China, there has also been noticeable change in temperature, precipitation, extreme weather event, glacial movement and sea level.

\footnotetext{
nitric acids. The rain from these clouds then falls as very weak acid - which is why it is known as 'acid rain'. 27 Above $\mathrm{n} 20$.

${ }^{28}$ For more details, see Chapter two 19.
} 
Annual average air temperature has increased by $0.5 \sim 0.8$ degree Celsius during the past 100 years, which is slightly larger than the average global temperature rise. ${ }^{29}$ Moreover, China is now experiencing the hottest temperature in over 50 years. 20 consecutive warm winters were observed nationwide from 1986 to 2005 . $^{30}$ Predominantly, the increase rate of temperature in northern part of Northeast China is more than 4 degrees Celsius in the last 50 years. ${ }^{31}$ In addition, the projections by Chinese scientists indicate that the nationwide annual mean air temperature would increase by 1.3 2.1 degrees Celsius in 2020 and 2.3 3.3 degree Celsius in 2050 as compared with that in $2000 .^{32}$

No trend has been found in precipitation change for the last 100 years, but the regional distribution of precipitation shows that the decrease in annual precipitation is significant in most North China, while precipitation significantly increased in South China.

Extreme precipitation events have become more frequent and intense. Floods in regions of south of the Yangtze River have become more severe, while in northern China, the droughts have become more frequent, especially in recent 20 years. What is worse, the severe droughts after the 1970s in northern China have caused shortage of water resources and great loss of agricultural production. ${ }^{33}$

\footnotetext{
${ }^{29}$ Above n 2, 4.

${ }^{30}$ Ibid.

31 Dahe Qin et al, 'Assessment of Climate and Environment Changes in China (I): Climate and environment changes in China and their projections' (2006) 2 (1) Advances in Climate Change Research 12.

${ }^{32}$ Above n 2, 5.

${ }^{33}$ Qin, above n 31, 2.
} 
In addition to this, the extreme minimum temperature in winter and the heat waves in summer have also increased in China.

Glacier areas in China decreased from 75,427 square kilometers to 59,414 square kilometers. ${ }^{34}$ The number of retreating glaciers contributes to 80.8 per cent of the total number of glaciers and the retreating rate has accelerated in the last 30 years. ${ }^{35}$

The rate of sea level rise along China's coasts during the past 50 years was $2.5 \mathrm{~mm} / \mathrm{a}$, slightly higher than the global average. ${ }^{36}$

Clearly, natural evidence has showed that China is undergoing global warming, and the trend of global warming in China is likely to intensify in the future.

Global warming has impacted on China in varied ways. The various ways global warming has impacted on China are examined with a view to discussing how serious the climate change issues are in China.

The main climatic problems in China include droughts, flooding, tropical cyclones, dust storms, cold waves and frost damage. ${ }^{37}$ Among these problems, drought and flooding are the biggest problems. ${ }^{38}$ Land degradation, which includes land

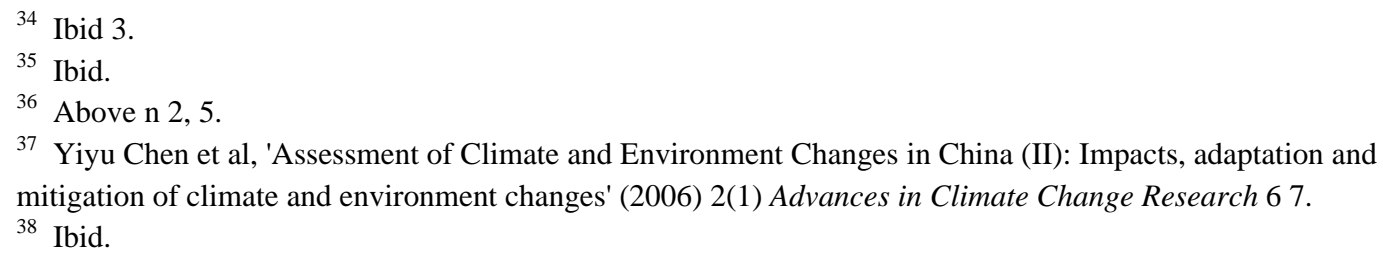


desertification and soil erosion, is the most pressing challenge currently faced by China. $^{39}$

From an individual's perspective, besides the fact that severe natural disasters cause death, global warming also has an impact on people's living conditions. People's health can be threatened by climate change induced diseases, urban heat island effect, ${ }^{40}$ air pollution and malnutrition arising from reduction agricultural production. As a result, medical care costs for people increase. ${ }^{41}$ Moreover, with the rising temperature, energy and water consumption in summer increases.

Climate change also influences all the industries in the society. ${ }^{42}$ Future global warming would increase instability in agricultural production, where the yields of crops are likely to decline if no proper adaptation measures are taken. Moreover, the changes in agricultural production conditions may cause increase in production costs and investment needs. As a consequence, the price of agricultural production would increase. As for industry, it would face the problems of increased prices of raw materials, water resource shortage and lack of clean technologies. The service industry would also be affected. Both the tourist landscape would change due to global warming and the extreme weather events may have a significant impact on tourism. Besides, the insurance industry may be influenced by the spreading of

\footnotetext{
39 Ibid.

40 The urban eat island effect refers to the fact that temperatures are often a few degrees higher in cities than they are in their surrounding rural areas.

${ }^{41}$ Chen, above $\mathrm{n} 37,10$.

${ }^{42}$ See ibid 7-8.
} 
climate change induced diseases and frequent disastrous hazards, such as flooding or dust storms.

Global warming incurs economic losses in mitigating and adapting its adverse impacts. The direct economic losses caused by flooding only may go beyond 100 billion RMB yuan per year. ${ }^{43}$ Dahe Qin, the director of China Meteorological Administration, noted that in 2006, severe natural disasters caused economic losses of 212 billion yuan (US\$27 billion) in China. ${ }^{44}$ Besides natural disasters, sea level rise and coastal ecosystem deterioration derived from global warming would seriously affect the national economic development as the coastal regions are the relatively developed parts in China, especially in eastern China, where the GDP accounts for more than 60 per cent. ${ }^{45}$

On the other hand, global warming has a positive impact on China. First, high $\mathrm{CO}_{2}$ concentration, the main contribution of global warming, may help species evolution, thus improving the regional biodiversity. ${ }^{46}$ Also, future climate change would accelerate the returning green period of some pasture grass by raising the decomposition rates of grassland litter. ${ }^{47}$

Second, facing the great challenge of global warming, people would become more aware of the seriousness of the problem and would not produce so much waste.

\footnotetext{
43 Ibid 7.

${ }^{44}$ See Ling Li, 'China Releases First National Report on Climate Change', Worldwatch Institute (Washington DC), 11 January $2007<$ http://www.worldwatch.org/node/4848 > at 4 March 2008.

${ }^{45}$ Chen, above $\mathrm{n} 37,8$.

46 Ibid 9.

47 Ibid.
} 
Third, the great pressure derived from global warming may stimulate industries to advance clean technologies and adjust inner structures with a view to increasing utilisation rate of resources. Besides, the global warming would promote the development of some light industries, such as soft drink manufacturers, and bring about some new industries, like environmental services for businesses and solar panel production, which in turn may provide more job opportunities. ${ }^{48}$

In summary, the negative impact of climate change on China obviously overweighs the positive one. Global warming poses a clear and present threat to China's development. Accordingly, China should place global warming issues on the top of agenda and make great efforts to reduce carbon emissions. However, according to China's national circumstances, at the current stage, more emission space is needed to develop economy. Given the significance of climate change issues in China, it is necessary to investigate China's capacity for addressing global warming.

\subsubsection{China's Capacity for Addressing Global Warming in a Domestic}

\section{Context}

Demand and supply of energy are affected by economic growth and structural change of the economic sectors. China has had a very high economic growth rate since the 'Economic Reform and Opening Up' policy ${ }^{49}$ was proposed. Its annual GDP growth

\footnotetext{
48 Ibid 10.

${ }^{49}$ It refers to the program of economic reforms called 'Socialism with Chinese characteristics' in the People's Republic of China (PRC) that were started in December 1978 by pragmatists within the Communist Party of China (CPC) led by Deng Xiaoping and are ongoing as of the early 21st century. The goal of Chinese economic reform was to generate sufficient surplus value to finance the modernization of the mainland Chinese economy. < http://en.wikipedia.org/wiki/Economic_reform_in_the_People's_Republic_of_China> at 10 August 2008.
} 
rate has remained appropriately 10 per cent in the consecutive seven years during the period of 2003-2009. ${ }^{50}$ In particular, the amount of GDP in 2007 reached 2.47 billion Yuan, with 11.4 per cent growth rate. ${ }^{51}$ Moreover, it is predicted that the high growth momentum will remain in the $21^{\text {st }}$ century. ${ }^{52}$

While China astonishes the world with its rapid economic development, however, energy problems emerge as to how it will fuel its future economic growth. China would certain need more energy.

First, China needs more electricity to advance industry and maintain its standard of living. Although the industrial structure has been improved through a series of policies with an aim of accelerating the development of tertiary industries and restructuring secondary industries, the ratio of secondary industry is still too high and tertiary industry is seriously low compared to developed countries. The National Bureau of Statistics of China indicates the breakdown of GDP across the primary, secondary and tertiary industry in 2007 was 11.7 to 49.2 to 39.1 , while in developed countries it is less than 5 to less than 30 to more than $65 .^{53}$ In this scenario, on the one hand, great efforts should be made to optimize the industry structure; on the other hand, more electricity and raw materials are needed as secondary industries still dominate. Furthermore, as the people's living conditions increasingly improve and urbanization speeds up, more electricity is needed to fulfill people's standard of

\footnotetext{
50 See Chinabilty <http://www.chinability.com/GDP.htm> at 10 August 2008.

51 See the primary accounting of China's National Statistics Bureau

<http://www.stats.gov.cn/english/> at 10 August 2008.

52 Ibid.

53 Above n 49.
} 
living.

In addition, China's transportation sector is developing rapidly. In the early 1980s, it was very rare to have a private car in China. This situation has changed. With the development of China's economy, the middle-class is emerging and growing in China. Thus, rising incomes make private cars more affordable to the middle-class. According to the report of China National Statistics Bureau, by 2001, China had 7.71 million private cars, a number which may mushroom to 140 million by $2020 .{ }^{54}$ Under this scenario, transportation fuel consumption would incur a massive increase in demand for energy and energy-related carbon emissions.

Facing this situation, China's energy structure is examined with a view to finding out how and where China could get the energy to meet the demand of such a phenomenal economic growth.

China is endowed with rich resources of coal and uses it as its main energy source. Historically, coal had supplied more than 70 per cent of China's energy. It was reported that share of coal in China's primary energy mix was 76.2 per cent in 1990, whereas the shares of oil, gas and hydro were 16.6 per cent, 2.1 per cent and 5.1 per cent respectively. ${ }^{55}$ Coal combustion in China produces 70 per cent of $\mathrm{CO}_{2}, 90$ per cent of $\mathrm{SO}_{2}$ emissions and 67 per cent of NOx emissions. ${ }^{56}$ Hence, facing the problems of drastic air pollution from coal combustion and international concerns

\footnotetext{
${ }^{54}$ See 'China to Have 140 Million Cars by 2020', China Daily (Beijing), 5 September 2004.

55 Above n 2, 9.

56 Jonathan E. Sinton et al 'Evaluation of China's Energy Strategy Options' (The China's Sustainable Energy Program, 2005) 19.
} 
over carbon emissions caused by coal use, China realised that its long-term reliance on this resource was simply unsustainable. Hence, China began to reduce coal's dominance by increasing the share of high grade and clean energy: oil, nuclear power, hydro, natural gas, and renewable energy. As a result, the share of coal in total primary energy supply in 2005 decreased to 63.4 per cent, with 13.0 per cent share of renewable and waste energy (See chart 3.1 below). With regard to the electricity generation by fuel in 2005, coal-fired power accounted for 79.0 per cent, and there were 15.9 per cent power generated by hydro and 2.1 per cent nuclear (See chart 3.2 below).

\section{Chart 3.1 Share of Total Primary Energy Supply in 2005}

\section{Share of Total Primary Energy Supply ${ }^{\star}$ in 2005}

People's Republic of China

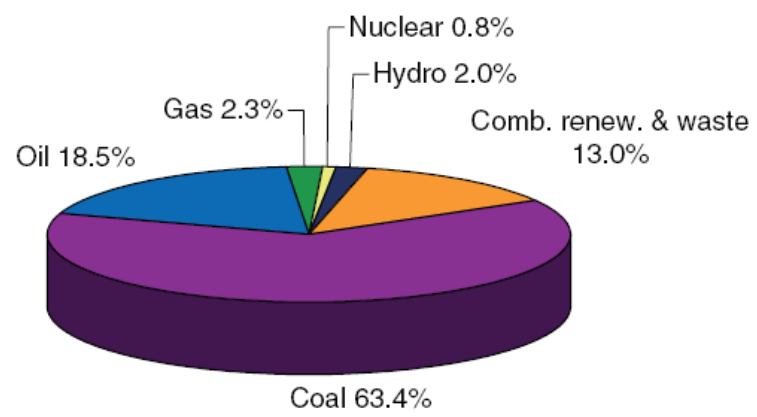

1717153 ktoe

* Share of TPES excludes electricity trade.

Note: For presentational purposes, shares of under $0.1 \%$ are not included and consequently the total may not add up to $100 \%$.

Source: IEA Energy Statistics <http://www.iea.org/textbase/stats/pdf_graphs/CNTPESPI.pdf> at 10 August 2008. 


\section{Chart 3.2 China - Electricity Generation by Fuel 2005}

\section{China - Electricity Generation by Fuel 2005}

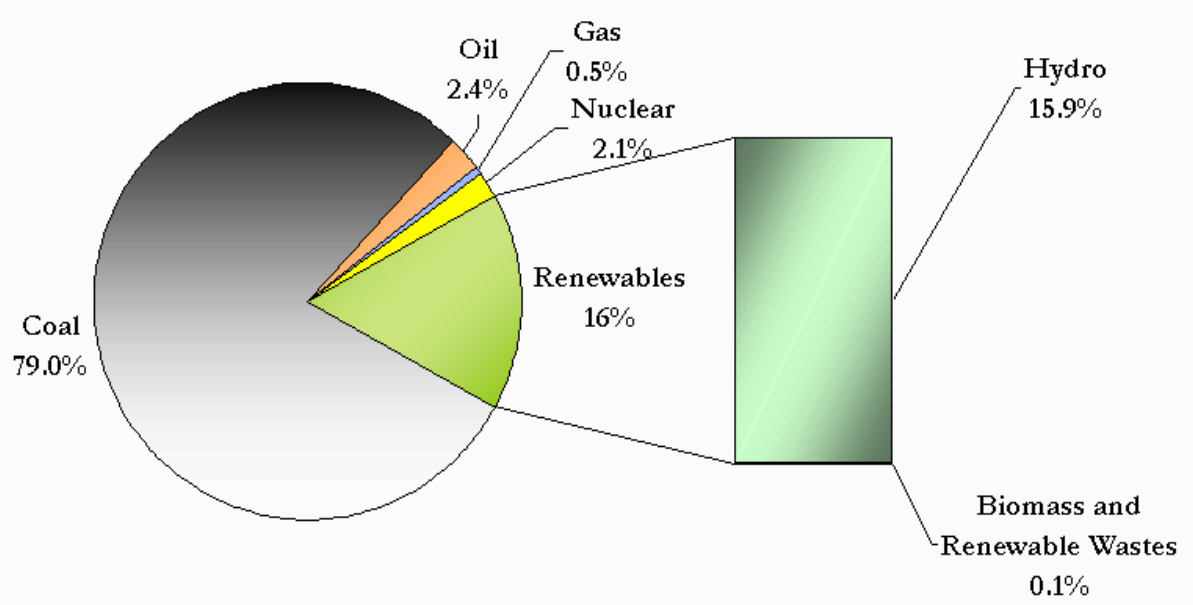

Source: IEA Energy Statistics - - OECDMEA 2007

Totals in graphs might not add up due to rounding.

Access to detailed data for almost all fuels for both $\mathrm{OECD}$ countries and over 100 other countries is available through the IEA website at:

ittp:IMwww iea.orgistatistics

Furthermore, low energy efficiency and high energy intensity, which are measured by the ratio of energy consumption to GDP, in China may even compound the energy problems. During 1977-97 China's energy intensity declined about 60 per cent. ${ }^{57}$ However, until 2002, China's percentage increase in energy consumption was lower in relative terms than its economic growth rate, which indicates efficiency began to gain. Still, the energy efficiency is relatively low by an international comparison of energy consumption per unit of GDP. The ratio in 2005 was 0.91 , which is 2.4 times higher than the global average, 4.9 times higher than in EU countries, and 8.7 times higher than in Japan. ${ }^{58}$

\footnotetext{
57 William Chandler et al 'Climate change mitigation in developing countries: Brazil, China, India, Mexico, South Africa, and Turkey' ( Prepared for Pew Centre on Global Climate Change, 2002) 13.

58 Jing Fu, 'Energy Law Aims at Power Conservation', China Daily (Beijing), 2 July 2006, 2.
} 
China's energy demand will continue to grow with economic development. According to World Energy Outlook 2007, China's energy demand is expected to more than double by 2030, with coal accounting for about half of the increase (see the chart 3.3 below). Per capita energy use, however, is low compared to international standards. It is equivalent to about half of the world average and only 10 per cent of the per capita energy use in the United States. ${ }^{59}$

\section{Chart 3.3 China's Primary Energy Demand}

\section{China's Primary Energy Demand}

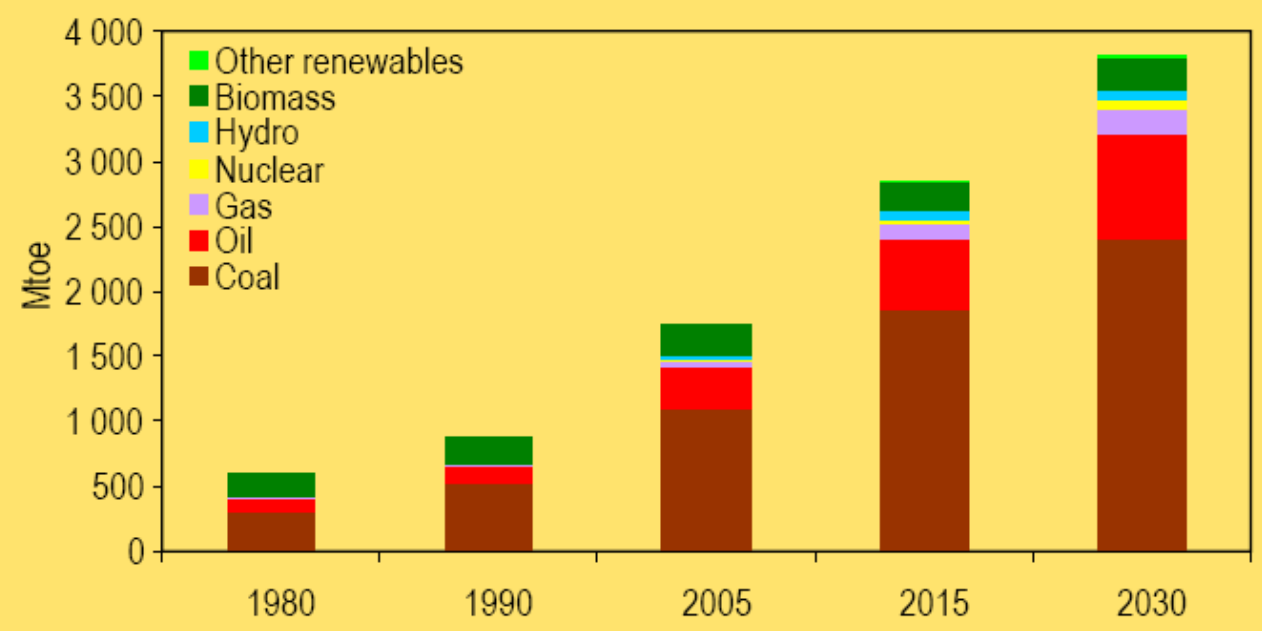

Source: IEA Energy Statistics <http://www.iea.org/textbase/speech/2007/Tanaka/weo_beijing.pdf pp8> at 10 August 2008.

Accordingly, China has endeavored to optimize on its energy mix by developing low carbon and renewable energy, but the dominance of coal as the primary energy supply

\footnotetext{
59 'China Human Development Report 2002' (Stockholm Environment Institute and United Nations Development Programme, 2002) 55.
} 
could not be completely changed in a short-term due to China's lack of clean technologies and large amount of coal reserves.

Based on the above analysis, large demand for energy, which is dominated by coal, would thus incur large amounts of energy-related carbon emissions in China.

According to the Initial National Communication on Climate Change of the People's Republic of China, ${ }^{60}$ China's GHG emissions in 1994 were 4,060 million $\mathrm{tCO}_{2} \mathrm{e}$ (tons of $\mathrm{CO}_{2}$ equivalent), of which 3,070 million tons of $\mathrm{CO}_{2}$. Also, China's GHG emissions in 2004 were about 6,100 million $\mathrm{tCO}_{2}$ e, of which 5,050 million tons of $\mathrm{CO}_{2}{ }^{61}$ From 1994 to 2004 , the annual average growth rate of GHG emissions was around 4 per cent, and the share of $\mathrm{CO}_{2}$ in total $\mathrm{GHG}$ emissions increased from 76 per cent to 83 per cent. ${ }^{62}$ Moreover, there are reports indicating their conclusions that China has overtaken the United States as the world's largest GHG emitter. ${ }^{63}$ In addition, China's energy-related $\mathrm{CO}_{2}$ emissions are expected to double soar by 2030 (See chart 3.4 below).

\footnotetext{
${ }^{60}$ Initial National Communication on Climate Change of the People's Republic of China 2007 (the People's Republic of China) <www.ccchina.gov.cn/file/en_source/da/da2004110901.pdf > at 10 August 2008.

${ }^{61}$ Above $\mathrm{n} 2,6$.

62 Above n 58, 6.

${ }^{63}$ See, eg, 'Chinese $\mathrm{CO}_{2}$ Emissions in Perspective' (Netherlands Environmental Assessment Agency 2007), 'the surging power demand from China's rapidly expanding economy caused $\mathrm{CO}_{2}$ emissions to rise by $9 \%$ in 2006 ...that increase, coupled with a slight United States decline meant that China's emissions for the year surpassed those of the US by $8 \%$.'
} 


\section{China's Energy-Related $\mathrm{CO}_{2}$ emissions}

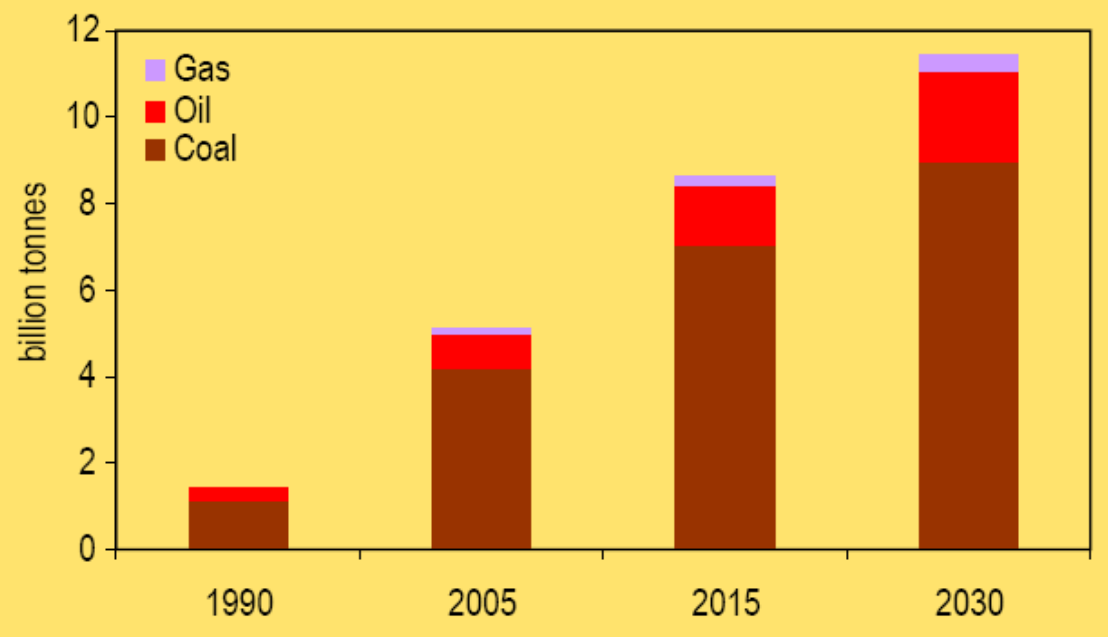

China's Energy-related $\mathrm{CO}_{2}$ Emissions $\odot$ OECD/IEA - 2007

Emissions soar from $5 \mathrm{Gt}$ in 2005 to $11 \mathrm{Gt}$ in 2030, though they remain below current OECD levels in per-capita terms

Most emissions come from electricity and heat generation, followed by industries

(See chart 3.5 below). Moreover, it could not be ignored the fact that transportation in China is likely to growth dramatically in a few decades, although in the last few years it was responsible for only 9 per cent of China's energy related carbon emissions. 


\section{Chart 3.5 $\mathrm{CO}_{2}$ Emissions in China}

\section{$\mathrm{CO}_{2}$ Emissions in China (Unit: million ton)}

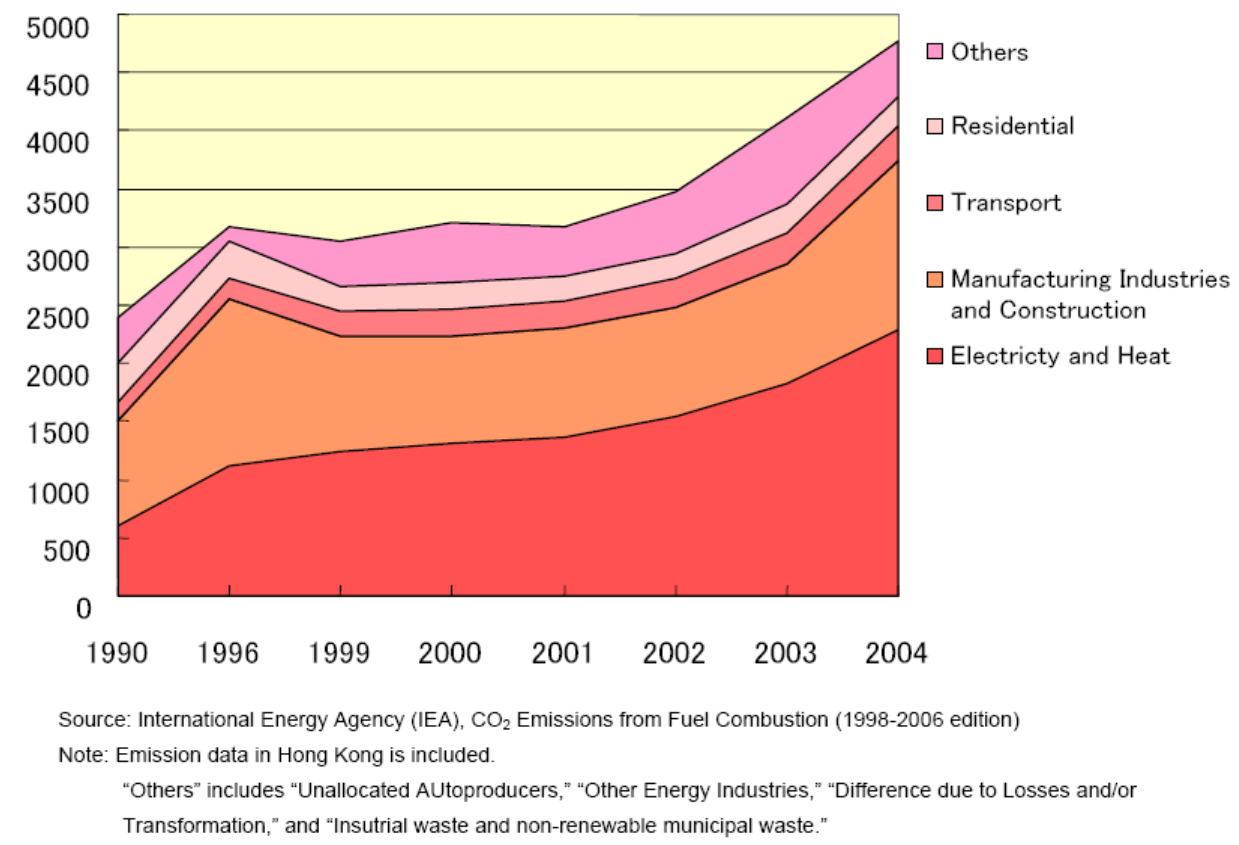

Despite China's increasing emissions, its historical and per capita GHG emissions are very low. In accordance with the study carried out by the World Resource Institute, cumulative emissions in China accounted for 9.33 per cent of the world total emissions during the period 1950-2002, and the cumulative $\mathrm{CO}_{2}$ emissions per capita were 61.7 tons over the same period, ranking the $92^{\text {nd }}$ in the world. ${ }^{64}$ Even viewed earlier and against the background of cumulative emissions during 1850-2002, China was only with a share of 7.6 per cent while the United States was with 29.3 per cent and the EU-25 was with 26.5 per cent. ${ }^{65}$ In addition, statistics from the International Energy Agency indicate that per capita $\mathrm{CO}_{2}$ emissions from fossil fuel combustion were 3.65 tons in 2004 in China, which were below the world average and equivalent

\footnotetext{
${ }^{64}$ Baumert, T. Herzog and J. Pershing, 'Navigating the Numbers: Greenhouse Data and International Climate Policy' (World Resources Institute, Washington DC 2005) 13.

${ }^{65}$ Ibid 14.
} 
to one third of the level in Organization for Economic Cooperation and Development (OECD) countries. ${ }^{66}$

The effectiveness of a governance system in general may influence the effective global warming mitigation. An effective governance system requires instruments for policy coordination, rule of law and the realisation of established goals. Base on the above, the section below explores how the Chinese Government has responded to the threat arising from global warming and carbon emissions.

The Chinese Government has adopted a series of policies and programs designed to alleviate the side effects of global warming.

First, climate change has been embodied in the overall national development guidelines and plans. In 1994, China's sustainable development strategy, China's Agenda $21^{67}$, which described concrete steps that it would take towards sustainable development and mounting a response to climate change in the $21^{\text {st }}$ century, with sustainable energy development as one of the major components, was released. Currently, the government is working on the $11^{\text {th }}$ Five-Year Programme for National Economic and Social Development $(2006-10)^{68}$, where GHG emissions is further stressed that energy consumption (per unit of GDP) will be reduced by 20 per cent over five years, that the amount of pollutant will be reduced by 10 per cent, and that

\footnotetext{
${ }^{66}$ See Statistics and Balance, International Energy Agency <http://www.iea.org/stats/index.asp>.

Organization for Economic and Cooperation Development (OECD) countries consists of most of the developing countries.

${ }^{67}$ China's Agenda 211994 (the People's Republic of China) <http://www.acca21.org.cn/english/index.html> at 3 March 2009.

${ }^{68}$ China's Eleventh-Five Year Plan (2006-2010) <http://en.ndrc.gov.cn/hot/t20060529_71334.htm> at 3 March 2009.
} 
forest coverage will be raised to 20 per cent of the national territory. ${ }^{69}$ In order to better understand the climate change in China, at the close of 2006, the warmest year in China since 1951, China released the country's first-ever National Assessment Report on Climate Change ${ }^{70}$, clearly showing that global warming poses a threat to China's development. In additional, as it is mandated under the UNFCCC that all parties are required to launch national strategies for climate change mitigation and adaptation to expected impacts, ${ }^{71}$ the Chinese Government formulated its first national policy specific on climate change: China's National Climate Change Program $^{72}$, in 2007, setting out broad goals for arresting global warming and cutting GHG emissions.

Second, besides the overall guidelines, China has carried out concrete programs to reducing GHG emissions. Many new standards on energy have been issued to improve energy efficiency and reduce energy consumption. The China National Institute of Standardization issued a series of new appliance efficiency standards for consumer appliances, such as refrigerators, electromagnetic ovens, washing machines and lamp, with the purpose of assisting to realise the objective of improving energy efficiency by 20 per cent in 2010 stipulated in the $11^{\text {th }}$ Five-Year Plan. Also, there are several developments in the area of energy conservation, with new national

\footnotetext{
${ }^{69}$ See China's Eleventh Five-Year Plan (2006-2010), Ch 6 <http://en.ndrc.gov.cn/hot/t20060529_71334.htm> at 3 March 2009.

${ }^{70}$ China's National Assessment Report on Climate Change (I)\&(II)

$<$ www.climatechange.cn/qikan/manage/wenzhang/01.pdf> and

<www.climatechange.cn/qikan/manage/wenzhang/02.pdf> at 3 March 2009.

${ }^{71}$ For details, see Chapter two 25.

${ }^{72}$ National Development and Reform Commission, People's Republic of China, China's National Climate Change Programme (2007) <en.ndrc.gov.cn/newsrelease/P020070604561191006823.pdf> at 3 March 2009.
} 
conservation standards for public and residential buildings seeking to reduce energy consumption by 65 per cent in Beijing, Chongqing, Shanghai, and Tianijng and by 50 per cent in small cities. ${ }^{73}$ By 2020, China plans to renovate 25 per cent of public and residential buildings in large cities, 15 per cent in medium-sized cities, and 10 per cent in small cities. ${ }^{74}$ With the increase of private cars in China, new passenger vehicle fuel-efficiency standards took effect in July 2005 that call for more stringent standards than those in the United States and Japan. ${ }^{75}$ What's more, in June 2007, the State Council decreed that public buildings could not set their air-conditionings below 26 degrees Celsius during the summer and above 20 degrees Celsius in the winter and even intended to legislate this regulation. ${ }^{76}$ China just recently released Emission Standard of Coalbed Methane/Coal Mine Gas (on trial) ${ }^{77}$ in order to enhance the management of emissions and mitigate global warming.

Finally, at a macroeconomic level, China has introduced many economic mechanisms to help fight against pollution and inefficiency. Government bodies are expected to make the tax rate more preferential for energy efficiency and renewable sectors. For example, according to China's new Corporate Income Tax Law ${ }^{78}$, a three-year tax exemption followed by a three-year half deduction is available for energy- and

\footnotetext{
${ }^{73}$ See Margret Kim and Robert E. Jones, 'China: Climate Change superpower and the Clean Technology Revolution' (2008) 22(3) Natural Resources \& Environment 911.

74 Ibid.

${ }^{75}$ See Hongyan H. Olive et al, 'China's Fuel Economy Standards for Passenger Vehicles' (Discussion Paper 2009-03, Harvard Kennedy School, 2009) 15 and 18.

${ }^{76} \mathrm{Kim}$ and Jones, above n 72. In fact, this regulation has been put into the Energy Conservation Law in 2007. See Chapter four 174.

77 Emission Standard of Coalbed Methane/Coal Mine Gas (on trial) 2008 (the People's Republic of China) <www.ep.net.cn/cgi-bin/dbbz/doc.cgi?id=1067> at 11 November 2008.

${ }^{78}$ Corporate Income Tax Law 2008 (the People's Republic of China) <www.investteda.org/downloads/Tax.doc> at 11 November 2008.
} 
water-saving projects. In addition, tariffs on environmental goods and services are lowered in order to attract cleaner technologies. China has recently imposed new restrictions on heavy polluters trying to list on domestic stock markets. ${ }^{79}$ According to the new rules, companies from sectors designated as high-polluting and high-energy consuming, which include thermal power, steel, cement and electrolytic aluminum, will have to submit to an environmental inspection if they wish to launch an Initial Public Offerings (IPO) or apply for additional financing. ${ }^{80}$

China has also enacted numerous specialised laws, regulations, procedures, and initiatives on climate change and GHG emissions reduction, which will be discussed in detail in Chapter four.

In addition, the Chinese Government has restructured official departments in order to further enhance their environmental protection capacities. In order to enhance the corporation of environmental policies, plans, and other significant environment problems, Ministry of Environmental Protection of the People's Republic of China (hereinafter referred to as MEP) has been set up to replace the State Environmental Protection Administration of China (SEPA) in accordance with the Government Reshuffle Plan of the State Council in March, 2008. Its administrative level was raised from administration to ministry, where it could better exert its environmental protection function.

\footnotetext{
79 Agencies, 'Heavy Polluters to be Restricted from Listing', China Daily (Beijing), 25 February 2008 <http://www.chinadaily.com.cn/bizchina/2008-02/25/content_6482947.htm> at 11 November 2008.

${ }^{80}$ Ibid.
} 
A new promotion system has also been launched, under which local officials' careers will be judged by their performance in meeting environmental protection and energy efficiency targets. The reason for the proposal of this new system is that local and provincial officials were judged mainly on their performance in promoting economic growth, and there was little incentive for them to improve environmental quality and energy efficiency. Owing to this green assessment of local officials, it is possible for local governments to put environmental issues on the agenda, thus enhancing the enforcement of environmental polices and laws.

The Chinese Government has also utilised more active media to highlight the significance of environmental issues and promote public participation. As the Olympic Games in 2008 was approaching, China attached more importance to atmospheric quality and committed to new environmental standards. It wanted to show the world that the environmental problems had been improved though its unremitting efforts and that it was ready to host the Games. Recently, 'environment and climate change' in China has become an importance part of media coverage. Climate change stories appear almost daily in China Daily, the Government's official English-language newspaper, let alone the other local newspapers; when a television is turned on, there is probably a piece of news or a commonweal advertisement about climate change on China Central Television Channel (CCTV).

The conclusion could be drawn that the Chinese Government has been making make arduous efforts to reduce GHG emissions and minimise an adverse impact of climate 
change domestically.

In terms of China's huge population, public attitudes and daily behaviors towards environmental protection will largely influence the progress of global warming mitigation.

Thanks to the economic development and improved education, Chinese, especially by people born after the 1970s, who have had obtain more opportunities to receive higher education, and thus could be more sensible regarding the environmental issues. According to the report of a nationwide survey released in April 2008, nearly 75 per cent of urban Chinese are aware of the importance of a sound ecological environment. ${ }^{81}$ As for the ideal living environment in China, clean air is on the top of list. ${ }^{82}$ Based on that, it can be concluded that most urban people have realized the importance of environmental protection. However, it should be noted that this result cannot represent the environmental awareness of all Chinese. There are large differences between urban areas and rural areas in regards to economic, education or living conditions. Urban people are better educated, and thus they may be better informed than people living in rural areas. Besides, the extensive access to internet and other media has placed urban people in a better position to obtain environmental information and express their views. On the contrary, in rural areas, which are more vulnerable to the adverse impact of environmental problems, and account for large

\footnotetext{
${ }^{81}$ The research was conducted by the Chinese Ecological Education Promotion Association and the Ecological Culture Research Center under the Peking University. It was carried out in the five cities in different regions of China and lasted more than three month. Accordingly, this survey could be considered to authentically reflect the public environmental awareness in urban areas.

82 Ibid.
} 
part of China, people are not concerned about the environmental protection due to the relatively low knowledge levels and living conditions. By this reckoning, environmental awareness in China is relatively low. In other words, most Chinese neglect the importance of environment.

In spite of the relatively low level, environmental awareness in Chinese society and consciousness of the tense energy situation have been enhanced. In addition, people would pay more attention to climate change as China launched its first national environmental health action plan to enable the research on health impacts of climate change in China. ${ }^{83}$ The World Bank data demonstrate that almost one billion Chinese people live in air that does not meet the WHO (World Health Organization) standard. ${ }^{84}$ However, China has focused too much on its market-driven economic growth and that environment-related health consequences have been neglected. As a result, there is little information available about the impact of the deteriorating environment on the health of the population and people do not know how seriously it affects their health. It is believed that the outcome of this research would alarm people to raise their awareness of the environment.

In conclusion, viewed domestically, the rapid development of China's economy has brought with it and will continue to bring massive GHG emissions. Despite enormous efforts to improve the capacity for cutting emissions and improving environmental

\footnotetext{
${ }^{83}$ See China Moves to Tackle Pollution Effects on Health (2007) People <http://scitech.people.com.cn/GB/6605794.html> at 11 November 2008.

${ }^{84}$ Taige Li, China Moves to Tackle Pollution Effects on Health, (26 November 2007) <http://www.scidev.net/en/news/china-moves-to-tackle-pollution-effects-on-health.html> at 11 November 2008.
} 
quality, it is difficult to shift to a low carbon consumption society in the short-term due to the lack of clean technologies and funding in China. Under this scenario, international assistance and cooperation could be of great significance for China to reduce GHG emissions.

\subsubsection{China's Position on Climate Change Issues in an International}

\section{Context}

Given the importance of international cooperation on addressing climate change, China's position on climate change issues regarding to international environmental law is examined.

China's position has been clear and consistent. As a party of the UNFCCC, China claim that it seriously fulfills its commitments and adheres to its principles under the Convention and the Kyoto Protocol, which are considered as a major legal framework for international community to address climate change. ${ }^{85}$

According to the principle of 'common but differentiated responsibilities' enshrined in the Kyoto Protocol, developed countries should take the lead in reducing GHG emissions based on their historical responsibilities and current high emissions levels. As for developing countries with less historical emissions and current low per capita emissions, their priority is to achieve sustainable development. Hence, as a developing county, China would take due measures to pursue a more sustainable, lower carbon future and contribute its share to tackling climate change, but not at the

\footnotetext{
${ }^{85}$ Above n 2, 58-60.
} 
expense of economic development. Besides, China declares that it would not accept any binding carbon emission reduction target.

Sufficient attention was not given to adaption to climate change, especially the promotion of developing countries' capacities against extreme climatic events, until the Bali Conference. ${ }^{86}$ China would cooperate with the international community to actively participate in activities for climate change adaptation and formulation of relevant legal documents.

Clean technologies and funding play essential roles in addressing climate change. China maintains that developed countries should honour their commitment to making technology transfers and providing financial support to developing countries. By strengthening international technology cooperation and transfer, the clean technologies are more accessible to developing countries. Also, a special fund should be established with the purpose of assisting developing countries to adapt to climate change.

China has participated in many other regional conferences and cooperation on climate change based on the premise that those conferences and cooperation, in any forms, should function as a helpful complement to the UNFCCC and Kyoto Protocol rather than replacing or weakening them. The purpose of them should be to stimulate all efforts to address climate change and boost practical international cooperation.

To conclude, on the hand, China has realised the irreversible adverse consequences

${ }^{86}$ For details about the Bali Conference, see Chapter five 261-5. 
would be brought about by climate change and has taken appropriate actions according to its national circumstance to address climate change; on the other hand, the rapid economic development in China would make the mission of reducing GHG emissions extremely difficult. Certainly, it is unfair for China to accept caps on GHG emissions at the cost of substantially slowing down its economic growth while the developed countries have already enjoyed advanced economic development at the expense of high carbon emissions. Likewise, it is also irrational to allow China to follow the carbon-extensive way just because the developed countries did it. In this predicament, international cooperation and developed countries' assistance may help China, to some extent; alleviate the pressure of reducing GHG emissions.

\subsection{Benefits of Implementing the CDM in China}

Based on analysis of the previous part, unprecedented climate change and the discrepancy between GHG emissions reduction and economic development have placed China under great pressure. The CDM would bring an opportunity for China to alleviate the pressure. Owing to the CDM, China may access to the global carbon market and attract clean technologies and foreign fund needed by reducing GHG emissions domestically. Against this background, this part looks at the benefits of implementing the CDM in China. The environmental, social, economic and international status aspects benefits that might be brought by the CDM are discussed respectively with a view to examining what the CDM means to China.

With the ultimate objective of stabilising GHG concentrations in the atmosphere at a 
level that would prevent dangerous anthropogenic interference with the climate system, the CDM could bring environmental benefits to China.

CDM projects deal with GHG emission reductions. As mentioned in Chapter two, different marginal abatement costs across countries provide the basis of and incentive to take cost-effective measures to reduce global GHG emissions. ${ }^{87}$ Accordingly, the CDM provides a cost-effective way for developed countries to achieve their emission reduction targets under the Kyoto protocol by investing CDM projects in developing countries. China has a competitive advantage in attracting potential investors to develop CDM projects as it has large amount of potential GHG emissions and low marginal abatement costs. Hence, utilising the clean technologies or the fund from developed countries through CDM projects would assist China to reduce GHG emissions.

The renewable energy project is one of the main types of CDM projects. ${ }^{88}$ Conducting the renewable energy project in China does not only support to accelerate the development of renewable energies, such as biomass, solar and tidal but also is beneficial to save natural resources by the use of renewable energies. In addition, the power project may diversify electricity generation sources by switching fuel from coal

\footnotetext{
${ }^{87}$ For more details, see Chapter two 35.

${ }^{88}$ The Chinese government issued Measures for the Operation and Management of CDM projects in China in 2005. Article 4 of the Measures stipulates that 'The priority areas for CDM projects in China are energy efficiency improvement, development and utilization of new and renewable energy, and methane recovery and utilization.' In addition, the Chinese government imposes different ratios of tax to encourage the energy sectors. Article 24 of the Measures stipulates that '(1) the Government of China takes 65\% CER transfer benefit from HFC and PFC projects; (2) the Government of China takes 30\% CER transfer benefit from $\mathrm{N}_{2} \mathrm{O}$ project; (3) the Government of China takes $2 \%$ CER transfer benefit from CDM projects in priority areas and forestation projects.'

$<$ http://cdm.ccchina.gov.cn/english/NewsInfo.asp?NewsId=905> at 9 October 2009.
} 
to natural gas, land-fill methane gas or the other renewable energies. Thus, the carbon emissions derived from coal to generate power could be reduced and the natural resources could be saved through the power project.

CDM projects lead to less local pollution. Air pollution in China is a serious problem. The energy-related climate change abatement produced by certain CDM projects reduces emissions to air of $\mathrm{SO}_{2}$, particulates, $\mathrm{NOx}$, heavy metals such as mercury, and a range of organic compound. ${ }^{89}$ Lower emissions to air help decease the frequency of induced acid rain, and improve local air quality. Correspondingly, water and ground water qualities are improved.

Apart from the environmental benefits, the implementation of CDM projects in China could also bring financial benefits to promote economic development. CDM projects could promote the development of clean technologies in China. In order to obtain the CERs to offset their limited emission credits, developed countries or entities participate in CDM projects in China through investing in startup funding and capital needed by the project, or transferring their clean technologies and know-how. On the one hand, through meeting the financial demand in the process of implementing CDM projects in China, the investment would partially promote diffusion of the advanced technologies that had been demonstrated by China but had not been applied; on the other hand, the introduced advanced technologies would stimulate scientific and technological progress in China, which is considered as the key point in reducing

\footnotetext{
${ }^{89}$ Haakon Vennemo et al, 'Domestic Environmental Benefits of China's Energy-related CDM Potential' (2006) 75(1-2) Climate Change 215221.
} 
emissions without undermining economic development.

The implementation of the CDM would not only improve the financial performance for industry but also increase tax revenues for the nation. The CDM credits are generated from 'certified emission reductions'. Given rapid growth in energy and electricity demand in China, systematic uptake of the CDM by Chinese developers could lead to large volumes of credit generation. Thus, it provides a new revenues stream by selling CERs in the carbon market, which may earn a good rate of return for projects developers and at the same time reduce the cost of products. Besides, China may obtain more tax revenues through imposing business tax for project implementation, income tax for employees and the tax for selling CERs. ${ }^{90}$

Taking part in the CDM projects would also expand employment. In China, employment issue is one of the top concerns for the government at all levels due to the huge population and the increased urbanization process. CDM projects may ease the pressure by providing more job opportunities from newly established CDM projects. In addition, it may help to start up new domestic industry sectors concerning renewable energies, which did not emerge due to the lack of advanced technologies or capital. Hence, more new jobs would be created.

Implementing $\mathrm{CDM}$ projects would also be beneficial to promote economic development in the rural and remote areas. As mentioned earlier, remarkable disparity in economic development exists among different regions of China. The remote areas

\footnotetext{
90 See above $n 88$.
} 
in the western part of China are the less developed regions and more than 30 million households without electricity are concentrated there where the large grid cannot reach. ${ }^{91}$ Facing this situation, China is carrying out the 'Large-scale Development of West China Policy' ${ }^{92}$. However, these regions abound with renewable energy, which may promote the development of solar and wind energy as a favorable factor to attract the CDM projects. Therefore, CDM projects implemented in these regions would not only improve the local economic development but also help to reduce region economic disparity in China.

Environmental improvement and economic development in China would also bring benefits to society in the following ways:

First, owning to implementation of CDM projects in China, improved local environmental quality has an immediate benefit to health. Epidemiological research into air pollution has shown that air pollution is damaging to human health. Although how damaging is uncertain, the conclusion can be drawn that improvement in air quality would save lives. If China were to realise its CDM potential, it could save between 2700 and 38000 lives annually. ${ }^{93}$ Besides, the economic benefits brought by CDM projects could promote national health and medical welfare, which could also contribute to better health.

\footnotetext{
${ }^{91}$ See Clean Energy Changes Life of People in Remote Regions (2005) China's Agenda 21 $<$ http://english.acca21.org.cn/acca21/news/news20051125_1.htm> at 11 December 2008.

92 Due to the remarkable disparity in economic development in different regions of China, the Chinese government introduced the strategy of large-scale development of its western regions in 2000 with a view to promoting the development in western regions.

93 Vennemo, above n 89, 220.
} 
Second, the implementation of CDM projects in China would strengthen awareness for environmental challenges. The CDM is a complex mechanism, which involves the participation of public sectors, private sectors and local communities, as well as cooperation with international entities. Accordingly, in order to successfully implement a CDM project in China, it is necessary to understand the CDM-related rules in both the international and domestic context. China has set up CDM information and education centres at the local levels and has carried out CDM training at a grass-roots level. In this circumstance, a sense of awareness from global warming would be enhanced along with the implementation of CDM projects in China. Besides, $\mathrm{CDM}$ projects may promote wider public participation from local communities as according to the CDM project cycles, stakeholder comments, an obligatory procedure for PDD approval and project registration contain the opinion from the local community. ${ }^{94}$

Third, CDM projects may improve the standard of living. The CDM project in rural areas could alleviate local poverty through offering new job opportunities and promoting local energy self sufficiency by implementing renewable energy projects. Moreover, it may also make people's daily life more convenient. For example, with CDM projects, coal is switched to gas for heating boilers in households.

With the rapid economic development, China has become one of the major developing countries and $\mathrm{CO}_{2}$ emitters. In this regard, China is expected to participate

\footnotetext{
${ }^{94}$ Project developers also needs to provide an analysis of environmental impacts.
} 
broadly in the international affairs. Global climate change is one of the hottest issues in the international regime. Thus, how China copes with climate change could influence its international status.

The CDM is currently the only mechanism that involves developing countries to tackle climate change in the international legal regime and enter into a global carbon market. With rapid economic development and large GHG emissions, China has plays a crucial role in the global carbon market and global warming mitigation through implementing CDM projects. Accordingly, CDM provides an opportunity for China to improve its international status by actively participating in CDM projects and addressing climate change issues.

In conclusion, implementation of CDM projects is of great significance for China. Thus, China should seize the opportunities that could be brought by the CDM.

\subsection{CDM Projects in China}

Based on the above analysis, the CDM may bring benefits to China. Meanwhile, according to its national circumstances, China possesses the large potential, which entails huge carbon emissions and relatively low abatement costs, to attract CDM projects. Therefore, theoretically, if $\mathrm{CDM}$ projects were to be successfully implemented in China, China could benefit a lot from them. In truth, CDM projects have been carried out in China for a few years. By looking at these projects, the development of CDM projects in China is examined and its performance is assessed. 


\subsubsection{The Development of CDM Projects in China}

(1) The start of CDM projects in China

Despite enormous potential for emission reductions, China did not rush into CDM activities when the CDM was proposed as it was concerned about the quality of the $\mathrm{CDM}$ and the integrity of the Kyoto Protocol. ${ }^{95}$ Moreover, along with withdrawal of the US from the Kyoto Protocol, China realised that size of the CDM market was much smaller than originally projected and that the CDM market was a competitive market. 96 However, the experience from the successful CDM projects implementation, together with China's growing belief that the CDM would play an indispensible role in future global effort to mitigate climate change, has led China to gradually recognize the importance of capacity building at national, local and enterprise levels to ensure that China is well positioned to take advantage of the $\mathrm{CDM}^{97}$ In the meantime, a growing number of international and bilateral donors were supporting CDM capacity building in China as they expected great potential of the CDM in China and felt the significant need for China to enhance its capacities to undertake CDM projects. The CDM capacity building projects aim to strengthen the research on the CDM in China through cooperation with the Chinese Government (as shown in table 3.1 below).

\footnotetext{
${ }^{95}$ Cited in the Report of the Asia Meeting on Efficient Clean Development Mechanism Operations, organized by the UNDP and the World Bank, 1-3 April 2003, Kuala Lumpur, Malaysia. See ZhongXiang Zhang, 'Towards an Effective Implementation of Clean Development Mechanism Projects in China' (Working Paper 61, East-West Center, 2004) 5 <www.eastwestcenter.org/fileadmin/stored/pdfs/ENVwp061.pdf> at 9 October 2009.

96 ZhongXiang Zhang, 'Towards an Effective Implementation of Clean Development Mechanism Projects in China' (Working Paper 61, East-West Center, 2004) 5 <www.eastwestcenter.org/fileadmin/stored/pdfs/ENVwp061.pdf> at 9 October 2009.

${ }^{97}$ Ibid 7.
} 
Table 3.1 Major CDM Capacity Building Projects in China

\begin{tabular}{|c|c|c|c|c|}
\hline $\begin{array}{l}\text { Project } \\
\text { title }\end{array}$ & $\begin{array}{l}\text { Donor } \\
\text { S }\end{array}$ & Projects Activities & $\begin{array}{l}\text { Donors' } \\
\text { Contributi- } \\
\text { ons } \\
\end{array}$ & Duration \\
\hline $\begin{array}{l}\text { China } \\
\text { Study }\end{array}$ & $\begin{array}{l}\text { WB, } \\
\text { WG, } \\
\text { GTZ }\end{array}$ & $\begin{array}{l}\text { Methodological and technical } \\
\text { issues, six CDM project } \\
\text { case studies from power } \\
\text { sector and renewable energy } \\
\text { field, China's CDM potential }\end{array}$ & US\$ 970,000 & $\begin{array}{l}\text { 2002-June } \\
2004\end{array}$ \\
\hline $\begin{array}{l}\text { Canada-China } \\
\text { cooperateon in } \\
\text { climate change } \\
\text { (C5) }\end{array}$ & CIDA & $\begin{array}{l}\text { CDM operational model, case } \\
\text { studies of urban } \\
\text { transportation and renewable } \\
\text { energy, research study in } \\
\text { carbon sink }\end{array}$ & $\mathrm{C} \$ 5$ million & $\begin{array}{l}\text { June } \\
\text { 2002-June } \\
2004\end{array}$ \\
\hline $\begin{array}{l}\text { Opportunities } \\
\text { for the CDM in } \\
\text { the energy } \\
\text { sector }\end{array}$ & $\begin{array}{l}\text { ADB } \\
\text { project } \\
\text { funded } \\
\text { by } \\
\text { CCFC } \\
\text { C }\end{array}$ & $\begin{array}{l}\text { Opportunities of the CDM in } \\
\text { the energy sector, develop } \\
\text { small scale CDM energy } \\
\text { projects, assess CDM relevant } \\
\text { institutional framework in } \\
\text { China }\end{array}$ & US\$ 775,000 & $\begin{array}{l}\text { September } \\
2002 \text {-August } \\
2003\end{array}$ \\
\hline $\begin{array}{l}\text { Building } \\
\text { capacity for the } \\
\text { CDM in China }\end{array}$ & $\begin{array}{l}\text { UNDP } \\
\text { project } \\
\text { funded } \\
\text { by UN } \\
\text { Founda } \\
\text { tion, } \\
\text { IMET, } \\
\text { NORA } \\
\text { D }\end{array}$ & $\begin{array}{l}\text { Facilitate projects approval } \\
\text { process, CDM training, three } \\
\text { CDM pilot projects } \\
\text { implementation in the areas } \\
\text { of renewable energy, energy } \\
\text { efficiency and coal bed } \\
\text { methane, information } \\
\text { dissemination }\end{array}$ & $\begin{array}{l}\text { US\$ } \\
1,458,000\end{array}$ & $2003-2006$ \\
\hline $\begin{array}{l}\text { EU-China CDM } \\
\text { facilitation } \\
\text { project }\end{array}$ & EU & $\begin{array}{l}\text { Support China's CDM } \\
\text { through research on the } \\
\text { regulatory and policy regimes } \\
\text { affecting the application of } \\
\text { the CDM in China, capacity } \\
\text { development, technical } \\
\text { exchange and training } \\
\text { activities. }\end{array}$ & $\begin{array}{ll}\text { Euros } & 2.8 \\
\text { million } & \end{array}$ & $\begin{array}{l}\text { June, } \\
2007-2010\end{array}$ \\
\hline
\end{tabular}

Note: WB: World Bank; SG: Swiss Government; GTZ: German Agency for Technical Cooperation; CIDA: Canada International Development Agency; ADB: Asian Development Bank; CCFCC: Canadian Co-operation Fund for Climate Change; UNDP: United Nations Development Program; EU: European Union

Source: Zhang, above n 54, 7-8; CDM Capacity Building Projects in China (2004) Clean Development Mechanism in China <http://cdm.ccchina.gov.cn/english/NewsInfo.asp?NewsId=826> at 12 December 2008; New EU-China Project on Climate Change (2007) Xinhua Net <http://news.xinhuanet.com/english/2007-06/29/content_6307713.htm> at 12 December 2008. 
The early capacity building activities are of great significance for implementing CDM in China in that they spread the CDM-related knowledge, promote the establishment and improvement of the CDM-related policies and propelled the research and application of the CDM methodologies in China. Thus, it can be said that they have paved the way for the successful development and financing of CDM projects in China.

(2) The number of registered CDM projects in China

The number of the registered CDM projects in China increases annually. There were three CDM projects in China registered by $\mathrm{EB}$ in 2005. The first CDM project, Huitengxile Wind farm Project of Inner Mongolia with credits purchased by Dutch Government (CERUPT Programme ${ }^{98}$ ) started bidding at the end of 2001, was approved by the Chinese Government in November 2004. Half a year later, it was successfully registered in June 2005, becoming the first registered CDM project in China and the first registered project for wind energy in the world. At the same time, there were 63 projects registered by EB worldwide in 2005. Thus, China's projects accounted for 4.76 per cent of the total amount in 2005 .

The CDM began to develop very quickly in 2006 worldwide, and so was the situation in China. In 2006, 33 Chinese CDM projects were registered and during the same year 409 projects were registered worldwide. China's projects accounted for 8.07 per cent. China made a big stride in the CDM in 2007 with 114 projects registered and

\footnotetext{
${ }^{98}$ CERUPT is short for 'Certified Emission Reduction Unit Procurement Tender'.
} 
accounted for 26.82 per cent of the 425 projects registered during the same year. The number of CDM projects in China still increased rapidly in 2008 and 2009. Up to 5 December 2009, there have been 679 CDM projects in China registered in total, increasing to accounting for 35.00 per cent, followed by India, accounted for 24.38 per cent. ${ }^{99}$ In addition, there have been 2279 projects that had been approved by DNA of China up to 5 December 2009. ${ }^{100}$

(3) Rejected and withdrawn CDM projects in China

Compared to the projects in other host countries, there were no CDM projects in China rejected by the CDM EB or withdrawn until the second half year of 2008 . However, the rejection and withdrawal rate of CDM projects in China has increased recently. For example, dozen of Chinese wind projects have been delayed or rejected due to concerns over their additionality. ${ }^{101}$

(4) The scopes and CERs of CDM projects in China

Among these 679 registered projects, most of them belong to energy industries, including renewable energy projects, energy efficiency projects, power projects and methane recovery projects. Although China lagged behind India in terms of the number of registered projects, China always leads the volume of CERs. The volume of expected annual CERs from the registered CDM projects in China accounts for 58.82 per cent of the worldwide amount, followed by India with 11.64 per cent. A

\footnotetext{
${ }^{99}$ See the information and statistics released by the UNFCCC website <http://cdm.unfccc.int/index.html> at 12 December 2009.

100 See Clean Development Mechanism in China <http://cdm.ccchina.gov.cn/english/ItemList.asp > at 30 December 2009.

${ }^{101}$ For more details, see Chapter five n 34.
} 
large share of the CERs is generated from the so-called 'low hanging fruit' CDM projects that reduce end-of-pipe emissions of HFC- $23^{102}$ or $\mathrm{N}_{2} \mathrm{O}$ in industry. The ten Chinese HFC-23 projects alone account for 27.27 per cent of the total expected CERs and 53.37 per cent of the CERs from Chinese projects. ${ }^{103} 7$ out of the 10 HFC-23 projects were registered in 2006.

The HFC-23 destruction projects were very popular in China in that they have a short cycle time and offer large volumes of credits for a low capital investment and mitigation cost and that the additionality assessments are relatively straightforward. In addition, China is estimated to account for more than half of global emissions of HFC-23. ${ }^{104}$ Therefore, developing the HFC-23 CDM projects could bring industries more economic benefits than innovating technology to reduce HFC-23 emissions. Based on the above, most of the Chinese industries would rather apply for CDM projects with the current HFC-23 emission level than reduce it. However, there is a limited potential for these projects as a significant proportion is already in the CDM pipeline, and thus cannot bring long-term benefits to China. Facing this situation, China began to attach great importance to the energy sector, primarily renewable energy and energy efficiency. ${ }^{105}$ The majority registered and issued credits in China

\footnotetext{
${ }^{102}$ HFC-23 (trifluoromethane) is generated as a waste gas in the manufacturing process of HCFC-22 which is a gas used as refrigerant and as feedstock, a raw material for other products. It has a global warming potential 11700 times greater than CO2. The UNFCCC and the Kyoto Protocol list the HFC-23 as a major potential GHG and one of the first types of projects established under CDM was the investment in the destruction of the compound HFC-23.

103 This is calculated according to the information on registered CDM projects disclosed by UNFCCC website. The Chinese HFC-23 projects are expected to generated 57,785,472 tons of CERs.

${ }^{104}$ Jane Ellis and Sami Kamel, 'Overcoming Barriers to Clean Development Mechanism Projects' (Organization for Economic Cooperation and Development and International Energy Agency, 2007) 10.

105 Above n 88.
} 
after 2007 began to be concentrated in the energy sector.

In spite of a large share of CERs, a huge gap between expected CERs and issued CERs is observed in China. The UNEP's 2007 report shows that according to the May 2007 pipeline of CDM projects (until 31st May, 2007), only 3.59 per cent out of 178 million expected CERs by 2007 have been issued in China, while the correspondingly figures in India and Brazil are 40.51 per cent and 40.10 per cent, respectively. ${ }^{106}$ Considering CERs only from registered projects, China's CER issuance rate is only a 9.1 per cent, as opposed to 86.5 per cent and 57.7 per cent for India and Brazil. ${ }^{107}$ This indicates the fact that CDM projects in China are unable to deliver its full potential of CERs.

(5) Scales of CDM projects in China

The majority of the registered CDM projects belong to large-scale bilateral or multilateral projects. No registered Chinese unlilateral CDM projects have been found. The large scale projects cover all the different scopes while most of the small-scale projects, which may apply simplified modality and procedure, are hydropower projects.

(6) Geographic distribution of CDM projects in China

\footnotetext{
106 Yi qun Huang, Assessing and Managing Regulatory Risk in China's CDM Market (Master of thesis, Oxford University, 2007) 3. See also UNEP (2007): CDM Pipeline Overview.

${ }^{107}$ Ibid 4.
} 
According to the information disclosed by the official CDM website in China ${ }^{108}$, CDM projects cover nearly all the provinces in China. Among them, Gansu province, located in West China, conducts the most CDM projects. Besides, Shandong province, Inner Mongolia province, Sichuan province and Chongqing autonomous region, and Jiangsu province undertake relatively more CDM projects. Therefore, the western China, a relatively poor region in China with abundant wind resources, attracts numerous CDM projects investors with its natural and geographic advantages for renewable projects. Also, CDM projects could promote the development of western region of China.

It can be seen from the above analysis that the CDM projects in China display the following characteristics: developing rapidly, a large amount of registered projects, large-scale bilateral projects being one of the reasons making the CDM projects in China generate more CERs compared to other developing countries, ${ }^{109}$ the scope of the projects in China having gradually turned to energy sector and the geographic distribution of CDM projects in China facilitating the elimination of regional economic disparity; on negative side, the main problems are the low CERs issuance rate, an increase of the rejected and withdrawn CDM projects.

\subsubsection{China's CDM Market}

China has entered into the global carbon market through implementing CDM projects.

\footnotetext{
108 See Clean Development Mechanism in China <http://cdm.ccchina.gov.cn/english/ItemList.asp> at 30 July 2009.

109 As mentioned earlier, these CERs are due in part to HFC-23 projects.
} 
The CERs generated by CDM projects can be sold or traded in global carbon market and bring benefits to the project participants. Thus, the development of CDM projects in China decides China's role in global carbon market and at the same time China's role in global carbon market also reflects the development of CDM projects.

China has already established a carbon emission trading system led by the China Beijing Environmental Exchange, Shanghai Environment Energy Exchange and Tianjin Climate Exchange, which were all set up in 2009. ${ }^{110}$ Among them, Tianjin Climate Exchange is established as China's first comprehensive platform for trading carbon credits under the CDM, and aims to promote environmental protection and emission reduction by means of market and financial measures. These exchanges build domestic platforms for carbon credit trade. From then on, overseas companies can come to China and buy the carbon credit on the exchange. In the meantime, the public trading of carbon emission credit on the exchange could help China gain its pricing rights in the global carbon emissions market.

But so far these exchanges have only served as platforms for individual small scale deals. ${ }^{111}$ There is no clear legal framework or policy for domestic carbon trading in China, and the government has yet to give clear signs of its approval.

\footnotetext{
110 See, Shai Oster, 'China Expand Markets for Carbon Trading', The Wall Street Journal (The US), 11 November 2008, A11.

111 Tianjin Climate Exchange Launch Carbon Contract (2009) China Tells

<http://blog.chinatells.com/2009/09/1976> at 12 December 2009.
} 
China has represented 60 per cent of the cumulative CDM market since 2002. ${ }^{112}$ Currently, China's CDM market is still extremely attractive for buyers due to its huge potential for reducing carbon emissions effectively together with the favorable carbon investment climate. Moreover, as mentioned earlier, the expected average annual CERs from registered CDM projects in China accounts for 51.01 per cent of the total amount, which strikingly surpasses the India accounting for only 14.36 per cent. A large proportion of expected CERs would be partly transformed into actual CERs and transacted in the carbon market, making China the largest host country in the CDM market.

According to the documents concerning registered projects, most projects in China are conducted by private Chinese enterprises with foreign partners. ${ }^{113}$ The other project participants include CDM service centres, the CDM-related consulting or information companies, research institutes, industry associations or international or regional banks.

According to the current international regulations, developing countries cannot sell their CERs directly in the international carbon market without the involvement of the independent brokers, most of which are international financial institutions like international carbon funds and companies, and the World Bank. ${ }^{114}$ The brokers buy carbon credits from the CDM developers in China, trade them in the carbon market,

\footnotetext{
112 Karan Capoor and Philippe Ambrosi, 'State and Trends of the Carbon Market 2007' (The World Bank 2007) 24.

113 There are no unilaternal CDM projects in China.

${ }^{114}$ See Alessandra Barreca, 'Carbon Market and Carbon Contracts for CERs Transactions' in Massimiliano Montini (ed), Developing CDM Projects in the Western Balkans Legal and Technical Compared (2010) 43, 48.
} 
and then sell them to the big enterprises with higher prices. In this case, the major buyers of CDM projects in China are brokers, mainly including international carbon funds and companies and the World Bank. Besides, other buyers may include governmental purchasers and private companies.

However, it should be noted that this situation is likely to be changed with domestic carbon emission exchanges set up in China. Thanks to the domestic exchanges, Chinese companies can directly sell or trade their carbon emissions to foreign entities at the exchanges without involvement of the brokers.

Although the contracting prices of the CERs from CDM projects tend to be confidential and fluctuate according to any political or economic changes, they have experienced a general increase during these years. Some early signed contracts were made into public. The price of the CERs for the first registered project in China, Huitengxile windfarm project, was set to be 5.4 Euro/tCO2e, which is closest to the maximum offering price of CERs for renewable energy program under the Dutch government CERUPT Program. ${ }^{115}$ However, the prices of CER saw remarkable stability over 2006 , at about US $\$ 10.90$ or $€ 8.40 .{ }^{116}$ China, as a dominant market leader in the CDM market, influences the overall market price through setting a relatively stable price floor for global supply of CERs. ${ }^{117}$ Currently, one CER trades between 10 and 15 Euros $(\$ 15.80-23.80) .{ }^{118}$

\footnotetext{
115 Zhang, above n 96, 11.

116 Capoor and Ambrosi, above n 112, 4.

117 Ibid, 32.

118 See Nord Pool <http://www.nordpoolspot.com/>at 20 December 2008.
} 
There have been no official statistics concerning the economic profits brought by CDM projects in China. However, CDM projects listing of The National Climate Change Coordinate Committee showed that about US\$0.93 billion capital was invested into four CDM projects in China between 2002 and 2005. ${ }^{119}$ Only Huitengxile windfarm project brings 770 million Euros (US\$930 million) economic profits to Chinese enterprise. ${ }^{120}$ Moreover, Zhenhua Xie, Vice-minister of the National Development and Reform Commission (the Chinese DNA) said that there had been 885 CDM projects approved by Chinese DNA by the end of October 2007 . If these projects are implemented, they would reduce GHG emissions equivalent to 1.5 billion tons of $\mathrm{CO}_{2}$ and generate credits worth $\$ 15$ billion. ${ }^{121}$

\subsubsection{Management of the CDM in China}

In order to comply with the requirements under the UNFCCC and the Kyoto Protocol, China has established its central government institutions for CDM project management and implementation. The Measures for Operation and Management of Clean Development Mechanism Projects in China (hereinafter referred to the Measures $)^{122}$, which is the basis of CDM project management in China, came into effect on October 12, 2005. According to the Measures, many governmental authorities are involved in CDM-related affairs in China. The major national CDM

\footnotetext{
119 Clean Development in China <http://cdm.ccchina.gov.cn/web/item_new.asp?ColumnId=62> at 3 December 2007.

${ }^{120}$ Liguang Liu, Clean Development Mechanism in China: Seeking Synergies to Achieve Sustainable Development (Master Thesis, Roskilde University, 2006) 58.

121 'China Launches CDM Fund to Address Climate Change', Beijing, 9 November 2007, Xinhua Net <http://news.xinhuanet.com/english/2007-11/09/content_7039202.htm> at 20 December 2008.

${ }^{122}$ Measures for the Operation and Management of CDM projects in China 2005 (the People's Republic of China) <http://cdm.ccchina.gov.cn/english/NewsInfo.asp?NewsId=905> at 9 October 2008.
} 
authorities in China include the following organizations:

The National Climate Change Coordinate Committee (NCCCC)

The National CDM Board (NCB), which is established under the NCCCC

The National Development and Reform Commission (NDRC), which is China's Designated National Authority for CDM

Table 3.2 CDM-related Management Institutions in China

\begin{tabular}{|c|c|c|}
\hline Authority & Member & Function \\
\hline $\begin{array}{l}\text { National Climate } \\
\text { Change Coordinate } \\
\text { Committee } \\
\text { (NCCCC) }\end{array}$ & $\begin{array}{c}\text { Chaired by the NDRC and } \\
\text { vice chaired by the MFA, } \\
\text { MOST, State } \\
\text { Environmental Protection } \\
\text { Agency (SEPA), China } \\
\text { Meteorological } \\
\text { Administration (CMA) } \\
\text { and other ministries. }\end{array}$ & $\begin{array}{l}\text { Review and coordination of } \\
\text { important CDM policies; } \\
\text { Approve members of the NCB }\end{array}$ \\
\hline $\begin{array}{l}\text { Office of the } \\
\text { NCCCC }\end{array}$ & Hosted by the DNRC & $\begin{array}{c}\text { Secretary of the NCCCC and } \\
\text { NCB; manage the review of CDM } \\
\text { application documents }\end{array}$ \\
\hline $\begin{array}{c}\text { The National CDM } \\
\text { Board (NCB) }\end{array}$ & $\begin{array}{l}\text { Co-chaired by NDRC and } \\
\text { MOST and vice chaired by } \\
\text { the MFA, and are } \\
\text { composed of MOF, MOA, } \\
\text { SEPA, and CMA }\end{array}$ & $\begin{array}{l}\text { Review and evaluation of CDM } \\
\text { projects }\end{array}$ \\
\hline $\begin{array}{l}\text { The National } \\
\text { Development and } \\
\text { Reform } \\
\text { Commission } \\
\text { (NDRC) }\end{array}$ & $\begin{array}{c}\text { Act as the Chinese DNA } \\
\text { and host the NCCCC } \\
\text { office }\end{array}$ & $\begin{array}{l}\text { Accept CDM project allocation; } \\
\text { Issue the approval letter; } \\
\text { Supervise the CDM } \\
\text { implementation }\end{array}$ \\
\hline $\begin{array}{l}\text { Ministry of Science } \\
\text { and } \\
\text { Technology( MOS } \\
\text { T) }\end{array}$ & Co-chair of NCB & $\begin{array}{l}\text { Open the documents for approved } \\
\text { projects to the public }\end{array}$ \\
\hline $\begin{array}{c}\text { Ministry of Foreign } \\
\text { Affairs(MFA) }\end{array}$ & Vice-chair of the NCB & $\begin{array}{c}\text { Open the documents for approved } \\
\text { projects to the public }\end{array}$ \\
\hline
\end{tabular}

Besides the central government institutions, there are other supporting services also organized with a view to promoting the development of CDM projects in China. These supporting services include the CDM training, provincial CDM technology and 
services centres, the CDM-related websites and a CDM Fund.

There are CDM training workshops, organised in different regions of the country to disseminate the relevant knowledge. In its initial stage, the trainings were mainly for the Chinese Governmental officials and researchers to give a general introduction to $\mathrm{CDM}$ projects. Later, as the CDM develops and carbon market expands, many enterprises show their enthusiasms in implementing CDM projects in China, and thus trainings are held for enterprises with emphasis on CDM operational rules and CDM market. Hence, the trainings promote the development of CDM in China at the project level.

China has also set up 27 provincial CDM technology and service centres through the cooperation with the developed countries. The responsibilities of the centres are to promote the institutional development of CDM, train CDM related agents and experts, disseminate the pertinent information to the local areas and provide consulting services for the local developers.

The websites providing updated CDM information and the latest relevant activities both at home and abroad are established. The most influential website is 'the Clean Development Mechanism in China ${ }^{123}$, established by the Office of the NCCCC. The CDM technology and services centres and the other CDM consulting companies also have their own websites providing the CDM related information.

Finally, China has utilised financial measures to promote the development of the

123 The website address is $\langle$ http://cdm.ccchina.gov.cn/english/index.asp $>$. 
CDM. The CDM Fund, managed by the Ministry of Finance, was launched in Beijing in November 2007 to finance the country's efforts to address climate change. The CDM Fund was proposed as a specialised financing mechanism to support promotion of CDM eligible projects through enhancing capacity building and awareness and other climate change mitigation and adaptation activities in China. The financial basis for the CDM Fund mainly comes from the levies on incomes generated through selling CER by CDM projects in China and capital cooperation with the international finance organizations. According to the current situation of CDM projects, more than $\$ 3$ billion will be injected into the CDM fund, which may help China improve energy efficiency, protect the environment by using clean energy for power generation, and raise money from various channels. ${ }^{124}$

\subsubsection{CDM Awareness in China}

Awareness of the Chinese Government and enterprises in developing the CDM in China has been increasingly enhanced.

Initially, Chinese enterprises knew little about the CDM and what it would bring to them. Guanghua Management College of Peking University conducted a CDM related questionnaire targeting at Chinese enterprises in $2000 .^{125}$ The result showed that only a few Chinese enterprises knew about the CDM and they were not concerned about its

\footnotetext{
${ }^{124}$ Lindsay Beck, 'China Emission-Cutting Fund to Reap up to $\$ 3$ bln', Reuters (Beijing), 9 November 2007 <http://www.reuters.com/article/idUSPEK28505> at 4 March 2008.

${ }^{125}$ Chinese Enterprisers' Understanding about the CDM (Trans of [中国企业对 CDM 的理解]) Clean Development in China <http://cdm.ccchina.gov.cn/web/NewsInfo.asp?NewsId=41> at 30 July 2009.
} 
influence. The main reason for the lack of the understanding of the CDM at that time is that they did not know what benefits the CDM could bring to them.

Subsequently, China's potential of implementing the CDM attracted developed countries to conduct CDM capacity building projects, which, to some extent, promote the development of the CDM in China and enhance the CDM-related training and education for the Chinese Governmental officials and researchers. Nonetheless, the involvement and awareness of local private sectors, who are supposed to be the major players in CDM, were neglected. There were few capacity building projects at an enterprise level and the cooperation and communication on concrete CDM projects were rare at that time. Consequently, most of the enterprises did not really understand the significance of the CDM, and thus did not participate in it.

However, the situation has changed since more and more CDM projects were successfully registered and brought economic benefits to project participants. The enterprises began to realise the commercial opportunities through implementing CDM projects in China. Also, the Chinese Government's guide and information promoted a favourable environment for enterprises to participate in CDM projects. Currently, the enthusiasm of Chinese enterprises about taking part in the CDM is increasing rapidly.

To summarize, CDM projects have been making striking progress in China. Under the support of international donors, China took steps to implement pilot projects and set up central institutions for CDM management. During the past a few years, a new CDM specific regulation has been enacted and the other supporting services have 
been developed to promote the implementation of CDM projects in China. As a result, more and more Chinese enterprises realise the great benefits brought about by the CDM and actively participate in it. Currently, China is the biggest host countries of CDM projects and lots of Chinese CDM projects are in the pipeline for registration. Furthermore, China has dominated the CDM market with its massive generated CERs.

\subsubsection{Assessment of the CDM Performance in China}

Although CDM projects have been implemented in China for five years, there is no officially recognised set of indicators for a quantified assessment of the CDM performance in China. However, some organizations may apply their own methodologies and criteria to assess the performance of CDM in certain countries. ${ }^{126}$ This part assesses the CDM performance in China through investigating two questions based on the current situation of the CDM. These two questions are whether or not CDM projects are successfully implemented in China and whether or not the corresponding benefits of implementing CDM projects in China are achieved.

First, based on the above introduction to development of CDM projects in China, it

\footnotetext{
${ }^{126}$ For example, Point Carbon, a world-leading Oslo-based carbon market adviser, continuously evaluate all important CDM host countries to what extent they are attractive for CDM-related investment based on a detailed assessment of factors related to climate institutions, project status and potential, and investment climate. According to its rating reports, China successively gets the highest grade, ranking the first place.

The rating are based on qualitative and quantitative analyses of three following faces of the CDM host countries' attractiveness :

Institutional conditions: Status of framework for approving CDM projects and government attitude to the CDM;

Investment climate: Degree of stability and investor-friendliness, capital and service markets, amount of Foreign Direct Investment;

Project status and potential: the CDM potential and number of projects approved by host country, signed and registered by the CDM executive board.
} 
can be seen that CDM projects have been developing rapidly in China. The number of CDM projects in China has annually increased during these years. Although China lagged behind India with respect to the number of registered CDM projects, it has overtaken India as the No. one host country of CDM projects as it has got the most registered projects as well as CERs issued from these projects. It should be noted that China has always led in the volume of CERs as it has more large-scale and HFC CDM projects compared to other host countries. Furthermore, the momentum of CDM development in China will remain in the future. There are over 2000 projects that have been approved by DNA of China prepared to require registration.

Accordingly, based on the quantitative study, more and more CDM projects have been successfully registered by the EB and implemented in China. Moreover, China has potential to promote the further development of CDM.

Second, there were no CDM projects in China rejected by the CDM EB or withdrawn until the second half year of 2008. The CDM regulations are designed through rigid approval, validation, registration and certification procedures, which help to guarantee the CERs are real, measurable and additional. ${ }^{127}$ That demonstrates that all the potential projects in China were of a quality to be eligible for the CDM projects criteria. With the expansion of capacity building activities, the management of CDM projects in China and the other CDM-related supporting services have been improved. Hence, the eligible CDM projects might be identified and developed under the guide

${ }^{127}$ For more details, see Chapter two 42. 
of the Chinese Government.

However, the rejection and withdrawal rates of CDM projects in China have increased recently. Basically, there are three major reasons leading to this situation. First, more and more Chinese energy-related companies have begun to realize the commercial benefits that would be brought by the CDM, and thus the total number of the projects in China applying for the CDM projects increases. Second, the CDM EB strengthens the management and supervision of the $\mathrm{CDM}$ as a result of universal questions about the CDM's contribution to addressing climate change and the quality of the registered projects. ${ }^{128}$ Finally, with the development of the CDM, its operational rules and procedures become stringent.

In addition, in spite of the increasing registered projects in China and the largest expected annual CERs, the volume of actual CERs issued by the EB is relatively low. In the other words, the CDM projects in China could not achieve all the expected CERs.

Therefore, based on the qualitative study, on the one hand, more eligible CDM projects could be indentified and developed in China with the improvement of CDM management, information dissemination and relevant knowledge; on the other hand, changes of CDM operational rules need to be noted. What is more, the huge gap between expected CERs and the actual CERs affect the successful implementation of the CDM projects in China.

${ }^{128}$ For details, see Chapter two Part 2.4.2 Pitfalls of the CDM 66-72. 
As mentioned above, CDM projects, if fully implemented, would bring environmental, social, economic and international status aspect benefits to China. Based on the above analysis, what benefits the CDM has brought to China are discussed below.

There have been no documents systematically assessing the environmental effect of implementing CDM projects in China. However, 170,987,349 tons of CERs issued by the projects in China and 193,564,516 tons of expected annual CERs from the registered projects in China ${ }^{129}$ show the contributions of implementing CDM projects to emission reductions.

In financial terms, China is actually the country that is benefiting from the CDM. First, the introduction of foreign investment to $\mathrm{CDM}$ projects and the revenues from selling the generated CERs have brought massive economic benefits to project participants and the Chinese Government. Second, according to the geographic distribution of CDM projects in China, western region possesses the most CDM projects, which helps to improve the local economic development and reduce region economic disparity in China. Finally, CDM projects in China begin to be concentrated in the energy industry. Based on China's national circumstances, most of the factories in China are carbon-extensive due to the dominance of coal in energy supply and a relatively low level of clean technologies. Hence, developing the CDM projects in the scope of the energy industry can assist China in transiting into a low-carbon economy in the future.

${ }^{129}$ For details, see Chapter two 55-8. 
The CDM enhances environmental awareness in China. It makes enterprises aware that they can derive economic benefits from taking social responsibilities. More and more entrepreneurs begin to realise the commercial benefits by reducing emissions through CDM projects. Reducing carbon emissions while improving energy efficiency have become a trend in China.

Through participating in the CDM, China, with its favorable conditions for CDM investment, is the major partner of developed countries in reducing emissions. The dominance of China in CDM market strengthens its influences in the international regime.

In conclusion, despite CDM projects practice in China for only a few years, it is clear that China has made improvement in CDM capacity building and institutional development to promote the development of CDM projects. As a result, CDM projects in China are booming. Although it may be hasty to draw a conclusion on the CDM performance in China due to the long-time cycle (at least ten years) for each project, it can be seen that the registered CDM projects have brought various benefits to China and its industries. Moreover, along with the boom of CDM projects, they would continue to bring benefits to China. On the other side, it should be noted that China still lags behind in promoting the small-scale CDM projects and delivering the full potential of CERs. The importance of advanced clean technologies, which are considered as a key factor to reducing carbon emissions, cannot be seen in the process of implementing CDM projects in China. 


\subsection{Barriers to CDM Projects in China}

In spite of extremely rapid progress in the development of CDM projects in China, various barriers still exist at the different phases of CDM projects cycle, impeding their development. This is because implementing CDM projects is extremely complex, detailed and time-consuming, requiring a broad understanding of the international climate change framework and its interaction with domestic circumstances. Some of these barriers can be removed or lessened by improving domestic legislation or enhancing institutional capacity while others, such as political instability, are difficult to overcome. In addition, some barriers exist in all types of CDM projects while others are particular to certain types of CDM projects. Accordingly, the next part endeavours to identify the barriers to CDM projects in China at an international level, national level and project level respectively.

\subsubsection{Barriers at an International Level}

The CDM is an outcome of international negotiations and trade-off. Conversely, any changes of the ongoing international negotiations and framework on CDM projects also affect its development. A number of barriers to CDM development exist at an international level. These barriers can be caused by several factors, including but not limited to, the international CDM framework, international CDM-related institutions and uncertainty about the post-2012 framework. 
Barriers could be caused by complex CDM operational rules and procedure. ${ }^{130}$ In order to better manage the operation of CDM project, complex and detailed procedures were stipulated. However, they may incur high transition costs, distortion of key information of CDM projects and the potential for corruption.

In spite of the constant improvement of the CDM framework, the limitation for certain types of CDM projects could hinder the development of the CDM in China. For example, certain types of projects are still permitted to be eligible CDM projects. In the Bali conference held in December, 2007, the implication of the establishment of new HCFC-22 facilities seeking to obtain CERs for the destruction of HFC-23 were considered. However, no agreement was reached. This type of project may bring great benefits to China. If HFC-23 reductions from new HCFC-22 plant was also eligible for the CDM, a further 30-40 million annual CERs could be generated from this sector in China. ${ }^{131}$

The functions of international CDM-related institutions may affect the development of CDM projects. The transparent and efficient international CDM-related institutions would promote the development of CDM while the institutions with low efficiency would blunt projects participants' enthusiasm and thus undermining development of the CDM in China. However, the working of the international part of the CDM approval process has been heavily criticised for being too slow, too expensive and too

\footnotetext{
${ }^{130}$ For details, see Chapter two 2.4.2.2 Shortcoming of CDM Complex Procedure 68-9.

${ }^{131}$ Ellis and Kamel, above n 104, 10.
} 
unpredictable. ${ }^{132}$ In this scenario, unless the institutions focus on their executive and supervision role and improve their functions to ensure a fair and equitable regulatory system, it might be impossible to promote the development of the CDM.

Considerable uncertainty surrounding the potential demand for CDM credits post-2012 still remains as the new climate regime for this period has not yet been established. ${ }^{133}$ Also, the concrete obligations of China and the US, two largest emitters, on carbon emissions reduction in the post-2012 era are uncertain. If the US decides to undertake reduction obligation and enters the carbon market post-2012, then there would be enormous demand for GHG credits. Under this scenario, more developers would take part in CDM projects. Therefore, the uncertainty about the post-2012 framework may be a barrier to promoting the development of further CDM projects.

\subsubsection{Barriers at a National Level}

CDM projects must be implemented in the host country and be affected by domestic investment environment. Accordingly, there are different types of national-level barriers impeding the development of CDM projects in China. Such barriers can be categorized into barriers not related specifically to the CDM in China and the CDM-related barriers in China.

The barriers not related specifically to the CDM in China may be affected by

\footnotetext{
132 Ibid 37.

${ }^{133}$ For details, see Chapter five.
} 
domestic investment environment and domestic energy-related regulations. The CDM provides a new way for China to introduce foreign investment. Thus, any domestic factors hindering the introduction of foreign investment may also be barriers to CDM projects in China. These barriers may derive from general institutional framework, financial framework and legislative framework.

The institutional framework within China is an important factor that impacts the level of investment. The perceived efficiency of the government in China may influence on investors' decisions on whether or not to invest in China. This is because to develop projects in China they have to undergo several authorizations, permits or assessments by the qualified governmental institutions. Investments would be slow if the required permits are not obtained in a timely manner. Moreover, since most of the CDM projects in China are bilateral and multilateral, they may be affected by custom-related delays of importing projects needed goods. Government corruption can also be identifies as a major impediment to investment in China. Furthermore, lack of the protection of intellectual property right (IPR) can be a barrier to developing projects or participating in the CDM in China. Concerns about not being able to maintain IPR mean that some technology providers may choose to not export to particular countries such as China. ${ }^{134}$

Financial framework is the other factor influencing the development of CDM projects in China. A simple and transparent tax system can attract investment while a high or

${ }^{134}$ Ellis and Kamel, above n 104, 22. 
discriminatory tax system can be a barrier to investment, as they reduce the effective rate of return.

Finally, stable, enforced and unambiguous legislation is required to promote the investment in China. Before investing in certain projects in China, investors would take all the relevant factors into account. Thus, they may be frustrated by the complex laws as they cannot make sure that they would remain in compliance with relevant laws. Moreover, investors of projects that have long lifetimes, such as CDM projects, need the stable legislative framework within China enabling them to implement their project for the expected lifetime. How legislation is implemented in China is the other consideration for the investors. To sum up, unstable and complex legislation without effective enforcement would be a barrier to the development of CDM projects in China.

The purpose of CDM projects is to produce emission reduction credits. In this regard, all the policies and regulations concerning emission reduction and energy utilization in China may help or hinder the development of CDM projects. As mentioned above, China has set up ambitious targets on emission reduction and energy efficiency improvement in its national plans and laws to address climate change. China has also provided various incentives, including tax relief for certain projects with renewable energy and clean technology, and reforms to reduce subsidies for fossil fuels, to promote the development of projects with low carbon emissions. If these policies are effectively carried out, they would be competitive conditions to attract CDM projects. 
Otherwise, the investors of CDM projects may choose to invest in other host countries with more favorable investment environment.

The CDM-related barriers in China are influenced by the CDM-specific policy framework, the CDM-specific institutional capacity and the CDM awareness.

Clear and consistent CDM-specific policy framework is vital for the development of CDM projects in China. China has issued the Measures as the basic legal guide of implementing CDM projects. The legal aspects of implementing CDM projects in China, such as the legal steps of implementing CDM projects in China, the clear sustainable development criteria as China's requirements for approving proposed projects, the regulations on the legal status and ownership of CERs, the restrictions on foreign ownership of the projects, and the levies on the projects, have been addressed in the measures. These aspects may affect the development of projects under the CDM. $^{135}$

China establishes NDRC as a DNA of the CDM. Hence, the capacity and framework of the Chinese DNA may affect the performance of CDM projects in China. The capacity of the Chinese DNA is composed of three following aspects:

(1) The institutional setup of Chinese DNA itself

For the Chinese DNA to be operational and efficient, various ingredients should be in place. A clear and transparent guideline is needed to regulate the DNA's work. Appropriate office equipment, adequate staffing and sufficient budget are critical

${ }^{135}$ It will be further discussed in Chapter four. 
issues to guarantee the operation of DNA. Particularly, participation from the other Chinese Government departments helps to reduce time-lag in approving proposed projects.

(2) The leading role in information dissemination

The Chinese DNA should possess adequate information on CDM modalities and procedure, CDM projects progress and $\mathrm{CDM}$ market. Moreover, the information should be made public available to guide CDM implementation in China. The availability of a web-based information platform has so far proven to be effective in promoting a host country as a CDM project destination. ${ }^{136}$ The Chinese DNA has its designated website. However, the CDM- related information cannot be updated in a timely manner.

(3) The efficiency in dealing with the proposed project

The Chinese DNA bears the basic function of issuing letters of approval for proposed projects according to sustainable development criteria in China. Hence, whether it makes decisions regarding the proposed project in a timely manner and provides clear justifications in cases of rejection would affect the process of CDM projects implementation. Furthermore, the timely responses to inquiries by the potential projects participants are also of significance.

The CDM awareness may influence the development of CDM projects in China. Lack of awareness and knowledge on CDM is a key barrier to implementing CDM projects.

${ }^{136}$ Ellis and Kamel, above n 104, 28. 
The awareness may be divided on the basis of at the government level, at the project level and at the local intermediary level. The government with high awareness and knowledge on CDM would promote the development of CDM projects. China does not only establish the central authorities for CDM projects but has also set up 27 provincial $\mathrm{CDM}$ services centres with a view to supporting the CDM projects. Moreover, enterprises' participation in and knowledge about the CDM affect the actual performance of CDM projects as ultimately the projects are conducted by enterprises. The awareness and knowledge of enterprises in China have been increasingly improved. Also, the other services from the local intermediary influence the development of CDM projects. Flourishing intermediaries help to reduce the risks in developing CDM projects. With the booming of CDM projects in China, the relevant intermediaries providing consulting services, legal services, financial services and so forth gradually develop. These intermediaries, to a certain extent, promote the development of the CDM in China.

\subsubsection{Barriers at a Project Level}

Various types of risks associated with CDM projects and transaction costs arising from completing the $\mathrm{CDM}$ project cycle represent the most common barriers inhibiting CDM project development. ${ }^{137}$ Therefore, how to mitigate project risks and reduce transaction costs pose great challenges to develop CDM projects in China.

The barriers to the CDM implementation in China have been analyzed systematically.

${ }^{137}$ For details, see Chapter two Transaction Costs and Potential Risks 74-6. 
There are potential barriers at different levels. In summary, these barriers could arise from both of the international and domestic legislation framework, institutional capacity, awareness and knowledge of CDM, and financial challenges. Fortunately, some country-specific barriers could be removed or lessened by taking appropriate actions to increase China's attractiveness as a location for a CDM host country.

\subsection{Conclusion}

China is facing up to the dilemma. On the one side, China's emissions keep rising with the ultra-rapid increase of its GDP. On the other side, the irreversible adverse consequences of global warming mainly caused by anthropogenic carbon emissions alarm China to take immediate actions on emission reductions. Facing this situation, the CDM has been implemented in China with a view to assisting in promoting sustainable development. In real terms, China has actively participated in CDM projects and has dominated the CDM market. Also, China has obtained considerable benefits from the CDM projects. In spite of the success, there are various barriers that may be observed in the process of implementation of the CDM in China.

This chapter comprehensively introduces the situation of implementing CDM projects in China. The next chapter will focus on the legal aspects of implementing the CDM in China. 


\section{Chapter 4 Legal Issues for Implementing CDM Projects in China}

\subsection{Introduction}

As a legal mechanism, the CDM is implemented under both the international and domestic legal frameworks. China has adopted a series of climate-related policies and laws which could directly or indirectly influence the implementation of CDM projects. Therefore, it is important to discuss the legal issues involved in implementing CDM projects under the exiting legal framework in China.

Since the UNFCCC was concluded in 1992, China has attached great importance to climate change and has gradually formed a climate regulatory framework. China did not only formulate its own policy strategy, called Agenda $21^{1}$ in 1994 but also took climate change into national Five-Year Plans. Besides general policies, China has also released specified national strategies, plans and laws on addressing climate change. Also, the competent official departments are set up and restructured. Besides the regulatory framework on climate change, a specified regulation for the CDM is enacted in order to regulate and manage CDM projects. In addition, due to the fact that most CDM projects are implemented with foreign investment and cooperation, the commercial laws concerning foreign trade may also affect the implementation of CDM projects in China.

\footnotetext{
1 China's Agenda 211994 (the People's Republic of China) <http://www.acca21.org.cn/english/index.html> at 3 March 2009.
} 
Within the Chinese legal system, the implementation of CDM projects may involve specific procedures and operational rules. As a result, there are various legal relationships, contracts and potential project risks in the process of developing CDM projects in China.

Against this background, this chapter focuses on legal issues for implementing CDM projects in China. Part two introduces how CDM projects are implemented in China under the existing legal framework. Part three explores the CDM-related regulatory framework. Policies concerning climate change and the other existing regulations and laws supporting the CDM are explored. Part four assesses the enforcement of the CDM-related policies and laws through analyzing the institutional frameworks and different measures adopted to enforce these policies and laws in practice. Based on the above analysis, Part five discusses the key legal issues for implementing CDM projects through investigating the legal relationships involved, various CDM project-related contracts and their legal effects on the development of CDM projects and sustainable development in China. Part six discusses potential CDM project risks under the existing legal framework.

\subsection{How to Implement CDM Projects in China}

In October 2005, the Chinese Government issued Measures for the Operation and Management of CDM projects in China (hereinafter referred to 'the Measures') ${ }^{2}$, which is regarded as a basic regulation to guide the implementation of CDM projects

\footnotetext{
${ }^{2}$ Measures for the Operation and Management of CDM projects in China 2005 (the People's Republic of China) <http://cdm.ccchina.gov.cn/english/NewsInfo.asp?NewsId=905> at 9 October 2009.
} 
in China. According to the Measures, legal requirements for CDM projects, key entities involved and legal steps in developing CDM projects are introduced.

\subsubsection{Legal Requirements for CDM Projects in China}

The general requirements for $\mathrm{CDM}$ project activities, with a view to protecting China's rights and interests, shall not only conform to the requirements under the UNFCCC, the Kyoto Protocol and relevant decisions by the COP in an international context, but shall also meet the following requirements:

- CDM project activities shall be consistent with China's laws and regulations, sustainable development strategies and policies, and the overall requirements for national economic and social development planning. ${ }^{3}$

- The implementation of CDM project activities shall not introduce any new obligation for China other than those under the UNFCCC and the Kyoto Protocol. ${ }^{4}$

- The implementation of CDM project activities shall conform to the requirements of the Convention, the Protocol and relevant decisions by the Conference of the Parties. $^{5}$

- CDM project activities should promote the transfer of environmentally sound

\footnotetext{
${ }^{3}$ Measures for the Operation and Management of CDM projects in China 2005 (the People's Republic of China) art 6.

${ }^{4}$ Measures for the Operation and Management of CDM projects in China 2005 (the People's Republic of China) art 8.

${ }^{5}$ Measures for the Operation and Management of CDM projects in China 2005 (the People's Republic of China) art 7.
} 
technology to China. ${ }^{6}$

- Funding for CDM projects from the developed country Parties shall be additional to their current official development assistance and their financial obligation under the UNFCCC. ${ }^{7}$

The Chinese Government also set up a rule with regards to project participation eligibility. Chinese funded or Chinese-holding enterprises within the territory of China are eligible to conduct $\mathrm{CDM}$ projects with foreign partners. ${ }^{8}$ In addition, the priority areas for CDM projects in China are energy efficiency improvement, development and utilization of new and renewable energy, and methane recovery and utilization. $^{9}$

\subsubsection{Key Legal Entities Involved in CDM Projects in China}

As introduced in the previous chapter, the relevant institutions for CDM project management are National Climate Change Coordination Committee (hereinafter referred to as 'the Committee') and National CDM Board (hereinafter referred to as 'the Board') and a CDM project management institution. The Committee is responsible for review and coordination of the important CDM policies; established

\footnotetext{
${ }^{6}$ Measures for the Operation and Management of CDM projects in China 2005 (the People's Republic of China) art 10.

${ }^{7}$ Measures for the Operation and Management of CDM projects in China 2005 (the People's Republic of China) art .9.

${ }^{8}$ Measures for the Operation and Management of CDM projects in China 2005 (the People's Republic of China) art 11.

${ }^{9}$ Measures for the Operation and Management of CDM projects in China 2005 (the People's Republic of China) art 4.
} 
under the Committee, the Board ${ }^{10}$ has the main responsibility of reviewing and evaluating CDM project activities; and National Development and Reform Commission (NDRC), serving as a CDM project management institute established under the Board, is China's DNA for the CDM with the responsibility of managing the concrete issues concerning implementation of CDM projects in China. These institutions' individual responsibilities are as follows:

The Committee: ${ }^{11}$

- $\quad$ to review national CDM policies, rules and standards;

- $\quad$ to approve members of the Board; and

- $\quad$ to review other issues deemed necessary.

The Board: ${ }^{12}$

- $\quad$ to review CDM project activities mainly from the following aspects:

(i) participation qualification;

(ii) project design document;

(iii) baseline methodology and emission reductions;

(iv) price of CERs; ${ }^{13}$

\footnotetext{
${ }^{10}$ It comprises of National Development and Reform Commission (NDRC) and Ministry of Science and Technology (MOST) serving as co-chairs of, and Ministry of Foreign Affairs (MFA) serving as the vice chair of, the Board and State Environmental Protection Administration, China Meteorological Administration, Ministry of Finance, and Ministry of Agriculture serving as members.

${ }^{11}$ Measures for the Operation and Management of CDM projects in China 2005 (the People's Republic of China) art 14.

${ }^{12}$ Measures for the Operation and Management of CDM projects in China 2005 (the People's Republic of China) art 15.

${ }^{13}$ If no foreign buyer is determined by the time a project is submitted for approval, and in result the price information is not available, it must be indicated in the project design document that the emission reductions generated by the project will be transferred into China's national account in the CDM registry and can only be transferred out with the authorization of China's Designated National Authority for CDM.
} 
(v) terms relating to funding and technology transfer;

(vi) crediting period;

(vii) monitoring plan; and

(viii) expected sustainable development effectiveness.

- to report to the Committee on the overall progress of CDM project activities, issues emerged, and further recommendations; and

- $\quad$ to make recommendations on the amendments to the Measures.

The NDRC as China's DNA: ${ }^{14}$

- $\quad$ to accept CDM project application;

- $\quad$ to approve CDM project activities on the basis of the conclusion made by the Board;

- $\quad$ to issue written approval letter on behalf of the government of China; and To supervise the implementation of CDM project activities.

The CDM project owner, which refers to the Chinese funded or Chinese-holding enterprises, shall be under the following obligations to: ${ }^{15}$

- $\quad$ undertake CDM project negotiations with foreign partners;

- be responsible for construction of the project and report periodically to NDRC on the progress;

\footnotetext{
${ }^{14}$ Measures for the Operation and Management of CDM projects in China 2005 (the People's Republic of China) art 16.

${ }^{15}$ Measures for the Operation and Management of CDM projects in China 2005 (the People's Republic of China) art 17.
} 
- implement the CDM project activities, develop and implement project monitoring plan to ensure that the emission reductions are real, measurable, long-term and additional, and accept the supervision of NDRC;

- contract DOE to validate the proposed project activities and to verify emission reductions of the project activities; provide necessary information and monitoring record, and submit the information to NDRC for record purpose; and protect state and business confidential information in accordance with relevant laws and regulations;

- $\quad$ report to NDRC on CERs issued;

- $\quad$ assist NDRC and the Board in investigating relevant issues and respond to the inquiries; and

- $\quad$ be under the other necessary obligations.

\subsubsection{Legal Steps in Developing CDM Projects in China}

Along with the international operational rules and procedures for the CDM, the legal steps in developing CDM projects in China are as follows:

Table 4.1 Legal Steps in Developing CDM Projects in China

\begin{tabular}{|l|l|l|l|l|}
\hline \multicolumn{1}{|c|}{ Phase } & \multicolumn{1}{|c|}{ Step } & Actor & \multicolumn{1}{|c|}{ Activities } & Period \\
\hline Application & Submission & PO & $\begin{array}{l}\text { Submit application } \\
\text { required } \\
\text { documents to NDRC }\end{array}$ & $\begin{array}{l}\text { Within } \\
30 \text { days }\end{array}$ \\
\cline { 2 - 5 } & Expert Review & NDRC & $\begin{array}{l}\text { Entrust organization for } \\
\text { review of the proposed } \\
\text { project }\end{array}$ & \\
\cline { 2 - 5 } & Submission & NDRC & Submit to the Board & Within \\
Approval & Approval & NDRC & Issue approval letter \\
\hline
\end{tabular}




\begin{tabular}{|c|c|c|c|c|}
\hline Phase & Step & Actor & Activities & Period \\
\hline & Validation & $\mathrm{DOE}$ & $\begin{array}{l}\text { Invited by PO to validate } \\
\text { the project }\end{array}$ & $\begin{array}{l}\text { Within } \\
30 \text { days }\end{array}$ \\
\hline \multirow[t]{4}{*}{ Registration } & Registration & EB & $\begin{array}{l}\text { Register the proposed } \\
\text { project }\end{array}$ & $\begin{array}{l}\text { Within } \\
8 \text { weeks }\end{array}$ \\
\hline & Report & $\mathrm{PO}$ & Report to NDRC & $\begin{array}{l}\text { within } \\
10 \text { days }\end{array}$ \\
\hline & \multirow[t]{2}{*}{$\begin{array}{l}\text { Implementation \& } \\
\text { Monitoring }\end{array}$} & $\mathrm{PP}$ & $\begin{array}{l}\text { Implement project; } \\
\text { monitor reductions; make } \\
\text { reports; }\end{array}$ & \\
\hline & & $\mathrm{PO}$ & $\begin{array}{l}\begin{array}{l}\text { Present } \\
\text { reports }\end{array} \\
\text { repC } \quad \text { DOE }\end{array}$ & \\
\hline \multirow[t]{3}{*}{ Issuance } & $\begin{array}{l}\text { Verification } \quad \& \\
\text { Certification }\end{array}$ & DOE & $\begin{array}{l}\text { Verify the reductions; } \\
\text { submit certification report } \\
\text { to EB }\end{array}$ & \\
\hline & CERs Issuance & EB & Issue the CERs & $\begin{array}{l}\text { Within } \\
15 \\
\text { days }\end{array}$ \\
\hline & CERs Record & NDRC & $\begin{array}{l}\text { Put CERs in file and } \\
\text { record }\end{array}$ & \\
\hline
\end{tabular}

(1) Phase one: Procedures for CDM project application and approval are as follows:

- Project application

Project owner, or together with its foreign partner, submit CDM project application and the documents to NDRC.

- Expert review

NDRC entrusts relevant organizations for expert review of the proposed project, which shall be concluded within 30 days.

- Reviewed application submission

NDRC submits the project applications that have reviewed by the experts to the Board.

- Project approval 
NDRC approves, jointly with MOST and MFA, project based on the conclusion made by the Board, and issues approval letter accordingly. NDRC shall make a decision on project application within 20 days (excluding the expert review time) at the date of accepting the application. ${ }^{16}$

(2) Phase two: Procedures for CDM project registration are as follows:

- Project validation

Project owner invites DOE to validate the project for registration within 30 days.

- Project registration

The CDM EB shall automatically register the proposed CDM project activities if there is no objection within 8 weeks since the date of receipt of the request.

- Approval report

Project owner shall report to NDRC on the approval decision by the CDM EB within 10 days as of the date of receiving the notice from the Executive Board.

(3) Phase three: Procedures for CDM project implementation are as follows:

- Project implementation and monitoring

Project participants implement the CDM project, monitor the emissions reductions, and then make the reports. Moreover, Project owner is responsible for presenting NDRC and DOE project implementation and monitoring reports. NDRC is authorized to supervise the implementation of the project to ensure the quality of the activities.

- Project verification

\footnotetext{
${ }^{16}$ The time limit for decision-making may be extended to 30 days, with the approval of the Chair or the Vice-chair of NDRC, if a decision could not be made within 20 days. The project applicant should be informed of such a decision and its reasons.
} 
Contracted DOE verifies the emission reductions of the project activities and submits certification report to the CDM EB.

(4) Phase four: Procedures for CDM project issuance are as follows:

- CERs issuance

The CDM EB automatically issues CERs for the projects within 15 days since the date of receipt of the request and informs its decision to the project participants.

- CERs record

NDRC or other organizations entrusted by NDRC will put the CERs issued by the CDM EB in file and record.

\subsubsection{Regulation Concerning the Proceeds of CDM Projects in China}

For the reason that emission reduction resource is owned by the Government of China and the emission reductions generated by specific CDM project belong to the project owner, the revenues from the transfer of CERs shall be shared by the government of China and project owner, with the allocation ratio defined as below: ${ }^{17}$

- $\quad$ The government of China takes 65 per cent CER transfer benefit from HFC and PFC projects.

- $\quad$ The government of China takes 30 per cent CER transfer benefit from N2O projects.

- $\quad$ The government of China takes 2 per cent CER transfer benefit from CDM projects in priority areas and forestation projects.

${ }^{17}$ Measures for the Operation and Management of CDM projects in China 2005 (the People's Republic of China) art 24 . 
The revenues collected from CER transfer of CDM projects shall be used to support the activities on addressing climate change.

\subsection{CDM-related Legal Frameworks in China}

As mentioned earlier, the CDM activities in China shall be consistent with China's laws and regulations, sustainable development strategies and policies, and the overall

requirements for national economic and social development planning. ${ }^{18}$ Conversely, many climate-related policies and regulations could affect the implementation of CDM projects in China.

\subsubsection{Climate Change Policy in China}

China ratified the UNFCCC and the Kyoto Protocol. As a party to the UNFCCC and the Kyoto Protocol and a developing country, China shall be under the obligations to: ${ }^{19}$

- develop national inventories of anthropogenic emissions by sources and removals by sink of all GHGs;

- $\quad$ launch national strategies for climate change mitigation and adaptation to expected impacts;

- $\quad$ take climate change into national policies; and

- $\quad$ promote activities for emissions reductions.

In order to fulfill its obligations, China has released national policies and has

\footnotetext{
18 See above $n 3$.

${ }^{19}$ See also Chapter two 25.
} 
promulgated dozens of laws and regulations that aim to promote sustainable development and reduce the negative impacts of climate change on China.

\subsubsection{China's Sustainable Development Strategy and Plans}

The UN Conference on Environmental and Development was held in $1992 .{ }^{20}$ The conference expressed new thinking about sustainable development of human society and called for each nation to develop and put into effect their individual national strategies and plans to promote sustainable development. ${ }^{21}$ In this scenario, based on its national circumstances, China unveiled its own Agenda 21 in 1994, which is the first national blueprint for sustainable development. Further, China has strengthened the sustainable development and climate change mitigation through integrating its Agenda 21 into the concrete successive national development plans.

China's Agenda 21 - White Paper on China's Population, Environment, and Development in the 21st Century was completed in May 1994. China's Agenda 21 explicitly expresses China's determination to take the path of sustainable development through the coordination of population, economy, society, natural resources, and the environment. It is clearly stated in China's Agenda 21 that

...taking the path of sustainable development is a choice China must make in order to ensure its future development into the next century...only by coordinating the work of all segments of society, conserving natural resources and improving the environment,

\footnotetext{
${ }^{20}$ The United Nations Conference on Environment and Development (UNCED), also known as the Earth Summit was a major United Nations conference held in Rio de Janeiro from 3 June to 14 June 1992. The UNCED resulted in the following documents: Rio Declaration on Environment and Development, Agenda 21, Convention on Biological Diversity, Forest Principles and Framework Convention on Climate Change (UNFCCC).

${ }^{21}$ See UN Conference on Environment and Development, United Nations, <http://www.un.org/geninfo/bp/envirp2.html> at 9 October 2009.
} 
can the goals of economic development be realized. ${ }^{22}$

Generally speaking, China Agenda 21 provides a comprehensive guideline for medium- and long-term socio-economic development planning for all levels of government to promote sustainable development.

With regard to climate change, China Agenda 21 states that

China wishes to bring the emission of GHGs under control, reduce the growth rate of carbon dioxide emissions, study measures for reducing emissions of methane and nitrous oxide, maintain, strengthen greenhouse gas sinks and constructs climate change monitoring, forecasting and service systems. ${ }^{23}$

In order to control the GHGs, a national program would be formulated, including afforestation and energy development plans and targets for emission levels. ${ }^{24}$ Emphasis is also placed on research on identification of GHGs, the impact of GHGs and countermeasures and methods for reducing GHGs. ${ }^{25}$ Improvement of energy efficiency and development of renewable energy resources through increasing public awareness, accelerating technological advances and international cooperation are also the significant activities for controlling GHGs. ${ }^{26}$ In addition, market mechanisms and financial, taxation and economic legislation that can be effectively used for promoting GHGs reduction are mentioned in China's Agenda $21 .{ }^{27}$

Obviously, China was just at its initial stage of controlling GHGs and thus the specified climate change policies and actions were not stipulated in detail in China

\footnotetext{
${ }^{22}$ China's Agenda 21 1994, ch 1(2).

${ }^{23}$ China's Agenda 21 1994, ch 18(31).

${ }^{24}$ China's Agenda 21 1994, ch 18(32).

25 China's Agenda 21 1994, ch 18(33).

${ }^{26}$ China's Agenda 21 1994, ch 18(34)(35).

${ }^{27}$ China's Agenda 21 1994, ch 4.
} 
Agenda 21. Nonetheless, many policies in the agenda concerning economic development and local environmental protection clearly match the UNFCCC's objective to address climate change, such as sustainable energy development, clean technology development, and action on forest issues. ${ }^{28}$

China's Agenda 21 has been gradually translated into national economic and social development plans. 'Five-Year Plan' is a major component of China's national economic plans, mainly functioning to make plans for major national construction programs, productivity distribution and major ratios in national economy, and set objectives of and make directions for national economic development in the long-term. ${ }^{29}$

In March 1996, the Ninth Five-Year Plan (1996-2000) and the 2010 Long-Term Program for National Economic and Social Development of the People's Republic of China was approved. At that time, China was at a crucial phase of deepening economic restructure and opening up to the outside world. Against this background, the main objective of the Ninth Five-Year Plan was to promote the stable, rapid and health development of national economy. ${ }^{30}$ Guided by China's Agenda 21, sustainable development was set as an important guideline and strategic objective of China’s social and economic development.

\footnotetext{
${ }^{28}$ Institute for Global Environmental Strategies and Chinese Renewable Energy Industries Association (ed), CDM Country Guide for China (First edition ed, 2005) 101.

${ }^{29}$ See Introduction to Five-Year Plans <http://www.china.org.cn/95e/95-english1/1.htm> at 6 April 2008.

${ }^{30}$ See Report on the Outline of the Ninth Five-Year Plan (1996-2000) for National Economic and Social Development and the Long-range Objectives to the Year $2010<\mathrm{http}: / /$ www.china.org.cn/95e/95-english1/2.htm> at 6 April 2008.
} 
The Tenth Five-Year Plan (2001-2005) and national development strategy for 2015 were issued in March 2001, where sustainable development was again the major focus. China recognized its position as the second largest emitter, following the US, and thus environmental issues were emphasized. ${ }^{31}$ Ten objectives were established in order to promote the sustainable development and improve environment in China. Among them, controlling $\mathrm{CO}_{2}$ emissions and energy restructure were the major energy and environment strategies. It was required to reduce energy consumption by improving energy efficiency and utilising renewable energy. In addition, forest coverage was raised to 18.2 per cent of national territory and amount of major pollutants were reduced by 10 per cent from 2000 level. $^{32}$

Currently, the Chinese Government is working on its Eleventh Five-Year Program for National Economic and Social Development (2006-10), which fully demonstrates the urgency to solve environmental and energy issues, which have posed a great threat to national economic development. ${ }^{33}$ Facing this situation, China should develop circular economy and saving society with a view to promoting sustainable development. Further, the clear targets concerning the GHG emissions are set. Energy consumption (per unit of GDP) will be reduced by 20 per cent over five years from 2005 level, the amount of pollutants will be reduced by 10 per cent from 2005 level,

\footnotetext{
31 'New Five-Year Plan Gives Priority to Environmental Protection', People's Daily, Beijing, 13 March, 2001 <http://english.people.com.cn/200103/13/eng20010313_64836.html> at 26 May 2008 .

32 China's New Five-Year Plan Gives Priority to Environment (2001) China Council for International Cooperation and Environment <http://www.harbour.sfu.ca/dlam/newsletters/0103.html> at 26 May 2008 .

${ }^{33}$ See China's Eleventh-Five Year Plan (2006-2010), Ch 6 <http://en.ndrc.gov.cn/hot/t20060529_71334.htm> at 3 March 2009.
} 
and forest coverage will be raised to 20 per cent of the national territory. ${ }^{34}$

To sum up, China began to attach great importance to environmental issues through bringing sustainable development thinking into general national strategies and plans. The regulations concerning climate change and energy development in these strategies and plans provide an overall guideline to reducing GHG emissions.

\subsubsection{Specified Policies on Climate Change}

Besides overall national policies, China has promulgated a series of specified policies and blueprints to deal with climate change.

In order to effectively fulfill the obligations under the UNFCCC and the Kyoto Protocol and portrait a picture of how China would be affected by a changing climate, China's first National Assessment Report on Climate Change $2006^{35}$ was formulated and released jointly by twelve government departments in 2006 .

This report reviews the fact and impact of climate change on China and projects the trend of climate change in the $21^{\text {st }}$ century on the basis of scientific research outcomes on climate change. Also, it assesses the potential impact of international climate change regulations on China's ecological, environmental, economic and social development and thus puts forward the relevant position, principles and policies on addressing global warming. The report is divided into three parts: Climate change in

\footnotetext{
${ }^{34}$ China's Eleventh-Five Year Plan (2006-2010), Ch 6 <http://en.ndrc.gov.cn/hot/t20060529_71334.htm> at 3 March 2009.

${ }^{35}$ China's National Assessment Report on Climate Change (I)\&(II)

<www.climatechange.cn/qikan/manage/wenzhang/01.pdf> and

<www.climatechange.cn/qikan/manage/wenzhang/02.pdf> at 3 March 2009.
} 
China and the Future Trend, Climate Change Impacts and Adaptation, and Integrated Evaluation on Policies of China Responding to Climate Change. The main conclusions indicated in the report are that climate change is happening in China; the temperature will continue to increase and dominantly, the adverse impact of climate change has been observed in China. In light of this report, China realised the urgency to actively address climate change and that it should be done through technological innovation and decision-making.

The authoritative and comprehensive report does not only demonstrate China's determination to address climate change, but also provides scientific evidence for making policies on promoting economic and social sustainable development in China.

As mandated under the UNFCCC and on the scientific basis of National Assessment Report on Climate Change 2006, the State Council hereby formulated and released China's National Climate Change Program $2007^{36}$ in 2007 , which is presented as a 'basic law' guiding China's efforts to cope with climate change.

The program outlines objectives, basic principles, key areas of actions, as well as policies and measures to address climate change for the period up to 2010 . It is a national strategy for climate change mitigation and adaptation to expected impacts, which cannot only play a positive role in addressing climate change in China, but would also make a new contribution to the international community.

\footnotetext{
${ }^{36}$ National Development and Reform Commission, the People's Republic of China, China's National Climate Change Programme (2007) <en.ndrc.gov.cn/newsrelease/P020070604561191006823.pdf> at 3 March 2009.
} 
China's Policies and Actions for Addressing Climate Change 2008 (White Paper) ${ }^{37}$ was released in October 2008. It systematically introduces the achievements of addressing climate change in China and carrying out the national strategies. With regard to the CDM, it states that 'China highlights the positive effect of the CDM on promoting sustainable development and is willing to make contribution to global GHG emissions reduction through participating in CDM projects. ${ }^{38}$

Other relevant policies were also released in order to support China's endeavors to combat climate change.

The first China Medium- and Long-Term Energy Conservation Plan $2004^{39}$ was launched by the NDRC in 2004. The plan sets out the energy conservation targets and priority areas by 2010 and put forward the targets by 2020. According to the plan, China would save energy by 2.2 per cent annually from 2003-2010 and 3 per cent before $2020 .^{40}$

In 2007, the NDRC issued the Medium- and Long-Term Plan on the Development of Renewable Energy in China $2007^{41}$. Under this plan, China sought to bring the proportion of the consumption of renewable energy to 10 per cent of total energy

\footnotetext{
37 China's Policies and Actions for Addressing Climate Change 2008 (Information Office of the State Council of the People's Republic of China) <http://www.gov.cn/english/2008-10/29/content_1134544.htm> at 20 March 2009.

${ }^{38}$ China's Policies and Actions for Addressing Climate Change 2008 (Information Office of the State Council of the People's Republic of China) pt VII. Enhancing International Cooperation on Climate Change.

${ }^{39}$ China Medium- and Long- Term Energy Conservation Plan 2004 (National Development and Reform Commission of the People's Republic of China)

<http://www.fourfact.com/images/uploads/China_Energy_Saving_Plan.pdf> at 20 March 2009.

40 China Medium- and Long- Term Energy Conservation Plan 2004 (National Development and Reform Commission of the People's Republic of China) 9.

${ }^{41}$ Medium- and Long- Term Plan on the Development of Renewable Energy in China 2007 (National Development and Reform Commission of the People's Republic of China).
} 
consumption by 2010 , and up to 15 per cent by $2020 .{ }^{42}$ In fact, in 2005 , the proportion was merely 7.5 per cent, as the country still relied heavily on coal and oil. ${ }^{43}$ These foresighted targets pose a great challenge to China. Hence, in order to realize these targets, the Chinese Government decided to investment 2,000 billion Yuan on the development of renewable energy before $2020 .{ }^{44}$ Additionally, the priority should focus on water energy, biomass energy, wind energy and solar energy.

In addition, China enhances the role that science and technology play in response to climate change. The Ministry of Science and Technology (MOST), in collaboration with other 13 ministries and agencies, released China's Scientific and Technological Actions on Climate Change. ${ }^{45}$ The issuance of the Actions is a follow-up action corresponding to the Climate Change Program 2007, demonstrating that China would strive to make breakthroughs by 2020 in a batch of key technologies to control GHG and arrest climate change. ${ }^{46}$

In conclusion, China has not only brought sustainable development and GHG emission reduction into national strategies and plans, but has also launched climate-specific programs. Particularly, China has found itself with a growing

\footnotetext{
${ }^{42}$ Medium- and Long- Term Plan on the Development of Renewable Energy in China 2007 (National Development and Reform Commission of the People's Republic of China) 5.

${ }^{43}$ Medium- and Long- Term Plan on the Development of Renewable Energy in China 2007 (National Development and Reform Commission of the People's Republic of China) 2.

${ }^{44}$ Deming Chen (deputy director of NDRC) said about the release of the Medium-and Long-Term Plan on the Development of Renewable Energy on China State Council Press Conference, Beijing, 4 September 2007.

${ }^{45}$ China's Scientific and Technological Actions on Climate Change 2007 (The Ministry of Science and Technology of the People's Republic of China) <www.ccchina.gov.cn/WebSite/CCChina/UpFile/File199.pdf > at 18 May 2008.

${ }^{46}$ China's Scientific and Technological Actions on Climate Change 2007 (The Ministry of Science and Technology of the People's Republic of China) 4.
} 
obligation to cut its mounting emissions of GHG since 2007, thus accelerating its steps to curb climate change. All these regulatory documents mentioned above may serve as the policy and legal guarantee to further enhance China's capabilities for addressing climate change. Moreover, the relevant regulations that support the sustainable development and climate change mitigation in these policies create favorable a regulatory framework to promote CDM projects in China.

\subsubsection{Existing Legislative Framework Supporting the CDM}

Besides the climate-related policies, there are a series of laws within China's domestic legal system that may affect the implementation of CDM projects.

\subsubsection{Climate Change Resolution}

China is going to draw up new laws and regulations to provide a legal basis for combating climate change. China's top legislative body approved its first climate change resolution in August 2009 and announced plans to draw up new laws to combat global warming. A draft called on the government to take further measures to control GHG emissions and accelerate efforts to tackle the challenge of global warming. In addition, the draft resolution says that 'the role of science and technology in leading and supporting the fight against climate change should be given fully play. ${ }^{, 47}$

\footnotetext{
47 'Legislators to Deliberate Draft on Climate Change', China Daily (Beijing), 25 August 2009 <http://www.chinadaily.com.cn/china/2009-08/25/content_8614750.htm> at 12 December 2009.
} 


\subsubsection{Legislation Promoting a Low-Carbon Economy}

According to the report made at the Sixteenth National Congress of the Communist Party of China in 2002, with a view to dealing with the environmental degradation caused by an unclean industrialization model, China shall lay out a new industrialization model as its only pathway to protect environment without undermining high-speed economic growth. ${ }^{48}$ Such industrialization features high-technology products, good economic returns, low levels of natural resources consumption and environmental pollution and efficient deployment of manpower. ${ }^{49}$ Hence, as for climate change, the new industrialization model may also assists to reduce carbon emissions through applying advanced technologies and decreasing energy consumption, thus promoting the shift to a low-carbon economy.

Against this background, China promulgated the Cleaner Production Promotion Law $2002^{50}$ and formulated the Circular Economy Law $2008^{51}$ which are supposed to provide a significant legal guarantee for supporting a new industrialization model in China.

The Cleaner Production Promotion Law 2002, approved by the Standing Committee of the National People's Congress (NPC), China's top legislative, in June 2002 and entering into effect in January 2003, is the first specified legislation targeting at

\footnotetext{
${ }^{48}$ See 'The Circular Economy in China', Cleaner Product in China $<$ http://www.chinacp.org.cn/eng/cppolicystrategy/circular_economy.html> at 8 June 2008.

49 See ibid.

${ }^{50}$ Cleaner Production Promotion Law 2002 (the People's Republic of China).

${ }^{51}$ Circular Economy Law 2008 (the People's Republic of China).
} 
preventing pollution. Since then, management of promotion and implementation of cleaner production $^{52}$ is one the way to becoming legislation.

This law consists of six chapters and 42 articles. Chapter one is general provisions, outlining the definition, objective, scope and other basic information about the cleaner production. Chapter two is about the Chinese Government's responsibilities to realize cleaner production. Chapter three focuses on the requirements of enterprises or individuals to implement cleaner production. Chapter four is concerned with the inducement measures to encourage the cleaner production while Chapter five states the legal liability. Chapter six is a supplementary article about when it comes into effect.

As for the CDM, Article 3 states that:

Within the territory of the People's Republic of China, any units or individuals engaged in activities relating to production or provision of services and their corresponding management agencies must organize and implement systems for cleaner production in accordance with the provisions therefore contained in this Law. ${ }^{53}$

Given the objectives and nature of CDM projects, their implementation in China needs to be in accordance with the Cleaner Production Promotion Law 2002.

The China NPC is preparing to issue a specified law with the aims of increasing resource utilization rate, protecting and improving environment and realising

\footnotetext{
${ }^{52}$ Cleaner production in this legislation means the 'continuous application of measures for design improvement, utilization of clean energy and raw materials, the implementation of advanced processes, technologies and equipment, improvement of management and comprehensive utilization of resources to reduce pollution at source, enhance the rates of resource utilization efficiency, reduce or avoid pollution generation and discharge in the course of production, provision of services and product use, so as to decrease harm to the health of human beings and the environment.'

${ }^{53}$ Cleaner Production Promotion Law 2002 (the People's Republic of China) art 3.
} 
sustainable development through promoting the circular economy in China, and the Circular Economy Law 2008 has been approved.

After the proposal of a new industrialization model, the circular economy was introduced into China and started to flourish. Circular economy is a new economic development model which is believed to be capable of becoming environmentally friendly to economic development by making a full and efficient use of resources and energies and minimizing waste discharge through the technological innovation of the traditional industries, thus fundamentally eliminating the sharp confliction between the environment and development that has existed. Compared to the traditional economy, circular economy is an eco-efficient economy with '3 Rs' principle Reduce, Reuse, and Recycle. Under the circular economy, one facility's waste, including energy, water, materials - as well as information - may be reused another facility's input. By working together, the whole society obtains a larger collective benefit, with low resources input, high utilization rate and low emissions. ${ }^{54}$ Therefore, the development based on a circular economy is essential for China to establish a new industrialized model and ultimately realize sustainable development.

In spite of the significance of circular economy in China, lack of theoretical framework and practical tools could be an impediment to its effective application. To countering this, the Chinese Government started to draft out the law on circular economy in December 2005.

\footnotetext{
54 Jianyu Zhang, 'Approaching Circular Economy', China Daily (Beijing), 1 October 2004 <http://www.chinadaily.com.cn/english/doc/2004-10/01/content_379348.htm> at 10 December 2008.
} 
According to the law, restructured and new industrial facilities must incorporate energy efficiency designs and must undergo environmental assessment. ${ }^{55}$ In addition, in order to promote its development, the circular economy appraisal and assessment would be established as a criterion of evaluating the performance of officials at local governments. ${ }^{56}$ These regulations are beneficial to reduce carbon emissions and promote the development of CDM projects in China.

Overall, the Cleaner Production Promotion Law 2002 and the Circular Economy Law 2008 could create a favorable legal environment for saving energy and reducing emissions. Clean production is the first step to reach the ultimate goal of circular economy. Only by developing the circular economy, can it be possible for China to realize the shift to a low-carbon economy.

\subsubsection{Environmental Protection Legislation}

Although $\mathrm{CO}_{2}$ is not a pollutant being regulated under the Chinese environmental legislation, some provisions in environmental protection laws may affect implementation of CDM projects in China. According to operational rules of the $\mathrm{CDM}$, developing a CDM project requires the developers to undertake an appropriate environmental impact assessment. ${ }^{57}$ In addition, developing or restructuring a project in China also needs to obtain the necessary environmental consents and licenses to build and operate the project. Therefore, environmental protection legislation is in

\footnotetext{
${ }^{55}$ Circular Economy Law 2008 (the People's Republic of China) art 29, para 4.

${ }^{56}$ Circular Economy Law 2008 (the People's Republic of China) art 14.

${ }^{57}$ For details, see Chapter 246.
} 
China is examined to figure out how it impacts the development of CDM projects.

Environmental Protection Law $1989^{58}$ was formulated by Standing Committee of the NPC in December 1989. It functions as a basic law to regulate environmental issues in China. However, with the social and economic development, the law is in need of revision.

The law comprises 47 articles and six chapters, which stipulate the general provisions, supervision and management of the environment, protection and improvement of the environment, prevention and control of environmental pollution and other public hazards, legal liability and supplementary provisions respectively. The climate-related provisions which may impact CDM projects are as follows:

Article 13: Units constructing projects that cause pollution to the environment must observe the State provisions concerning environmental protection for such construction projects.

The environmental impact statement on a construction project must assess the pollution the project is likely to produce and its impact on the environment and stipulate the preventive and curative measures; the statement shall, after initial examination by the authorities in charge of the construction project, be submitted by specified procedure to the competent department of environmental protection administration for approval. The department of planning shall not ratify the design plan descriptions of the construction project until after the environmental impact statement on the construction project is approved. $^{59}$

Article 25: For the technological transformation of newly built industrial enterprises and existing industrial enterprises, facilities and processes that effect a high rate of the utilization of resources and a low rate of the discharge of pollutants shall be used... ${ }^{60}$

Article 30: A ban shall be imposed on the importation of any technology or facility that fails to meet the requirements specified in the regulations of our country concerning

\footnotetext{
58 Environmental Protection Law 1989 (the People's Republic of China).

${ }^{59}$ Environmental Protection Law 1989 (the People's Republic of China) art 13.

${ }^{60}$ Environmental Protection Law 1989 (the People's Republic of China) art 25.
} 
environmental protection. ${ }^{61}$

Therefore, on the one hand, the Chinese Government encourages clean technological transformation; on the other hand, developing CDM projects in China need to meet the relevant environmental requirements and have to undergo the environmental impact examination by the competent departments.

\subsubsection{Energy-related Legislation}

The Chinese Government has attached great importance to addressing climate change through the legislation concerning energy efficiency and utilisation of renewable energy.

The main legislation for energy efficiency is the Energy Conservation Law $1997^{62}$, which was enacted by the NPC Standing Committee in November 1997. The law was revised in October 2007 and entered into force in April 2008 as the former energy conservation law no longer met China's development need of transiting the focus of economic development from energy and resources consumption to energy saving. For this reason, the Energy Conservation Law 1997 was revised to secure a strong legal framework for building an energy-saving society.

The revised Law consists of seven chapters. The main content is about administration of energy conservation, rational use of energy and energy conservation on the general aspect, industrial energy aspect, construction energy aspect, transport energy aspect,

\footnotetext{
${ }^{61}$ Environmental Protection Law 1989 (the People's Republic of China) art 30.

${ }^{62}$ Energy Conservation Law 1997 (the People's Republic of China), amended in 2007.
} 
energy conservation by public institutions aspect and by key energy consuming entities aspect, technological progress in energy conservation, incentive measures and legal liabilities.

The outstanding achievement of the new law lies in adopting many effective measures and regulations to decrease energy consumption in China, which are as follows:

Energy conservation has been set as a basic national policy of China. ${ }^{63}$

In order to effectively promote energy conservation, the energy conservation target responsibility system and the energy conservation examination system should be implemented. ${ }^{64}$

The energy conservation evaluation and review system to fixed investment projects should be implemented. ${ }^{65}$

The indoor temperature control system shall be implemented to public buildings using air-conditioning heating and refrigeration and urban power conservation management should be enhanced with a view to strengthening construction energy conservation. ${ }^{66}$

The public transport, non-vehicles and the utilization of clean fuels are encouraged. ${ }^{67}$

The management of the major energy consuming industries ${ }^{68}$ is emphasized. ${ }^{69}$

The Chinese Government places an emphasis on energy conservation technological development and propels enterprises to carry out energy conservation technological transformation. ${ }^{70}$

\footnotetext{
${ }^{63}$ See Energy Conservation Law 1997 (the People's Republic of China), amended in 2007, art 4 'Energy conservation constitutes a long-term strategic policy in the nation's economic development'.

${ }^{64}$ See Energy Conservation Law 1997 (the People's Republic of China), amended in 2007, art 6 'The State takes the completion of energy conservation targets as an item to assess and evaluate the performance of the local people's government and the persons in charge thereof'.

${ }^{65}$ See Energy Conservation Law 1997 (the People's Republic of China), amended in 2007, art 15 'With respect to the projects inconsistent with compulsory energy conservation standards, the competent examination and approval department shall not approve or verify...'.

${ }^{66}$ Energy Conservation Law 1997 (the People's Republic of China), amended in 2007, art 37-40.

${ }^{67}$ Energy Conservation Law 1997 (the People's Republic of China), amended in 2007, s 4.

${ }^{68}$ The key energy consuming industries fall into two categories: the industries with over 10 thousand tons of energy consumption volumes per year and the industries with 5 thousand to 10 thousand tons of energy consumption volumes per year specified by the competent departments. They often include electric power, iron and steel, non-ferrous metals, building materials, oil processing, chemical, coal and other industries.

${ }^{69}$ See Energy Conservation Law 1997 (the People's Republic of China), amended in 2007, art 49 'The major energy consuming industries should make annual reports concerning energy consumption last year to the energy conservation administrative department'.
} 
China would implement energy conservation favorable tax policies, would guide financial institutions to raise the credit supports for energy-saving projects and would adopt energy-saving favorable price policies. ${ }^{71}$

In February 2005, the NPC adopted the Renewable Energy Law of the People's Republic of China 2005, confirming the role of renewable energy in China's national energy strategy and promoting the development and utilization of renewable energy.

The Law is divided into eight chapters. Chapter one is a general introduction to the objectives and application of this law. The law explicated stated that 'the government encourages economic entities of all ownerships to participate in the development and utilization of renewable energy and protects legal rights and interests of the developer and uses of renewable energy on the basis of law. ${ }^{, 72}$ In addition, energy authorities of the State Council is the competent department for the management of renewable energy at the national level and energy authorities of local people's governments above the county level within their own jurisdiction.

Chapter two is concerned with resource survey and development plan. Medium- and long-term targets of the total volume for the development and utilisation of renewable energy at national level and local level would be set on the basis of the result of renewable energy. Meanwhile, national and local renewable energy development and utilization plans shall be prepared.

Chapter three focuses on industry guidance and technology support, setting out the responsibilities of the government in guiding the renewable energy industries and

\footnotetext{
70 Energy Conservation Law 1997 (the People's Republic of China), amended in 2007, art 60-6.

${ }^{71}$ Energy Conservation Law 1997 (the People's Republic of China), amended in 2007, art 76.

${ }^{72}$ Renewable Energy Law2005 (the People's Republic of China) art 4 para 2.
} 
highlighting the importance of scientific and technical research.

Chapter four formulates the details concerning promotion and application of grid-connected renewable power generation, biological fuel and energy crops, solar energy and the renewable energy in rural areas.

Chapter five stipulates price management and fee sharing of renewable energy power. Differentiated pricing and public cost sharing (realised by a grid cost-sharing system) systems are set up, whereby all citizens are required to share the extra costs associated with developing renewable energy.

Chapter six and Chapter seven state economic incentives and legal responsibilities, which would encourage the entire society, particularly companies, to develop and use renewable energy, as well as financially penalize companies and individuals that do not meet the obligations set out for them by the law. In order to support the development of renewable energy, a renewable energy development fund was established through a preferential loan with financial interest subsidy to certain renewable energy projects by financial institutions and tax befits to certain projects are granted.

To sum up, the Renewable Energy Law 2005 provides a legal guarantee for supporting renewable energy development and utilisation in China through protecting legal interests and rights of the projects developers, removing barriers to the development of the renewable energy market, setting up a financial guarantee system and creating a 
social atmosphere conductive to renewable energy. In this sense, CDM projects concerning the renewable energy would be encouraged and could enjoy a favorable legal environment in China.

As mentioned in the previous chapter, massive energy demand in China derives from power generation. ${ }^{73}$ Therefore, it is necessary to review the legislation concerning power in China.

The Electricity Law $1995^{74}$, adopted in 1995 and entered into force in 1996, is the fundamental law in electrical legislation in China. The law has made a contribution to promoting the power industry in China. However, with the development of a market economy and reform in China, this law, which features administrative monopolization on the management of power, has hardly been able to meet the economic and social development in China. Based on that, the amendment to the Electricity Law 1995 has already been brought into national law-making plans. In spite of the flaws existing in the current Electricity Law 1995, it may also affect the CDM projects in China through the following articles:

Article 13: Investors in electric power shall enjoy legal rights and interests over the electricity generated from their investment. Where electricity thus generated feeds into the power network, the investor shall have the priority in utilization; where a captive power plant is not in parallel operation with the power network, the investor shall have the authority in deciding the utilization on its own. ${ }^{75}$

Article 14: Power construction projects shall conform to the electric power development planning as well as the State's industrial policies on the power industry. ${ }^{76}$

\footnotetext{
${ }^{73}$ For details, see Chapter two 94.

74 Electricity Law 1995 (the People's Republic of China).

75 Electricity Law 1995 (the People's Republic of China) art 13.

${ }^{76}$ Electricity Law 1995 (the People's Republic of China) art 14.
} 
Article 16: Land used for power construction projects shall be handled in accordance with relevant laws and administrative regulations. ${ }^{77}$

Article 35: The electricity price shall be based on the principle of uniform policy, unified pricing and be regulated at different levels. ${ }^{78}$

It can be seen that the legal interests and rights of investors of CDM projects concerning power generation could be protected while the implementation of CDM projects concerning power generation should also conform to the relevant provisions in the Electricity Law1995.

In addition, Law of the People's Republic of China on the Coal Industry $1996^{79}$ was issued with a view to rationally developing, utilizing and protecting the coal resources, standardizing the production and marketing of coal, and promoting and ensuring the development of the coal industry. ${ }^{80}$ However, the environmental aspect and sustainability aspect are not emphasized under the Law on Coal Industry.

In addition, methane recovery and utilisation is a major type of CDM project. However, there are no special provisions in the legislation in place to promote that in China. In spite of that, several measures have been issued at a national level as well as a local level to accelerate the use of methane, especially in rural areas. China has released the Emission Standard of Coalbed Methane/Coal Mine Gas (on trial) ${ }^{81}$ in order to enhance the management of GHG emissions and global warming mitigation.

\footnotetext{
77 Electricity Law 1995 (the People's Republic of China) art 16.

${ }^{78}$ Electricity Law 1995 (the People's Republic of China) art 35.

79 Law of the People's Republic of China on the Coal Industry 1996 (the People's Republic of China).

${ }^{80}$ Law of the People's Republic of China on the Coal Industry 1996 (the People's Republic of China) art 1.

${ }^{81}$ Emission Standard of Coalbed Methane/Coal Mine Gas (on trial) 2008 (General Administration of Quality Supervision, Inspection, and Quarantine of the Environmental Protection Ministry of the People's Republic of China) <www.ep.net.cn/cgi-bin/dbbz/doc.cgi?id=1067> at 20 November 2008.
} 
In conclusion, China has created a favorable legislative framework to promote energy efficiency and renewable energy projects in China. Moreover, investing in and developing these projects within the territory of China also need to meet the relevant requirements in the laws.

\subsubsection{Specified Legislation for the CDM}

Measures for the Operation and Management of CDM projects in China 2005, which is the specified law for the CDM, was issued in 2005.

\subsubsection{Other Legislation Affecting the CDM}

Many provisions in other legislation concerning foreign direct investment, tax, ownership issues with regards to CERs and clean technologies may also affect the implementation of CDM projects in China.

The working mechanism of the CDM is that the developed countries and developing countries cooperate to reduce emissions through financial and/or technological investment. In this sense, if any participants, financiers, controlling shareholders or owners of CDM projects are not national of China, it may be affected by the foreign direct investment framework in China.

The Chinese Government has issued three laws promoting foreign direct investment: Law of the People's Republic of China on Chinese-Foreign Equity Joint Ventures 
$1979^{82}$, Law of the People's Republic of China on Chinese-Foreign Contractual Joint Ventures $1988^{83}$ and Law of the People's Republic of China on Foreign-Funded Enterprises $1979^{84}$. Article 17 of the Measures clearly stipulates that 'Project owner refers to the Chinese funded or Chinese-holding enterprises', which can be interpreted that the Chinese partner must have minimum 51 per cent shares. In this regard, Law of the People's Republic of China on Chinese-Foreign Equity Joint Ventures 1979 and Law of the People's Republic of China on Chinese-Foreign Contractual Joint Ventures 1988 affect the implementation of CDM projects in China.

Law of the People's Republic of China on Chinese-Foreign Equity Joint Ventures 1979, consisting of 15 articles, was adopted in July 1979 and was revised a second time on March, 2001. The law regulates equity joint venture which shall take the form of a limited liability company and whose parties shall share the profits, risks and losses in proportion to their contributions to the registered capital. The main content which may affect the foreign investments in the CDM projects are as follows:

The Chinese Government protects, in accordance with the law, the investment of foreign joint ventures, the profits due to them and their other lawful rights and interest in a joint venture, pursuant to the agreement, contract and articles of association approved by the Chinese Government. ${ }^{85}$

The state does not practice nationalization and expropriation of a joint venture; under special circumstances, the state, in accordance with the needs of social public interest, expropriates a joint venture pursuant to legal procedures and offers corresponding

\footnotetext{
${ }^{82}$ Law of the People's Republic of China on Chinese-Foreign Equity Joint Ventures 1979 (the People's Republic of China), amended in 2001.

${ }^{83}$ Law of the People's Republic of China on Chinese-Foreign Contractual Joint Ventures 1988 (the People's Republic of China), amended in 2000.

${ }^{84}$ Law of the People's Republic of China on Foreign -Funded Enterprises 1986 (the People's Republic of China), amended in 2000.

${ }^{85}$ Law of the People's Republic of China on Chinese-Foreign Equity Joint Ventures 1979 (the People's Republic of China), amended in 2001, art 2 para 1.
} 
compensations. $^{86}$

The parties to an equity joint venture may make their investment in cash, building, premises, equipment or other materials, industrial property, know-how, or the rights to the use of a site. ${ }^{87}$

An equity joint venture may, in accordance with provisions of the relevant laws and administrative rules and regulations of the state on taxation, enjoy preferential treatment for reduction of or exemption from taxes. A foreign joint venturer that reinvests its share of the net profit within the territory of China may apply for partial refund of the income tax already paid. ${ }^{88}$

An equity joint venture may, in its business operations, directly raise funds from foreign banks. ${ }^{89}$

The legal requirements and approval and termination procedures for developing a

Chinese-foreign equity joint venture are as follows:

The proportion of the foreign joint venturer's investment in an equity joint venture shall be, in general, not less than 25 per cent of its registered capital. ${ }^{90}$

The equity joint venture agreement, contract and articles of association signed by the parties to the venture shall be submitted to the state's competent department in charge of foreign economic relations and trade (hereinafter referred to as the examination and approval authorities) for examination and approval. The examination and approval authorities shall decide to approve or disapprove the venture within three months. When approved, the equity joint venture shall register with the state's competent department in charge of industry and commerce administration, acquire a business license and start operations. ${ }^{91}$

In case of heavy losses, failure of a party to perform its obligations under the contract and the articles of association, or force majeure etc., the parties to the joint venture may terminate the contract through their consultation and agreement, subject to approval by the examination and approval authorities and to registration with the state's competent department in charge of industry and commerce administration. In cases of losses caused by a breach of contract, the financial responsibility shall be

\footnotetext{
${ }^{86}$ Law of the People's Republic of China on Chinese-Foreign Equity Joint Ventures 1979 (the People's Republic of China), amended in 2001, art 2 para 3.

${ }^{87}$ Law of the People's Republic of China on Chinese-Fforeign Equity Joint Ventures 1979 (the People's Republic of China), amended in 2001, art 5 para 1.

${ }^{88}$ Law of the People's Republic of China on Chinese-Foreign Equity Joint Ventures 1979 (the People's Republic of China), amended in 2001, art 8.

${ }^{89}$ Law of the People's Republic of China on Chinese-Foreign Equity Joint Ventures 1979 (the People's Republic of China), amended in 2001, art 9.

${ }^{90}$ Law of the People's Republic of China on Chinese-Foreign Equity Joint Ventures 1979 (the People's Republic of China), amended in 2001, art 4 para 2.

${ }^{91}$ Law of the People's Republic of China on Chinese-Foreign Equity Joint Ventures 1979 (the People's Republic of China), amended in 2001, art 13.
} 
borne by the party that has breached the contract. ${ }^{92}$

Disputes arising between the parties to an equity joint venture which the board of directors has failed to settle through consultation may be settled through mediation or arbitration by an arbitration agency of China or through arbitration by another arbitration agency agreed upon by the parties. ${ }^{93}$

Law of the People's Republic of China on Chinese-Foreign Contractual Joint Venture 1988s, consisting of 28 articles, was first adopted in April 1988 and was revised in October 2000. The law targets at contractual joint venture where the Chinese and foreign parties shall prescribe in their contractual joint venture contract such matters as the investment or conditions for cooperation, the sharing of risks and losses and the ownership of the property at the time of the termination of the contractual joint venture and which meets the conditions for being considered a legal person under Chinese law, shall acquire the status of a Chinese legal person in accordance with law. The main content which may affect foreign investment in CDM projects are as follows:

The state shall, according to law, protect the lawful rights and interests of the contractual joint ventures and of the Chinese and foreign parties. ${ }^{94}$

The state shall encourage the establishment of productive contractual joint ventures that are export-oriented or technologically advanced. ${ }^{95}$

The investment or conditions for cooperation contributed by the Chinese and foreign parties may be provided in cash or in kind, or may include the right to the use of land, industrial property rights, non-patent technology or other property rights. ${ }^{96}$

\footnotetext{
${ }^{2}$ Law of the People's Republic of China on Chinese-Foreign Equity Joint Ventures 1979 (the People's Republic of China), amended in 2001, art 14.

${ }^{93}$ Law of the People's Republic of China on Chinese-Foreign Equity Joint Ventures 1979 (the People's Republic of China), amended in 2001, art 15.

${ }^{94}$ Law of the People's Republic of China on Chinese-Foreign Contractual Joint Ventures 1988 (the People's Republic of China), amended in 2000, art 3.

${ }^{5}$ Law of the People's Republic of China on Chinese-Foreign Contractual Joint Ventures 1988 (the People's Republic of China), amended in 2000, art 4.

${ }^{96}$ Law of the People's Republic of China on Chinese-Foreign Contractual Joint Ventures 1988 (the People's
} 
A contractual joint venture shall conduct its operational and managerial activities in accordance with the approved contract and articles of association for the contractual joint venture. The right of a contractual joint venture to make its own operational and managerial decisions shall not be interfered with. ${ }^{97}$

A contractual joint venture may obtain loans from financial institutions within the territory of China and may also obtain loans outside the territory of China. ${ }^{98}$

A contractual joint venture must establish its account books within the territory of China, file its accounting statements according to relevant provisions and accept supervision by the financial and tax authorities. ${ }^{99}$

A contractual joint venture shall, in accordance with state provisions on tax, pay taxes and may enjoy the preferential treatment of tax reduction or exemption. ${ }^{100}$

The legal requirements and approval and termination procedures for developing a

Chinese-foreign equity joint venture are as follows:

For the purpose of applying for the establishment of a contractual joint venture, such documents as the agreement, the contract and the articles of association signed by the Chinese and foreign parties shall be submitted for examination and approval to the department in charge of foreign economic relations and trade under the State Council or to the department or local government authorized by the State Council (hereinafter referred to as the examination and approval authority). The examination and approval authority shall, within 45 days of receiving the application, decide whether or not to grant approval. ${ }^{101}$

When the application for the establishment of a contractual joint venture is approved, the parties shall, within 30 days of receiving the certificate of approval, apply to the administrative authorities for industry and commerce for registration and obtain a business license. The date of issuance of the business license of a contractual joint venture shall be the date of its establishment. A contractual joint venture shall, within 30 days of its establishment, carry out tax registration with the tax authorities. ${ }^{102}$

Republic of China), amended in 2000, art 8.

97 Law of the People's Republic of China on Chinese-Foreign Contractual Joint Ventures 1988 (the People's Republic of China), amended in 2000, art 9.

${ }^{9}$ Law of the People's Republic of China on Chinese-Foreign Contractual Joint Ventures 1988 (the People's Republic of China), amended in 2000, art 17 para 1.

${ }^{99}$ Law of the People's Republic of China on Chinese-Foreign Contractual Joint Ventures 1988 (the People's Republic of China), amended in 2000, art 15 para1.

${ }^{100}$ Law of the People's Republic of China on Chinese-Foreign Contractual Joint Ventures 1988 (the People's Republic of China), amended in 2000, art 20.

${ }^{101}$ Law of the People's Republic of China on Chinese-Foreign Contractual Joint Ventures 1988 (the People's Republic of China), amended in 2000, art 5.

${ }^{102}$ Law of the People's Republic of China on Chinese-Foreign Contractual Joint Ventures 1988 (the People's 
A contractual joint venture shall, upon the expiration or termination in advance of its term, cancel its registration with the administrative authorities for industry and commerce and the tax authorities. ${ }^{103}$

Any dispute between the Chinese and foreign parties arising from the execution of the contract or the articles of association for a contractual joint venture shall be settled through consultation or mediation. In case of a dispute which the Chinese or the foreign party is unwilling to settle through consultation or mediation, or of a dispute which they have failed to settle through consultation or mediation, the Chinese and foreign parties may submit it to a Chinese arbitration agency or any other arbitration agency for arbitration in accordance with the arbitration clause in the contractual joint venture contract or a written agreement on arbitration concluded afterwards. The Chinese or foreign party may bring a suit in a Chinese court, if no arbitration clause is provided in the contractual joint venture contract and if no written agreement is concluded afterwards. ${ }^{104}$

It can be seen that the Chinese Government has created a favorable environment to attract foreign investments. However, in order to implement a CDM project in China, project developers need to undergo certain procedures under the foreign investment laws.

Besides the specified levies on CDM projects stipulated in the Measures, there are preferential tax regulations with a view to attracting foreign investment and promoting clean technological development, as detailed below:

The new Enterprise Income Tax Law $2007^{105}$ was adopted by the Chinese Government in March, 2007 and entered into force in January, 2008. The law, containing 8 chapters and 60 articles, stipulates many new provisions concerning the enterprise income tax. With regards to CDM projects, the relevant provisions are as

Republic of China), amended in 2000, art 6.

${ }^{103}$ Law of the People's Republic of China on Chinese-Fforeign Contractual Joint Ventures 1988 (the People's Republic of China), amended in 2000, art 23 para 2.

${ }^{104}$ Law of the People's Republic of China on Chinese - foreign Contractual Joint Ventures 1988 (the People's Republic of China), amended in 2000, art 25.

105 Enterprise Income Tax Law 2007 (the People's Republic of China). 
follows:

Taxpayers of enterprise income tax shall be enterprises and other organizations that obtain income within the People's Republic of China (hereinafter referred to as 'Enterprises') and shall pay enterprise income tax in accordance with the provisions of this Law. ${ }^{106}$

The industries and projects with key support and under encouraged development by the State may be given preferential enterprise income tax treatment. ${ }^{107}$

The rate of enterprise income tax shall be $25 \% .^{108}$

The following income may be subject to exempted or reduced enterprise income tax:

1. income from investment and operation of infrastructure projects with key state support such as habour, pier, airport, railway, highway, electricity and hydroelectricity by Enterprises;

2. income from engaging in qualified projects of environmental protection and energy and water conservation;

3. income from qualified transfer of technology by Enterprises. ${ }^{109}$

The investment by Enterprises on procurement of special facilities for environmental protection, energy and water conservation and safe production may be subject to an offset tax amount at a certain ratio. ${ }^{110}$

Further, the concomitant Implementing Regulations of Law of the People's Republic of

China on Enterprise Income Tax ${ }^{111}$ was released to explain the implementation of the law in detail. The specific circumstances under which the income may be subject to exempted or reduced enterprise income tax and how it may be exempted or reduced are demonstrated.

The income from investment and operation of infrastructure projects with key state support is subject to a three-year tax exemption followed by a three-year half tax deduction. ${ }^{112}$

\footnotetext{
106 Enterprise Income Tax Law 2007 (the People's Republic of China) art 1.

107 Enterprise Income Tax Law 2007 (thePeople's Republic of China) art 25.

108 Enterprise Income Tax Law 2007 (the People's Republic of China) art 4.

109 Enterprise Income Tax Law 2007 (the People's Republic of China) art 27.

110 Enterprise Income Tax Law 2007 (the People's Republic of China) art 34.

111 Implementing Regulations of Law of the People's Republic of China on Enterprise Income Tax (the State Council of the People's Republic of China).

112 Implementing Regulations of Law of the People's Republic of China on Enterprise Income Tax (the State
} 
The qualified projects of environmental protection and energy and water conservation in the law include public liquid waste disposal, public garbage disposal, technological transformation for energy-saving and emissions reductions desalinating and etc.

The income from investment and operation of above projects is subject to a three-year tax exemption followed by a three-year half tax deduction. ${ }^{113}$

Hence, according to the law and regulations, CDM projects in China may be given preferential enterprise income tax treatment.

With the main purpose of encouraging import of advanced foreign technology and equipment, the Chinese Government formulated the Circular of the State Council on Adjustment of Imported Equipment Taxation Policies $1997^{114}$ (hereinafter referred to Circular) stating that 'starting from January 1, 1998, imported equipment of domestic investment projects and foreign investment projects encouraged by the State shall enjoy exemption from tariff and import-stage value-added tax within the special scope' ${ }^{115}$

According to the Circular, equipment imported for foreign-invested and domestic-invested projects that are encouraged and supported by the state, which involve technology transfer, foreign government loans and international financial organization loans, shall, enjoy tariff and import-state value-added tax exemption. ${ }^{116}$

\footnotetext{
Council of the People's Republic of China) art 87 para 2.

113 Implementing Regulations of Law of the People's Republic of China on Enterprise Income Tax (the State Council of the People's Republic of China) art 88.

${ }^{114}$ Circular of the State Council on Adjustment of Imported Equipment Taxation Policies 1997 (the State Council of the People's Republic of China).

115 All enterprises and individuals engaged in the sale of goods, manufacturing processing, repairs, and replacement services, and the import of goods within the territory of the People's Republic of China must pay a basic value-added tax rate of $17 \%$. Some renewable energy for power enterprises is levied a lower rate, such as wind power at $8.5 \%$ and small hydropower at $6 \%$.

${ }^{116}$ Provided that such items are not among commodities listed in the Catalogue of Imported Commodities not Entitled for Tariff Exemption for Projects with Foreign Investment.
} 
Therefore, CDM projects which involve the technology transfer and foreign loans may enjoy preferential imported duty.

There is also environmental tax. Many developed countries levy environmental taxes, which mainly consist of fuel tax, water pollution tax, waste tax and noise tax, to adjust environmental economic interests and activities by legislation. Although there is no specified environmental tax in China at the current stage, the government is considering launching an environmental tax in order to encourage the efficient use of energy and stem the growth of GHG emissions.

Little consideration has been given to the allocation of legal title and ownership issues concerning the private or public with respect to CER as it is a relatively new concept that a valuable commodity (CERs) may be created from reducing GHGs. Therefore, the newly released Property Law $2007^{117}$ in China does not cover CERs or more generic emission reductions. Rather, the ownership with respect to CERs is dealt with in the Measures. According to the Measures, revenues from the transfer of CERs shall be owned jointly by the government of China and the project owner, with allocation ratio of the revenue being decided by the government of China. ${ }^{118}$

As mentioned in the previous chapter, lack of the legal protection of transferred technology may be a great barrier to attracting investment in CDM projects in China. ${ }^{119}$ Technology transfer and diffusion have to follow the contracts under

\footnotetext{
117 Property Law 2007 (the People's Republic of China).

118 For details, see below Part 4.5.3.1 241.

119 See Chapter four 139.
} 
Intellectual Property Rights (IPR). In this regard, it can be said that protecting the IPR is a favorable condition for attracting foreign investment.

On the one hand, the Chinese Government has ratified international conventions such as Paris Convention for the Protection of Industrial Property, ${ }^{120}$ Agreement on Trade-Related Aspects of Intellectual Property Rights, ${ }^{121}$ Convention and the Treaty on Intellectual Property in Respect of Integrated Circuits ${ }^{122}$, Patent Cooperation Treaty $^{123}$ and etc. to create a favorable environment for technology transfer. On the other hand, the legal system concerning technology transfer remains weak in China. Crucially, there is no legislation at a national level specifically targeting at technology transfer. As a result, the relevant interested parties, the distribution of obligations and the ownership of property rights are obscured. Facing this situation, the draft of National Technology Transfer Promotion Regulations ${ }^{124}$ was completed in November 2007 and was listed in the legislation plan in 2008.

\subsubsection{Summary}

After the UN Conference on Environmental and Development was held in 1992, China formulated its own Agenda 21, setting up the important role of sustainable development and mounting a response to climate change in the $21^{\text {st }}$ century. After the

\footnotetext{
${ }^{120}$ Paris Convention for the Protection of Industrial Property, opened for signature 20 March 1883.

${ }^{121}$ Agreement on trade-related aspects of intellectual property rights, opened for signature 15 April 1994, 1869 UNTS 299, 33 ILM 1197 (entered into force 1 January 1995).

122 Convention and the Treaty on Intellectual Property in Respect of Integrated Circuits, opened for signature 26 May 1989.

123 Patent Cooperation Treaty, opened for signature 19 June 1970.

124 National Technology Transfer Promotion Regulations 2007 (The Ministry of Science and Technology of the People's Republic of China).
} 
unveiling of the agenda, the sustainable development thinking was incorporated into China's consecutive Five-Year Plans, which describe concrete steps and targets that it would take towards sustainable energy development. Also, the Chinese government launched China's National Assessment Report on Climate Change, China's National Climate Change Program and China's Policies and Actions on Addressing Climate Change with a view to better understanding the climate change issues in China. Besides these polices, in order to support China's efforts to address climate change, the Chinese Government released many corresponding regulations, such as China Medium- and Long- Term Energy Conservation Plan, Medium- and Long-Term Plan on the Development of Renewable Energy and China's Scientific and Technological Actions on Climate Change.

Given the nature and operational rules of the CDM, the legislation concerning the promotion of a low-carbon and circular economy in China, environmental protection, energy utilization and the other financial and economic issues may also affect the implementation of the CDM projects in China. The Cleaner Production Promotion Law and Circular Economy Law were enacted to promote a low-carbon and circular economy in China; the Environmental Protection Law stipulates the environmental requirements and standards in China; the Energy Conservation Law was formulated to improve energy efficiency; the Renewable Energy Law was launched to promote the utilization of the renewable energy; the Electricity Law was adopted to enhance power generation management; the Measures for the Operation and Management of CDM projects in China was issued to specifically support the implementation of CDM 
projects; the foreign direct investment related provisions in the Law on Chinese-Foreign Equity Joint Ventures and Law on Chinese-Foreign Contractual Joint Ventures provide legal supports for investments in CDM projects in China; the relevant provisions in the Law on Enterprise Income Tax and Circular of the State Council on Adjustment of Imported Equipment Taxation Policies express the tax policies for developing CDM projects in China; and finally, there are some regulations concerning the legal ownership of CERs and the legal protection of transferred technology while they are not complete and need to be improved.

\subsubsection{Conclusion}

China begins to set up a systematic legal framework to address global warming and other climate change issues. These laws and regulations could also support the implementation of CDM projects.

The general national development strategies and plans provide the overall direction for sustainable development and climate change mitigation. The further implementation of these policies are stated and strengthened by the specified policies. The specified legislation for the CDM is adopted and the other legislation concerning the development of a low carbon economy, clean technologies and energy efficiency and utilization that have been adopted may also facilitate the implementation of CDM projects in China. Moreover, the relevant financial and taxation regulations create a comparatively favorable environment to attract foreign investment in CDM projects. However, the incomplete regulations concerning the ownership of CERs and legal 
protection of transferred technology have been improving continuously.

\subsection{Enforcement of the CDM-related Laws and Regulations in China}

As mentioned above, China has promulgated a range of policies and blueprints concerning climate change and laws supporting the implementation of CDM projects. Nonetheless, with good intentions, the establishment of these policies and laws is not equivalent to effective implementation. More work is needed to translate such policies and laws into on-the-ground action. In truth, the road of enforcing the CDM-related laws and regulations is not even and may encounter various barriers. In particular, China has the tradition of sacrificing environmental profits to pursue economic development due to the relatively poverty of China. Against this background, this part examines the enforcement issues of the CDM-related legal frameworks in China.

\subsubsection{Institutional Framework of Enforcing the CDM-related Laws and Regulations in China}

Specified institutions and mechanisms concerning the general environmental protection, climate change issues, energy development, advancement of clean technologies and the relevant financial issues in China may be involved in the process of developing CDM projects. These institutions and mechanisms determine the enforcement of the CDM-related laws and regulations and thus affect the implementation of CDM projects. 


\subsubsection{Institutional Framework of General Environmental Protection in China}

Given that climate change is only one of many environmental problems, the general circumstances of environmental protection in China may affect the effective enforcement of the climate-related policies and laws. In this regard, the institutional framework of general environmental protection in China is examined through discussing its evolution, function and characteristics.

At present, the central institution managing environmental issues in China is the Ministry of Environmental Protection. With the significance of environmental issues, the institutional arrangement for environmental protection in China has been constantly reformed. Since the new People's Republic of China was founded in 1949, the environmental management institution in China has undergone major restructuring four times, gradually forming a relatively comprehensive system. ${ }^{125}$

The first phase was from 1949 to early 1970s. During this period, there were no institutions set up to specifically tackle the environmental issues due to the fact that environmental problems were not so critical. ${ }^{126}$ They were under the management of the relevant ministries and agencies and the various sectoral pollution problems were under the supervision of their own industry ministries.

The second phase was from 1978 to 1987. During this period, in spite of three central government institutional reforms, the environmental management institution was still

\footnotetext{
125 The 30 Years' Development of Environmental Protection in China (2008) People <http://politics.people.com.cn/GB/1026/6978808.html> at 10 October 2008.

${ }^{126}$ Ibid.
} 
affiliated to the other national agencies. ${ }^{127}$ In 1978, the office of State Council Environmental Protection Leading Group was set up under the National Construction Commission. In 1982, it was restructured to an Environmental Protection Bureau under the Urban and Rural Construction Environmental Protection Ministry. In 1984, in order to follow the trend of enhancing environmental protection in an international context, it was renamed as State Environmental Protection Administration, which was still under the Construction Ministry.

The third phase was from 1987 to 2008. During this period, the State Environmental Protection Administration was restructured to be an independent environmental management institution directly under the State Council. It was reformed to be a vice-ministry level institution in 1987 and a ministry level institution in 1998.

The fourth phase was from 2008 to date. The State Environmental Protection Administration of China was promoted to be the Ministry of Environmental Protection of China in March 2008 as one component department of the State Council, demonstrating the increasing significance of environmental protection in social and economic development in China.

The institutions involved in environmental protection management in China include, the Ministry of Environmental Protection of a central government's level (the top level), and below it different environmental protection administrations at different local government levels as well as other environment related organizations. Also,

127 Ibid. 
local governments are responsible for certain environmental issues.

According to the Decision on the Government Reshuffle Plan of the State Council ${ }^{128}$ approved at the first meeting of the $11^{\text {th }}$ National People's Congress in March 2008, the Ministry of Environmental Protection was established with a view to strengthening the overall planning and coordination on environmental policies, strategies and major issues. Its main responsibilities are to establish and take the lead in implementing environmental protection plans, policies and standards, organize to divide the environmental function areas, supervise environmental pollution prevention management and coordinate the resolution of the major environmental issues. ${ }^{129}$ Moreover, the state administrative department of marine affairs, the harbor superintendence administration, the fisheries administration and fishing harbor superintendence agencies, the environmental protection department of the armed forces and the administrative departments of public security, transportation, railways and civil aviation at various levels conduct corresponding supervision and management of the prevent and control of environmental pollution. ${ }^{130}$

The environmental departments at the local government levels have their respective functions. According to the Environmental Protection Law 1989, the competent department of environmental protection administration of the local governments at or above the county level shall conduct unified supervision and management of the

\footnotetext{
128 'China's Parliament Meets to Hear Gov't Reshuffle Plan', Xinhua (Beijing), 11 March 2008 $<$ http://english.chinamil.com.cn/site2/special-reports/2008-03/12/content_1160416.htm> at 12 March 2008.

129 See Mission, Ministry of Environmental Protection of the People's Republic of China <http://english.mep.gov.cn/About_SEPA/Mission/200803/t20080318_119444.htm> at 30 March 2008.

130 Environmental Protection Law 1989 (the People's Republic of China) art 7.
} 
environmental protection work within areas under their jurisdiction. ${ }^{131}$ In addition, the competent administrative departments of land, minerals, forestry, agriculture and water conservation of the local governments at or above the county level conduct corresponding supervision and management of the protection of natural resources. ${ }^{132}$

The governments at various levels support the environmental protection. The local governments at various levels are responsible for the environment quality of areas under their jurisdiction and take measures to improve the environment quality. ${ }^{133}$ It is the responsibility of the governments at various levels to take measures to protect the ecological environmental while natural resources are being developed or utilized. Also, the governments of provinces, autonomous regions and municipalities directly under the Central Government may establish their local standards for environment quality and the discharge of pollutants for items not specified in the national standards. $^{134}$

The current environmental management institutions have two characteristics. The first one is the integration of unified supervision and management along with departmental management. The Ministry of Environmental Protection and the competent departments of environmental protection administration of the local governments at or above the country level conduct unified supervision and management while other departments, in accordance with the relevant provisions, conduct supervision and

\footnotetext{
131 Environmental Protection Law 1989 (the People's Republic of China) art 7.

132 Environmental Protection Law 1989 (the People's Republic of China) art 7.

133 Environmental Protection Law 1989 (the People's Republic of China) art 16.

134 The local standards for the discharge of pollutants set by the local governments should be more stringent than the national standards.
} 
management of the environmental pollution prevention and natural resources protection. The second one is the integration of management of central government and local governments. In light of a large territory and the complex environmental problems in China, the central government conducts macroscopic management over the national wide environmental issues while the local governments, including provincial governments, city governments and county and town governments conduct microcosmic management over the environmental issues within their jurisdiction.

\subsubsection{Institutional Framework of Addressing Climate Change in China}

The Chinese Government has formed institutional framework to addressing climate change, which can be divided into institutional framework of general climate change issues and institutional framework of energy management.

As early as 1990, the Coordination Group was established under the Environmental Protection Committee of the State Council at that time to face the challenges presented by climate change. An office of the Committee was set up in State Meteorological Administration. In 1998, Central Government organizations were streamlined, and National Coordination Committee on Climate Change (NCCCC) was set up. It was a cross-ministries body under the State Council and was responsible for deliberation and coordination on climate-related policy issues and activities and negotiations with foreign parties. In the past a few years, it provided guidance to central government departments and local governments to address climate change issues. The NCCCC was updated in October 2003, which presently compromises 17 
ministries and agencies. ${ }^{135}$ The Office of the National Coordination Committee on Climate Change is situated in the Department of Regional Economy of NDRC and responsible for routine work of the Committee.

In order to strengthen the leadership on addressing climate change and reducing GHGs, the State Council decided to establish an enlarged body - the National Leading Group to Address Climate Change and Reduce GHGs under the directorship of the Chinese Premier. The Leading Group is responsible for deliberating and determining key national strategies, guidelines and measures on climate change, as well as coordinating and resolving key issues related to climate change. The office, whose capacity is enhanced compared with that of the NCCCC, is set up within the NDRC.

Thus, the NCCCC and the Leading Group at a central government's level may strengthen coordination and cooperation of relevant ministries and departments of the State Council and ensure they fulfill their responsibilities concerning climate change. With regard to the regional administration system, it is required that the local governments at different local levels should enhance the organization and leadership on local responses to climate change, and formulate and implement local climate change programs as a matter of priority. ${ }^{136}$ This is because the risks from the future

\footnotetext{
135 These ministries and agencies include the National Development and Reform Commission (NDRC), the Ministry of Foreign Affairs, the Ministry of Science and Technology, China Meteorological Administration, Environmental Protection Ministry, Ministry of Finance, Ministry of Commerce, Ministry of Agriculture, Ministry of Construction, Ministry of Communications, Ministry of Water Resources , State Forestry Administration, Chinese Academy of Science, State Ocean Administration, Civil Aviation Administration, National Bureau of Statistics and the Ministry of Land of Resources.

${ }^{136}$ National Development and Reform Commission, the People's Republic of China, China's National Climate Change Programme (2007) 56.
} 
impact of climate change would vary between and within different regions in China. Hence, only if the actions are made at the local level to address climate change, will it be possible for these policies and strategies to have a real effect in the coming years.

Raising energy efficiency and promoting renewable energy utilization are key to addressing climate change. The institutional arrangements for energy management have undergone several reforms since the new People's Republic of China was founded in 1949. Nevertheless, there is no specialized energy management institution in China. Instead, the power of energy management is scattered throughout different ministries and departments.

The National Energy Commission was set up in 1980, followed by the Energy Ministry set up in 1988 and the Coal Ministry in 1993. After the Coal Ministry was revoked in 1998, the power of energy management in China began to be scattered in different ministries and departments. The Bureau of Energy under the NDRC was established in April 2003. It is responsible for studying energy development and utilization both at home and abroad, putting forward the relevant strategies, plans and major policies for energy development, administering energy utilization in China and formulating policy measures for energy conservation and renewable energy development. ${ }^{137}$ Furthermore, the National Energy Leading Group was set up in June 2005 headed by the Premier with the main task of conducting research on major energy development and utilisation policies, strategies and programs. The Office of

\footnotetext{
${ }^{137}$ Main Functions of Departments of the NDRC National Development and Reform Commission <http://en.ndrc.gov.cn/mfod/t20050519_0901.htm> at 11 November 2008.
} 
the National Energy Leading Group is set within the NDRC, responsible for undertaking the day-to-day work of the Leading Group.

Besides the Bureau of Energy and the National Energy Leading Group, the other ministries and agencies concerning the energy management are NDRC, Environmental Protection Ministry, the Ministry of Land and Resources, the Ministry of Water Resources, Ministry of Science and Technology, State Electricity Regulatory Commission, State-owned Assets Supervision and Administration Commission and etc.. Amongst these organizations, the NDRC is responsible for formulating energy policies and deciding energy price; State-owned Assets Supervision and Administration Commission takes in charge of managing the assets and high level personnel of state-owned energy corporations; and the Ministry of Land and Resources is the main department to manage the development of hidden resources.

In conclusion, on the one hand, many departments are involved in the energy management, not only indicating the importance of energy issues, but also ensuring the inter-supervision; on the other hand, lack of a unified standard for energy management system would bring about low work efficiency and conflicts between different policies, regulations and institutions.

\subsubsection{Institutional Framework of Managing CDM projects in China}

The role of the DNA is important in developing CDM projects in China. The implementation of CDM projects in China has to undergo national approval before 
submitting for the registration by the CDM EB and is under the management of the Chinese DNA, NCCC and National CDM Board. In this regard, the performance of these institutions, NDRC in particular, on managing the CDM implementation affects its development in China. This part gives a concrete introduction to the institutional arrangement for the Chinese DNA and other CDM-related authorities on administrative capacity, personnel and funding aspects respectively.

Several approaches have been taken by countries to date to establish DNAs. China takes the approach of establishing the DNA within an existing Government Department or Ministry (Particularly those organizations responsible for dealing with direct foreign investment and trade, environmental or energy). ${ }^{138}$ The DNRC functions as the DNA in China. The DNCR is a macroeconomic management agency under the State Council. It studies and formulates policies for economic and social development, maintains a balance of economic aggregates and guides the overall economic system restructuring. ${ }^{139}$ Generally speaking, the administrative capacity of an organization is proportional to its administrative level. Therefore, given the high administrative level of the DNCR, it also has a relatively high administrative capacity for managing CDM projects.

Ideally, the Chinese DNA is expected to understand with some expertise the CDM and function as a facilitator to supervise and guide the implementation of CDM projects in

\footnotetext{
${ }^{138}$ Other approaches that can be used to establish a DNA are as follows: 1) within the existing UNFCCC focal point for the CDM, to be found on the UNFCCC website; 2) as an independent and new office; and 3) through a specific Government Ministry.

139 Brief Introduction of the NDRC National Development and Reform Commission <http://en.ndrc.gov.cn/brief/default.htm> at 11 November 2008.
} 
China. Thus, it is important to ensure that the DNA is adequately staffed with individuals who have an understanding of the Kyoto Protocol rules as well as expertise in general project structuring, project finance, foreign investment, sustainable development considerations and environmental laws. ${ }^{140}$ In addition, the NDRC should not be overstaffed due to the limited funding. The NDRC has twenty-six functional departments, bureaus or offices with an authorized staff size of 890 civil servants. ${ }^{141}$ However, it is not clear how many staff within the NDRC are specifically dealing with the CDM projects. Rather, due to the soaring number of CDM projects presented in China, the DNA is overloaded. As a result, the approval of CDM projects delays in China, taking up to 4-6 months, while it was very fast in 2006 (around 4 weeks). ${ }^{142}$

Moreover, sufficient, stable and predictable financial resources are needed to maintain the operation of NDRC. In this regard, due to the significant role of NDRC and high administrative level, the Chinese Government appropriates adequate funds to cover the operating budget. ${ }^{143}$ Therefore, it can be assumed that enough funds have been allotted for the supervision of CDM projects in China.

Besides the Chinese DNA, the NCCC is responsible for review and coordination of the important CDM-related policies and the CDM Board has the main responsibility of reviewing and evaluating CDM project activities. Both of them are cross-ministries

\footnotetext{
140 'Legal Issues Guidebook to the Clean Development Mechanism' (The UNEP Project CD4CDM, 2004) 24.

141 Above $\mathrm{n} 137$.

${ }^{142}$ Paula Castro and Axel Michaelowa, 'Opinions of Project Developers regarding Performance of CDM projects ' (Institute of Political Science, University of Zurich, 2007) 4.

${ }^{143}$ The details of the budget are not available due to the fact that the relevant information is not transparent and available in China.
} 
bodies, which demonstrate high administrative levels. Also, the staff of the NCCC and Board are almost minister or deputy minister levels.

As for the financial issues, the CDM Fund, with a potential funding of more than $\$ 3$ billion $^{144}$, was launched in November 2007 with a view to supporting the capacity building of China's response to climate change and promoting climate-relevant activities. The CDM Fund, managed by the Ministry of Finance, mainly generates money by taking part of the proceeds from undertaking the CDM projects ${ }^{145}$ and from the contributions and cooperation funds from other financial organizations, like the World Bank and the Asian Development Bank. Against this background, besides funds from the Chinese Government, the CDM fund may also facilitate the sound operation of the institutions to promote the development of CDM projects in China.

\subsubsection{Institutional Framework of enforcing other CDM-related laws in China}

As discussed earlier, China has created a favorable investment environment to attract foreign investment and develop economy. As for financial issues involved in implementing a CDM project in China, the relevant institutional framework is as follows:

- The Chinese Government protects the investment of foreign joint ventures and the due profits, lawful rights and interests.

\footnotetext{
${ }^{144}$ Zhiming, Xin, ' Green Fund to Help Cut Emissions', China Daily (Beijing), 10 November 200710. According to Xie Zhenhua, vice-minister of the NDRC, by the end of October 2007 the NDRC had approved 885 $\mathrm{CDM}$ projects. If those projects are implemented, it will trade a greenhouse gas emission reduction of 1,500 million tons of carbon dioxide, with a turnover of about $\$ 15$ billion, more than $\$ 3$ billion of which will be injected into the new CDM fund.

${ }^{145}$ See Measures for the Operation and Management of CDM projects in China 2005 (the People's Republic of China) art 2.
} 
- Department of Foreign Investment Administration under the Ministry of Commerce is in charge of the overall examination and approval of the joint ventures. In order to simplify the examination and approval procedures, the Ministry of Commerce has released most of its power of examination and approval to the commerce departments of the local governments since March 2006. Thus, the provincial level commerce departments are the major institutions in charge of the examination and approval of foreign investment corporations.

- The State Administration for Industry and Commerce and the local Administrations for Industry and Commerce authorized by the State Administration are the institutions in charge of the registration for commencement, changes and termination of the foreign investment enterprises. ${ }^{146}$

- The Ministry of Finance and the State Administration of taxation are in change of providing the specific regulations of implementation the taxation policies on foreign investment enterprises and the local taxation administrations are the institutions managing and imposing the due taxations on the foreign investment according to the relevant laws and polices.

\subsubsection{Enforcement Measures of the CDM-related Laws and} Regulations

Administrative measures, such as fines, permit, is often used worldwide to address

\footnotetext{
146 See Article 2 of Measures for the Authorized Registration Management of the Foreign Enterprises, 'the management of foreign enterprises registration shall apply the principle of registration management by State Administration for Industry and Commerce and authorized local administrations for Industry and Commerce...'
} 
environmental issues. This is also true in China. The measures to enforce the laws concerning environmental issues in China are mainly administrative measures and civil sanctions. This part explores the existing measures that are utilized to enforce the CDM-related laws in China.

The Chinese Government often applies the following administrative measures to protect environment and address climate change.

First, the competent environmental protection departments may impose warning, fine and order for suspension of operation or shut-down on the enterprises and institutions that violate the environmental protection laws. ${ }^{147}$ Moreover, any person conducting supervision and management of environmental protection who abuses his power, neglects his duty or engages in malpractices for personal gains shall be given administrative sanction by the unit to which he belongs or the competent higher authorities. $^{148}$

Second, the Chinese Government addresses climate change through launching administrative guides and setting up various standards concerning energy saving, energy efficiency, and the development of renewable energy.

Finally, the competent institutions strengthen the management and supervision of foreign investment corporation through examination, approval and registration CDM projects and imposing due tax.

\footnotetext{
147 See, eg, Environmental Protection Law 1989 (the People's Republic of China) art 35-40.

148 See, eg, Environmental Protection Law 1989 (the People's Republic of China) art 45.
} 
Civil sanctions are also used to solve disputes deriving from environmental issues. The civil sanctions concerning environmental protection in China include discontinuance of the offending activity, removal of hazard and compensatory remedies. According to the environmental protection laws, an enterprise has the obligation to eliminate environmental pollution hazard that is caused by it and make compensate to the unit or individual that suffered direct losses. In addition, a dispute over the liability to make compensation or the amount of compensation may, at the request of the parties, be settled by the competent department of environmental protection administration or another department invested by law with power to conduct environmental supervision and management. If a party refuses to accept the decision on the settlement, it may bring a suit before a people's court. The party may also directly bring a suit before the people's court. ${ }^{149}$

Disputes arising between the parties to a joint venture may be solved through conciliation and mediation, arbitration or litigation. In addition, the financial responsibility shall be borne by the party that has breached the contract of an equity joint venture to cover the losses caused by the breach of contract. ${ }^{150}$

In addition, criminal sanctions can be used to address environmental issues in China. However, criminal sanctions play a limited role in addressing environmental issues in China. According to the environmental protection laws and criminal law, if a serious

\footnotetext{
149 See, eg, Environmental Protection Law 1989 (the People's Republic of China) art 41-2.

150 See, eg, Law of the People's Republic of China on Chinese-Foreign Equity Joint Ventures 1979 (the People's Republic of China), amended in 2001, art13-4 and Law of the People's Republic of China on Chinese-Foreign Contractual Joint Ventures (the People's Republic of China), amended in 2001, art 26.
} 
environmental pollution accident is caused, leading to grave consequences of heavy losses of public or private property or human injuries or deaths of persons, the persons directly responsible for such an accident shall be investigated for criminal responsibility according to the law. ${ }^{151}$ Thus, it can be seen that criminal sanctions are imposed only on individuals, not corporations, as the relevant regulation does not provide for corporation liability on environmental offences.

The criminal law also stipulates that a criminal responsibility for a person conducting supervision and management of environmental protection, who abuses his power, neglects his duty or engages in malpractices for personal gains will be criminally responsible. $^{152}$

Finally, criminal sanctions are also utilised to punish the person or unit that upsets the economic environment. ${ }^{153}$

Other measures are also utilized to enforce environmental protection laws and address climate change. These measures include utilizing economic tools, conducting research on climate change issues in China, education and enhancing public awareness and public participation.

Economic tools, containing favorable tax and tariff rates and price intervene, are utilized to promote the development of enterprises with less pollutants, high energy

\footnotetext{
151 Environmental Protection Law 1989 (the People's Republic of China) art 43-4. See also Criminal Law 1979 (the People's Republic of China), amended in 1997, pt 2 ch5 s6.

152 Criminal Law 1979 (the People's Republic of China), amended in 1997, pt 2 ch9 art 408.

153 Criminal Law 1979 (the People's Republic of China), amended in 1997, pt 2 ch3 s4.
} 
efficiency and renewable energy. In that case, the incentives for different stakeholders to promote sustainable development and reduce GHGs are created by economic regulations.

Research on climate change issues is strengthened. China has conducted research on impact of climate change, China's potential to combat climate change, development of clean technologies, capacity building of CDM projects and etc.. The research is not only beneficial to realize the objectives in environmental protection and climate-related laws, but also promotes the development of CDM projects in China.

Public awareness and education are highlighted in order to promote the enforcement of environmental laws. Effective enforcement of environmental law relies on awareness and compliance of the population. Lack of basic knowledge about hazardous materials can lead to massive violation of the law. ${ }^{154}$ In this regard, the Chinese Government enhances the publicity of the urgency of climate change issues through media, schools and trainings.

Another alternative to effectively enforce laws concerning environmental issues is public participation. Individual citizens are closely affected by the atmosphere around them and in turn, environmental issues may be improved through public participation. Chinese laws have stipulated the role of public participation in protecting environment and combating climate change.

\footnotetext{
154 Vincent Cheng Yang, 'Punishing for environmental protection?-Enforcement Issues in China' (1995) 44(3) International \& Comparative Law Quarterly 671672.
} 


\subsubsection{Analysis of the Enforcement of the CDM-related Laws and Regulations in China}

\subsubsection{The Enforcement of Environmental Laws in China}

With the growing number of environmental laws and the restructure of institutional arrangement for environmental management in China, it is obvious that the Chinese Government has realised the seriousness of environmental issues. In spite of the determination and good intention of central government to settle environmental issues, there are barriers for local governments to effectively enforce the environmental laws and achieving the objectives of environmental policies.

First, there is a lack of adequate incentive to protect the environment in China. From a local official's perspective, economic development is the major criterion used when judging their work performance. Although a promotion system of judging the local officials' performance by meeting environmental protection and energy efficiency targets has been launched, it is difficult to seriously carry out this system. This is because there is no standard to reasonably allot environment and energy efficiency targets for different regions. Also, the improvement of environment cannot be judged in the short-term. Thus, local governments face the dilemma of pursuing economic development and sacrificing part of these profits to protect the environment.

From an industry perspective, the environmental costs have not been responsibly accounted for in business. In this circumstance, it is impossible to ask the corporate 
sector, which is profit-oriented, to take on too many social responsibilities, including environmental protection.

Moreover, from a citizen's perspective, environmental issues are so complicated that they could not be solved by individuals. When someone realises that his behavior mean little to change a bad situation, he could probably not take any action and want the others to solve the problem, from which he could also on benefits. This is the so-called 'free rider" ${ }^{155}$. In this situation, an individual has a little incentive to take action to help solve climate change issues. Therefore, unless an effective incentive system is set up, it would be difficult to effectively enforce environmental laws and address environmental issues.

Second, the enforcement measures of environmental laws are limited. First of all, the Criminal Law 1979 does not provide for corporate liability while actually, the true polluters are always the corporations. Organized polluters, let alone legal entities, are never prosecuted for a crime against the environment. ${ }^{156}$ In other words, there is no effective measure to punish the most serious polluters in China. Besides, Chinese people rarely prefer to solve the environmental disputes through litigation. This is because, on the one hand, environmental issues are complicated and hard to prove the liabilities; on the other hand, Chinese people have a tradition of "cherishing the

\footnotetext{
155 The name 'free rider' comes from a common textbook example: someone using public transportation without paying the fare. If too many people do this, the system will not have enough money to operate. In economics and political science, 'free riders' are those who consume more than their fair share of a public resource, or shoulder less than a fair share of the costs of its production. Free riding is usually considered to be an economic 'problem' only when it leads to the non-production or under-production of a public good,or when it leads to the excessive use of a common property resource. The free rider problem is the question of how to limit free riding (or its negative effects) in these situations <http://en.wikipedia.org/wiki/Free_rider_problem> at 13 August 2008.

156 Yang, above n 154.
} 
harmony'. Thus, Chinese people often rely on government or other alternatives to solve the environmental disputes. In this scenario, the effectiveness of enforcing the environmental laws would be limited.

Other issue is deep-rooted bureaucracy and protectionism existing in the Chinese Governments could not be dealt with in a short-term, seriously affecting the enforcement of environmental laws. Most major polluters in China have various economic connections with the local governments, making the local governments show more mercy to dealing with the environmental issues. These economic connections may be caused by state-owned enterprises or bribery. In addition, institutional arrangement for environmental protection makes the power of environmental management too scattered and easy to be conflicted at local areas. In this situation, there is a lack of independent and powerful environmental organizations which could effectively address environmental issues at local areas. Thus, it is difficult for the Chinese Governments at different levels to effectively enforce the environmental laws and protect the environment.

In conclusion, there are many barriers to effective enforcement of environmental laws in China.

\subsubsection{The Enforcement of Climate Change Policies and Laws in China}

Currently, China considers climate change issues as a matter of priority. The China government has adopted a series of legal, economic, administrative and technological 
measures to address climate change. With regard to management institutions of climate change in China, the relatively high level of specialized climate change institution - NCCCC - demonstrates the significance of climate change issues in China. In addition, the local governments at different levels have the responsibility of enhancing the organization and leadership on local responses to climate change, illustrating the essential role of local efforts in combating climate change.

Furthermore, the legislation concerning the development of circular economy and energy efficiency, utilisation and development play crucial roles in supporting the effective enforcement of climate change policies and laws in China. China has not only formed a relatively complete energy legislative framework, but has also set up many fixed energy conservation and development targets. Although there is no specialized and high level energy management institution in China, which has impeded the energy development, the Chinese government is making efforts to deepen the reform of energy management and decision systems. ${ }^{157}$ A more powerful and effective energy management institution system is set to be established.

In summary, China has seriously considered climate change issues and has launched a wide range of policies and strategies. Also, effective measures are being adopted in order to implement these policies and strategies and realize energy development and conservation objectives.

\footnotetext{
${ }^{157}$ See Information Office of the State Council of the People's Republic of China, China's Energy Conditions and Policies (2007).
} 


\subsubsection{The Enforcement of Regulations for the CDM in China}

Viewed from the administrative level of CDM projects management and supervision institutions, these institutions are composed of ministerial level organizations, strengthening the management and implementation of CDM projects in China. Second, viewed from internal structure of these institutions, the relevant research has demonstrated the necessity to increase the qualified staff dealing with the CDM with the increase of CDM projects. Finally, the current booming state of CDM projects also reflects the effective enforcement of CDM regulations in China.

Hence, on the one hand, CDM projects have been under the comparatively effective management and supervision in China and have brought considerable benefits to China; on the other hand, the corresponding institutions and management need to be improved according to the needs of rapid development of CDM projects.

\subsubsection{The Enforcement of Other CDM-Supporting Laws in China}

As the current priority in China is economic development and getting rid of poverty, the Chinese government has created a favourable investment environment through relevant laws and policies to attract foreign investment and advanced technologies. In this regard, foreign investment laws are effectively enforced in China.

\subsubsection{Summary}

In summary, this part introduces and analyses the problem if enforcing CDM-related 
laws and regulations in China. First, the Chinese Government has strengthened environmental protection in China mainly through revising the existing legislations and restructuring environmental management institutions. Nonetheless, effective enforcement of environmental laws encounter many difficulties in the long term due to the fact that China's priority is economic development and no advanced technologies have been innovated so far to resolve the conflicts between economy and environment and that the deep-rooted bureaucracy and protectionism trammeling of the institutions affects the enforcement of environmental laws for the long term. Moreover, enforcement measures of environmental laws in China are limited. Second, the climate change issues have been put on the top of agenda in China. The efforts have been made to create a low carbon economy. In addition, CDM projects are under the relatively effective management and guide, having brought lots of benefits. Rather, with the rapidly evolving climate change policies in an international context, the climate change policies and the CDM-related regulations in China should be modified accordingly. Finally, the favourable investment environment China has created plays an important role in promoting the development of CDM projects.

\subsection{Research on Legal Issues for Implementing CDM Projects in China}

After introducing the legal frameworks of implementing CDM projects in China, this part focuses on concrete legal issues. First of all, the various legal relationships and shareholders involved in the implementation of CDM projects in China are explored. 
Following this, the contracts that may be signed by different legal entities involved in implementation of CDM projects are analysed. Finally, the key legal problems existing in the implementation of CDM projects under the current legal frameworks are discussed.

\subsubsection{Legal Relationships Involved in Implementing CDM Projects in \\ China}

According to the CDM-related policies and regulations, several legal relationships are involved in the implementation of CDM projects in China. These relationships mainly consist of administrative legal relationships between the Chinese Government and the CDM developers and investors, and civil legal relationships between CDM projects participants.

\subsubsection{Administrative Legal Relationships}

According to the CDM-related regulations and laws, various administrative legal relationships may be involved in the process of implementing CDM projects in China. The major relationships are administrative permission legal relationship between the DNRC and CDM project developers, administrative trust legal relationship between the DNRC and the relevant organizations for expert review of the proposal CDM project and the other administrative permission legal relationships involved in developing CDM projects concerning foreign investment.

According to the regulations of ' $\mathrm{CDM}$ project to be implemented in China shall be 
approved by relevant departments under the State Council.' ${ }^{158}$, 'NDRC is China's DNA for $\mathrm{CDM}^{159}$ and 'Project owner, or together with foreign partner, submits to NDRC project application and documents as required. Relevant departments and local governments may facilitate such project application. ${ }^{160}$, the administrative subject in the administrative legal relationship about administrative permission of implementing CDM projects in China is the NDRC and the administrative counterpart is the Chinese funded or Chinese-holding enterprises within the territory of China ${ }^{161}$ and its foreign partners if they take part in projects. The administrative action is the NDRC permitting the implementation of certain $\mathrm{CDM}$ project requested by project developers. In this administrative permission legal relationship, the NDRC exerts the responsibilities of accepting CDM project application, reviewing the application and making decision about approval of the application while the applicants of CDM projects should submit project application documents in accordance with the Measures, report to NDRC on the progress of the project, assist in investigating and respond to the inquiries. The legal effect is that the CDM project developers obtaining the permission may be entitled with the right to developing GHGs emissions reduction resources.

In addition, there is an administrative trust legal relationship. The Measures stipulates

\footnotetext{
${ }^{158}$ Measures for the Operation and Management of CDM projects in China 2005 (the People's Republic of China) art 3.

159 Measures for the Operation and Management of CDM projects in China 2005 (the People's Republic of China) art 16.

160 Measures for the Operation and Management of CDM projects in China 2005 (the People's Republic of China) art 18 , item 1.

161 As mentioned above, only the Chinese funded or Chinese-holding enterprises within the territory of China are eligible to conduct CDM projects.
} 
that 'NDRC entrusts relevant organizations for expert review of the applied project, which should be concluded within 30 days. ${ }^{162}$ According to this regulation, there is an administrative trust legal relationship between the NDRC and relevant organizations. In this legal relationship, the trustor is the NDCR and the trustee is the relevant organizations. The authority of the trust is the expertise review of the proposed project. In addition, the Measures states that 'NDRC submits those project applications reviewed by the experts to the board. ${ }^{163}$ Thus, the NDRC approves the applications totally based on the conclusion of expert review. Clearly, the conclusion of the expert review may have the legal consequences of directly refusing some applications.

Other administrative legal relationships can also be involved in developing CDM projects in China. With regard to the CDM projects with foreign partners and foreign investments, the implementation of these projects should undergo administrative approval by the department in charge of foreign economic relations and trade under the State Council or the department or local government authorized by the State Council. When approved, the CDM project developers shall register with the state's competent department in charge of industry and commerce administration, acquire a business license and then start operation. In this case, there are administrative permission legal relationships between the Department of Foreign Investment Administration under the Ministry of Commerce, the provincial level commerce

\footnotetext{
162 Measures for the Operation and Management of CDM projects in China 2005 (the People's Republic of China) art 10, item 2.

163 Measures for the Operation and Management of CDM projects in China 2005 (the People's Republic of China) art 10 , item 3 .
} 
departments and CDM project developers, and also between the State Administration for Industry and Commerce and the local Administrations for Industry and Commerce authorized by the State Administration and the CDM project developers. The administrative actions are concerned with the administrative permission of developing a project with foreign investment in China.

Based on the above analysis, first, it is necessary for the government to have administrative management of $\mathrm{CDM}$ projects in China. The Chinese Government manages and supervises the implementation of CDM projects through administrative measures using the Measures as a legal basis. The necessity of this administrative management of $\mathrm{CDM}$ projects lies in the public interest. Although the CDM is market-oriented and must be carried out by project developers, its implementation also influences the realization of sustainable development which belongs to the public interest. The public interest needs to be regulated by administrative measures. In this regard, the Chinese Government should not only have power to manage the CDM projects but also have the responsibility of promoting CDM projects through providing an effective guide to potential CDM participants.

Second, rationality for conducting the administrative permission for CDM projects in China are as follows: the Measures stipulates that 'This measure is formulated in accordance with the provisions of the UNFCCC and its Kyoto Protocol ratified and approved by China respectively, and the adopted by the COP...' ${ }^{164}$ It can be seen that the UNFCCC, the Kyoto Protocol and the relevant decisions are the legal basis of

\footnotetext{
${ }^{164}$ Measures for the Operation and Management of CDM projects in China 2005 (the People's Republic of China) art 1 .
} 
establishing administrative permission of implementing CDM projects in China. This is concerned with whether the international treaties and conventions ratified and approved by China could be considered as the sources of administrative law in China. According to Article 16 of Administrative Permission Law $2003^{165}$,

'Within the scope of the matters for which the procedure for administrative permission is instituted by superordinate laws, specific provisions on the granting of such permission may be formulated in rules. Also, additional procedure for administrative permission shall not be instituted in the specific provisions formulated in the regulations and rules for the granting of administrative permission for which the procedure is instituted by superordinate laws. ${ }^{166}$

The superordinate laws hereby refer to the laws enacted by NPC and NPC Standing Committee and the regulations formulated by State Council but not the international conventions ratified by China.

However, in legal practice in China, some international conventions and protocols could have a legal effect after being translated into domestic legislation while the others may be directly applied in a domestic context. In the administrative legal regime in particular, any conventions and protocols ratified by China which concern the administrative management and remedies are the sources of administrative laws. ${ }^{167}$ Moreover, in light of the urgency of addressing climate change and seizing the opportunity of implementing CDM projects, it would be too late to wait for the launch of new regulations or laws concerning the management of CDM projects, which would undergo a long and complex law-making process. Therefore, considering the legal practice and the characteristics of the CDM in their current state,

\footnotetext{
165 Administrative Permission Law 2003 (the People's Republic of China).

166 Administrative Permission Law 2003 (the People's Republic of China) art 16.

167 Zhijiao Wu, Analysis on the Administrative Legal Relationships Involved in the CDM

<http://www.acla.org.cn/pages/2008-8/08/p48020.html> at 8 November 2008 [ trans of : 清洁发展机制中的行政 法律关系评析].
} 
it is reasonable to set up administrative permission for CDM implementation in China.

Third, there are some disputes about the legal effect of expert review. ${ }^{168}$ Expert review is introduced to evaluate the eligible proposed projects and plays an essential role in approving the proposed projects. NDRC could only submit those project applications reviewed eligibly by the experts to the Board and approve the projects accordingly. In this case, the expert review does not only function as public participation, but also exerts public power of the administrative permission. The main reason for the significance of the expert review lies in the complex and technical characteristics of CDM projects. On the one hand, legal experts with expertise in complicated climate change legal frameworks both at home and abroad and in detailed and time-consuming CDM operational rules are needed to examine the legal eligibility of the proposed projects; on the other hand, the proposed projects demand for technical expertise to evaluate their 'additionality'. Thus, it is necessary to conduct expert review, which consists of the experts mastering technological knowledge and operational rules of the CDM before submitting for approval. Moreover, the professional quality of the experts also plays a significant role in promoting the implementation of CDM projects in China.

In spite of the necessity of setting up the expert review, ambiguities exist in this legal relationship. First, what kinds of relevant organizations can be entrusted for expert

168 See, eg, ibid. 
review are not specified. Secondly, the standards for selecting the qualified experts are not clear.

Implementation of CDM projects in China is concerned with sustainable development. Therefore, it is necessary and rational to take administrative measures to manage CDM projects. The DNRC entitles the eligible CDM project owners right to develop GHGs emissions resources through administrative permission. In the administrative trust legal relationship between the DNRC and the relevant organization, expert review is essential for approval of the proposed project due to the highly complex and technical procedures of CDM projects while some ambiguities exist and need to be defined. Also, there are administrative legal relationships between the relevant departments and the CDM projects concerning foreign investment in order to promote and regulate the foreign investment in China.

\subsubsection{Economic Legal Relationships}

The Chinese Government adopts economic measures to facilitate the development of CDM projects. Two types of economic legal relationships exist in the implementation of CDM projects in China. The first one is the legal relationship in taxation and the other one is the economic legal relationship arising from the CDM Board's responsibility of reviewing the price of CERs.

Besides the Chinese Government attracting foreign investment through applying the favorable taxation polices to CDM projects with foreign partners, it also collects 
certain ratios of the revenue from the proceeds of CERs transaction. The legal basis of the collection of CERs proceeds lies in the property right to emission reduction resource is owned by the Chinese Government according to the Measures. Rather, the proportional collection of the revenue is because the emission reductions generated by specific CDM projects belong to the project owner. The different allocation ratios of different types of the projects ${ }^{169}$ demonstrate that the Chinese Government encourages energy efficiency improvement and renewable energy development through providing economic incentive to promote the energy development in a sustainable way.

Due to the multiple market failures ${ }^{170}$ and in order to protect China's interests and rights, it is one of the responsibilities of the CDM Board to regulate the price of CERs. In truth, according to the report of the State and Trends of the Carbon Market 2007, China, as dominant market leader in the CDM projects since 2002, influenced the overall market price through its informal policy of requiring a minimum acceptable price before providing DNA approval to projects. ${ }^{171}$ Moreover, other countries were able to use China's price floor as a basis of negotiation of near-equivalent prices in their transactions as well. ${ }^{172}$

\footnotetext{
169 According to Article 4 of the Measures, the priority areas for CDM projects in China are energy efficiency improvement, development and utilization of new and renewable energy, and methane recovery and utilization. ${ }^{170}$ Market failure is a term used to describe a situation in which markets do not efficiently allocate goods and services. Prices do not reflect all publicly available information. Market failures are often associated with non-competitive markets, externalities or public goods. The existence of a market failure is often used as a justification for government intervention in a particular market.[

${ }^{171}$ Karan Capoor and Philippe Ambrosi, 'State and Trends of the Carbon Market 2007' (The World Bank 2007) 32.

172 Ibid.
} 
Under this circumstance, the Chinese Government's regulation concerning the CERs price, in certain degree, facilitates the implementation of CDM projects in China. Although the CDM projects in China develop at an increasing rate and has obtained considerable economic profits so far, the CDM is still new for most of the potential CDM developers. Also, the persons with expertise in the operational rules and technical aspect of the CDM are much needed at this stage. Therefore, the competent departments, which are equipped with certain experts in the CDM, should take the responsibility of guiding and supervising the CDM implementation in China. The staff with experience and relevant knowledge in the operation of carbon market may provide relatively updated and accurate market information to set the CERs price for the CDM developers. In conclusion, it is necessary for the Chinese Government to review the CERs price before the CERs enter into the global carbon market.

\subsubsection{Civil Legal Relationships}

Four types of civil legal relationships may be involved in the process of implementing CDM projects in China. The first one is a civil legal relationship based on CERs transactions between the CERs seller and purchaser. The second one is a civil legal relationship based on the contract between CDM project owners and the DOEs. In addition, a financial civil legal relationship might emerge between the project owner and the financial institution and finally, there may be a civil legal relationship based on the commercial service for developing CDM projects between the project owner and the CDM service institution. 
The first type is a transaction civil legal relationship. The benefits of implementing the CDM projects are ultimately achieved through CERs transaction in carbon market. Thus, there is a civil legal relationship between CERs sellers and purchasers, which is definitely the most significant factor in the process of developing CDM in China. In such a civil legal relationship, CDM project developers sell emission reductions to CERs purchasers and the purchasers pay to the CDM project developers to get the certain mount of CERs.

In accordance with the procedure of implementing CDM projects, project owners shall contract DOEs to validate the proposed project activity and to verify emission reductions of the project activity so as to prove real reductions in GHGs. Civil legal relationships therefore exist between the project owners and DOEs to validate and verify the project activity. In such a legal relationship, project owner has the right to choose the same or different qualified DOEs to validate the project and verify its operation and the DOEs are paid by the project owner to provide their expertise.

The financial civil legal relationship might emerge between the project owner and the financial institution in order to enhance the financial capacity of developing the potential CDM project. This relationship often exists in the circumstance of implementing the unilateral CDM projects whose owners may lack capital to put it into operation. In this case, a loan agreement is contracted. The owner obtains a loan from the financial institution to develop the CDM project.

Finally, a service civil legal relationship can also be involved in developing CDM 
projects in China. With the boom of CDM projects in China and the increasing demand for expertise dealing with complex CDM projects, commercial organizations providing relevant services for CDM development are set up. The major organizations are CDM consulting companies and firms providing specialised legal services for the CDM. Hence, for the CDM developers seeking professional services for the CDM, civil legal relationships would be formed between them and service companies.

\subsubsection{CDM-related Contracts}

In light of the various civil legal relationships involved in the implementation of CDM projects in China, project developers tend to adopt a contractual approach to discuss the major issues and define their rights and obligations. Accordingly, Emission Reduction Purchase Agreement (ERPA), Validation and Verification Contracts, Loan Contract, Service Contract may be negotiated for each project. Although these contracts are generally tailored to meet the specific circumstances of projects and parties involved, for any CDM project, the major issues in different types of contracts could be identified respectively. In this circumstance, this part introduces the CDM-related contracts and analyses the key issues involved.

\subsubsection{Emission Reduction Purchase Agreement (ERPA)}

On the one hand, sale of CERs from a CDM project is similar to the sale of any commodity from a project; on the other hand, a CDM project bears particular risks 
and pitfalls due to its complex and technical operational rules and procedures. ${ }^{173}$ However, most risks and pitfalls could be manageable through the deliberate consideration about the ERPA. In this sense, amongst all the CDM related contracts, ERPA is regarded as the key of the CDM project implementation, determining the destination of CERs. It functions as the legal basis of defining legal rights and obligations of the CERs purchasers and sellers, and how the CERs arising from that project would be sold. Thus, it is of great significance to research EPRA with a view to avoiding the surmountable risks and pitfalls in the implementation of CDM projects.

In addition, most ERPAs with complex and detailed items are often provided by the CERs buyers. These kinds of ERPAs are likely to protect the buyer's interests while disadvantaging the CERs seller's interests and rights in the transaction. ${ }^{174}$ In addition, most ERPAs are in English, compounding the difficulties of the cooperation between buyers and project developers in China as their mother language is Chinese. Therefore, it is necessary to fully understand the ERPA and protect the interests and rights from a project developer's perspective.

In spite of the specific circumstances of the project and the parties involved, the key legal issues to be addressed in an EPRA for any CDM project could include the objective of the contract, legal title to CERs, transfer of legal title to CERs, quantity and purchase price of CERs, payment of costs occurring in project implementation,

\footnotetext{
173 See above n 140, 99.

174 See ibid 112-8.
} 
liability and Indemnity and disputes resolution.

First of all, the objective of an ERPA should be identified. Strictly speaking, the objective of ERPA should only be CERs as they will ultimately be used for compliance purposes. In reality, the contract may also stipulate transfer or Verified Emission Reduction (VER) or even Emission Reduction (ER).

There is a huge difference between ER, VER and CER. The ERs, produced with the operation of CDM projects, turn into VERs after the verification by DOEs. Then, the VERs would turn into CERs after the examination by the CDM EB. What is more, the different objectives of the contract have different legal effects towards sellers and buyers. First, buyers may take more risks in purchasing ER or VER than CER as there is a possibility that the ERs could not be verified by DOEs or the CDM EB refuses to issue CERs. Correspondingly, the purchase price is relatively lower for ER and VER. Second, the transfer approach and time are also different. Sellers are likely to receive payment under the ERPA upon the transfer of VERs through the submission of a Verification Report while buyers are likely to pay for the CERs when they are issued into national registry account. Given such differences, the nature of the rights being sold must be stated clearly in the ERPA.

In addition, it should be noted that currently, the CDM contracts tend to deal with CERs only. The VER and ER were likely to be chosen as the objective of ERPA during the early period of CDM development before the CDM EB began to issue CERs. 
It is important that contractual warranties should be provided in the ERPA to the effect that sellers have full right and title to emission reductions and have not previously transferred to another party.

In the case of China, the Chinese Government claims a pre-existing right to emission reduction, which is considered as a type of natural resource. The emission reductions generated by a specific CDM project belongs to project owners and therefore they can be sold by project owners. In this sense, revenue from the transfer of CERs shall be owned jointly by the Government of China and project owners.

How and when CERs are to be sold and transferred to buyers should also be clearly provided by the contract. Crucially, the exact point at which the legal title to CERs transfers should be agreed by parties and clearly provided in the ERPA. For example, does legal title transfer upon the submission of a Verification Report or the issuance of CERs by the CDM EB, or is it contingent upon issuance into the buyer's account and receipt of payment from the buyer.

The different transfer approaches of legal title to CERs mean different things to sellers and buyers. Sellers want to ensure that buyers are obligated to pay for the CERs before they receive legal title to CERs while buyers generally tend to receive legal title to CERs as quickly as possible. In this scenario, the ERPA should clearly provide the point at which legal title is deemed to have passed from seller to buyer after their negotiations. 
The contract should clearly specify the details about CERs, which include the quantity of CERs being acquired, the timeframe in which they are to be acquired and the CER unit price.

On the one hand, sellers wants to make sure their delivery obligations under the ERPA in order to plan the operation of the project; on the other hand, buyers prefer to be clear about total amount of CERs which it should expect from the seller and their obligations to pay under the ERPA for the CERs.

In practice, the CERs are sold in two major ways: a spot transaction and a forward sale. The spot transaction is a direct and immediate sale of CERs which have been already generated by a project over a certain period and the forward sale is a direct sale of CERs from a future activity of a CDM project. Under the spot transaction, the contract can specify the quantity of CERs being acquired and provide a fixed unit price for each CER delivered. Rather, under the forward, the contract is flexible. The contract may frame a delivery schedule for the CERs which accords with the expected performance of the project according to the PPD. Furthermore, due to the uncertainties of future project performance and unstable CER market price, the contract can set up minimum delivery obligations for sellers within the expected project capacity and also link the price to the market price for CERs at the time of delivery. The EPRA should also clearly provide specifications for an option to purchase further CERs from the project.

Although China dominates the global carbon market, most project developers cannot 
have the desirable CER unit price. ${ }^{175}$ The reason for the relatively low CERs price is that project developers in China cannot sell their CERs directly in the international carbon market. Thus, the brokers make lots of profits through buying the CERs from project owners in China and selling them in the carbon market at higher price. In this circumstance, it is necessary for China to set up a carbon exchange and access to carbon market directly. ${ }^{176}$

The contract should also contain provisions relating to the payment costs leading to the creation of CERs. Unlike a common project, creating the CERs may involve a significant amount of costs at various stages of developing the project, including registering a CDM project, monitoring emission reductions, hiring a DOE to undertake verification and certification and etc. In this regard, sellers should negotiate with buyers about the CERs creation costs. The contract should specify what the costs include and the allocation of costs.

Generally speaking, sellers would be responsible for covering all costs involved in creating CERs and factor these costs into their costs. Also, buyers could provide upfront payment for the CERs for sellers to cover the project implementation related costs in recognition the project developer's limited financial capacities for paying upfront. This amount would then be deducted form future payment due for CERs under the ERPA.

\footnotetext{
175 This is according to the results of field work conducted by the author.

${ }^{176}$ In fact, China has established three domestic environmental exchanges. For details, see Chapter seven Establishing a domestic carbon trading scheme 393-4.
} 
In addition, commercial profits apart from selling CERs can also be obtained through developing certain types of CDM projects, for example, the power project, whose developers can make profits through selling electricity. In these cases, there should be provisions concerning share of the proceeds under the ERPA.

The contract should include clauses relating to liabilities for each party under the ERPA and identifies for actions leading to a loss or a breach of the ERPA. Under the ERPA, the actions or events which may constitute a breach of the contract include CERs generation failure, CERs transfer failure, the actions of the third party, force majeure, or any other event that the buyers think is possible to exert negative influence on the performance of CDM projects.

The generation failure happens when the annual amount of CERs generation has not reached the objective agreed in the contract. Generally speaking, sellers should be liable for the failure, whereas most contracts provide that if there are enough surplus CERs generated previously to offset the shortage, the CERs generation shortage this year does not constitute a generation failure. Likewise, the transfer failure refers to the shortage of CERs transferred to buyers. Also, if there are enough surplus CERs transferred previously to offset the shortage, the CERs transfer shortage this year does not constitute a transfer failure.

The agreement on the events of default related to CDM project is very special. The scope of force majeure is a matter for negotiation. Sellers want to ensure that any potential disasters that befall the project will be covered by the force majeure 
provision while many ERPAs clearly provide that any project performance seriously falling behind the project plan is deemed a breach of contract regardless of the reasons. Therefore, both parties, the seller in particular, should carefully consider their liabilities and indemnities under the ERPA.

Dispute resolution arising under a CDM project challenges project developers and CER purchasers. By their nature, CDM projects involve cross-border transactions between entities which may be from different countries. Besides, the contracts are drafted in a new and developing area of law which the local courts may not have experience with. It is therefore essential to find an acceptable resolution for both parties when disputes arise.

There have been many dispute mechanisms used by project participants and CER buyers to date. The Alternative Dispute Resolution (ADR), like discussion, negotiation, mediation, is preferable if a dispute arises. Both parties should be obligated to friendly negotiations and choose a mutually acceptable solution in the first instance. This obligation should be reflected in the EPRA. If the negotiations have failed within a certain time frame, the formal dispute resolution procedures should be started.

Both parties should agree in advance about choosing the dispute resolution mechanism in the contract. The major dispute resolution procedures are arbitration and litigation. The arbitration is often preferred in international commercial transactions due to the fact that it is more neutral. Similarly, the carbon buyers have 
preferred arbitration as a means of dispute resolution, but arbitrators' fees are costly, particular for sellers in China. In this regard, the responsibility of undertaking such expensive costs should be considered when choosing a resolution mechanism.

Another mechanism is litigation. First of all, by its nature, the litigation is a potential time consuming and expensive option for resolving international commercial disputes. Furthermore, there may also be a prolonged process to enforce the judgment. Secondly, in the CDM project case, the seller and buyer should determine which legal system the contract falls under. However, there are many difficulties with choosing the due jurisdiction which will govern the contract as the choice of one jurisdiction over another may place one party at a disadvantage. Moreover, local courts may not have the relevant experience to adjudicate a CDM contract. Under this circumstance, legal advice is needed for sellers and buyers to make them familiar with the choice of law and the enforceability of the contract in that jurisdiction.

In conclusion, the current ERPA mode is provided by CERs buyers, most of which have much more financial capacities than sellers. Therefore, the CERs sellers should fully understand the complicated provisions in the contracts and attach great importance to protect their rights and interests under the EPRA.

\subsubsection{Validation and Verification Contracts}

In the process of developing a CDM project, there must be two types of contracts between CDM project developers and DOEs, which are mainly commercial 
certification companies. First, projects ideas have to be validated through the DOEs regarding compliance with the operational rules. Besides, an independent verification of the emission reductions by a DOE is the precondition for issuance of CERs by the CDM EB. It is the project owner's responsibility to find appropriate DOEs and contract to validate the proposed project and to verify emission reductions. However, two problems of the effectiveness of DOEs intervention in China and the credibility of the emissions reduction are brought by validation and verification contracts.

The third party validation and verification systems lie in the heart of CDM. The DOEs are supposed to be arbitrary not only in validating the expected CERs and addtionality of proposed project before submission to DNA but also in verifying the issuance of CERs before certification by CDM EB. In this regard, DOEs have the overwhelming power to decide the implementation of CDM projects.

Nonetheless, the effectiveness of DOEs can be questioned. First of all, highly qualified validators and verifiers are much needed to deal with CDM issues. In fact, there is a lack of such staff due to the technical CDM operational rules and the newly established CDM. ${ }^{177}$ In addition, there is no objective standard for validators and verifiers to make judgments and they come to the conclusion of CDM projects with their own experience and expertise. Thus, the conclusion may vary a lot between different validators or verifiers. In addition, the asymmetric information between the CDM owner and DOE undermines the development of CDM projects in China.

177 Catro and Michaelowa, above n 142, 67. 
Currently, there are no Chinese-owned DOEs. This situation displaces the CDM project owners in China a disadvantage. In addition, language barriers could make it difficulty for Chinese CDM project developers to communicate with DOEs.

The credibility of DOE's performance is also problematic. As mentioned in the previous chapter, the current CDM projects in China have relatively low CER issuance rate. The validation process and the role of validators is one of the reasons explaining the overestimation of CERs. This is because validators - commercial entities - have an interest to collude with the audited project developers as they are hired by the project developers. ${ }^{178}$ As many project developers are developing more than one project, validators have an incentive to let the projects pass with the forecast of CERs in the PDD to get future assignments from that developer. ${ }^{179}$ Further, this is exacerbated by a fierce competition between validators, with severe downward pressure on price and few effective controls on quality. ${ }^{180}$

The verification process has the same problem. The verifiers are paid by project developers and thus are reluctant to contradict them. Recently, because of the widespread issue of the credibility of DOEs, the CDM EB has made supplementary review of CDM projects after the verification in order to tighten the standards within the CDM. This challenges the independent role of verification and the meaning of its existence.

\footnotetext{
178 Ibid.

179 Ibid.

180 Ibid.
} 
Given all these problems of the validation and verification contracts, there is a need to shift payment for DOEs services from project developers to the CDM EB itself or to find ways to establish truly independent the third party's audit of CDM projects.

\subsubsection{Loan Contract}

In the case of developing a unilateral CDM, the project owners would develop a CDM project by themselves, obtain the necessary financing, register it with the CDM authority, receive all or most of the certified project CERs and then bank, lease or sell them in the international market. Hence, the project owners may contract financial institutions to get the necessary fund needed by developing a CDM project in China. The project owners should carefully consider the cost of the loan contract before they start a CDM project.

\subsubsection{Service Contract}

The CDM-related service contract plays an important role in implementing CDM projects in China. Basically, the foreign buyers need the consulting agencies' assistance in developing CDM projects in China. Also, the consulting agencies manage and develop the CDM projects on behalf of the project owners throughout the whole process due to the fact that most project owners rarely have the CDM-related expertise. The project owners, instead, are only responsible for constantly providing the relevant documents and information to the consulting agencies as required. 
In spite of the significant role of the consulting services for CDM projects, there are no unified management and standard for CDM consulting industries in China. In this scenario, many disputes would arise under a CDM services contract. Project developers and consulting agencies should therefore negotiate carefully the responsibilities and rights of both parties and how any disputes arising from CDM services would be resolved.

In summary, this part introduces and analyses the CDM-related contracts. The ERPA is of great importance in the process of developing CDM projects. However, most of the purchase agreements are provided by the seller, putting the buyer at a disadvantage. In this case, the CDM project developers should carefully study the ERPA and effectively protect their interests and rights. Besides ERPA, the project owners should contract DOEs to validate the proposed project and verify the CERs. Currently, the validation and verification contracts to a certain extent undermine the performance of CDM as a result of extremely complex and technical CDM operational rules and procedures. Thus, there is a need to improve the validation and verification schemes. Loan contracts may also be necessary for unilateral project owners to obtain the financing to implement the potential project. Finally, the CDM service contract plays an indispensable part in promoting the development of CDM projects in China. Nonetheless, both parties should pay particular attention to define their responsibilities and rights and the dispute resolution under the service contract due to the lack of unified regulation for managing CDM related service industries in China. 


\subsubsection{Assessing Key Legal Issues for Implementing CDM Projects in}

\section{China}

Under the existing legal frameworks analyzed above, there are some legal issues which may undermine or promote the development of CDM projects and sustainable development in China. This part discusses these key legal issues and analyses their impact on CDM projects and sustainable development in China.

\subsubsection{Ownership Issues with respect to CERs in China}

A CER, a valuable commodity created by the CDM, is the destination of a CDM project. Therefore, the rights and benefits associated with emission reductions generated by CDM projects are of great significance for project participants. However, as the CER is a relatively new concept, no universal recognition has been reached about its legal nature and who will be legally entitled to any benefits from the GHG reductions so far. In these circumstances, it is crucial for host countries to consider the ownership issues with respect to CERs and determine a way in which the legal ownership is to be allocated.

The Chinese legal system has not clearly defined the legal nature of CERs and who has the right to them. Only the Measures addresses the ownership issues concerning CERs. The Measures stipulates that:

Emission reduction resource is owned by the Government of China and the emission reductions generated by specific CDM project belong to the project owner, revenue from the transfer of CERs shall be owned jointly by the Government of China and the 
project owner. $^{181}$

According to this provision, GHGs reduction is considered to be a 'natural resource' and therefore the property of the Chinese Government. Also, the Chinese Government allows eligible private CDM project owners to enter into concession arrangements to manage these resources and create CERs from them. Based on the fact that CERs are sovereign rights, the Chinese Government may take a proportion of the CERs from the project and revenue from the transfer of CERs, which are owned jointly by the Chinese Government and the project owner.

The problem here is these provisions about the CERs are in violation of the existing legislation in China. Item 1 Article 9 of the Constitution of the People's Republic of China 1982 states that: All mineral resources, water, forests, mountains, grasslands, unreclaimed land, beaches and other natural resources are owned by the state, that is, by the whole people. ${ }^{182}$ On the one hand, there is no clear indication in the Chinese law that the emission reduction resource is classified as a natural resource; on the other hand, even if assuming that the GHG reduction belongs to a natural resource, the statement in the Measures that the emission reduction resource is owned by the Chinese Government does not comply to the relevant provision in the Constitution. Therefore, it is necessary to review the current ownership issues concerning CERs in China. $^{183}$

\footnotetext{
${ }^{181}$ Measures for the Operation and Management of CDM projects in China 2005 (the People's Republic of China) art 24.

182 Constitution of the People's Republic of China 1982 (the People's Republic of China), last amended in 2004, art 9, item 1 <http://english.people.com.cn/constitution/constitution.html> at 5 March 2010.

183 See also Mingyuan Wang, 'Supervision of Clean Development Mechanism Projects in Chin-Illusory Rules of Law and Real Government Intervention' (2008) 11 (1) Asia Pacific Journal of Environmental Law 121, 129.
} 
First, the legal nature of CERs needs to be clarified. The Chinese legal system has given little consideration to clearly defining the legal nature of CERs. Viewed practically, however, the Chinese legal arrangement takes a property-based approach to environmental protection. That is to say the right to CERs is also considered to be a property right.

Given its special characteristics, the property right legal nature of CERs may have an adverse impact in the long term on sustainable development in China, which are caused by the double functions of CERs. On the one hand, a CER is a commodity which is expected to bring enormous economic profits to the potential CDM project developers. In other words, the more CERs the project owners have, the more money could be brought in to the project. In this scenario, the industries with heavy pollution and low clean technologies would have the potential to become the biggest money recipients. In many cases, there is a possibility that some companies are more willing to earn money through developing $\mathrm{CDM}$ projects rather than to reducing their emissions through advancing their clean technologies. On the other hand, sustainable development in China requires a low carbon economy, which is to say that less carbon emissions should be pursued as a long term goal. Only technology innovation can lead to a low carbon economy in China. In this case, with the widespread use clean technologies by energy industry, there would be fewer emissions and therefore less money obtained from CDM projects.

Therefore, establishing a property right to CERs may promote the development of 
CDM projects in China and assures economic profits in the short term, while these CERs cannot actually assist in leading to sustainable development in China in the long term.

There are three kinds of ownerships in the environmental legal regime: public ownership, private ownership and common ownership, which are mainly divided based on different owners. Private ownership refers to ownership by individuals while public property refers to ownership by a governmental body. Common ownership in environmental legal regime is a principle according to which the environment or resources are held indivisibly rather than in the names of the individual members or by the government. ${ }^{184}$ Thus, rather than being owners of environment and resources its members are held to be trustees of them for future generations. ${ }^{185}$ However, there is no universal, first-best property-based solution to all environmental problems that covers all circumstances. Each has its uses and limits, which may be maximized or minimized, respectively, depending on the different circumstances. The Chinese Government clearly defines the public ownership of CER and the right to use of CERs for CDM owners. Some scholars argue that clear and full ownership rights should be given to CDM project developers while safeguarding Chinese national interest by holding back specific proportion of CER from each CDM project in order to reduce the high investment risk for foreign investor. ${ }^{186}$

\footnotetext{
${ }^{184}$ Common Ownership, <http://en.wikipedia.org/wiki/Common_ownership> at 10 July 2009.

185 Ibid.

${ }^{186}$ See, eg, Tobias Koch, 'Proposal for further development of Chinese CDM rules' (International Capacity Building, p.p. InWEnt gGmbH, Germany 2005) 8.
} 
In China's case, establishing a public ownership for CERs may be a great benefit to sustainable development in China in the long term. Taken individually, the CERs mean enormous amounts of money to CDM project developers. If establishing private ownership of CERs, it would be possible that the eligible CDM project companies with their 'Economic Man' ${ }^{187}$ attribute may pursue the maximum economic profits brought by selling CERs regardless of the environmental aspect of developing the CDM projects. Although the projects need to be approved to meet Chinese sustainable development criteria and meet the CDM rules, the project developer may doing this for the sake of getting project approval with the purpose of making money rather than considering environmental aspect. As a result, they may have a tendency to sell the emission reductions from $\mathrm{CDM}$ projects than spend money on promoting technological innovation. This is because the profits coming from implementing a CDM project has the possibility to be larger than spend money and energy on technological innovation.

Therefore, the Chinese Government should play a significant role in balancing the advantages and pitfalls of implementing CDM projects. In this scenario, it is necessary and reasonable to establish the public ownership for CERs in China.

\subsubsection{Marketing of CERs}

The Chinese Government has set a fixed floor price for CERs generated within

\footnotetext{
${ }^{187}$ It is a term used in classical economic theory (see Laissez-Faire Economics), denoting the individual's rational deployment of labour or resources in the marketplace, in systematic pursuit of his or her own self-interest.
} 
China. ${ }^{188}$ Some scholars argue that the regulation of CER prices does not conform to the economics principle that market decides price and could also pose a problem to the global price. ${ }^{189}$

On the contrary, it is necessary and reasonable for the Chinese Government to regulate CER prices. That is because the CDM is relatively new and technical and requires expertise to develop $\mathrm{CDM}$ projects and enter into the international carbon market. In fact, CDM experts are not widespread in China and most of them are concentrated in the governmental institutions. ${ }^{190}$ Most CDM project owners and developers in China, however, lack the concomitant knowledge and information about the implementation and marketing of CDM projects. Instead, they often resort to CDM consulting companies and sell their CERs through the CDM brokers in the international carbon market. Consequently, CDM projects in China would probably at a disadvantage without the support of the government.

The state and trend of the carbon market also show that the Chinese Government's responsibility in fixing floor price for CERs largely decides the current market price of CER due to China's dominance in the international CDM carbon market. ${ }^{191}$

In this regard, the direct price fixing policy in China does not only protect Chinese

\footnotetext{
${ }^{188}$ See the Measures for the Operation and Management of CDM projects in China 2005 (the People's Republic of China) art 15, item 4.

189 Koch, above n 186, 11.

${ }^{190}$ Most of CDM project owners do not have the corresponding expertise. For more details, see Chapter three Section CDM awareness 129. At the initial stage of the development of CDM projects in China, the CDM capacity buildings were for the government officials. However, this situation has changed as more and more projects get registered.

${ }^{191}$ See Capoor and Ambrosi, above n 173.
} 
national and CDM project owners' interests, but also guarantees that CERs gain optimal value in the international carbon market.

\subsubsection{Participation Eligibility}

According to the CDM-related legislation in China, only Chinese funded or Chinese-holding enterprises within the territory of China are eligible to conduct CDM projects with foreign partners. ${ }^{192}$ This can be interpreted that the Chinese partner must have a minimum of 51 per cent share in a CDM project.

Although the limit of foreign majority ownership of CERs is made with a view to maintaining the initiative of Chinese CDM developers in implementing CDM projects, this regulation could actually undermine the development of CDM projects in China. First of all, this regulation about the project ownership could frustrate the potential investors. Many factors, including the investment in a CDM project, the technology transfer and the economic profits in particular, are of great significance when investors are considering participating in a CDM project in China. They therefore want to hold a larger share in CDM project ownership or take the initiative in implementing a CDM project in order to protect their own interests. By comparison, the Chinese project developers, who lack the funds and the clean technology to reduce emissions, could only provide the project itself. Moreover, all the proceeds of CERs cannot be obtained until a transaction was made in the international carbon market. In this circumstance, the project ownership limit could have an adverse impact on the

${ }^{192}$ Measures for the Operation and Management of CDM projects in China 2005 (the People's Republic of China) art 11 . 
implementation of CDM projects in China, making the potential investors abandon directly investing in projects in China and choose to invest in other host countries or buy the CERs in the carbon market instead. Second, this unfavorable position for investors not having a majority interest may pose problems for introduction of technical know-how, which is regarded as the key to a low carbon economy in China. Also, the intellectual property right of transferred technologies remains weak both at home and abroad. ${ }^{193}$ In this case, most investors are more cautious about transferring their advanced technologies under the existing legal frameworks in China. Finally, the limitation in the CDM project ownership makes it impossible to allocate the CERs according to ownership structure. ${ }^{194}$ Otherwise, the foreign partner, who is expected to invest more funds and technologies than the Chinese partner in CDM projects, on the contrary, could be allocated relatively fewer CERs and accordingly obtain less proceeds from selling CERs. As a result, the rearrangement about the allocation of CERs and CER proceeds between the investors and the project owners complicates the implementation of CDM projects in China.

To conclude, it will beneficial to allow CDM projects to be operated with foreign majority in China.

\subsubsection{Technology Transfer for Sustainable Development in China}

In many instances international environmental regimes include provision of positive

\footnotetext{
193 For details, see below section.

194 See, eg, Law of the People's Republic of China on Chinese - foreign Contractual Joint Ventures 1988 (the People's Republic of China), amended in 2000, art 4, para 2 'The parties to the venture shall share the profits, risks and losses in proportion to their contributions to the registered capital.'
} 
measures to support clean technologies transfer to developing countries due to the fact that technological advances are often the key to environmental gains ${ }^{195}$. Likewise, the CDM was designed the objective of assisting the developing countries in realizing sustainable development through technology transfer and investment. However, the promotion of technological innovation and diffusion in developing countries has not been in real terms very successful.

Since it is a competitive project-based CER generating and trading scheme, the pursuit of cost-effectiveness and commercial profits dominates the CDM scheme. In addition, the actual ownership of the technology and know-how in project implementation process is in the hands of private ownership, which is subject to trade secrecy and intellectual property rights under the TRIPs agreement. ${ }^{196}$ Therefore, their use is subject to the payment of royalties and sure licensing fees and such technology is diffused on commercial market terms. ${ }^{197}$ Meanwhile, there are an inadequacy funds and a loose legal systems to support technology transfer in both the international and domestic environmental regimes.

Accordingly, against the existing legal and institutional background, developing CDM projects cannot actually overcome the barriers to effective technology transfer in China.

\footnotetext{
195 Daniel C Esty and Maria Ivanova,, 'Globalization and Environmental Protection-A Global Governance Perspective' (Working Paper No.0402, Yale Center for Environmental Law and Policy, 2004) 15. See also, Chertow, M. and D.Esty (ed), Thinking Ecologically: The Next Generation of Environmental Policy (1997). 196 This is short for Agreement on Trade-Related Aspects of Intellectual Property Rights, Annex 1C of the Marrakesh Agreement Establishing the World Trade Organization, signed in Marrakesh, Morocco on 15 April 1994.

${ }^{197}$ Zainal Abidin Sanusi 'Technology Transfer Under Multilateral Environmental Agreements: Analyzing The Synergies' (Working Paper No. 134, UNU-IAS, 2005) 2.
} 


\subsubsection{Public Participation}

In the process of implementing CDM projects in China, two phases involve public participation. One is the expert review of the proposed project in project application and the other one is the stakeholders' consultation in Project Design Document (PDD) preparation. ${ }^{198}$

As introduced earlier, NDRC entrusts relevant organizations for expert review of the proposed projects and approves the projects based on the review conclusion made by experts. ${ }^{199}$ Hence, opinions from the experts about 'additionality' of the proposed CDM project play a decisive role in approving the projects. Apparently, the expert review here has exceeded the boundary of general public participation and actually exercises the public power of administrative permission. The expansion of the right of expert review is due to the technical and complex natures of CDM projects. Accordingly, it is reasonable and necessary to enhance the influence of expert review when approving CDM projects in China.

In addition, a CDM project must receive a national approval from the DNA, which is based on reviewing how the project will contribute to sustainable development. To this end, the PDD has to explicitly detail what the expected sustainable benefits are to be achieved by a project through presenting the documentation related to the environmental impact assessment of the project and describing how the relevant local

\footnotetext{
198 For details, see Chapter two Section CDM Project Cycle 34.

199 See Measures for the Operation and Management of CDM projects in China 2005 (the People's Republic of China) art 15
} 
stakeholders are allowed to participate and provide comments and feedback on the project. However, the Chinese Government has not satisfactorily fulfilled this CDM requirement. First of all, under the existing institutional framework, there is no specific procedure for carrying out stakeholder consultation in CDM projects In China. Then, with respect to consultation processes described in the PDD, there still lacks transparency and an effective way to reflect the local population's demands. Most of the CDM projects in China do not take stakeholder consultation seriously in their PDD. ${ }^{200}$ Some of the CDM projects do not state in their PDDs what kind of consultation process they organise at all; most of them may use a written survey or questionnaire as a tool to gather comments; and only a few of them may organize a public meeting or public discussion with the local population. ${ }^{201}$ Given the written media limiting the range of stakeholders allowed to participate, it seems that the current stakeholder consultation process in China is not sufficient for gathering opinions from local residents and reflecting their concerns. ${ }^{202}$ Therefore, the public participation needs to be improved when developing CDM projects in China.

\subsubsection{Lack of a Basic Energy Law in China}

The main task of implementing CDM projects and tackling climate change is to reduce carbon emissions through improving energy efficiency and developing renewable energy. Although the Chinese Government has formulated a series of specific policies and laws with a view to promoting energy efficiency and

\footnotetext{
200 Catro and Michaelowa, above n 140, 52-9.

201 Ibid

202 Ibid.
} 
development of renewable energy, there still lacks a basic energy law to support CDM project implementation and energy utilization in a sustainable way in China.

Currently, a basic energy law is much needed in China. The major difference between a basic law and a specific law in China is that a basic law may provide more systematic and comprehensive norms of specific conduct in certain area. The Law on Legislation of the People's Republic of China 2000 stipulates that 'state legislative power shall be exercised by the National People's Congress and its Standing Committee. The National People's Congress (NPC) enacts and amends basic laws and the Standing Committee of the NPC enacts and amends laws other than those that shall be enacted by the NPC. ${ }^{203}$ In this respect, the basic law has more binding effect than specific laws.

These large energy demands and energy security issues challenge China, which demand for more effective regulation on energy utilization and management behaviors. Against this background, only the specific laws concerning energy cannot be effective and powerful enough to address energy issues. Similarly, the existing specific energy laws cannot provide adequate legislative support for CDM projects implementation in China. In this case, the basic energy law is expected to provide a legal basis for the formulation and amendment of the specific laws concerning energy, assist in solving the conflicts between the different specific energy laws and the specific laws in other areas, and effectively safeguard the implementation of energy

${ }^{203}$ Law on Legislation of the People's Republic of China 2000 (the People's Republic of China) art 7. 
strategies and programs in China.

Therefore, unless a basic law for energy is made according to China's national circumstances as soon as possible, climate change issue will not be effectively addressed in China.

In conclusion, within the exiting Chinese legal system, the legal nature of CERs is still unclear. In spite of that, the public ownership of CERs and the Chinese Government's responsibility of setting a fixed floor price for CERs would promote the development of the CDM projects in a sustainable way. As for the public participation issues in the process of implementing CDM projects in China, there are two sides to the argument. On one side, it is necessary to enhance the legal effect of expert review when examining the applied project; on the other side, the public opinions on the proposed CDM project are not fully reflected before implementing a CDM project. Moreover, the international and domestic legal and institutional arrangements for promoting the technology transfer to China remain weak. Finally, a basic energy law should be made with a view to ultimately promoting sustainable development in China.

This part has explored the relevant legal issues for implementing CDM projects in China. The CDM is a complex and time-consuming scheme, involving various governmental institutions, agencies, projects participants and the other stakeholders. Consequently, the administrative legal relationships between the competent CDM-related governmental institutions and the CDM developers, the economic legal 
relationship concerning taxation and the marketing of CDM projects and the civil legal relationships between the CDM project developers are involved in the process of developing CDM projects in China. Based on the analysis of these legal relationships, different types of the CDM-related contracts were discussed in order to identify the due responsibilities and rights of both parties and the potential pitfalls under contracts. These contracts contain Emission Reduction Purchase Agreement (ERPA), validation and verification contracts, a loan contract and a service contract. Against this legal background, the influences of the key legal issues on the development of CDM projects in China and sustainable development were then assessed.

\subsection{Exploring Potential Risks arising from Implementing CDM Projects under the Legal Frameworks in China}

In light of technical and complex procedure of the CDM, there are a multitude of risks that would exist at various stages in the process of implementing CDM projects in under the China's existing legal framework. Some risks may arise at any time during the overall process of the project while others are specifically related to a particular stage of project development. ${ }^{204}$ Also, some risks can be manageable through appropriate legal and contractual arrangements while the others are beyond control but can be reasonably allocated to project participants. Based on the above, this part explores the risks occurring at different stages as well as at any time of the life cycle of a CDM project respectively. Moreover, the factors that may influence the possible

\footnotetext{
${ }^{204}$ Above n 140, 94.
} 
risks are analysed.

\subsubsection{Potential Risks at Different CDM Project Development Stages}

According to the major steps involved in developing a CDM project in China, the project cycle may be divided into four stages, which are: stage one CDM project preparation and design, stage two CDM project application and registration, stage three CDM project operation and stage four CERs issuance and transaction. Each stage has its own particular risks.

(1) Stage one: CDM Project Preparation and Design ${ }^{205}$

Before starting to implement a CDM project, project developers need to design the proposed project and make preparation for project application. During this period, the CDM project developer is the major actor to undertake the risks involved in developing a CDM project.

There are three types of risks would occur in CDM project preparation and design. The first risk is that the potential CDM project in China cannot be identified or the project owners do not realize that their project may be qualified as a CDM project. The second risk is that the project has been identified but the project owners do not have the adequate CDM-related information and knowledge to further develop the project. The third risk is that the project is eligible under the CDM rules and Chinese legal frameworks but the developer cannot get enough funds to develop the project.

${ }^{205}$ See ibid 95. 
Generally speaking, at this first stage nobody is undertaking legally binding obligations to develop a project. However, it is the obligation of CDM project owners to design and develop the project at this stage. The concrete obligations of the project owners include undertaking the initial analysis of the project's eligibility, seeking legal and other CDM-related advice, finding potential investors and presenting the project to them, trying to obtain upfront payment for the CERs in future and putting together the PDD as required.

In the case that a project owner finds a foreign investor, the foreign partner should share the obligation of developing the CDM project at stage one. The level of risks exposed by each party will be proportional to the amount of legal commitments they have undertaken and will be reflected in the share price of CERs in the future.

Given the technical nature of CDM projects, whether the project developers havs good working knowledge about the requirements for CDM projects plays an importance role in mitigating the aforementioned risks. However, most potential CDM project owners currently do not have the adequate expertise to develop CDM projects in China. Moreover, most CDM experts are concentrated in the relevant governmental departments. In this case, it is necessary for the project developers to seek guidance from these governmental departments.

In addition, whether the project developers have an understanding of the type of considerations that the potential investors will be taking into account will largely influences how many investments they can get on board for the project. In these cases, 
the experience of developing a CDM project is needed. Hence, the qualified CDM service agencies which have a lot of experience of dealing with CDM projects may also provide professional information to assist the project developers in mitigating the risks.

(2) Stage two: CDM Project Application and Registration ${ }^{206}$

At stage two, project owners, or together with its foreigner partners, should submit to the NDRC a project application and documents of CDM PDD, a certificate of enterprise status, general information of the project and a description of the project's financing. ${ }^{207}$ When the application is approved, project owners should invite DOE to validate the project and then submit the eligible project to the CDM EB for registration.

The potential risks that may exist in project application and registration are as follows:

- $\quad$ The proposed project fails to obtain the approval letter from the NDRC (Chinese DNA) to confirm that the project has met sustainable development criteria in China.

- The DOE does not validate the project to have it registered with the CDM EB because the proposed project is not qualified as a CDM project and does not pass the additionality criteria or that the baseline methodology it uses is not approved by the CDM EB.

\footnotetext{
206 Ibid 96.

207 See Measures for the Operation and Management of CDM projects in China 2005 (the People's Republic of China) art 12.
} 
- The CDM EB does not usually register the project smoothly due to upholding objections from a party involved in the project activity or at least three members of the EB.

In addition, the project must conform to legal requirements and obtain the necessary authorizations and consent for the project under the Chinese legal framework. In this case, the potential risks may include:

- The proposed project does not meet the relevant environmental requirements or pass the environmental impact examination by the competent departments.

- The proposed project fails to register with the state's competent department in charge of industry and commerce administration. Thus, project owners cannot start operation without acquiring a business license.

At stage two, the project developers will incur more costs and enter into contractual obligations. The project owners' obligations are as follows:

- $\quad$ to obtain an approval letter from the NDRC;

- $\quad$ to obtain a Validation Report from DOE;

- $\quad$ to seek legal and other CDM-related advice;

- $\quad$ to pass the environmental impact examination and acquire a business license; and

- to find potential CER purchasers for the projects without foreign 
partners.

As for the project foreign investors, if they decide to start investing in the project at stage two, they should take the main obligations of:

- providing sufficient funds or transferring the clean technologies as stipulated in the contract; and

- $\quad$ assisting the project owners in submitting and registering the CDM project.

Based on the above analysis, two factors may influence the risks at stage two. One is whether the project developers understands the Chinese legal system and has adequate knowledge of operational rules and procedure of implementing CDM projects in China. A good understanding of the eligibility requirements and procedure for developing CDM projects under the Chinese legal frameworks would mitigate the risk of failing in project approval and registration. The other influencing factor is whether the project developer has enough budgets to cover the costs spent in meeting the legal requirements of developing a CDM project in China. In this case, it is essential for project developers to have sufficient financial backing.

(3) Stage three: CDM Project Operation

At stage three, project developers should implement, monitor the project as planned in the PDD and contract with DOE to verify the emission reductions of the project activities. 
The risks at this stage are mainly decided by whether the project may perform as expected. In this circumstance, the risks are as follows:

- $\quad$ The project cannot be successfully constructed by a certain date due to the fact that the construction costs are significantly more than estimated.

- The project does not perform as expected and generate sufficient emission reductions.

- $\quad$ The technology for the project does not work as expected and the project developer is not capable of following the monitoring plan.

- $\quad$ The DOE does not accurately verify and certify the emission reductions.

- $\quad$ The project has trouble with generating the additional products (e.g. electricity) as anticipated to make it financially sound.

In order to make sure the project is operated as planned, project developers should take on the following obligations of:

- $\quad$ entering into a contract with a construction contractor with a view to having the project commissioned by a certain date. The obligation of commissioning the project by a certain date may be passed on to the construction contractor once the contract is signed;

- $\quad$ implementing and monitoring the project and inviting a DOE to verify the emission reductions of the project; and

- presenting the NDRC and DOE the project implementation and monitoring report. 
As for the project owners who contract with the CER purchasers at stage three, they may be in breach of the obligations to the CER purchase under the ERPA and face penalties. As well as this, the project manager may be contractually liable for any faulty monitoring of the project in accordance with the monitoring plan.

As for the other CDM project participants, their responsibilities may include:

- $\quad$ The DOE should accurately verify the emission reductions and is liable for any incorrect verification.

- $\quad$ The CER purchaser who has agreed to provide upfront payment under the ERPA should make the sufficient funds for the project available.

- The NDRC should supervise the implementation of the project to ensure the quality of the activity.

Based on these risks at stage three, three factors decide the performance of CDM projects. The first risk is whether the Chinese Government has created a stable legal and social environment for implementing CDM projects. In light of the long time project cycle which may last more than ten years, it is important to make sure that the project would be operated under a stable legal and social and thus the emission reductions would be generated as expected. The second risk is whether the project developers have the expected technology and adequate funds to follow the monitoring plan. The last risk is whether the DOE has qualified technical personnel to accurately verify the emission reductions of the project. 
(4) Stage four: CER Issuance and Transaction ${ }^{208}$

At stage four, the DOE submits certification report of the VER (Verified Emission Reduction) to the CDM EB. Then, project developer and CER purchaser would enter into a contract to transact CERs.

Given that the emission reductions have been generated, the major task at stage four is CER transactions. The major risks in CER transactions in the international carbon market may include:

- $\quad$ The CDM EB does not smoothly issue the CERs for the project due to any objection from a party involved in the project activity or at least three members of the EB.

- $\quad$ The project owner does not deliver sufficient CERs to the purchaser.

- $\quad$ The market price for CERs moves significantly up or down so that one party has an incentive to breach the ERPA.

- $\quad$ Any disputes arise under the ERPA.

The CDM developer and CER purchaser's obligations with regard to developing a CDM project and CER transactions should be clearly defined under the ERPA. Generally speaking, the CDM developer is responsible for delivering sufficient CERs as stipulated in the agreement while the CER purchaser has an obligation of paying for the CERs at a certain price. In spite of that, considering project developers would face numerous risks in developing a CDM project in China, these risks should be

208 Above n 140, 98. 
reasonably allocated and assigned between the project developers and CER purchasers under the ERPA through carefully consultation before signing a contract. Moreover, project developers should make sure that they have adequately transferred certain risks which they take under the ERPA to other project participants such as the construction contractor, project additional products (e.g. electricity) buyer and the DOE through contracts.

At stage four, the possible risks may be influenced by two factors. One is whether the obligations of each project participants are clearly defined under the ERPA and other contracts. The other is whether project developers and CER purchasers agree to a price for CERs.

In conclusion, each $\mathrm{CDM}$ project development stage has the particular risks. The primary risk is whether the project developers could deliver the sufficient CERs as expected. In this case, project developers are prone to have more risks in developing a CDM project in China. Therefore, it is necessary for project developers to clearly define each party's rights and obligations under the contract and legally pass on parts of the risks to other parties through contracts.

Two major factors can play importance roles in mitigating the potential risks in developing CDM projects in China. One factor is whether the project developer has a good understanding of the CDM operational rules and procedures and a high level of expertise on developing a project in China; the other factor is whether adequate funds are available to cover the large costs spent by project developers in developing a 
CDM project in China.

Furthermore, these two factors are largely influenced by whether the Chinese Government has created a stable legal and institutional environment to attract foreign investment and whether the Chinese Government has widespread the knowledge and information about the CDM.

\subsubsection{General Risks in CDM Development in China}

Besides the particular risks in developing CDM projects, there are two types of general risks which could influence the implementation of CDM projects in China. One risk derives from an evolving international environmental legal framework; the other risk may arise from any political or legislative changes in China as a result of adapting to the new international environmental regime beyond 2012.

As the expiration of the first Kyoto period is approaching, the various negotiations on international policy architecture for global climate change beyond 2012 are currently underway. The uncertainty of the international climate change framework beyond 2012 would bring changes to the CDM scheme. Meanwhile, the price of CERs and the international carbon market would also be impacted. Although the Bali Conference and Copenhagen Conference have provided a signal to assure the continuation of $\mathrm{CDM}$ beyond $2012,{ }^{209}$ the future of the CDM is still uncertain. Furthermore, most CDM projects have long time cycles, which may take at least ten years. For this reason, the project investor is not willing to participate in the CDM

209 See Chapter five 261-9. 
project without a stable legal and market environment. In this scenario, the uncertainty of the future international climate change regime would challenge the implementation of CDM projects.

Currently, China with its surging economic growth and huge energy demands is expected to play a crucial role in addressing global warming beyond 2012. Against this background, China is not only under the great international pressure of taking measures to combat global warming, but also faces the dilemma of developing economy and reducing carbon emissions in a domestic context. Accordingly, China is likely to adopt more active policies and legislation to avert global warming instead of relying upon implementation CDM project in China. As a result, the changes of climate-related policy and legislation in China beyond 2012 would also incur risks in implementing CDM projects.

\subsection{Conclusion}

This chapter looked into the implementation of CDM projects in China from a legal perspective. Up till now China only has had only government policy to address climate change, which local governments could challenge, but a law would be challenge or violate. Given the great pressure of reducing global warming, China has not only adopted a specific regulation for the operation and management of CDM project in China, but also released a series of policies and laws with a view to promoting energy efficiency and the utilization of renewable energy. China used to be a good example of 'enacting strict environmental laws without effective enforcement', 
but it is improving the enforcement of environment-related and climate-related laws. Thus, these policies and laws, coupled with foreign direct investment laws have created a more favorable legal and investment environment to support CDM projects in China.

In spite of the favourable environment, implementing CDM projects in China still complex and time-consuming legal operational processes and cross-jurisdictional transaction of rights. As a result, a high degree of risk arises from developing a CDM project. Facing this situation, in order to protect its national interests, the Chinese Government has set limitation on CDM project participation eligibility and regulate the marketing of CERs as well as ownership concerning CER. As for the CDM project participants, the various project risks could be identified, eliminated or reduced through spreading the risks reasonably to each of participants. 


\section{Chapter 5 The CDM in China in the Post-2012 Era}

\subsection{Introduction}

The Kyoto Protocol is a starting point of the international environmental framework to deal with climate change. However, the treaty's ambitious targets for emission reduction are very limited and the agreement only lasts until 2012. Item 9 of the Article 3 of the Kyoto Protocol stipulates in explicit terms that 'the COP shall initiate the consideration of new commitments at least seven years before the end of the first period', ${ }^{1}$ which means that the post-2012 international climate negotiations should be activated no later than 2005. In fact, various proposals on post-2012 international climate agreement have already been made through academic, semi-official and official channels, since the Marrakech Agreement in $2001 .^{2}$

Great achievements have been made since 2007. The Bali Conference to the UNFCCC was held in December 2007 and culminated in the adoption of the 'Bali roadmap' for a future international agreement on climate change. Furthermore, the United National Climate Change Conference in Copenhagen was held in December 2009 and the Copenhagen Accord has been produced. Besides, other alternatives to the Kyoto protocol itself regarding the climate change have been discussed at many other high-level meetings around the world, which include G8+5 summit and APEC Economic Leaders' Meeting. Moreover, a regional grouping - the Asia-Pacific

\footnotetext{
${ }^{1}$ Kyoto Protocol to the United Nations Framework Convention on Climate Change, opened for signature 11 December 1997, art 3, item 9 (entered into force 16 February 2005). Text of the Kyoto Protocol is available at <http://unfccc.int/resource/docs/convkp/kpeng.pdf> at 9 October 2009.

2 Jiahua Pan, 'Roadmap to Post-Kyoto Climate Agreements' (2006) 2 Advances in Climate Change 22, 23.
} 
Partnership on Clean Development and Climate - was also set up with an intention to complement but not replace the Kyoto Protocol. Accordingly, building a new framework dealing with climate change in the post-2012 period has attracted worldwide attention. Under this scenario, these negotiations could have an impact on the CDM.

In addition, China will play a significant role in combating climate change in the post-2012 period as it has become the largest GHG emitter in the world and is a major developing country. Hence, it is necessary to look into how the reformed CDM would impact on climate change mitigation and sustainable development in China beyond 2012.

Against this background, this part discusses the CDM in China in the post-2012 period. First, the tendencies of an international climate legal framework for the post-2012 period and the fate of the CDM beyond 2012 are discussed based on the current negotiations until now. Following this, the challenge that China needs to face in the post-2012 period is analysed. Based on the above, the impact of the CDM on China in the long-term are discussed.

\subsection{The CDM in the Post-2012 Period}

\subsubsection{The Proposal under the UN for the Post-2012 Period}

Various bodies under the umbrella of the UNFCCC met several times to prepare the ground for a new agreement regarding climate change issues. Owing to their 
unremitting endeavors, the Bali Conference as the thirteenth Conference of the Parties (COP 13) of the UNFCCC and the Copenhagen Conference as the fifteenth Conference of the Parties (COP 15) of the UNFCCC were held to deal with the new climate change framework beyond 2012.

(1) The United Nations Climate Change Conference in Bali

For the sake of achieving a breakthrough to fight climate change in the period after 2012 and for longer term cooperation, the Bali Conference, hosted by the Government of Indonesia, took place in the Bali between 3 December and 15 December 2007 and brought together more than 10,000 participants, including representatives of over 180 countries together with observers from intergovernmental and nongovernmental organizations and the media. ${ }^{3}$

The main goal of the Bali Conference was to launch a two-year negotiation phase on climate change for the post-2012 period. The adoption of the Bali Roadmap is viewed as a systematic way to achieve this goal by setting out a clear and comprehensive agenda for negotiations and a timetable ending in 2009. In addition, the agenda for the next two years would largely focus on three main issues - deforestation, adaptation fund and technology.

Deforestation is an area characterized by intense debate over many years. ${ }^{4}$ However, the agreement in Bali paved the way for an incentive to reduce emissions from

\footnotetext{
3 This data is available from United Nations Climate Change Conference in Bali <http://unfccc.int/meetings/cop_13/items/4049.php> at 11 March 2008.

${ }^{4}$ Whether the deforestation projects should be included into CDM projects has been under discussion for many years. For more details, see Chapter two 44-5.
} 
deforestation in developing countries. Parties recognized deforestation's important role in a future climate change regime beyond 2012 and affirmed the urgent need to take further meaningful action to reduce emissions from deforestation and forest degradation in developing countries. ${ }^{5}$ Furthermore, a work program for further methodological work was adopted and the rules for projects to reduce deforestation were set out. ${ }^{6}$

The Adaptation Fund was launched at the Bali Conference with the purpose of assisting the vulnerable developing countries to cope with the climate change that is already evident, such as droughts and floods, through funding for adaptation projects in their respective countries. The fund is filled by means of the 'adaptation levy' which amounts to two per cent of the CERs issued for a CDM project activity and is therefore not dependent on donors. ${ }^{7}$ In addition, it is managed by the Adaptation Fund Board under the guidance of the COP/MOP. ${ }^{8}$ Considering the amount of CDM projects in the pipeline, the fund will become an estimated US\$80-300 million in the period 2008-2012. ${ }^{9}$

The Bali Conference also made important progress on the issue of clean technology,

\footnotetext{
${ }^{5}$ See Reducing Emissions from Deforestation in Developing Countries: Approaches to Stimulate Action, Decision -/CP.13 (2007) <http://unfccc.int/files/meetings/cop_13/application/pdf/cp_redd.pdf> at 11 March 2008.

${ }^{6}$ Ibid.

${ }^{7}$ Funding Adaptation in Developing Countries, 4, UN Doc FCCC/TP/2008/6 (2008)

<unfccc.int/resource/docs/2008/tp/06.pdf> at 11 July 2008.

${ }^{8}$ See Adaptation Fund Draft, Decision -/CMP.3 (2007)

<http://unfccc.int/files/meetings/cop_13/application/pdf/cmp_af.pdf> at 11 March 2008. In the past meetings, proposals to appoint the Global Environmental Facility (GEF) as the Fund's manager have generated controversies between developed and developing countries for the reason that the GEF operated on the principle of 'one dollar, one vote', meaning that its backers-the rich countries-may control the adaptation fund. The establishment of the Adaptation Fund Board was considered to be a significant breakthrough.

${ }^{9}$ United Nation, United Nations UN Breakthrough on Climate Change Reached in Bali (2007), press release, 3.
} 
one of the key concerns of developing countries to promote sustainable development. There was an agreement on a strategic program covering both mitigation and adaptation that provides the basis to scale up the level of investment in technologies that developing countries need. The aim of that program is to give an extra push to concrete demonstration projects, to create more attractive environments for investment, as well as provide incentives to the private sector for technology transfer. $^{10}$

According to these decisions and plans, the Bali conference marks the start of the road leading to reach a post-2012 deal, which is set to come into force by 2013 , following the expiry of the first period of Kyoto Protocol, in Copenhagen in December 2009 via Poznan, Poland in December 2008.

With regard to the CDM under the Kyoto Protocol, a decision was reached to reform its management in CMP 3 (Third Conference of the Parties Serving as the Meeting of the Parties to the Kyoto Protocol). In terms of the decision of Further Guidance relating to the Clean Development Mechanism, ${ }^{11}$ several CDM-related issues were discussed.

First, the COP/MOP agreed guidance aimed at improving the way the CDM and its Executive Board (EB) function. The EB was encouraged to focus on the enhancement of its executive and supervisory role, and where possible simplify the CDM

\footnotetext{
${ }^{10}$ Draft decision -/CMP.5, Further Guidance Relating to the Clean Development Mechanism, para 17, UN Doc FCCC/KP/CMP/2009/16 (2009).

${ }^{11}$ Decision -/CMP.3, Further Guidance relating to the Clean Development Mechanism, UN Doc FCCC/KP/CMP/2007/3 (2007) <unfccc.int/files/meetings/cop_13/.../pdf/cmp_guid_cdm.pdf> at 4 May 2008.
} 
procedures and improve its functions to ensure a fair and equitable regulatory system. $^{12}$

Second, several methodological issues were addressed. ${ }^{13}$ These issues included broadening the application of methodologies, continuing to work on energy efficiency and renewable energy, improving the additionality tool and approving use of non-renewable biomass CDM. ${ }^{14}$

Third, the CDM has been criticised for imposing expensive registration fees on carbon reduction projects, making it uneconomical for smaller projects to involve in the CDM and carbon market. ${ }^{15}$ Eventually, the COP/MOP recognized this barrier and decided to abolish registration fees and levies on CDM projects in the least developed countries. $^{16}$

In addition, other CDM-related issues including the implications of the establishment of new HCFC-22 facilities seeking to obtain CERs for the destruction of HFC-23 and whether Carbon Capture and Storage $(\mathrm{CCS})$ projects ${ }^{17}$ could qualify for carbon credits were considered in the conference. However, no agreement was reached.

(2) The United Nations Climate Change Conference in Copenhagen

After years of preparation, the COP 15 of the UNFCCC commenced on 7 December

\footnotetext{
12 Ibid s II.

13 Ibid s III.

${ }^{14}$ It means that the projects such as cooking with more efficient cooking stoves are allowed to enter the CDM scheme.

${ }^{15}$ For more details, see Chapter two 68-70.

${ }^{16}$ Above n 11, s IV.

${ }^{17} \mathrm{CCS}$ is a process that captures $\mathrm{CO}_{2}$ emissions and stores them in geological formations kilometers deep inside of the earth. CCS technology involves capturing carbon dioxide emissions from industrial sources and transporting them by pipeline to sites where they are injected into deep rock formations for permanent storage.
} 
2009, and adjourned two weeks later on 19 December. ${ }^{18}$ The original purpose of the conference had been to complete negotiations on a new international agreement on climate change to come into force when the Kyoto Protocol's first commitment period comes to an end in 2012. However, there is no agreement on whether to extend Kyoto and add extra national commitments under a separate pact, or end Kyoto and agree a new treaty which specified actions by all countries. After two chaotic weeks, 188 countries reached a limited agreement - the Copenhagen Accord ${ }^{19}$ - to continue global efforts to reduce emissions of GHG in order to address climate change. ${ }^{20}$

The Copenhagen Accord is a short document of appropriate 1,400 words, limited in detail and ambition. Though it is largely in line with the text of the UNFCCC, it is not legally binding. It mainly includes the following three aspects:

First, the accord formally recognises that average global temperature should not be allowed to increase by more than 2 degrees Celsius. ${ }^{21}$ However, the accord is not detailed enough to suggest that how such a goal should be achieved.

Second, there was some progress on providing finance to developing countries. New and additional, predictable and adequate funding, ${ }^{22}$ will be provided to developing

\footnotetext{
${ }^{18}$ See UNFCCC, <http://unfccc.int/meetings/cop_15/items/5257.php> at 1 March 2010.

${ }_{19}$ Decision -/CP.15, Copenhagen Accord, art 1, (2009) <unfccc.int/resource/docs/2009/cop15/eng/107.pdf> at 3 March 2010.

${ }^{20}$ As of February 10, 2010, the UNFCCC Secretariat had received submissions from more than ninety countries, representing more than $80 \%$ of global greenhouse gas (GHG) emissions, regarding their plans to reduce their GHG emissions and/or their wish to be "associated" with the Copenhagen Accord. Around half of these countries have pledged specific emission reduction targets. China has pledged to endeavour to lower its emissions by 40-45 per cent by 2020 compared to 2005 levels, but does not explicitly mention the Copenhagen Accord in setting these goals. See Daniel Bodansky, The Copenhagen Climate Change Accord (2010) The American Society of International Law Insight <http://www.asil.org/insights100212.cfm> at 3 March 2010.

21 Above $n 19$.

22 Ibid art 8.
} 
countries for emissions mitigation, including reducing deforestation, adaptation, technology development and transfer and capacity building. Up to US\$30 billion will be provided for the period 2010-2012. ${ }^{23}$ Developed countries also committed to finding a more substantial US $\$ 100$ billion a year by $2020 .{ }^{24}$ A significant portion of financing will flow through a newly established Copenhagen Green Climate Fund. ${ }^{25}$ The Accord lays out a framework to establish a 'high-level panel' ${ }^{26}$ to assess financial contributions by rich nations to help poor countries adapt to climate change and limit their emissions.

Third, the Accord lays out a framework for verification of emissions commitments by developing countries. The issue of monitoring the "nationally appropriate mitigation actions $^{27}$ taken on by developing countries - for instance, China's target to reducing carbon intensity, ${ }^{28}$ was highlighted in the accord. Determining how these actions would be measurable, reportable and verifiable was a disputable issue in the negotiations. Finally, the accord allows for 'domestic measurement, reporting and verification', but requires that this be reported 'through national communications, with international consultation and analysis., ${ }^{29}$

Although the Copenhagen Conference drops the expected goal of concluding a binding international treaty by the end of 2012, which leaves the implementation of

\footnotetext{
23 Ibid.

24 Ibid.

${ }^{25}$ Ibid art 10.

${ }^{26}$ Ibid art 9.

27 Ibid art 8.

${ }^{28}$ China announced in the Copenhagen Conference that it would reduce its carbon intensity by $40 \%$ to $45 \%$ by 2020, based on 2005 levels.

${ }^{29}$ Above n 19, art 5.
} 
the provisions of Accord uncertain, it also had implications for the future of climate change mitigation. The world's countries came together and concluded an agreement to begin tackling global warming. Furthermore, the Copenhagen Accord marks the first time that the developed countries, the United States in particular, have agreed to provide substantial amount of money to developing countries to address climate change.

Besides the Copenhagen Accord, the UN also released a number of technical documents, including an agreed set of changes to the CDM titled Further Guidance Relating to the Clean Development Mechanism. ${ }^{30}$ Under the agreement, a number of important reforms had been agreed.

First, the CDM EB has been granted permission to streamline registration and issuance procedures for emission reduction projects. In addition, it provides new funding to accelerate the development of CDM projects in countries with fewer than $10 \mathrm{CDM}$ approved projects in operation in order to improve impartiality of regional and sub-regional distribution of the CDM projects. ${ }^{31}$

Second, in order to deal with a question about the independent operation of the third-party certifiers in verifying that $\mathrm{CDM}$ projects deliver real emission reductions, ${ }^{32}$ the proposed reforms also call for an improved system of 'continuous

\footnotetext{
${ }^{30}$ Draft decision -/CMP.5, Further Guidance Relating to the Clean Development Mechanism, UN Doc FCCC/KP/CMP/2009/16 (2009) <unfccc.int/files/meetings/cop_15/application/pdf/cmp5_cdm_auv.pdf>at 3 March 2010.

${ }^{31}$ Ibid para 48.

${ }^{32}$ For details, see Chapter two 69.
} 
performance monitoring' for the DOE that assess requests for registration and issuance. $^{33}$

Third, in response to anger over the decision to reject the applications of over ten Chinese wind energy projects, ${ }^{34}$ the Copenhagen Conference agreed that the EB should establish new procedures for stakeholders to appeal against such decisions. ${ }^{35}$

Finally, the agreement allows entire sectors to join the CDM scheme. ${ }^{36}$ However, decisions on whether or not nuclear, deforestation or carbon capture and storage projects could be included in the CDM after 2012 were deferred to the next meetings.

\subsubsection{Other High-Level Meetings}

Climate change issues beyond 2012 are also the subject of discussion at other high-level meetings around the world.

\section{(1) G8+5 Summit}

The Group of Eight (G8) is one of the most important international forums for dealing with global issues. ${ }^{37}$ It is not an international organization but an informal forum of Heads of State and Government. The G8 members are Germany, France, the United Kingdom, Italy, Japan, the United States of America, Canada (since 1976) and Russia

\footnotetext{
33 Above n 30, para 17.

${ }^{34}$ Dozens of Chinese wind projects have been delayed or rejected due to concerns over their additionality. The CDM officials claimed that China had lowered its feed-in tariff for wind energy in order to male some projects appear less commercially viable than they really were.

35 Above n 30, para 8.

${ }^{36}$ Ibid para 2. It is called Sectoral CDM. For more details, see Chapter two 51.

${ }^{37}$ See G8 Summit 2007 <http://www.g-8.de/Webs/G8/EN/Background/background.html> at 10 April 2008.
} 
(since 1998). ${ }^{38}$ The European Commission is also represented at all the meetings.

From June 6 to 8, 2007, the G8 leaders met for their annual summit in Heiligendamm, Germany with the central theme of 'Growth and Responsibility'. A major step forward concerning climate change was taken at the G8 summit in that the G8 expressed its commitment to moving forward in the UN climate process and called for active and constructive participation in the Bali meeting with a view to achieving a comprehensive post-2012 agreement. ${ }^{39}$ More importantly, it was supported by the Group of 5 countries with emerging economies: China, India, Brazil, Mexico and South Africa. In addition, the G8 addressed the typical climate change issues such as technology, market mechanism, deforestation and adaptation.

The breakthrough of G8+5 Summit on climate change lies in the announcement of their commitment to achieving the emission reduction goals and participating in the negotiations on post-2012 agreement cooperating with the major emerging economies. In addition, the G8 expressed that they want to use new financial tools to support climate protection projects in the developing countries in the future, for example the proceeds from the auctioning off emissions rights. ${ }^{40}$

\section{(2) APEC Economic Leaders' Meeting}

As the only inter-governmental grouping in the world operating on the basis of

\footnotetext{
${ }^{38}$ Ibid.

${ }^{39}$ G8 Summit 2007, Growth and Responsibility in the World Economy (2007) 16

<http://www.g-8.de/Webs/G8/EN/G8Summit/SummitDocuments/summit-documents.html> at 10 April 2008.

${ }^{40}$ G8 Summit, Breakthrough on Climate Protection (2007)

<http://www.g-8.de/nn_92160/Content/EN/Artikel/_g8-summit/2007-06-07-g8-klimaschutz_en.html> at 10 April 2008.
} 
non-binding commitments, open dialogue and equal respect for the views of all participants, the Asia-Pacific Economic Cooperation (APEC), is the premier forum for facilitating economic growth, cooperation, trade and investment in the Asia-Pacific region. It was established in 1989 to further enhance economic growth and prosperity for the region and to strengthen the Asia-Pacific community. To the present date, it has 21 members. $^{41}$

The fifteenth APEC Economic Leaders' Meeting was held in Sydney, Australia on 8-9 September 2007, where the leaders made a declaration about climate change, energy security and clean development. ${ }^{42}$ In the declaration, the leaders agreed to support for a post-2012 international climate change arrangement within the United Nations framework. In order to underpin an equitable and effective arrangement, the leaders underlined the importance of the effective operation of market mechanisms, low carbon technologies cooperation, sustainable forest management and land use, open trade and investment and effective adaptation strategies as well. ${ }^{43}$

The APEC's discussion on climate change is significant as it makes some of the world's largest emitters got together to make their commitment to a post-2012 deal under the UNFCCC. Moreover, they all agreed to promote clean development through bilateral, regional and global partnerships, and in the meantime recognised the fact

\footnotetext{
${ }^{41}$ Its members include the US, China, Japan, Canada, Mexico, Australia and most south-east Asian countries.

42 APEC, Sydney APEC Leader's Declaration on Climate Change, Energy Security and Clean Development (2007)

<http://203.127.220.67/etc/medialib/apec_media_library/downloads/news_uploads/2007aelm.Par.0001.File.tmp/07 _aelm_ClimateChangeEnergySec.pdf> at 10 April 2008.

${ }^{43}$ See ibid 4-5.
} 
that the UN is still the primary forum for dealing with climate change. ${ }^{44}$

(3) Asia-Pacific Partnership on Clean Development and Climate

The regional cooperation on development and climate also appears in the form of partnership.

On 28 July 2005, the Australian Government along with counterparts from the China, Japan, India, South Korea and the United States of America - announced the formation of the Asia-Pacific Partnership on Clean Development and Climate (APP). ${ }^{45}$ This partnership, with the intention to complement but not replace the Kyoto Protocol, serves as a framework for supporting agile, constructive, and productive international cooperation among the Partners to meet their development, energy, environmental, and climate objectives. ${ }^{46}$

Three ministerial meetings have been held to date. The first meeting was in Sydney, on 12 January 2006, where Ministers reached a Charter, Communique, Work Plan and Vision that outlined a ground-breaking new model of private-public taskforces ${ }^{47}$ to address climate change, energy security and air pollution; the second meeting was in New Delhi, India on 15 October, 2007, where Canada officially joined the APP; and the third meeting was in Shanghai, China on 26-27 October, 2009, where the

\footnotetext{
44 Ibid 2.

45 Canada officially joined APP at the Ministerial meeting held in New Delhi on October 152007.

46 This is according to the Charter of APP

<http://www.asiapacificpartnership.org/pdf/resources/charter.pdf.> at 6 October 2009.

${ }^{47}$ Eight public-private sector Task Forces were established covering (1) cleaner fossil energy; (2) renewable energy and distributed generation; (3) power generation and transmission; (4) steel; (5) aluminium; (6) cement; (7) coal mining; and (8) buildings and appliances.
} 
Shanghai Communiqué was made to discuss ways to strengthen further cooperation under the Partnership.

The APP is a regional grouping of great significance as it brings together - for the first time - key developing countries and developed countries in the region to address the challenges of climate change, energy security and air pollution in a way that is designed to promote economic development and reduce poverty. Also, the seven partner countries taken together collectively account for more than half of the world's population, economy, energy consumption and global GHG emissions. ${ }^{48}$ Based on that, working together, this group can have a significant impact on a solution to climate change issues.

\subsubsection{The Tendencies of an International Climate Policy for the Post-2012 Era}

Based on the above introduced the international and regional meetings concerning a successor to the Kyoto Protocol, the tendencies of an international climate policy for the post-2012 era are discussed.

(1) Why is a new agreement needed? - Indisputable scientific evidence

As mentioned in chapter 2, early 2007, scientific evidence of global warming, which was concluded in the fourth assessment of the Intergovernmental Panel on Climate Change (IPCC), put the reality of human-induced global warming beyond any doubt

\footnotetext{
${ }^{48}$ See Asia-Pacific Partnership on Clean Development and Climate

< http://www.asiapacificpartnership.org/english/default.aspx> at 11 November 2009.
} 
and clearly stated its corresponding implications. ${ }^{49}$ According to the most stringent scenario outlined by the IPCC, if immediate action is not taken, greenhouse gas emissions will increase between $25-90$ per cent in 2030 relative to 2000 , causing global temperatures to rise and creating a host of environmental problems. In order to slow such a catastrophe, global emissions need to be reduced at least 50 per cent below the 1990 level by $2050 .{ }^{50}$ Facing this situation, all countries agree in the Copenhagen Accord that '...we shall recognize the scientific view that the increase in global warming should be below 2 degrees Celsius...' ${ }^{51}$ Therefore, all the countries around the world have recognized the urgency of climate change issues and have decided to work together to reduce emissions and minimize an adverse impact of climate change.

(2) Who will participant in a new agreement? - Key nations' involvement

A new agreement concerning climate change in the post-2012 period will involve major industrialized countries and key developing countries. China and the United State are the biggest GHG emitters and play a crucial role in addressing global warming. However, both countries are not included in the Kyoto Protocol to be allocated with fixed targets to reduce emissions. The United States, as one of the biggest emitters and the only developed country that has not ratified the Kyoto Protocol, is expected to participate in the new agreement due to the indisputable scientific evidence on global warming, international pressure and its domestic

\footnotetext{
49 For more details, see Chapter two 19.

50 Yvo de Boer, Welcome to the United Nations Climate Change Conference in Bali (Bali Conference, Bali, 3 December 2007) <http://unfccc.int/meetings/cop_13/welcome_message/items/4209.php> at 3 March 2009.

${ }^{51}$ Above n 19.
} 
environmental protection voice. ${ }^{52}$ Moreover, the relatively advanced developing countries, like China, India and Brazil, China in particular, may take on more obligations beyond 2012 in that it will be impossible to arrest global warming without concerted action by leading developing countries in a world where they already account for about half of global emissions and will account for 75 per cent of the growth in global emissions over the next 25 years. $^{53}$ The developing world should take substantial steps to cut emissions rather than reply on offset projects mainly funded by Europe. Therefore, a new agreement in the post-2012 period will involve commitments for economies at all levels of development.

(3) What needs to be done in a new agreement - Fixed targets and a voluntary system Based on the current situation of international negotiations on climate change, fixed emission targets as well as a voluntary reduction system are likely to be established in the post-2012 framework. All the countries are assigned their individual obligation to reducing emissions based on common but differentiated responsibilities principle and according to their domestic economic and technological capacities. The current major divide between developing and developed countries lies in the fact that developed countries claim that the major developing countries, China and India in particular, should take real actions to cut their emissions based on their current and future contributions to global $\mathrm{CO}_{2}$ levels, which are calculated by the total emissions of a

\footnotetext{
${ }^{52}$ For Example former vice president of the US Al Gore and world climate scientists acting under the auspices of the UN's Intergovernmental Panel on Climate Change (IPCC) won the 2007 Nobel Peace Prize for the documentary film An Inconvenient Truth directed by him.

53 Todd Stern and William Antholis, 'A Changing Climate: The Road Ahead for the United States' (2008) Winter 2007-2008 The Washington Quarterly, 175, 182.
} 
country while developing countries insist that developed countries should accept fixed targets to emission reductions based on their accumulative contributions as well as high $\mathrm{CO}_{2}$ levels of per capita allocation of emissions. Hence, the standardisation of calculating the contributions to global warming should be clear and unified.

Based on the above, two stages are likely to be set up. At the first stage, the major developed countries, which have high accumulative and per capita emission levels, would accept fixed targets to reduction and the major developing countries would adopt their reduction targets according to their national circumstances. At the second stage, all the major countries are required to accept fixed reduction targets.

(4) How long will the targets be realised? - A long-term path and mid-term goals A new global agreement on climate change in the post-2012 period tends to take a long-term path and set up mid-term goals.

The Kyoto Protocol's short-term targets, an average of five per cent reduction from 1990 levels by 2008-2012, may sound modest, but this time frame is too short for developed countries to reach this target. Global warming is a long-term problem caused by high carbon production and consumption patterns over two centuries. Fighting global warming needs long-time efforts because these patterns cannot be changed in such a short-term. However, the Kyoto Protocol's short-term targets fail to reflect the cumulative nature of these environmental problems. The short-term compliance also adds the uncertainties of implementation of flexible mechanisms under the Kyoto Protocol. 
Therefore, more stringent action plans for long-term reduction will be enacted with a view to motivating technological change which will gradually lead to a low carbon economy. In addition, mid-term reduction targets should be set up in order to assess the performance of different countries on realization of their long-term goals.

(5) How will the targets be realised? - Carbon market, assistance and monitoring

The new deal concerning climate change in the post-2012 Protocol is likely to continue to employ market-based instruments to address global warming. The financial emission reduction mechanisms, created and promoted by the Kyoto Protocol, provide an opportunity to reduce GHG emissions in a cost-effective way. Despite the limits of carbon market in carbon reductions, its performance may be increasingly improved through unremitting efforts on revising operation rules, and it will also play an important role in the post-2012 period.

The financial and technological assistance and cooperation with developing countries to help them leapfrog the carbon-intensive stage of development that industrialized countries have gone through will be highlighted in the post-2012 period. The Copenhagen Summit has demonstrated developed countries' commitment to providing financial assistance to help developing countries fight against climate change. Under this circumstance, developed countries are likely to be required to take on more obligations of providing financial and technological support to developing countries.

In addition, as a voluntary system is about to be set up, monitoring plays an 
indispensible role in examining mitigation actions in the post-2012 framework. In fact, at the Copenhagen conference, the United Sates emphasized the necessity of establishing a monitoring system to assess how China realises its voluntary reduction target. Consequently, the developed countries agreed to provide financial support to developing countries in the context of transparency on implementation of meaningful mitigation actions. ${ }^{54}$ Under this scenario, the monitoring system will not only be used to examine how developing countries realize their voluntary reduction targets, but also to supervise whether developed countries realise their commitments beyond 2012.

\subsubsection{The Fate of the CDM in the Post-2012 Regime}

There is no agreement yet on how the CDM will operate or even survive beyond 2012. Hence, there is some fear that all structures under its umbrella will be folded up and swept away when the Kyoto Protocol sunsets. Based on the above, the fate of the CDM in the post-2012 regime, including the continuation, orientation and improvement of the CDM beyond 2012, are discussed below.

(1) Continuation of the CDM beyond 2012

Although there is criticism about performance of the CDM on global warming mitigation, ${ }^{55}$ as the only financial mechanism that involves both the developed and developing countries in working together to reduce GHG emissions, contribution of the CDM to emission reductions cannot be neglected. It is estimated that some $\$ 95$

\footnotetext{
${ }^{54}$ Above n 19, art 8.

${ }^{55}$ For details, see Chapter two 66-72.
} 
billion in clean energy investment benefited from the CDM over 2002-08. ${ }^{56}$ Although the Copenhagen Conference did not produce a new agreement on climate change for the post-2012 period, there will be a new agreement in the future. Because of the enormous value that have brought by the CDM, it can be said that the CDM established under Kyoto will be recognised under any new regime.

Furthermore, neither the Bali Conference nor the Copenhagen Conference made a clear statement with regard to the fate of the CDM beyond 2012, but two documents were produced at both conferences with a view to improving the CDM. It can be inferred that a signal has been provided by international community to assure the continuation of CDM beyond 2012.

Continuation of the CDM in the post-2012 period has a positive impact on the current implementation and development of CDM projects in that the CDM project has a long operation cycle. A CDM project may take at least two years from concept to issuance of first credits, and this slowness, coupled with the uncertainty about future of the $\mathrm{CDM}$, has caused a reduction in project registrations. ${ }^{57}$ In addition, the certainty enhances market stability for CERs.

(2) Orientation of the CDM beyond 2012

The CDM will be re-oriented to be a complementary instrument assisting developed countries to achieve their binding emission targets and developing countries to

\footnotetext{
${ }^{56}$ See Karan Capoor and Philippe Ambrosi, 'State and Trends of the Carbon Market 2009' (The World Bank 2009) 28.

${ }^{57}$ For example, China did not issue any Letters of Approval that extended past the end of 2012 until recently.
} 
promote sustainable development.

The CDM is pointed to be 'a zero-sum-game' regarding its effect on GHG emission reduction. ${ }^{58}$ It provides an opportunity for developed countries to avoid taking practical actions to reduce emissions at home at the cost of money. In light of the critical task of combating climate change, it is the time for developed countries to cut their larger emissions at home to meet targets rather than pay for emission reductions elsewhere. Based on that, there is likely to be a certain limitation on the amount of the emission reductions generated from CDM projects. These emission reductions should be proportional to developed countries' individual emission target under the new agreement in the post-2012 period in order to promote developed countries to take practical and effective measures to reduce emissions at home.

As mentioned earlier, the CDM has a pitfall in promoting sustainable development in all developing countries. ${ }^{59}$ Geographical disproportion of CDM projects has been observed. The less developed countries, which should foremost be expected to accept the assistance to avert the influence caused by climate change, on the contrary, cannot fully participate in the CDM. In light of this, the CDM should be reformed to eliminate the geographical disproportion and be oriented to promote sustainable development in all developing countries. The major developing countries, which will be required to take on more obligations of reducing emissions beyond 2012, should take the CDM as a complementary tool to cut emissions as the favourable rules will

\footnotetext{
${ }^{58}$ For details, see Chapter two 66.

${ }^{59}$ For more details, see Chapter two 67.
} 
be made to promote the development of CDM projects in poor countries.

(3) Improvement of the CDM beyond 2012

The road of optimizing the function of the CDM will not be even due to its inevitable pitfalls and the fact that it is a newly established mechanism which has emerged and developed for only several years. However, based on the current experience and lessons learned about conducting CDM projects, the CDM will be improved in the following areas with a view to making sure that it could be better utilized to address global warming in the future.

First, the scope of CDM will be expanded and be more flexible. Programme activity ${ }^{60}$ and sectoral approach ${ }^{61}$ have been included in CDM projects and nuclear, deforestation or carbon capture and storage projects are under consideration. With the extended and flexible scope, the CDM will make developed countries cut more emission reductions at the same cost and promote greater participation by developing countries. However, the expansion must be beneficial to promote the shift toward a low carbon economy rather than provide an opportunity for developed countries to avoid cutting emissions at home.

Second, the function of the CDM EB and the CDM operational rules and procedures will be further improved. Efforts have already been made and more will be made to improve transparency, consistency and impartiality of the EB to ensure a fair and transparent regulatory system for CDM implementation. Furthermore, CDM

\footnotetext{
${ }^{60}$ For details, see Chapter two 51.

${ }^{61}$ For details, see Chapter two 52-3.
} 
procedures will be simplified in order to effectively reduce the transaction costs and risks which may occur in the time-consuming and complex $\mathrm{CDM}$ application and monitor processes.

Third, the impartiality, independence and technical competence of the DOE will be further enhanced. A better system for monitoring of the performance of the DOE will be put in place. Moreover, there will be a unified standardization for examining the technical capacity of the DOE staff and qualification of the DOE in verifying CDM projects.

Fourth, an appeal system will be set up and completed. As more and more projects participate in the CDM and the EB improves its function and tightens its supervision, project rejection rates will increase. As a result, more disputes will arise. As a result, the stakeholders involved may be entitled to defend their rights and appeal under the appropriate procedures.

Finally, more preferential rules will be made to address geographic disproportion of CDM projects and assist the least developing countries in implementing CDM projects. Besides mitigating or deferring the payment of expensive registration fee and levies on CDM projects in poor developing countries, developed countries are likely to continue to enhance the CDM capacity building in developing countries in the future so as to assist them in implementing CDM projects. 


\subsection{China in the Post-2012 Period}

In terms of its rapid economic development and large emissions, China is the focus of negotiations on mitigating global warming for the post-2012 era. This part discusses the potential challenges that China needs to face in the post-2012 period through exploring different major countries' stances and strategies on the post-2012 regime.

\subsubsection{China's Position on the Post-2012 Regime}

China is not subject to binding emission cut target in the first Kyoto period before 2012. However, according to its national circumstances, both the economy and emissions growths in China have been increasing rapidly. Owing to such a significant role in reducing emissions, China has been actively participating in the UN post-2012 negotiations as well as other arenas where key countries can meet to discuss global warming mitigation. These include, but not limited to, the United Nations Climate Change Conferences, the G8+5 Summit, the APEC Economic Leaders' Meeting and the Asia-Pacific Partnership on Clean Development and Climate.

Through these climate change negotiations, China's position on the post-2012 regime is clearly expressed. First, China highlights the major role of the UNFCCC for international community to structure a post-2012 regime and insists on 'common but differentiated responsibilities principle'. Second, China advocates reducing emissions with technical and financial support by developed countries rather than accepting mandatory emission cuts in any post-2012 regime. Third, China recognizes the urgent 
need to address climate change and is willing to take on a range of domestic commitments provided that real action is taken from the developed countries. China announced in the Copenhagen Conference that it would reduce its carbon intensity by 40 per cent to 45 per cent by 2020, based on 2005 levels. This essentially means that China will continue to grow, but will do so more efficiently and in ways that will emit less.

\subsubsection{Other Major Countries' Positions on the Post-2012 Regime}

Based on their national circumstances, different countries have their different positions on the post-2012regime. Due to different interests, the three stances are held by three groups: the European Union (EU), the so-called Umbrella Group, a group of developed countries excluding the EU and developing countries.

(1) The EU's position

The EU sees itself as a champion in the fight against climate change, leading the world in legislation, action and technology regarding energy saving and emission reduction. As the strong advocate of the Kyoto Protocol, the EU as a whole promises an 8 per cent cut of emission between 2008 and $2012 .^{62}$ Its emissions are now very close to this target through a series of new policies introduced. In addition, EU's active participation promotes the development of global carbon market. As mentioned previously, Europe and China are the leading players in the fast-growing business of

\footnotetext{
${ }^{62}$ Stefania Bianchi, 'Environment-EU: Carbon Trading Scheme Challenged', Inter Press Service News Agency (Brussels), 15 May 2006 <http://ipsnews.net/news.asp?idnews=33233> at 8 August 2008.
} 
the CDM. ${ }^{63}$ The EU is buying more than 80 per cent of all emission credits globally. ${ }^{64}$

The EU has committed to reducing its greenhouse gas emissions by 20 per cent by 2020 compared with the levels of $1990 .{ }^{65}$ Furthermore, it was considering raise its carbon cutting target to a 30 per cent cut if a legally binding treaty for post-2012 era was concluded. ${ }^{66}$ Although the EU has committed to battling global warming with the binding target beyond 2012, it is watching the move of the US and the major developing countries. It believes that the shift in economic weight for developing countries as well as the US could impact on the future approaches to global warming. The economic growth of developing countries in combination with relatively low economic growth rates in the EU implies that the latter's relative share in global GDP, global energy demand (from 16.6 per cent in 2001 to 12.5 per cent in $2030^{67}$ ), and global $\mathrm{CO}_{2}$ emissions (from 14 per cent in 2000 to 8 per cent in $2050^{68}$ ) will decrease, while the shares of developing countries will increase. In this case, countries such as China, the US, India, Japan, Russia and Brazil will be the leading economies of the future and should be part of new commitments to address global warming. ${ }^{69}$ The EU has urged them to set emissions reduction targets. Moreover, the European Commission has proposed freezing new demand for new CDM projects in 2012

\footnotetext{
${ }^{63}$ For more details, see Chapter two 60-1.

${ }^{64}$ Capoor and Ambrosi, above n 96, 33.

65 'Information Note on the UNFCCC' (Council of the European Union), 15838/09, 11 November 2009, 2 <www.consilium.europa.eu/uedocs/cmsUpload/ST15838_09.pdf> at 30 December 2009.

${ }^{66}$ Ibid 6.

${ }^{67}$ See 'World Energy Outlook 2004' (International Energy Agency, 2004) 59-80.

${ }^{68}$ See 'Winning the battle against global climate change' (European Commission, 2005) 35.

${ }^{69}$ Wilbur Perlot, 'Post-Kyoto and the Position of the European Union' (Briefing papers, Clingendael International Energy Programme, 2005) 4.
} 
unless the major polluters, like the US, China and India, set emissions reductions. ${ }^{70}$

(2) The Umbrella Group members' positions

The Umbrella Group is a loose association of developed countries. Without a formal list, the group includes the United States, Australia and Japan. These countries have the similar positions regarding their reduction obligations in the post-2010 regime. Their medium-term emission reduction targets for 2020 are low and conditional on the participation of major developing countries.

\section{- The United States}

The United States is not only the largest and most technologically powerful economy in the world but also has the largest share of historical emissions. Moreover, the US ranks the first in the world regarding per capita emission level. However, the economic growth of the US is not as rapid as that of the major developing countries, like China and India. The GDP growth rate in the US has been less than 3 per cent for the four consecutive years from 2006-09, ${ }^{71}$ which means the increase rate of energy demand would be relatively low compared to the other major developing countries.

In spite of the huge contribution to the global carbon emissions, the US has not ratified the Kyoto Protocol. ${ }^{72}$ The United States former President Bush announced in

\footnotetext{
${ }^{70}$ See 'State and Trends of the Carbon Market 2008' (2008) The World Bank <http://web.worldbank.org/WBSITE/EXTERNAL/TOPICS/EXTENERGY2/0,,contentMDK:21759158 menuPK: 4137780 pagePK:64020865 piPK:149114 theSitePK:4114200,00.html> at 9 October 2009.

${ }^{71}$ United States GDP Growth Rate (2009) Global Economic Research < http://www.tradingeconomics.com/Economics/GDP-Growth.aspx?Symbol=USD> at 1 January 2010.

${ }^{72}$ President Bush gave three reasons why the US refused to ratify the Kyoto Protocol: 1) the goals of this protocol could greatly hurt the economy of the US, leading to economic losses of $\$ 400$ billion and costing 4.9 million jobs. 2) large developing countries, like China and India, are exempted from the reduction obligations under the Kyoto Protocol.3) there are still some scientific uncertainties.
} 
2007's G8 summit that the US would work with other nations to establish a new international approach to energy security and climate change. Moreover, the US has promised to lead the world to produce fewer GHG emissions, but do it in a way that does not undermine economic growth or prevent nations from delivering greater prosperity for their people. ${ }^{73}$ With regards to the GHG emissions in the post-2012 regime, Bush was reported to say that the US cannot be expected to agree to emissions reductions unless China and India undertake similar obligations. ${ }^{74} \mathrm{He}$ also argued that doing so would result in the US industries and jobs moving out to the countries that do not have emission reduction commitments and would in any case not lead to global warming mitigation. ${ }^{75}$

The US has become less negative in tackling climate change since President Barack Obama took office. The Obama government actively promotes new energy policies and the American Clean Energy and Security Act ${ }^{76}$ which is an energy bill establishing a variant of a cap-and-trade plan for GHG and to address climate change was approved in June 2009. Based on this act, the United States is empowered to impose carbon tariffs on imports from the countries that do not have limited emission reduction targets. In spite of the active stance, this country still refuses to adopt the Kyoto Protocol. However, it has promised to commit to enhancing financial support

\footnotetext{
73 President Bush Participates in Major Economies Meeting on Energy Security and Climate Change $<$ http://www.state.gov/g/oes/rls/rm/2007/92938.htm> 1 January 2008.

${ }^{74}$ Shyma Saran, Climate Change - From Back Room to Board Room - What Indian Business Needs to Know about India's Approach to Multilateral Negotiations on Climate Change (2008) 2

<www.climatechallengeindia.org/.../230-Climate-change-from-back-room-to-board-room-what-Indian-business-ne eds-to-know> at 1 June 2008.

75 Ibid.

${ }^{76}$ American Clean Energy and Security Act of 2009, ACES (2009).
} 
for developing countries to address climate change in the context of transparency of the mitigation actions of the major developing countries.

\section{- Japan}

Japan, one of the world's biggest emitters of GHGs, has a target under the Kyoto Protocol to cut its emissions by 6 per cent from 1990 levels over the period from 2008-2012. However, meeting the Kyoto target may be difficult as Japan's GHGs emissions are set to rise over the next few years. According to an interim report issued by a Japan government advisory panel, Japan's emissions are forecast to rise by 0.9 per cent in the fiscal year ending in March 2011 and are likely to increase 0.9-2.1 per cent from $1990 .{ }^{77}$ In spite of the difficulties, Japan still shows determination to fulfill its pledges and is thinking of new measures to achieve the target.

With regard to the post-2012 regime, the Japanese Prime Minister said Japan would assume the responsibility for creating a post-2012 framework and setting a fair emissions reduction target for the world as a whole, including all the major polluter nations. ${ }^{78}$ The 'sectoral approach' to reducing carbon emissions was proposed. ${ }^{79}$ Also, Japan seeks to design an emissions trading program helping fight climate change after the Kyoto Protocol expires in 2012. A target of reducing GHG emissions by 25 per cent by 2020 against 1990 levels was announced in Copenhagen, but it

\footnotetext{
77 See Elaine Lies, Japan Emissions to Rise, Reaching Kyoto Goals Hard (2007) Reuters < http://www.reuters.com/article/idUST285136> at 15 August 2009.

${ }^{78}$ Yukio Hatoyama, 'Statement by H.E. DR. Yukio Hatoyama Prime Minister of Japan at the United Nations Summit on Climate Change' (New York, 22 September 2009) 3

<www.montreal.ca.emb-japan.go.jp/pdf/PM_statement_220909.pdf> at 10 December 2009.

79 As mentioned earlier, This debatable bottoms-up approach is to identify carbon-intensive industries, such as power, steel, cement, transportation and building and construction and to set uniform global efficiency norms and lower carbon emission standards for each sector, which added up would then form a national target.
} 
would be contingent on a deal involving all major emitters. ${ }^{80}$

\section{- Australia}

Australia, with 0.32 per cent of the global population, contributes 1.43 per cent of the world's carbon emissions. ${ }^{81}$ Hence, it is not surprising that Australia's per capita emissions are higher in comparison with other developed countries. Its per capita emissions in 2004 were 4.5 times the global average, just below the value for the US. ${ }^{82}$ Despite the big emission on a per capita basis, Australia was granted a limitation of an 8 per cent increase Kyoto target. ${ }^{83}$

The Australian Government moved to ratify the Kyoto Protocol in December 2007. The Australia Government had committed to reducing emissions by 60 percent on 2000 levels by 2050 and has studied how to achieve this target or better for Australia. ${ }^{84}$ The government has taken measures, including the Renewable Energy Target Scheme, which is to ensure that 20 per cent of Australia's electricity supply comes from renewable sources by 2020 and the Emission Trading Scheme, to slow the rise of carbon emissions. Regarding the post-2012 regime, the Prime Minister said that China and India as well as the US must be prepared to make commitments in the

\footnotetext{
${ }^{80}$ Hatoyama, above $\mathrm{n} 78,1$.

${ }^{81}$ Mike Raupach, 'CO2 Emissions Increasing Faster than Expected' (Working Paper No 07/89, CSIRO Marine and Atmospheric Research and the Global Carbon Project, 2007) 3.

${ }^{83}$ The UNFCCC gives special considerations to some countries. Article4, section 8(h) of the UNFCCC stipulates that' Countries whose economies are highly dependent on income generated from the production, processing and export, and/or on consumption of fossil fuels and associated energy-intensive products'. Australia belongs to that kind of countries as it is the world's largest coal exporter and is reliant on fossil fuel for transportation and energy.

${ }^{84}$ See Hon Martin Ferguson, Australia's Energy Security and the Clean Energy Challenge (2008) Minister for Resources and Energy <http://minister.ret.gov.au/TheHonMartinFergusonMP/Pages/Australia'sEnergySecurityandtheCleanEnergyChallen ge.aspx.html> at 3 March 2009.
} 
fight against global warming.

(3) Developing countries' positions

Based on different interests, Copenhagen saw three demands from three groups: the Group of 77 (G 77) and China, ${ }^{85}$ Small Island Developing States (SIDS) and Topical Forest Group.

\section{- The G 77 and China}

The G 77 includes most of the developing countries and their positions are consistent with China's. They agree long-term cooperative actions on climate change, mitigation of emissions, adaptation to the impact of climate change, as well as provision of financial and technological support to developing countries. ${ }^{86}$ In addition, they said developed nations should honor their commitment to accomplishing or establishing the medium-term emission reduction targets and concerns of the least developed countries, small island developing states and African countries should be considered. ${ }^{87}$

In addition, after China announced to reduce it carbon intensity, India followed with an announcement of 24 per cent reduction by $2020 .{ }^{88}$ India is regarded as another so-called 'major emitter' due to its huge population and rapid economic growth, and

\footnotetext{
${ }^{85}$ The Group of 77 at the United Nations is a loose coalition of developing nations, designed to promote its members' collective economic interests and create an enhanced joint negotiating capacity in the United Nations. There were 77 founding members of the organization on 1964, but the organization has since expanded to 134 member countries. China is not its member, but it supports the G 77's claims.

86 'Backgrounder: Three major stances in Copenhagen climate change negotiations' Xinhua (Beijing), 9 December 2009 <http://www.chinataiwan.org/english/specialreports/sr/Climate/267/43/200912/t20091209_1168909.htm> at 12 December 2009.

${ }^{87}$ Ibid.

${ }^{88}$ Aaron Wiener, India steps up and pledges emissions targets (2009) UN Dispatch <http://www.undispatch.com/india-steps-and-pledges-emissions-targets> at 12 December 2009.
} 
is also the focus of negotiations on mitigating global warming for the post-2012 era.

However, India does not consider itself to be a major emitter as it argues that neither the total volume of its $\mathrm{CO}_{2}$ emissions nor its per capita emissions today, would qualify it in the category of 'major emitters'. ${ }^{89}$ It insists on the per capita standard and emphasizes the distinction between 'lifestyle emissions' and 'survival emissions' to address global warming issues. ${ }^{90}$ Accordingly, India claims that it is not prepared to accept any limitation on its carbon emissions in the post-2012 period.

Brazil, as another major developing country, made an ambitious proposal to fight climate change at meetings in Copenhagen. It pledged to reduce the pace of the Amazon's deforestation by 80 per cent and make its emission levels reach to the levels of 2005 by $2020 .{ }^{91}$ Furthermore, it promised to provide funding for the least developed countries to address climate change.

\section{- Small Island Developing States (SIDS)}

SIDS is another coalition of developing countries, representing 43 island developing countries with low coastlines. These countries are most vulnerable to sea level rises caused by climate change. Facing this situation, they put forward Tuvalu's Proposals ${ }^{92}$ at the Copenhagen Conference to call for a new legally binding agreement to include

\footnotetext{
${ }^{89}$ See Saran, above n 74. In spite of 1.15 billion population and $8.5 \%$ GDP growth rate in 2007, India's total emissions are $4 \%$ of the global figure and it emits about 1.1 tons of $\mathrm{CO} 2$ per capita while the corresponding figure for the US is more than 20 tons. Furthermore, India accounted for only $2 \%$ of the cumulative $\mathrm{CO}_{2}$ emissions in the period between 1850 and 2000 .

${ }^{90}$ Ibid 78.

91 Raymond Colitt, 'Brazil eyes capping emissions at 2005 levels', Reuters (Brasilia), 13 October 2009 <http://www.alertnet.org/thenews/newsdesk/N1315528.htm> at 12 December 2009.

92 Tuvalu was calling for a discussion on what form the final deal from Copenhagen will take. The small island states put forward a proposal for a new protocol - in addition to the Kyoto Protocol - to include the commitments from the US and the other issues such as adaptation and finance.
} 
commitments from the US and other issues such as adaptation and finance. In addition, they also claimed that the global emissions should be reduced by 85 per cent by $2050 .^{93}$

\section{- Topical Forest Group}

The Topical Forest Group is composed of rainforest countries in Africa and South America. These countries need the security of finance to realize the objective for reducing deforestation by at least 50 per cent by $2020 .{ }^{94}$ They stress developed countries' responsibility to provide financial support.

\subsubsection{Conclusion}

It can be concluded from the above that: first, all the countries have recognised the urgency of reducing carbon emissions and are involved in the post-2012 negotiations. Although the post-2012 negotiations have not been concluded, most of countries have set their individual numerical target for addressing emission reduction beyond 2012 . Moreover, they are taking or have promised to take measures to reduce their domestic emissions in different forms.

Second, national interests are the root cause of different positions on the post-2012 regime. The divisions between developing and developed countries and between the EU and the US originate in different national interests and according to different

\footnotetext{
93 Ahead of Copenhagen talks, small island nations sound alarm at UN on climate change (2009) UN New Center < http://www.un.org/apps/news/story.asp?NewsID=32265> at 12 December 2009.

94 The EU's negotiating position for Copenhagen (2009) Federal Ministry for the Environment, Nature Conservation and Nuclear Safety < http://www.un.org/apps/news/story.asp?NewsID=32265> at 12 December 2009.
} 
national circumstances.

Third, China's and the United State's positions play a decisive role in designing a post-2012 framework. China set up a model for other developing countries. When China leads, other developing countries will follow. In addition, the United State's position influences the other countries' stances with regard to their obligations in the post-2012 regime.

Finally, divisions between developing countries and developed countries, especially between the United States and China, are the critical factor impeding the post-2012 negotiations. Nature of the divisions are: Should countries share their reduction obligations on the basis of historical emissions or future emissions? Also, should countries share their reduction obligations based on per capita emissions or nation wide emissions. The major developing countries, which have both relatively low historical and per capita emissions, are expected to produce massive emissions in decades with their rapid economic growth. By contrast, the major developed countries, which are the main contributors to the current global warming, will decrease their shares in global carbon emissions with their relatively low economic growth rates. In this scenario, most developed nations believe that for the next global agreement to be meaningfully, it must contain GHG reduction commitments from China, India and the other large developing economies. The developing countries, however, are reluctant to deal in specific targets because of the restrictive effects that such targets may have on their industrial development. Consequently, although the developed countries under 
the Kyoto Protocol are urging the US and China to accept mandatory emission cuts in a post-2012 regime, neither of them are willing to move.

\subsubsection{What will the Post-2012 Regime Bring for China?}

Based on the above analysis, the US and China would play a decisive role in the post-2012 period. If China insists its position on climate change for the post-2012 regime era, other developing countries would follow China and not possibly accept any fixed reduction targets. In terms of the promises regarding emissions reductions that have been made by some developed countries, two scenarios would probably occur. One scenario is that a new global agreement on climate change would go forward beyond 2012 without the US and China's involvement; the other scenario is that all the developed countries, including the US would agree a new pact with fixed reduction targets beyond 2012 .

The first scenario would be a new agreement without inclusion of the US and China beyond 2012. First, from a global perspective, it will be a formidable task of slashing overall emissions by 50 per cent from 1990 levels by 2050 without the inclusion of the US and China. A concrete reduction target averting the irreversible consequence of global warming has been concluded by IPCC. Nonetheless, it is impossible to achieve the 50 per cent reduction target by 2050 without inclusion of the US and the major developing countries, which together account for more than half of the world emissions. Furthermore, the fact that emission figures in the developing countries would continue to increase at a speedy rate in a few years complicates the problem. 
Although the US is seeking less demanding alternatives and China has endeavored to improve its energy efficiency, whether these measures will prove to be more or less effective than the new agreement with the fixed targets in the post- 2012 period is a question that will not be answered until it may be too late to plot a new approach.

The US and China would face great pressure of not accepting fixed targets beyond 2012. The other developed countries that have determined to reduce emissions with the fixed targets under the new agreement in the post-2012 period may constantly urge for the involvement of the US and major developing countries. Moreover, the competition among developing countries in the CDM market would be more intensive beyond 2012 without the carbon credits demand from the US and the support from EU.

Another scenario would be a new agreement without the inclusion of China beyond 2012. In this scenario, all the major developed countries would ratify a new agreement to replace the Kyoto Protocol beyond 2012, leaving China and the other major developing countries without binding reduction targets. In this circumstance, on the one hand, China would not sacrifice its economic development to reduce carbon emissions; on the other hand, China would have to face many challenges that may arise beyond 2012.

First, China and the whole world may suffer the consequences of global warming. It is predicted that China and other developing countries would account for more than half of planet emissions in a few decades. Therefore, unless the carbon emissions are 
effectively reduced in these countries, global warming would not be averted.

Second, China would be under great pressure internationally. When the US is included in the new agreement, China, which has already become the world's biggest GHG emitter, together with other rapidly developing countries would undoubtedly be a focal point in the climate regime.

Third, although China may benefit from massive carbon credits demands in the CDM market as a result of the inclusion of the US in the new agreement beyond 2012, there would be a negative impact on China's economic development in the long-term. In the context of economic globalization, China has become the world industry base with its cheap labor and relatively favorable investment climate. As a world factory, although China has obtained much needed capital and technologies, and has promoted its economic growth, the expenses could not be neglected. Once the infrastructure and equipment of these factories, most of which are with high energy consumption and emissions, are put into use, their average duration would be at least between 15-50 years. During this period, the corresponding technologies and capital would be locked until the investment is returned. ${ }^{95}$ Hence, when China accepts reduction obligations in the future, these factories would be an impediment to the development of a low carbon economy in China. Even if China transfers these factories, the economic development and employment would be undermined. What is more, the problem of carbon emission leakage ${ }^{96}$ would derive from the fact that realizing fixed reduction

\footnotetext{
${ }^{95}$ In the economic science this is called 'Lock in Effect'.

${ }^{96}$ Emission leakage is a concept referring to the problem that emission abatement achieved in one location may be
} 
target could accelerate the trend of developing carbon-intensive industries overseas by developed countries. In this circumstance, it is not surprising that how much the pressure China would face in the future.

In addition, China's foreign trade would be affected beyond 2012. Entering into the new century, foreign investment in China has been steadily growing. According to the statistics unveiled by the website of Ministry of Commence of China, ${ }^{97}$ the value of foreign trade in China has accounted for nearly 70 per cent of GDP and the export value with nearly 40 per cent. The US is the No. one export pattern with China. Against this backdrop, China and other countries, in particular the US, have become more interdependent in their economic development. However, as claimed by the US former President Bush, the goal of emissions reduction would incur economic losses in the US. ${ }^{98}$ In terms of the interdependence, the decrease of the US economic development would also weaken China's foreign trade. In this regard, China's economic development would be under attack beyond 2012 .

In conclusion, with China jumping past the US as the largest $\mathrm{CO}_{2}$ emitter, it would face a great challenge of reducing its carbon emissions beyond 2012. Even if China is not allocated with binding reduction target under the new agreement, it would be subjected to considerably adverse consequences of global warming, not limited to environmental consequences. Facing this situation, it is urgent for China to find a way

\footnotetext{
offset by increased emissions in unregulated locations.

${ }^{97}$ See the website of Ministry of Commerce People's Republic of China

<http://english.mofcom.gov.cn/statistic/statistic.html>.

${ }^{98}$ For details, see the above $n 72$.
} 
that leads to sustainable development and a low carbon economy.

\subsection{The Impact of the CDM on China beyond 2012}

Any changes of the CDM may influence its implementation in China. Hence, based on the tendencies of an international climate policy and the fate of the CDM for the post-2012 era, how the CDM impacts China's sustainable development in the post-2012 period are analysed below.

\subsubsection{Implications of implementing the CDM beyond 2012 for China}

Based on the above discussion that the CDM would exist in the post-2012 regime, China could continue to obtain the benefits from implementing CDM projects beyond 2012. However, the reforms of the CDM could have an impact on the current situation in China. First, some post-2012 climate regime options concerning the CDM that were discussed at the Bali Conference and the Copenhagen Conference including an expanded scope for CDM projects, simplified procedures for CDM projects implementation and the improvement of CDM EB and the DOE's performance. These improvements in the CDM would further promote its development in China beyond 2012. However, other improvements, including reducing projects geographical disproportion and providing preferential rules for least developed countries to implement the CDM, would make the competition more intense. Second, the EB and the DOEs begin to tighten their supervision and verification on China's CDM projects as China has become the No. one host country and the largest beneficiary and the 
questions about Chinese projects' additionality also arise. It puts CDM projects in China a disadvantage. Finally, the EU, the biggest buyer of CERs, has proposed freezing new demand for projects from developing countries, creating uncertainty about the development of the CDM projects in the post-2012 period. Accordingly, without the demand for CERs from the EU, the momentum of implementing CDM projects in China would be hindered.

Therefore, although the CDM operation rules and management are expected to be improved, the uncertain and unstable factors in the global carbon market would affect the performance of CDM projects in China in the post-2012 period.

\subsubsection{Limitations of the CDM in Promoting Sustainable Development in China beyond 2012}

As for the impact on sustainable development in China, on the one hand, the CDM has brought lots of benefits to China ${ }^{99}$; on the other hand, the CDM's contribution to sustainable development in China is limited beyond 2012 as a result of its inevitable commercial attribute. The threats imposed by implementing CDM projects to China in the long term may be demonstrated from the following four facets: limitation in forming the clean development idea, limitation in promoting clean technology transfer and diffusion, a negative impact on low-carbon development, and uncertainty of the CDM per se in the post-2012 period.

(1) The limitation in forming the clean development idea

\footnotetext{
99 For details, see Chapter three 109-115.
} 
There is no denying the fact that the CDM promotes sustainable development in China with bringing clean development idea. Both the Chinese Government and enterprises have taken part in carbon reduction projects during a past few years. However, the CDM per se is designed to be a market-based instrument. As a result, the project participants are bound to pursue the maximum economic profits at the lowest cost possible. In this circumstance, most CDM developers in China only undertake the projects for the financial and technological benefits. However, they have not really realised what should and need to do to address climate change in China. In this regard, the CDM has its limitation in bringing about real clean development in China.

(2) The limitation in clean technology transfer and diffusion

There is no doubt that environmentally sound technology is the decisive factor influencing the sustainable development in China. However, the CDM in China has its limitation in promoting the energy-related technology transfer and diffusion.

The widespread technology transfer and diffusion through the CDM faces many difficulties. Despite clear encouragement by the international community, the technology transfer is a very complex process as under the CDM, there is no obligation for the developed countries to treat technology as anything other than a commodity. Given the commercial attribute of the CDM projects, most CDM investors in developed countries choose to achieve their emission targets in the easiest and most cost-effective way with least investment and least technology transfer in 
order to keep the competitive advantages. In this case, the extent of clean technology transfer that can be brought in from the CDM is limited.

In addition, the ownership of corresponding technology in the developed countries may hinder its transfer and diffusion in China. There are only a few public-owned technologies in developed countries which governments have controlled over. ${ }^{100}$ Most of the technologies are invented through research by public investments and then developed by private sectors who then claim ownership. ${ }^{101}$ Accordingly, the potential technology transfer between the developed countries and China is relatively rare.

Finally, China's regulations about Intellectual Property Rights (IPR) also impede the transfer and diffusion of technology in China. However, there is no legislation at a national level specifically targeted at the technology transfer. ${ }^{102}$ Therefore, the conflict between IPR and technology transfer cannot be effective solved.

(3) The negative impact on low-carbon development

Admittedly, with the objective of promoting sustainable development, the CDM brings benefits to China. Nonetheless, there is a concern that implementing CDM projects in China may exert a negative impact on low-carbon development in the long-term. On the one hand, as mentioned above, the environmental-friendly technologies through the CDM are limited. On the other hand, in order to develop a

\footnotetext{
100 Ogunlade Davidson 'CDM and Technology Transfer: African Perspective' (Point de Vue 2001) 14.

101 Ibid.

${ }^{102}$ For more details, see Chapter four 184.
} 
low-carbon economy in the future, a significant breakthrough of high efficiency technological innovation is much needed. However, the CDM sends a signal that the additional carbon emissions and the poor technologies could be a favorbable condition to attract foreign investment and cooperation. ${ }^{103}$ Therefore, under the CDM, there may be a lack of incentive to stimulate the technogical self-innovation. In this connection, the CDM is not beneficial for technological innovation in China.

In addition, in the long-term, the CDM would bring challenges in that China is expected to take on more obligations of reducing carbon emissions in the post-2012 period. The emission reductions through CDM projects are limited. Moreover, the current CDM projects in China are dominated by large-scale industrial projects. As a result of lock in effect and problem of emission leakage, which were discussed above, this situation is likely to increase the cost of realising the reduction obligations in the future. Accordingly, the only solution for China is to make unremitting efforts to enhance technological innovation on climate change mitigation and adaptation.

(4) The uncertainty surrounding the CDM in the post-2012 period

In spite of the tendencies of the CDM discussed above, its fate in the post-2012 period is still uncertain. The first commitment period of Kyoto Protocol is from 2008 to 2012. As the expiration of the first Kyoto period is pending, the various negotiations on the post-2012 international climate change agreement are underway. The international climate regime and concomitant mechanisms are likely to be changed. Therefore, the development of the CDM is uncertain and China cannot rely on CDM to realize its

${ }^{103}$ For more details, see Chapter two 68. 
sustainable development in the long term.

\subsection{Conclusion}

The international community and regional organisations are working on negotiations with regard to the post-2012 framework. However, no agreement has been reached due to the huge divisions among countries as a result of the different interests and national circumstances. China and the United States, the two largest emitters and major economies, play a decisive role in addressing climate change in the post-2012 regime. Accordingly, China is facing the great challenge of reducing carbon emissions without undermining its economic development. China should adapt to the reforms of the CDM and make full use of CDM projects to attract foreign investment and clean technologies, but, due to the limitations of the CDM in promoting sustainable development in China, it should only be regarded as a complementary instrument for China to realise a low-carbon economy beyond 2012. 


\section{Chapter 6 A Comparative Study on the Implementation of CDM Projects in India}

\subsection{Introduction}

After exploring the situation of implementing CDM projects in China, it would be useful to compare this situation with other major developing countries. Under the UNFCCC and its Kyoto Protocol, the international climate legal framework is divided into two parts - developed countries and developing countries - according to their historical responsibilities for cumulative carbon emissions and national circumstances. Developed countries with a large contribution to the current emission level and advanced economic development are required to reduce their carbon emissions to a fixed target, while developing countries do not have a fixed emission target in the first Kyoto period. In this scenario, the CDM is established to assist the developed countries in meeting their targets and help the developing countries enhance climate change mitigation capacity. In addition, with the rapid economic development and large energy demand, the major developing countries are set to emit more carbon emissions and thus are expected to take on more responsibilities to combating climate change in the post-2012 period.

Against this background, on the one hand, all the major developing countries have lots in common with regard to the implementation of CDM and the responsibilities to mitigating climate change beyond 2012. China and India, in particular, are facing the similar situation. Both of them, with relatively advanced economy compared to the 
other developing countries have so far received the most attention from CDM project investors and have accounted for a large proportion of world carbon credits. Accordingly, it is necessary to investigate how India makes use of the CDM. In addition, India is also regarded as another large emitter due to its surging economic growth and huge population. Therefore, it is necessary to examine how India plans to meet the challenge of reducing carbon emissions without undermining economic development beyond 2012.

On the other hand, the competition of attracting foreign investment and clean technologies through CDM projects also exists between China and other major developing countries. India, in particular, is a strong competitor of China in the CDM regime. Therefore, it is crucial to study India's experience and lessons regarding developing and managing CDM projects in order to critically find better strategies toward the implementation of CDM projects and climate change issues in China.

This chapter is divided into four parts. Part two introduces and analyses the situation of implementing CDM projects in India. The basic national circumstances with regard to climate change, the development of CDM projects, the regulatory framework and institutional arrangements governing various aspects of the CDM and climate change-related activities and policies beyond 2012 in India are presented. Based on the above, Part three summaries the differences and similarities between India and China in implementing CDM projects and climate change policies. Part four analyses what China can learn from implementing the CDM in India and making strategies on 
addressing climate change in the post-2012 period.

\subsection{The CDM in India}

Comparatively, India is the country most similar to China with respect to the development of the CDM. First, viewed from the background to the implementation of CDM projects, India's basic national circumstances, including economic development, population, the impact of climate change and the state and projection of carbon emissions are similar to China's. Along with China, India has been ranking as one of the largest suppliers of CDM credits worldwide. In addition, and due to the surging economic growth and huge energy demand in future, both India and China are the focal point in the negotiations on the post-2012 framework with regard to climate change. Hence, India also released its national action plan on climate change in June 2008, clearly describing its national strategy for sustainable development and demonstrating its position on climate change issues beyond 2012.

Based on the above overview, this part introduces and analyses India's basic national circumstances, the development of CDM projects and India in the post-2012 period.

\subsubsection{Climate Change Issues in India}

\subsubsection{India's Basic National Circumstances}

(1) Physical feature

India, the major portion of the Indian subcontinent, is located in South Asia. It is the 
seventh largest country in the world, with a total land area of 3,287,263 square kilometers ${ }^{1}$, which is equivalent to one third of China's territory. Bounded by the Indian Ocean on the south, the Arabian Sea on the west, and the Bay of Bengal on the east, India has a coastline of 7,517 kilometers. $^{2}$

The geography of India is diverse with landscape ranging from the snow-capped Himalayan range in India's east and northeastern border to plains in most of northern, central and eastern India, plateaus in most of southern India and Thar Desert to the west of the country. 90.44 per cent of India's territory is land while 9.56 per cent is water. $^{3}$ The rivers of India can be classified into four groups: Himalayan Rivers, Deccan Rivers, Coastal rivers, and Rivers of the inland drainage basin. ${ }^{4}$ The Himalayan Rivers are formed by melting snow and glaciers and therefore, continuously flow throughout the year. The Deccan Rivers on the other hand are rain fed and therefore fluctuate in volume. The Coastal streams, especially on the west coast are short in length and have limited catchment's areas. The streams of inland drainage basin are few.

India's unique geography - extending from the snow-covered Himalayan heights to the tropical rain forests of the south - strongly influences its climate. The Himalayas acts as a barrier to the frigid winds flowing down from Central Asia, keeping most

\footnotetext{
${ }^{1}$ See India Details on Official India Government Website <http://india.gov.in/knowindia/profile.php> at 8 September 2008.

${ }^{2}$ V. Sanil Kumar et al., 'Coastal processes along the Indian coastline'(2006) 91 (4) Current Science 530, 531.

${ }^{3}$ See Geography of India Wikipedia <http://en.wikipedia.org/wiki/Geography_of_India>_at 8 September 2008.

4 Above $\mathrm{n} 1$.
} 
parts of India warmer than most locations at similar latitudes..$^{5}$ Thus, India is warm or only cooled during winter and extremely hot in summer. Winters in India, from January to February see mild to warm days and cool nights. ${ }^{6}$ Temperatures on some parts of the Indian plains sometimes fall below freezing. ${ }^{7}$ Summer, lasting between March and June in most parts of India, may have temperatures exceeding 40 degrees Celsius during the day. ${ }^{8}$ The coastal regions exceed 30 degrees Celsius coupled with high levels of humidity. ${ }^{9}$ In the Thar Desert area temperatures can exceed 45 degrees Celsius. ${ }^{10}$

Many natural disasters in India are related to the climate, causing massive losses of life and property. Floods are the most common natural disaster in India. Almost all of India is flood-prone, and extreme precipitation events, such as flash floods and torrential rains caused by the heavy southwest monsoon rains, have become increasingly common in central India over the past decades. ${ }^{11}$ Landslides in the Lower Himalayas, tropical cyclones along coastal regions, droughts caused by the failure of monsoons and frequent summer dust storms are also common in India. ${ }^{12}$

\section{(2) Population}

India has large total population and most of the population live in the rural areas.

\footnotetext{
5 Stanley Wolpert, A New History of India $\left(6^{\text {th }}\right.$ ed, 2000) 544.

${ }^{6}$ Above $\mathrm{n} 1$.

7 Above $n 3$.

8 Ibid.

${ }^{9}$ Ibid.

10 Ibid.

${ }^{11}$ See Natural disasters in India Wikipedia <http://en.wikipedia.org/wiki/Natural_disasters_in_India>at 8 September 2008.

12 Ibid.
} 
Moreover, the literacy rate is relatively low.

The most recent census of India was performed in $2001^{13}$ and the result of census showed that India is the second most populous country in the world, with a population of 1,028 million people comprising approximately one-sixth of the world population. ${ }^{14}$ The population growth rate is very high in India. The per cent decadal growth of population in the period 1991-2001 varied from a low of 9.43 to a very high $64.53 .^{15}$

Most people live in rural areas in India. India has more arable land area than any country except the United States, and more water area than any country except Canada and the United States. ${ }^{16}$ Indian life, therefore, revolves mostly around agriculture and allied activities in small villages, where the overwhelming majority of Indians live. According to the 2001 census, 72.22 per cent of the people live in more than 550,000 villages, and the remainder in more than 2000 towns and cities. ${ }^{17}$

(3) Economic development

Although relatively large government influence still exist in broad sections of the economy nowadays, economic reforms with a view to opening up the market through economic restructuring and reducing government controls on foreign trade and investment, implemented since 1991, have resulted in faster growth of the Indian

\footnotetext{
${ }^{13}$ Ministry of Home Affairs of Government of India, We also Count People in India Census of India <http://www.censusindia.net/ > at 9 September 2008.

${ }^{14}$ Ibid.

15 See Demographics of India Wikipedia <http://en.wikipedia.org/wiki/1991_Indian_census\#cite_note-2> at 9 September 2008.

${ }^{16}$ See Demographics of India <http://en.academic.ru/dic.nsf/enwiki/8738> at 9 September 2008.

17 Above n 13.
} 
economy. GDP growth rates have averaged roughly eight per cent during 2004-2008 ${ }^{18}$ which make India the second fastest big emerging economy after China in the world.

Despite the phenomenal rate of economic growth, there are 27.5 per cent of the population still living below the poverty line and 44 per cent of the population are still without access to electricity. ${ }^{19}$ Based on the above, the World Bank classifies India as a lower-middle-income economy. ${ }^{20}$ Moreover, wealth distribution in India is fairly uneven. The World Bank estimates that about one third of the global poor now reside in India. ${ }^{21}$ Against this background, the rapid economic development has been put at the top of India's agenda as an essential precondition to poverty eradication and improved standards of living.

The economic development in India is highly dependent upon various sectors like agriculture, manufacturing and services. Most India labor force, about 60 per cent earns their livelihood directly or indirectly through agriculture and related industries ${ }^{22}$ and despite of its share in the GDP, agriculture is still the largest economic sector and plays a significant role in the overall development of India. The smallest labor force is employed in the industrial sector and, which accounts for less than one fifth of GDP. ${ }^{23}$

\footnotetext{
${ }^{18}$ Prime Minister's Council on Climate Change, the Government of India, National Action Plan on Climate Change (2008) $13<\mathrm{http} / / /$ pmindia.nic.in/Pg01-52.pdf > at 9 September 2008.

19 Above n 13.

20 World Bank Country Classification Groups, The World Bank <http://web.worldbank.org/WBSITE/EXTERNAL/DATASTATISTICS/0,,contentMDK:20421402 pagePK:64133 150 piPK:64133175 theSitePK:239419,00.html\#Low_income> at 9 September 2008.

${ }^{21}$ Rama Kant Mishra, India, Home to One Third of the World's Poor (2008) Ground Report $<\mathrm{http} / / /$ www.groundreport.com/World/India-the-home-of-world-s-one-third-poor_1/2868168> at 9 September 2008.

${ }^{22}$ Factbook: India Central Intelligence Agency

$<$ https://www.cia.gov/library/publications/the-world-factbook/geos/in.html> at 9 September 2008.

${ }^{23}$ See Economy of India - Industry and Services Wikipedia <http://en.wikipedia.org/wiki/Economy_of_India > at 9 September 2008.
} 
The major industries in India include automobiles, manufacturing and cement.

It should be noted that corruption has been one of the pervasive problems affecting India. The chief economic consequences of corruption are the loss to the exchequer ${ }^{24}$, an unhealthy climate for investment and an increase in the cost of government-subsidised services. ${ }^{25}$

To conclude, India's basic national circumstances show the facts that: first, poverty remains a serious problem In India. It faces a fast-growing population and the challenge of reducing economic and social inequality. Along with India's fast economic growth comes its growing demand for energy. While more electricity is needed to improve people's living condition under its hot weather, India's tropical climate is ideal for the deployment of solar generation capacity. Another problem is that the agriculture sectors play an indispensable role in India's economy and supports most of Indians, but this makes India more vulnerable to any change of climate and weather conditions.

\subsubsection{Climate Change in India}

There have been some changes in climate change observed in India. First, at the national level, increase of 0.4 degree Celsius has been observed in surface air temperatures over the past century. ${ }^{26}$ However, a warming trend and cooling trends

\footnotetext{
24 It means government's funds.

25 See Demographics of India Wikipedia <http://en.wikipedia.org/wiki/1991_Indian_census\#cite_note-1> at 9 September 2008.

26 Above n 18, 15.
} 
coexist in the different parts of India. Second, as for extreme weather event in India, instrument records over the past 130 years do not indicate any marked long-term trend in the frequencies of large scale droughts and floors. ${ }^{27}$ Third, Indian scientists have estimated that sea level rise was between $1.06-1.75 \mathrm{~mm}$ per year, which is consistent with 1-2 mm per year global sea level rise estimates of IPCC. ${ }^{28}$ Finally, there has been no establishment of long-term trends or causation of the recession of Himalayan glaciers in India. ${ }^{29}$

In addition, some modeling and other studies have projected the following changes due to increased global anthropogenic emissions. First, simulations by Indian Institute of Tropical Meteorology (IITM) show that annual mean surface temperature rise by the end of century, ranging from 3 degree Celsius to 5 degrees Celsius under A2 scenario and 2.5 degrees Celsius to 4 degrees Celsius under B2 scenario of IPCC. ${ }^{30}$ Also, some simulations by IITM have indicated that summer monsoon intensity may increase beginning from 2040 and by 10 per cent by 2100 under A2 scenario of IPCC. ${ }^{31}$ Finally, there would be changes in frequency and/or magnitude of extreme temperature and precipitation events in India. Some results show that peak increase by extreme hot events would be amplified. ${ }^{32}$

Based on the projection of future climate change, the following consequences would

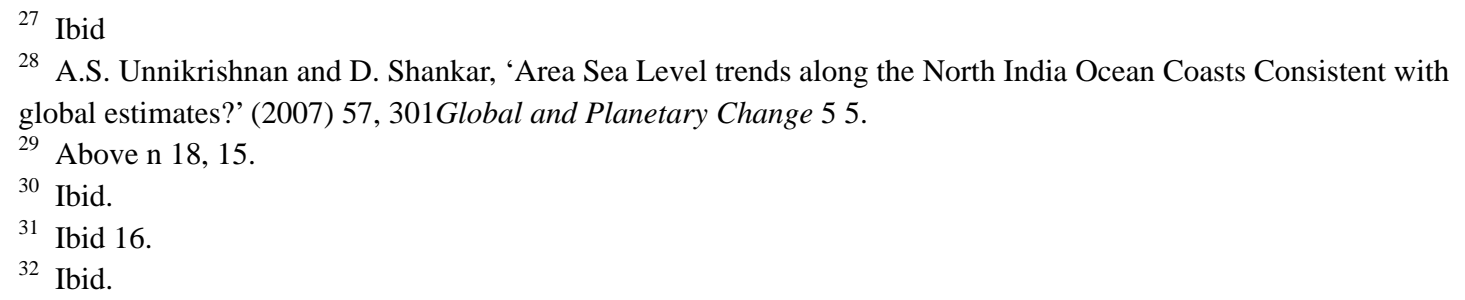


be caused by projected climate change in India:

First, climate change might have a substantial adverse impact on Indian agriculture and food production. The UNFCCC objective states that GHG concentrations should be stabilized at levels where food production is not threatened. ${ }^{33}$ Crucially, agriculture, playing an important role in India, is sensitive to climate changes. Even small changes in temperature and rainfall have significant effects on the quality of food production. Studies by Indian Agricultural Research Institute (IARI) and others indicate that every 1 degree Celsius rise in temperature reduces wheat production by 4-5 million tones. ${ }^{34}$ Besides, climate change might also impact on agriculture-related sectors, such as lower yields from dairy cattle and decline in fish breeding and harvest. $^{35}$

Second, it is predicted that the sea levels would rise as a result of global warming. If a one meter sea level rise were to take place today, it would displace 7 million persons in India. ${ }^{36}$ A mean sea level rise of $15-38 \mathrm{~cm}$ is projected along India's coast by the mid $21^{\text {st }}$ century and $46-59 \mathrm{~cm}$ by $2100 .{ }^{37}$ Another concern might come from the possible large scale emigration from coastal zones in Bangladesh, which borders India. It is reported that 35 per cent of the land in Bangladesh would be submerged by a one-meter sea level rise. ${ }^{38}$ In this scenario, given the fact that it is unlikely to be able

\footnotetext{
${ }^{33}$ United Nations Framework Convention on Climate Change, opened for signature 12 June 1992, art 2 (entered into force 21 March1994).

34 Above n 18, 16.

35 Ibid.

36 Vandana Asthana, 'Climate Change in Asia' (Asian Development Bank 1995) 3.

37 Above n 18, 17.

${ }^{38}$ Asthana, above n 36.
} 
to pay for protective measures, tens of millions of people would be displaced in Bangladesh and many of them might rush into India.

Third, heavily populated regions in India may be particularly impacted by extreme events due to climate change. For example, the intensity of tropical cyclones is projected to increase, posing a threat to the heavily populated coastal zones; most areas in India are frequented by drought while about 40 million hectares of land is flood-prone, including most of the river basins in the north India affecting about 30 million people on an average each year. ${ }^{39}$

Fourth, water resources and forests are likely to be adversely impacted. Changes in key variables, namely temperature, precipitation, and humidity, may have significant long-term implications for the quality and quantity of water. Consequently, a decline in run-off for Indian river basins and salt intrusion of the fresh water sources near the coastal regions due to sea level rise would occur. ${ }^{40}$ As for the impacts on forests, studies show that more than two thirds of the forest areas in India are likely to experience shift in forest types by the end of century, with changes in forests produce and livelihood based on those products. ${ }^{41}$ Correspondingly, the associated biodiversity is likely to be adversely impacted. ${ }^{42}$

Finally, global warming might have an adverse impact on Indian people's health. With climate change, there would be increasing scarcity of water, a reduction in yields of

\footnotetext{
39 Above n 18, 17.

${ }^{40}$ Ibid 16.

41 Ibid.

42 Ibid.
} 
forest biomass and an increased risk to people's health with children, women and the elderly in a household becoming the most vulnerable. ${ }^{43}$ Due to the tropical monsoon climate, Indian people would also be prone to diseases caused by vector species, such as malarial mosquitoes. ${ }^{44}$ The increase of temperature and humidity as a result of global warming may prolong the active period of transmission windows for important vector species and thus increase the spread of such diseases they carry to new areas. Furthermore, with the possibility of decline in availability of food grains, the threat of malnutrition may also increase.

In conclusion, although global warming is not apparently observed in India, studies have showed that temperature in India would rise for the $21^{\text {st }}$ century. In this scenario, climate change might also have an adverse impact on various aspects of India.

\subsubsection{Carbon Emissions in India}

Since the global warming due to the increase in anthropogenic atmospheric GHG concentrations is expected to have a substantially adverse impact on India, it is necessary to review carbon emissions in India. Hence, this part explores the profile of India's emissions, then introduces energy consumption and analyses the costs and challenges of reducing carbon emissions in India.

It was estimated by IEA that carbon emissions in India ranked the fifth in 2002, accounting for 4.2 per cent share of global carbon emissions compared to 23.4 per

\footnotetext{
${ }^{43}$ Ibid 14.

${ }^{44}$ Ibid 16.
} 
cent for the US, and 13.6 per cent for China. ${ }^{45}$ Moreover, considering the historical $\mathrm{CO}_{2}$ emissions between the period 1850-2000, India was with 2 per cent, compared to the US leading with 30 per cent, the EU-25 with 27 per cent and China with 7.3 per cent. ${ }^{46}$ If taking per capita figures, then India's $\mathrm{CO}_{2}$ emissions per capita are well below the world's average. ${ }^{47}$ The per capita $\mathrm{CO}_{2}$ emission of India is 1.02 (metric tons), compared to one fourth of the world average, one twentieth of the US and one third of China. ${ }^{48}$

In spite of the fact that they are only a fraction of the global emissions figure, carbon emissions in India are expected to significantly increase in that rapid economic expansion will continue to drive up India's energy needs. The strong positive correlation between energy use and human development is well recognised. However, as mentioned previously, about a half of the Indian population have no access to electricity. Facing this situation, it is obvious that India needs to substantially increase its electricity consumption to provide a minimally acceptable level of well being to the people. In this scenario, primary energy demand in India more than doubles by 2030. ${ }^{49}$ Power generation capacity, most of which is coal fired, more than triples by $2030 .^{50}$ Coal remains India's most important fuel, with its use nearly tripling between

\footnotetext{
${ }^{45}$ See Frances C. Moore, Carbon Dioxide Emissions Accelerating Rapidly (2008) Earth Policy Institute <http://www.earth-policy.org/Indicators/CO2/CO2_data.htm\#fig4> at 10 September 2008.

${ }^{46}$ Shyma Saran, Climate Change - From Back Room to Board Room - What Indian Business Needs to Know about India's Approach to Multilateral Negotiations on Climate Change (2008) 2.

${ }^{47}$ R.W. Bacon and S. Bhattacharya, 'Growth and $\mathrm{CO}_{2}$ Emissions - How do different countries fare?' (World Bank Environment Department 2007) 14. See also above n 18, 14.

${ }^{48}$ See above $\mathrm{n} 18,14$.

49 What are the Consequences of India Sustaining Its Rapid Energy Growth over the Next Two-and-a-half Decades? (World Energy Outlook 2007: Fact Sheet India).

50 Ibid.
} 
2005 and 2030. ${ }^{51}$ Based on India's clean technology level and resources structure, India is expected to become the world's third-largest emitter of $\mathrm{CO}_{2}$ by 2015 , following China and the US. The GHG emissions in India are projected to increase by almost three times with respect to the 1990 emissions in $2020 .^{52}$ Meanwhile, per capita $\mathrm{CO}_{2}$ emissions double between now and 2030, but, in 2030, will be well below the world average level. ${ }^{53}$

India's main energy resource is coal, but, it is poor in oil resource. Thus, India is currently heavily dependent on coal and foreign oil imports for its energy need. The chart below shows the share of total primary energy supply in 2005 .

\footnotetext{
51 Ibid.

52 IEA Statistics, CO2 Emissions from Fuel Combustion 1971-2002 (2004 Edition) 560.

${ }^{53}$ Ibid.
} 


\section{$\begin{array}{lllllll}\text { Chart 6.1 Share of Total Primary Energy Supply in } 2005 & \end{array}$ \\ IEA Energy Statistics

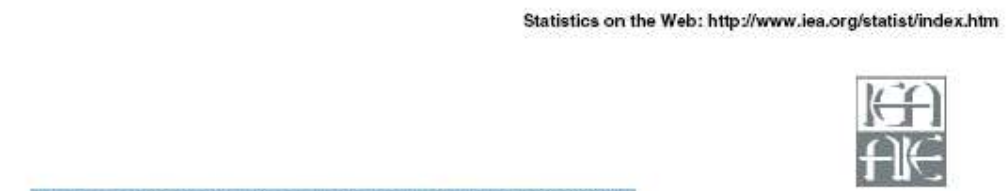

Share of Total Primary Energy Supply* in 2005

India

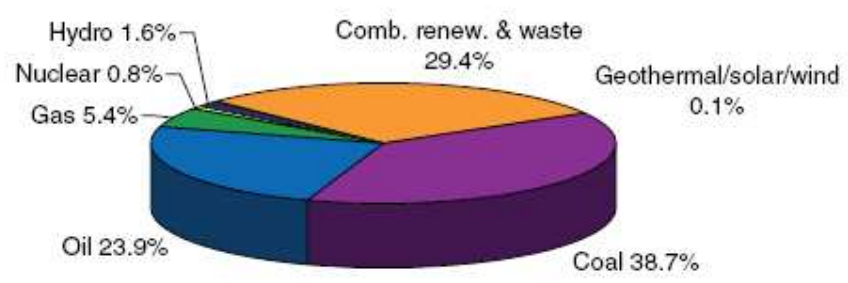

537309 ktoe

- Share of TPES excludes electricity trade.

Note: For presentational purposes, shares of under $0.1 \%$ are not included and consequently the total may not add up to $100 \%$.

OOECDIEA 2007

For more detailed data, please consult our on-line data service at http $: /$ data.iea.org.

Source: IEA Energy Statistics <www.iea.org/statist/index.htm>

It can be seen from the above chart that coal accounts for a large share of total energy supply in India. Meanwhile, renewable energy and waste are effectively utilized. Oil makes up of nearly a quarter of the energy supply. Other energy, including hydro, nuclear, wind and solar, however, only account for a fraction of the total primary energy supply in India.

As a matter of fact, India has sufficient solar energy. Viewed geographically, India is largely located in the equatorial sun belt of the earth, thereby receiving abundant radiant energy from the sun. In most parts of India, clear sunny weather is experienced 250-300 days a year. ${ }^{54}$ Thus, just 1 per cent of India's land area can meet

\footnotetext{
54 Above n 18, 20.
} 
India's entire electricity requirements till $2030 .^{55}$ The Government of India has launched 'The National Solar Mission' with a view to promoting the use of solar energy for power generation and other applications. ${ }^{56}$

Viewed in sectors, the industrial sector is the largest user of commercial energy in India, accounting for 42 per cent of the country's total commercial energy use during 2004-2005. ${ }^{57}$ As per the national GHG inventory, the direct $\mathrm{CO}_{2}$ emissions from industrial sources accounted for nearly 31 per cent of the total $\mathrm{CO}_{2}$ emissions from the country. ${ }^{58}$ In spite of a large amount of emissions, the industrial sector would continue to play a major role in the overall development of India. In addition, the residential sector accounts for around 13.3 per cent of total commercial energy use in India. ${ }^{59}$ Furthermore, as the life quality and health is improved, more electricity is expected to increase in the future. In this regard, emphasis should be laid on the industrial and residential sectors in order to reduce carbon emissions.

With the threat of climate change, India has been called upon to change its energy strategy based on coal, its most abundant resource, and to use other energy sources (e.g. oil, gas, renewable and nuclear energy) instead, which may turn out to be expensive. The costs associated with a low GHG energy strategy in terms of foregone income and welfare of the poor was estimated. ${ }^{60}$ The consequences of alternative

\footnotetext{
55 Ibid.

${ }^{56}$ See National Action Plan on Climate Change (Government of India) National Solar Mission.

57 Above n 18, 22.

${ }^{58}$ Ibid

${ }^{59}$ Ibid 25.

${ }^{60}$ See N.S. Murthy, Manoj Panda and Kirit Parikh, 'CO2 Emissions Reduction Strategies and Economic Development of India' (WP-2006-004, Indira Gandhi Institute of Development Research 2006) <www.eaber.org/intranet/documents/109/1430/IGIDR_Murthy_2006.pdf> at 2 October 2008.
} 
$\mathrm{CO}_{2}$ emission strategies on economic development and, in particular, the implications for the poor by empirically implementing in an economy-wide model across India over a 35-year time horizon were examined in the paper. ${ }^{61}$ The results show that $\mathrm{CO}_{2}$ emission reduction imposes costs in term of GDP and higher poverty. Taking 2000 as the baseline, a 30 per cent $\mathrm{CO}_{2}$ reduction over a period of 30 years using annual emissions reduction targets leads to a fall in GDP of 4 per cent and raises the number of poor by 17.5 per cent in the $30^{\text {th }}$ year. ${ }^{62}$ Therefore, India faces a great challenge of balancing poverty alleviation and emission reduction.

In conclusion, in spite of the low per capita emissions, India is expected to largely increase its carbon emissions based on its economic growth. In this regard, the India Government should re-orient its energy strategy according to its national circumstances with a view to mitigating and adapting to global warming.

\subsubsection{Implementing CDM Projects in India}

Since the Kyoto Protocol entered into force in 2005, India has emerged as one of the most active suppliers of CDM credits. A considerable number of CDM projects are currently being developed in India. It has its own CDM projects characteristics and status, CDM implementation management rules and procedures and supporting policies and laws. Against this background, the status and legal issues for implementing CDM projects in India are explored.

\footnotetext{
${ }^{61}$ See Ibid.

${ }^{62}$ Ibid 12.
} 


\subsubsection{Status of CDM Projects in India}

With cut-off date of late December 2009, India has 479 CDM projects having been registered by the CDM EB, accounting for about 23.76 per cent of the world total of 2,016 projects registered with the CDM EB, following China with 36.01 per cent. ${ }^{63}$ About 366 million CERs have been issued to projects worldwide, of which India accounted for 20.26 per cent, China 47.73 per cent, and Republic of Korea 12.99 per cent. $^{64}$

As mentioned previously, India led in the number of registered CDM projects. ${ }^{65} \mathrm{Up}$ to September 2008, India had 358 CDM projects, accounting for about 31 per cent of the world total of 1,162 projects registered by the CDM EB, followed by China (23 per cent) and Brazil (12 per cent). ${ }^{66}$ Meanwhile, about 186 million CERs had been issued to projects worldwide, of which India accounted for 26 per cent, China 35 per cent, Republic of Korea 16 per cent and Brazil 13 per cent. ${ }^{67}$ The reason for this was the large ratio of small and medium-sized CDM projects in India. Of all the projects registered till September 2008, 65 per cent were small scale projects. ${ }^{68}$

Among the current 479 projects registered with the EB, renewable energy, including renewable biomass, accounts for the largest number of the projects, followed by energy efficiency, and industrial processes. Very few projects in the forestry and

\footnotetext{
${ }^{63}$ See the information released on the UNFCCC website CDM Statistics $<$ http://cdm.unfecc.int/Statistics/index.html> at 1 January 2010.

${ }^{64}$ Ibid.

${ }^{65}$ For details, see Chapter three 132.

${ }^{66}$ See CDM Statistics UNFCCC < http://cdm.unfecc.int/Statistics/index.html> at 20 September 2008.

${ }^{67}$ Ibid.

68 Ibid.
} 
municipal solid waste sector are included, despite their large potential. The portfolio is dominated by unilateral projects. Most of the investors are Indian parties. They employ locally available technologies, and use domestic financial resources. In this regard, CDM has not assisted in leading to the technology transfer from industrialized countries to India envisaged by the Kyoto Protocol. Moreover, out of 137 rejected projects till December 2009, 43 projects were from India. ${ }^{69}$ A high proportion of them were all rejected due to problem with the projects participants' inability to prove the 'additionality criteria' for the project.

The ratio between actual CERs issued and estimated in the request for registration is called CER issuance rate. The countries where most CDM projects are being developed are not necessarily the ones with best performance in terms of CER issuance rates. ${ }^{70}$ India has been issued more CERs than expected so far.

By June 2008, 969 CDM projects had already awarded host country approval by the India DNA. ${ }^{71}$ The number of expected annual CERs from registered projects in India is around 31 million, accounting for 14 per cent of the total amount and following China, which accounts for 52 per cent. ${ }^{72}$ In addition, about 493 million CERs are expected to be generated until 2012 if all these host countries approved projects in India go on stream. ${ }^{73}$

\footnotetext{
${ }^{69}$ Above n 63.

${ }^{70}$ Paula Castro and Alex Michaelowa, 'Empirical Analysis of Performance of CDM Projects' (Climate Strategies Report, Political Economy and Development, Institute of Political Science, University of Zurich, 2008) 5.

71 Above $\mathrm{n} 66$.

72 Ibid.

${ }^{73}$ See the information released on the India National CDM Authority website
} 
The India Government has launched eight national missions to combating climate change. ${ }^{74}$ Among them, solar energy, enhanced energy efficiency in industry, energy efficiency in the residential and commercial sector and forestry in India are emphasized. Accordingly, there would be lots of potential CDM projects in India.

Compared to its position in the CDM pipeline, India has a relatively low market share of transactions. India, at 6 per cent market share, transacted the highest volumes after China, which topped the list with a huge 73 per cent, in $2007 .^{75}$ Viewed historically, after India has lost considerable ground in trading project-based emission reductions in 2005 with 3 per cent, which was as a result of the excessive price demands of Indian sellers, it raised its market stake in 2006 with 15 per cent. ${ }^{76}$ In the view of the World Bank, the reason is the strong project pipeline and a greater readiness by project operators to conclude supply contracts on 'fair' terms. ${ }^{77}$ Market participants repeated cited high price expectations in India, and reported that project sponsors focused on transacting issued CERs at attractive prices in the range of $€ 15-16.50$ per CER instead of selling (riskier and therefore less remunerative) forward CER streams. ${ }^{78}$ Therefore, high price expectations for CERs in India hinder the growth of CDM projects.

In summary, India is currently the second largest host country in the world with

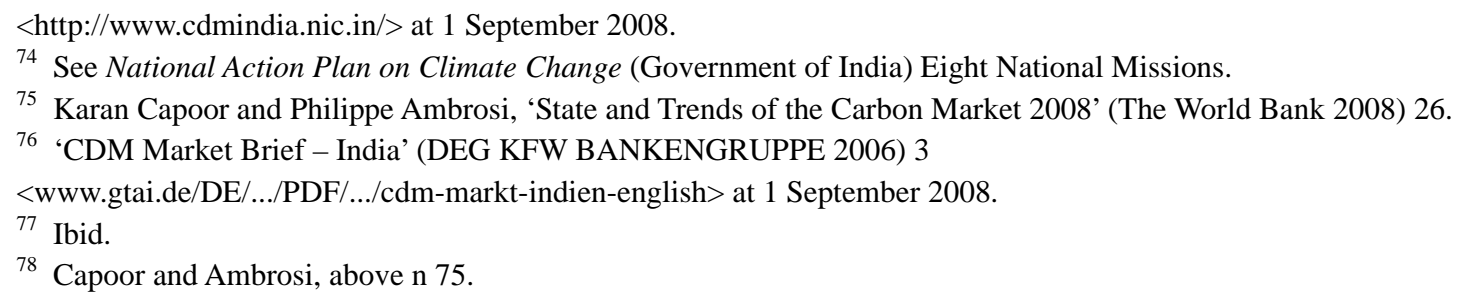


respect to the number of registered CDM projects and expected average annual CERs from the registered projects. Hence, it will continue to play an important role in developing CDM projects and CERs transactions in the future. In spite of that, the price expectation for CERs in India has been identified as a key factor impeding its performance in the global carbon market. In addition, most projects in India are unilateral and its issuance rate is the highest among all the host countries.

\subsubsection{Legal Issues for Implementing CDM Projects in India}

The legal issues for implementing CDM projects in India are discussed. First, how to implement a CDM project in India is illustrated from a legal perspective. Subsequently, the CDM-related policies and laws in India are explored.

(1) How to implement a CDM project in India

The potential legal actors involved in the implementation of CDM projects in India are as follows:

- India: India is a Party to the UNFCCC. A\$o, India acceded to the Kyoto Protocol in August 2003 and thus fulfills the prerequisites for implementation of the CDM. The government of India plays an important role in promoting and guiding the implementation of CDM projects.

- The National Clean Development Mechanism Authority (NCDMA): the NCDMA is an institutional setting concerning the CDM approval. Indian National CDM Authority was established with Ministry of Environment and Forests (MoEF) in 
December 2003. It is chaired by the Secretary of the MoEF and also managed by the MoEF. It is made up of eight representatives of six ministries (environment, foreign affairs, finance, industry, power and non-conventional energy sources) and a member of the Planning Commission. It clears projects on a monthly basis and is in charge of formulating the appropriate guidelines.

The functions of the NCDMA include ${ }^{79}$ :

- $\quad$ receiving projects for evaluation and approval as per the guidelines and general criteria laid down in the relevant rules and modalities pertaining to $\mathrm{CDM}$ in addition to the guidelines issued by the $\mathrm{EB}$ and $\mathrm{COP}$;

- recommending certain additional requirements to ensure that the project proposals meet the national sustainable development priorities and comply with the legal framework so as to ensure that the projects are compatible with the local priorities and stakeholders have been duly consulted; - $\quad$ carrying out the financial review of project proposals to ensure that the project proposals do not involve diversion of ODA and also ensure that the market environment of the $\mathrm{CDM}$ project is not conducive to under-valuation of CERs, particularly for externally aided projects; and - carrying out activities to ensure that the project developers have reliable information relating to all aspects of implementing the CDM in India which include creating databases on organizations designated for carrying out activities like validation of CDM project proposals and monitoring and

\footnotetext{
${ }^{79}$ See National CDM Authority CDM India <http://www.cdmindia.nic.in/cdm_india.htm> at 20 October 2008.
} 
verification of project activities, and to collect, compile and publish technical and statistical data relating to CDM initiatives in India.

In addition, the NCDMA has the following responsibilities: ${ }^{80}$

- $\quad$ inviting the CDM related officials and experts when it is necessary;

- interacting with concerned authorities, institutions, individual stakeholders for matters relating to CDM;

- $\quad$ taking up any environmental issues pertaining to CDM; and - recommending guidelines to the India Central Government for consideration of projects and principles to be followed for according host country approval.

- CDM project owners: as mentioned prevøusly, most of the CDM projects in India are unilateral. Accordingly, most of the CDM project investors are domestic entrepreneurs. In addition, there are no particular requirements for the eligibility of potential CDM projects in India. All the projects that can meet the criteria under the UNFCCC and the Kyoto Protocol are qualified for consideration as CDM projects in India.

- CDM consultants: generally speaking, consltants help project owners develop the PDD, methodologies, provide procedural support and sometimes act as a broker once the CERs are generated. The intermediary role of consultant becomes more important in India in that the process until registration and issuance of potential CDM projects is

\footnotetext{
${ }^{80}$ Ibid.
} 
complex and that the number and specifications of methodologies and UNFCCC regulations have changed fast so that the whole registration procedure becomes more and more inscrutable. In India, the fees charged by the consulting firms for preparing a PDD depend on project size and complexity and the methodology used. ${ }^{81}$ If additional consulting services are needed (e.g. supplementary assistance in validation and registration or searching for prospective emission buyers), a success fee is usually charged. ${ }^{82}$

- Validates and verifiers: the DOEs with exensive activities on the Indian market are from Europe and Japan. The prices for project validations and verifications in India are commensurate with international standards. ${ }^{83}$

- Other CDM actors: the other major CDM actos refer to the institutions that provide financial assistance to project developers. In 2008, the India's largest lender and state-owned, the State Bank of India (SBI), joined up with three entities to provide a comprehensive framework for industries to take advantage of CDM projects. The services include advisory services and finance to implement CDM projects. Beside, the private banks, like ICIC Bank Ltd and Industrial Development Bank of India Ltd (IDBI) also provide services to promote the CDM projects.

In addition, India has established domestic exchanges. As per Multi Commodity Exchange of India Ltd. (MCX), industries like agriculture, energy, manufacturing,

\footnotetext{
81 Above n 76, 4.

82 Ibid.

${ }^{83}$ Ibid.
} 
fuels, mining \& mineral, chemicals and afforestation and reforestation are the most viable industries to generate carbon credits. ${ }^{84}$ With MCX interested in playing a major role on the emission trading by adding carbon credits to its existing portfolio of commodities, the existing and potential market of carbon credits had increased many times over. ${ }^{85}$ This will also help in getting around the price hedging, advance selling and avoiding counterparty risk. ${ }^{86} \mathrm{MCX}$ also will give the seller a platform for demonstrating their bargaining capabilities.

As mentioned earlier, Indian CDM sector is mostly composed of small- to medium-sized projects requiring low levels of upfront investment. As a result, India's lack of public financing has allowed China to take an enormous lead in attracting the investment under the CDM. Facing this situation, India has studies China's strategy for drawing foreign investment through the CDM, and the recent results are encouraging. In July 2008, the India venture capital firm IVCF launched the $\$ 80$ million Green India Venture Fund, which would invest the majority of its capital in CDM projects. ${ }^{87}$ Another fund, New York-based Green Ventures International, launched a $\$ 300$ million India Carbon Fund to promote the development of CDM projects in India. ${ }^{88}$

In order to implement a CDM project in India, the potential project must meet three

\footnotetext{
${ }^{84}$ Sray Agarwal, Pay or Get Paid for GHG (2008) Business \& Economy <http://www.businessandeconomy.org/20032008/storyd.asp?sid=3098\&pageno=1 > at 6 October 2008.

${ }^{85}$ Ibid.

86 Ibid.

${ }^{87}$ Jacob Brody, India Joins the Race for Carbon Credit Investment (2008) Green Beat <http://green.venturebeat.com/2008/07/23/india-joins-the-race-for-carbon-credit-investment/> at 6 October 2008.

${ }^{88}$ Ibid.
} 
criteria regarding additionality, sustainable development indicator and baseline to get approval. $^{89}$

The potential project must meet the requirements for emission and financial additionalities. ${ }^{90}$

- As for the sustainable development, the India Government attaches great importance to improvement of the quality of life of the very poor from the environmental standpoint. The social well being, economic well being, environmental well being and technological well being aspects should be considered when designing CDM project activity. ${ }^{91}$

- The project proposal must clearly and transparently describe methodology of determination of baseline. It should confirm to the requirements for baseline. ${ }^{92}$

\footnotetext{
${ }^{89}$ See Host Country Approval India National CDM Authority <http://cdmindia.nic.in/host_approval_criteria.htm> at 1 January 2010.

90 The project should lead to real, measurable and long term GHG mitigation. Also, the procurement of Certified Emission Reduction (CERs) should not be from Official Development Assistance (ODA).

${ }^{91}$ Social well being: The CDM project activity should lead to alleviation of poverty by generating additional employment, removal of social disparities and contribution to provision of basic amenities to people leading to improvement in quality of life of people.

Economic well being: The CDM project activity should bring in additional investment consistent with the needs of the people.

Environmental well being: This should include a discussion of impact of the project activity on resource sustainability and resource degradation, if any, due to proposed activity; bio-diversity friendliness; impact on human health; reduction of levels of pollution in general.

Technological well being: The CDM project activity should lead to transfer of environmentally safe and sound technologies that are comparable to best practices in order to assist in upgradation of the technological base. The transfer of technology can be within the country as well from other developing countries also.

${ }^{92}$ It should confirm to the followings:

- Baselines should be precise, transprent, comparable and workable;

- Should avoid overestimation;

- The methodology for determination of baseine should be homogeneous and reliable;

- Potential errors should be indicated;

- System boundaries of baseline should be established;

- Interval between updates of baselies should be clearly described;

- Role of externalities should be brought out (social, economic and environmental);

- Should include historic emissiondata-sets wherever available;

- Lifetime of project cycle should be clearly mentioned
} 
In addition, the project proposal must clearly describe financial issues and technological feasibility involved in the implementation of applied project. Moreover, the project proposal should clearly state various risks associated with a project. Finally, establishing and implementing a CDM project in India must fulfill the legal requirements under the Indian domestic legal system.

The NCDMA is a single window clearance for CDM projects in the country. The below chart demonstrates procedure for applying for CDM projects in India.

\section{Chart 6.2 Procedures for Applying for CDM Projects in India}

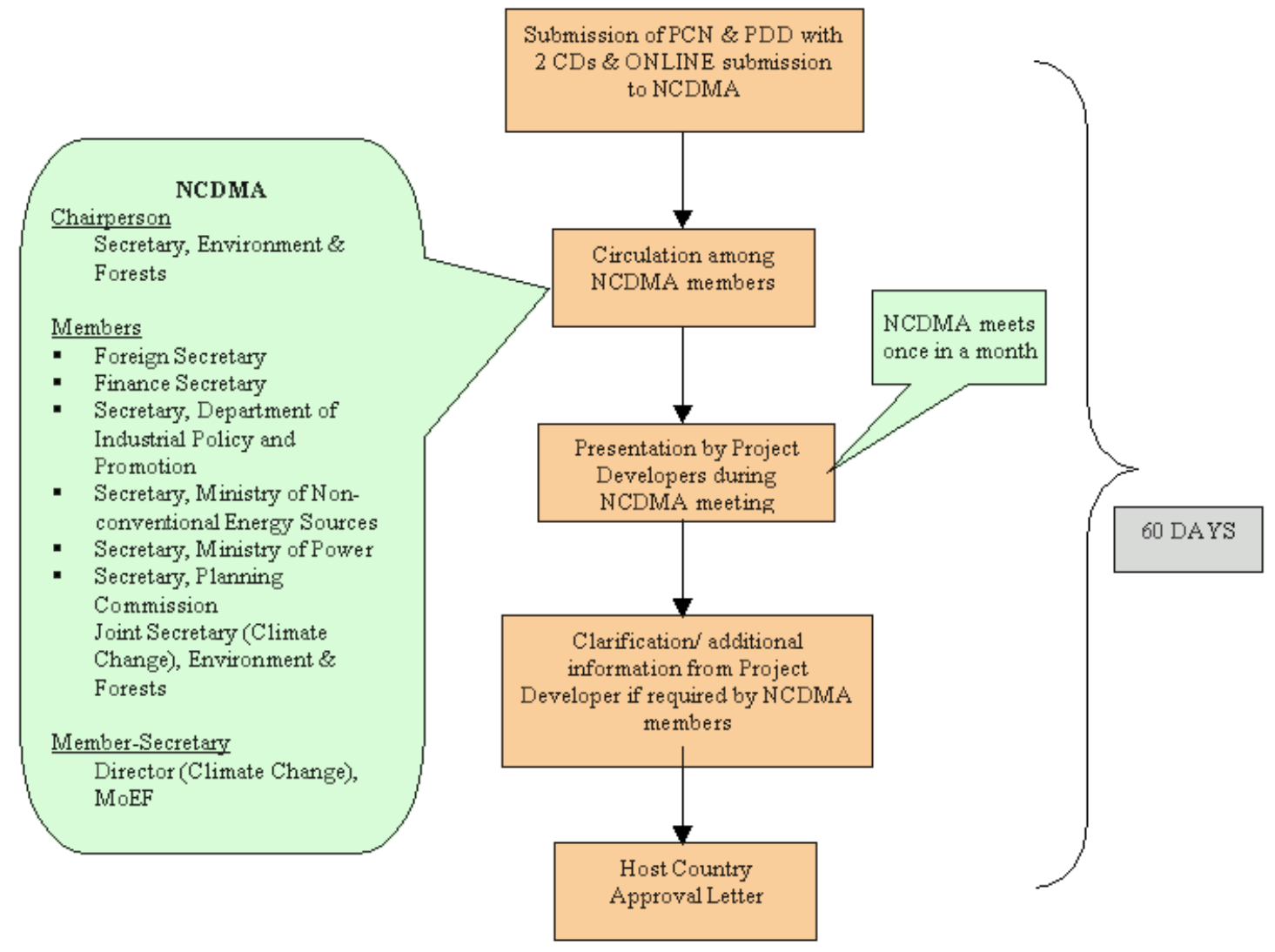

Source: CDM India <http://cdmindia.nic.in/host_approval_process.htm>

To start the application, the project proponents are required to submit one soft copy of 
Project Concept Note (PCN) and PDD through online form and 20 hardcopies each of PCN and PDD along with two CDs containing all the information in each of them. The NCDMA examines the documents and answers preliminary queries asked from the project proponents. After that, the project proponent and his consultants are required to give a brief power point presentation regarding their $\mathrm{CDM}$ project proposals at the Authority's regular meeting. The presenter should provide clarifications and information during the presentation in case the members feel that some additional clarifications or information is required. Once the members of Authority are satisfied, the Host Country Approval (HCA) is issued by the Member-Secretary of the National CDM Authority.

(2) CDM supporting legal frameworks in India

There is no specific CDM legislation in India. Nevertheless, India has in place a detailed policy, regulatory, and legislative structure that relates strongly to GHG mitigation and CDM implementation.

- National climate change plan

After China released its climate change action plan calling for improved energy efficiency and expansion of renewable and nuclear energy sources in 2007, India launched its first-ever climate change plan in June 2008. The India's National Action Plan on Climate Change (NAPCC) ${ }^{93}$ outlines existing and future policies and programs addressing climate mitigation and adaptation. The plan identifies eight core

\footnotetext{
${ }^{93}$ Above n 18.
} 
'national missions' for sustainable development running through 2017. These include solar energy, energy efficiency, creating a sustainable habitat, conserving water, preserving water, preserving the Himalayan ecosystem, creating a green India, creating sustainable agriculture and finally, a strategy knowledge platform for climate change. Among them, solar energy is particularly emphasized because of India's favourable climate for solar energy. Besides, the plan reiterates India's position that it is looking to technology for a solution, and not through any mandatory cuts. In this regards, there are no specific targets set for energy efficiency, solar power use or water conservation.

Since China and India are the only two developing countries that have released their national climate change plans, it is useful to compare them. The policy makers of Indian Government believe that India has a better climate change plan in comparison to China. They suggest that India has an evolved and far-sighted climate change policy than China in that its action plan focused on energy security and sustainable development while China's plan mainly focused on emission reduction. ${ }^{94}$

The plan also broadens the scope of potential CDM projects and thus may promote the development of CDM projects in India.

- Energy-related policies and laws

The India Government has released a series of policies and laws to enhance energy

94 'India's Climate Change is Better than China's', The Times of India (New Delhi), 30 July 2008. 
efficiency and promote renewable energy utilisation. The Integrated Energy Policy ${ }^{95}$ was adopted in 2006. Some of its key provisions are as follows: ${ }^{96}$

- $\quad$ promotion of energy efficiency in all sectors

- $\quad$ emphasis on mass transport;

- $\quad$ emphasis on renewables including biofuels plantations;

- $\quad$ accelerated development of nuclear and hydropower for clean energy; and

- $\quad$ focused R\&D (Research and Development) on several clean energy related technologies.

The New and Renewable Energy Policy $2005^{97}$ promotes utilisation of sustainable, renewable energy sources, and accelerates deployment of renewable energy through indigenous design, development and manufacture. The Energy Conservation Act $2001^{98}$ provides a legal mandate for the implementation of the energy efficiency measures through the institutional mechanism of the Bureau of Energy Efficiency (BEE) in the Central Government and designed agencies in each state. Under the Energy Conservation Act 2001, nine energy intensive industrial sectors in India are required to employ a certified energy manager, conduct energy audits periodically, and adhere to specific energy-consumption norms that may be prescribed. ${ }^{99}$ As for the institutional framework, the Ministry of Non-Conventional Energy Source

\footnotetext{
95 Integrated Energy Policy 2006 (the Government of India).

96 Above n 18, 18.

97 New and Renewable Energy Policy 2005 (the Government of India).

98 Energy Conservation Act 2001 (India)

<http://www.powermin.nic.in/acts_notification/energy_conservation_act/index.htm> at 9 October 2008.

99 Energy Conservation Act 2001 (India) ch II.
} 
(MNES), an independent ministry was formed by the Government of India to encourage renewable energy development in India through providing policy and support measures. The Indian Renewable Energy Development Agency Limited (IREDA), working directly under the MNES, was formed to finance renewable energy projects.

As well as this, the Indian Government applies financial incentives to promote energy efficiency and the development of renewable energy. Electricity Act $2003^{100}$, Tariff Policy $2003^{101}$ and Petroleum \& Natural Gas Regulatory Board Act $2006^{102}$ include several provisions relating to reforming energy markets. The provisions taken together are designed to ensure that energy markets are competitive, and energy prices reflect true resource costs.

Furthermore, independent laws and regulations are introduced. According to its national circumstances, electricity development is on the top of India's agenda. The Electricity Act 2003 has now been enacted to provide the entire legal framework governing the electricity sector. Under the Electricity Act 2003, there is no licensing requirement for power generation as long as the generating station complies with technical standards relating to grid connectivity. Instead, a generating company intending to set up a hydro-electric generating station would require the appropriate authority's approval. These plans must be planned give due attention to displacement

\footnotetext{
100 Electricity Act 2003 (2003 No. 03) (India) <aptel.gov.in/pdf/The\%20Electricity\%20Act_2003.pdf > at 9 October 2008.

101 Tariff Policy 2003 (the Government of India)

102 Petroleum \& Natural Gas Regulatory Board Act 2006 (2006 No 19) (India)

<indiacode.nic.in/fullact1.asp?tfnm=200619> at 9 October 2008.
} 
of people, the use/misuse of water bodies, destruction of water bodies, destruction of forests, and so on. ${ }^{103}$ Moreover, in order to reduce the carbon emissions, the Electricity Act 2003 and the National Tariff Policy 2006, provide for both the Central Electricity Regulatory Commission (CERC) and the State Electricity Regulatory Commissions (SERC), which have jurisdiction over the relevant power station of the generating company, to prescribe a certain percentage of total power purchased by the grid from renewable based sources. It also prescribes that a preferential tariff may be followed for renewable based power to the promotion of generation for electricity from renewable sources of energy. ${ }^{104}$ As for the technological support, the Rural Electrification Policy $2006^{105}$ promotes renewable energy technologies where grid connectivity is not possible or cost-effective. ${ }^{106}$

Building is another major contributor to energy consumption in India. Thus, a diverse portfolio of policy instruments would be required to address the barriers to efficient energy use in the residential and commercial sectors. An Energy Conservation Building Code $(E C B C)^{107}$ was launched in May, 2007, which addresses the design of new, large commercial buildings to optimize the buildings' energy demand based on their location in different climatic zones. The ECBC aims to reduce the baseline energy consumption by supporting adoption and implementation of efficiency savings and savings in GHG emissions. It has been estimated that if all the commercial

\footnotetext{
103 Jaya Singhania, 'Experiences with the Clean Development Mechanism in India' in David Freestone and Charlotte Streck (ed), Legal Aspects of Implementing the Kyoto Protocol Mechanisms: Making Kyoto Work (2005) $341,343$.

${ }^{104}$ See above n 18, 19.

105 Rural Electrification Policy 2006 (the Government of India).

106 Above n 18, 18.

${ }^{107}$ Energy Conservation Building Code 2006 (India) <www.hareda.gov.in/ECBC.PDF> at 9 October 2008.
} 
buildings in India every year conform to ECBC norms, energy consumption in this sector can be reduced by $30-40$ per cent. ${ }^{108}$ Compliance with ECBC norms is voluntary at present but is expected to become mandatory. Also, it has been incorporated into the mandatory Environment Impact Assessment (EIA) requirements for large buildings in India.

- Environmental policies and laws

There are several provisions in environmental policies and laws that may also affect the implementation of CDM projects in India.

The EIA provisions may promote environmental sustainability. The National Environment Policy $2006^{109}$, and the Notification on Environment Impact Assessment, $2006^{110}$, reform India's environmental assessment regime. Under the current regulatory framework, a number of economic activities are required to prepare environment impact assessments, and environment management plans, which are appraised by regulatory authorities prior to start of construction. In addition, the MoEF has developed a manual on norms and standards for environmental clearance for large construction projects after wide consultation with experts from different disciplines $^{111}$. The manual would be used as a technical guideline to assist the project proponents/stakeholders/consultants for the preparation environmental impact

\footnotetext{
108 Above n 18, 19.

109 National Environment Policy 2006 (the Government of India).

110 Notification on Environment Impact Assessment 2006 (the Government of India).

111 See, eg, 'Inviting proposals from consultants for preparing the following documents' (Solar Energy Division) 4 <www.mnes.nic.in/pdf/uica-solar.pdf> at 11 November 2008.
} 
assessments of projects and obtain environment clearance. ${ }^{112}$

Several provisions in the pollution laws in India may also affect the implementation of CDM projects. Under the Water (Prevention \& Control of Pollution) Act 1974 (Act No 6 of 1974) as amended in $1988^{113}$ and the Air (Prevention \& Control of Pollution) Act 1981 (Act No 14 of 1981$)^{114}$, there are several restrictions on use of certain industrial plants. They stipulate that any industry, operation or process that would bring pollution to water and air could not be operated without the consent of the State Board. Accordingly, all CDM projects must require a clearance from the relevant pollution control boards.

Forests constitute one of the most-effective carbon sinks. The afforestation process was accelerated by the enactment of the Forest Conservation Act $1980^{115}$, which aimed at stopping the clearing and degradation of forests through a strict, centralized control of the rights to use forest land and mandatory requirements of compensatory afforestation in case of any diversion of forest land for any non-forestry purpose. ${ }^{116}$ Furthermore, India also has a rapidly growing afforestation programme. The objective of increase in forest cover has been put in the India's National Plan. The final target of the $11^{\text {th }}$ Five-Year Plan (2007-2012) is to bring one-third of the geographic area of

\footnotetext{
112 Ibid.

113 Water (Prevention \& Control of Pollution) Act 1974 (Act No 6 of 1974) (India) as amended in 1988 <envfor.nic.in/legis/water/water7.html> at 11 November 2008.

114 Air (Prevention \& Control of Pollution) Act 1981 (Act No 14 of 1981) (India)

<envfor.nic.in/legis/air/air1.html> at 11 November 2008.

115 Forest Conservation Act 1980 (India) as amended in 1988 <http://envfor.nic.in/legis/forest/forest2.html> at 11 November 2008.

116 Above n 18, 17.
} 
India under forest cover while the current area under forest is 23 per cent. ${ }^{117}$

- Other regulations applicable to CDM projects

There are other regulations applicable to CDM projects and several legal provisions apply for direct foreign direct investments may also affect the development of the CDM projects in India.

First of all, direct foreign direct investments and equity interests in the energy sector (except for nuclear power) are not subject to any restrictions in India. As a rule, all the investors have to do is to notify the Reserve Bank of India of the capital transfer within 30 days. ${ }^{118}$

Second, there are no uniform regulations on the taxation of CER income in India. While there is no national tax on CERs so far, some federal states have introduced additional taxes. Companies should therefore make enquiries at the competent authorities on current legislation in the respective federal state before developing the CDM project in India.

Overall, the policy and legal initiatives in India are likely to favor CDM. Nevertheless, in order to protect the national interests, it will take some time before applying for implementing any kinds of CDM projects under the current legal frameworks in India. First, project developers must obtain general approval by different government departments such as the pollution control board, commission of industries, land

\footnotetext{
${ }^{117}$ Eleventh Five-Year Plan (2007-2012) (Planning Commission, Government of India) ch 6 <http://planningcommission.nic.in/plans/planrel/11thf.htm> at 11 November 2008.

118 Above n 76, 4.
} 
revenue department and so on. In addition, most of the CDM projects are required to submit an EIA report before commencement of any activity. This includes a demarcation of the area which would be affected by development of the project, environmental social and economic impact of the project, providing for mitigation measures for adverse impact within an affected area, and so on.

(3) CDM-related programmes in India

A number of schemes and programmes have been initiated to promote energy efficiency in India and thus may influence the implementation of CDM projects. The major programmes among them are as follows:

An energy labelling programme for appliances was launched in 2006, and comparative star-based labeling has been introduced for fluorescent tube light, air conditioners, refrigerators, and distribution transformers in order to accelerating the shift to energy efficient appliances. The labels provide information about the energy consumption of an appliance, and thus enable consumers to make informed decisions. ${ }^{119}$ The standards and labeling programme for manufacturers of electrical appliances is expected to lead to significant savings in electricity annually. ${ }^{120}$

In March 2007 the conduct of energy audits was made mandatory in large energy-consuming units in nine industrial sectors. ${ }^{121}$ These units are required to employ certified energy managers, and report energy consumption and energy

\footnotetext{
119 Above n 18, 19.

120 Ibid.

121 Ibid.
} 
conservation data annually.

The Bureau of Energy efficiency has introduced 'The Bachat Lamp Yojana', a programme under which households may exchange incandescent lamps for CFL (compact fluorescent lamps) using CDM credits to equate purchase price. Some states have made mandatory the installation of solar water heaters in hospitals, hotels and large government and commercial buildings. ${ }^{122}$

The Indian Government has also developed fiscal and financial instruments to promote energy efficiency. For example, subsidy is provided for installation of solar water heater in residential buildings. The Government applies differential taxation on appliances that have been certified as energy efficient through energy labeling programme. The energy efficiency financing platforms are initiated with a view to enabling public-private-partnerships to capture energy savings through demand side management ${ }^{123}$ programmes in the municipal, buildings, and agricultural sectors. Carbon finance through the CDM would also be relevant.

A market-based mechanism has been created to enhance cost effectiveness of improvements in energy-intensive large industries and facilities through certification of energy saving that could be traded. The Energy Conservation Act 2001 provides a framework to certify energy savings in excess of the mandated savings in large energy consuming industries and facilities, which have been notified as Designated

\footnotetext{
122 Ibid.

${ }^{123}$ It entails the actions that influence the quantity or patterns of the use of energy consumed by end users.
} 
Consumers. ${ }^{124}$ The certified excess savings may be traded amongst companies to meet their mandated compliance requirements, or banked for the next cycle of energy savings requirements.

It can be seen that the Indian Government, on the one hand, has formed its own strategies to promote energy efficiency, while; on the other hand, the CDM is expected to be made full use of to assist in realizing the energy efficiency objective.

\subsubsection{Empirical Analysis of the Performance of CDM Projects in India}

India has been taking part in the CDM implementation for more than five years. Thus, the CDM projects may have a certain influence on India. Against this background, this part conducts empirical analysis of the performance of CDM projects in India. General factors affecting the success of project operation in India are examined respectively. Subsequently, factors affecting sustainability benefits of CDM project in India are investigated in order to review the contribution of the CDM to sustainable development of India.

(1) Empirical analysis of the operation of CDM projects in India

The way to judge the success of CDM projects in India is to investigate whether the potential CDM projects could be registered by the CDM EB and could deliver the forecasted volumes of CERs as stated in the PDDs. Nonetheless, due to the time-consuming CDM project cycle and an internationally unprecedented set of rules, the implementation of the CDM project bear a number of serious pitfalls and

${ }^{124}$ Energy Conservation Act 2001 (India) the Schedule. 
underestimated risks at each stage. In this regard, the factors of the number of registered projects as well as the volume of issued CERs, time from project identification to project registration, project rejections or withdrawals rate and the ratio between actual CERs issued and estimated in the request for registration may reflect the operation of CDM project in India. Based on the above, these factors in the implementation of CDM projects in India are analysed and the corresponding influencing factors are discussed.

\section{- Quantitative research on CDM projects in India}

The number of registered projects and the volume of issued CERs are the most important indicator of the performance of CDM projects. The number of registered projects does not only reflect the overall state of CDM projects, but also demonstrates CDM awareness as well as capacity building. Also, the volumes of issued CERs reflect the quality of the registered CDM projects.

The major factors that affect the number of registered projects and the volumes of CERs in India may include: the Indian Government's efforts to promote the CDM, including CDM awareness enhancement and capacity building, the response from Indian entrepreneurs to the $\mathrm{CDM}$ as well as the current investment environment and CDM-related frameworks.

At the early development stage of the CDM, India dominated the carbon market in terms of the number of registered projects as well as the volume of issued CERs. Then, although India still led in the number of registered projects, China was at the forefront 
in terms of CER volumes. Nowadays, China dominates the carbon market, followed by India. ${ }^{125}$ Accordingly, the India Government is doing well in enhancing CDM awareness and promoting the potential projects developers to participate in the CDM and the domestic investment environment composing of specific taxes or levies on CDM projects and the energy, industry and other sector specific policies is relatively favourable in India. Where it is not doing so well is that the CDM projects in India have relatively low issued CERs compared to the projects number. According to the data released by UNFCCC, the main reason leading to the relatively low CERs is the large ratio of small-scale CDM projects in India, which in the same time encounter high transactions costs.

- Project lead time

Project lead time here is defined as the time period from the day when a CDM project is identified and the project registration date. The project lead times have an effect on the expected project start and may reflect whether the CDM project is smoothly developed in India. In other words, if there are more risks and pitfalls existing in the implementation of a CDM project in India, the longer lead times could be. Therefore, the CDM project lead times reflect implementation environment of the CDM projects in India.

Based on various project stages in India, the project lead times include the times spent on project identification, project design, project approval, project validation and

${ }^{125}$ For more details, see Chapter three 117-123. 
project registration. Thus, the domestic variables that may affect the project lead times include CDM awareness and capacity building in India, the domestic requirements for implementing the CDM projects, the performance of Indian DNA concerning project approval as well as the project types. Among them, the delays are most frequently related to the project types.

Longer delays of the CDM projects are not observed in India. ${ }^{126}$ There is encouraging response from Indian entrepreneurs to the CDM across different sectors. Besides, there is no complexity and duration of project approval process in India as India institutes a streamlined approval process. The in-country required permits and licenses are not so many that they are not likely to delay the development of the CDM projects in India so long. As for the project types, most of the projects in India are industrial, such as cement, energy efficiency and HFC gas, which are usually easier than renewable energy projects in that their baselines can be easier to calculate, ${ }^{127}$ and that the development of the industrial projects requires smaller investments and less governmental permits. As mentioned before, the portfolio is dominated by unilateral projects in India, which have on average shorter lead times than bilateral ones. Overall, India does not face a problem of project delay.

- Project rejection and withdrawal rates

Project rejection and withdrawal rates may reflect the potential CDM projects' quality and whether they could meet the international standards. According to the data

\footnotetext{
${ }^{126}$ Castro and Michaelowa, above n 70, 51.

${ }^{127}$ See ibid 38.
} 
released by UNFCCC website, India had hosted the most rejected and withdrawn projects until 2009. Some projects were rejected by the CDM EB and others were withdrawn by the project developers themselves, and thus never got registered. However, this situation has been changed when the CDM EB strengthens its supervision and more and more Chinese projects are rejected. ${ }^{128}$

Many factors, like the Indian Government's performance in appraising the applied CDM projects, consultants' expertise in the development of CDM projects and the project foreign partner's assistance, may affect project rejection rate. The project type, however, turns out to be the most decisive factor leading to rejection. The major of rejected projects belong to the energy efficiency category. Among the 33 rejected projects in India till October 2008, five of them were cement blending projects, which were all rejected due to insufficient demonstration of additionality. ${ }^{129}$ Also, the renewable electricity for the grid project is with the second highest share.

As for the withdrawal rate, India hosted 10 withdrawal projects till October 2008. ${ }^{130}$ The possible reasons leading to withdrawing are that the project developers encounter unexpected difficulties, which demonstrating the project participants failing to accurately estimate the potential CDM project before registering. However, 10 withdrawn projects were not so many when comparing the large number of registered projects in India.

\footnotetext{
${ }^{128}$ For more details, see Chapter five 281-3.

129 Above $n 66$.

130 Ibid.
} 
Accordingly, although India has many rejected and withdrawn projects, it cannot be concluded that the CDM projects in India do not perform as well as in other countries.

\section{- CER issuance rate}

CER issuance rate demonstrates the ratio between expected CER issuance volume and actual CER issuance volume, which reflects project success. In case the CER issuance rate is less than 100 per cent, there must be some factors or unexpected difficulties impeding the implementation of CDM project.

Based on different project development steps, a CDM project is supposed to go through a design stage, a DOE validation stage and a project operation stage, which may affect CER issuance rate. At the project design stage, project developers need to forecast the amount of emission reductions they will achieve in due time and justify the adopted methodology and monitoring plan concerning counting the emission reductions. Thus, the project developers' knowledge about the CDM and CDM consultant's participation play important roles in emissions reduction estimation. At the DOE validation stage, the DOE examines the CDM project PPD before submission for registration.

In this regard, the DOE's expertise in the CDM influences whether the emissions reduction could be accurately forecasted. In addition, various incentives are crucial for explaining overestimation before registration. As for CDM developers, they are likely to estimate more emissions reduction to attract foreign investors as the more emissions would be reduced in due time, the more profits would be made. Also, both 
the CDM consultants and DOEs have an economic connection with project developers. Thus, their judgment and examination about the CDM project are likely to be influential. Finally, at the project operation stage, various technical, financial and other unexpected difficulties may affect emissions reduction. In addition, the mode, type and size of CDM project and the type of project developers may also affect the CER issuance rate.

In terms of CER issuance rate, India has issued more CERs than expected so far. The most important reason for concern is that the major mode that having been issued in India is unilaterally. In this circumstance, project developers have no incentive to overestimate emissions reduction in order to attract foreign investors and thus are prone to forecast emissions reduction based on the objective technical and financial facts. Another important reason is the dominance of small-scale projects in India. In general, the smaller the project the better its performance regarding the CER issue rate due to the less complexity and financial support involved in them. Accordingly, relatively accurate emissions reduction estimation from the beginning of the CDM project may prevent the low CER issuance rate in the future.

To conclude, the CDM projects in India are with the characteristics of a large number of registered projects, relatively low issued CERs compared to the projects number, relatively short project lead time and high CERs issuance rate.

(2) Empirical analysis of the sustainability benefits of CDM projects in India The CDM also bears the aim of promoting sustainable development in developing 
countries. In this regard, it is necessary to analyse the sustainability benefits of implementing CDM projects in India with a view to examining the CDM's sustainability contribution to India.

India does not have any specific indicators for making the assessment of CDM project's contribution to sustainable development. However, since the goal of poverty alleviation lies at the core of the country's priorities, the India National CDM Authority specially emphasizes that ' $\mathrm{CDM}$ projects should be oriented towards improving the quality of life of the poor from the environmental standpoint ${ }^{131}$. Moreover, the criteria it utilises for approving the potential projects relate to social, economic, environmental and technological well-being aspects. ${ }^{132}$ Based on that, this section discusses the performance of the CDM projects through examining CDM's contribution to cost-effective reduction of GHG emissions, technology and capital transfer from industrialised countries to India and poverty alleviation.

- Cost-effective reduction of GHG emissions

With the rapid economic development and large demand for electricity, India is expected to generate enormous GHGs in following decades. Actually, the CDM, which was supposed to reduce emissions, is subsidizing the fossil-fuel industry in India. The plant that has the potential to generate the largest GHGs may become the biggest winner under the CDM.

\footnotetext{
131 See above n 89.

132 See above n 91, 51.
} 
Taking a case study, there is a huge controversy over India's Tara Power. The wider Tara group has an appalling environmental and human rights record across the India-with controversy currently raging around its Tara Nano factory in West Bengal, where six farmers committed suicide, allegedly after their land was acquired for the plant. In addition, it is building one of the world's largest coal-fired plants in Gujarat, which, when it becomes operational, will pump put 23.4 million tonnes of $\mathrm{CO}_{2}$ a year. ${ }^{133}$ The International Finance Corporation, which is helping to finance the plant, claims that it will emit 3.6 million tonnes less of $\mathrm{CO}_{2}$ each year than any other subcritical coal plant in India. If it was able to sell those reductions at current market prices, it could earn about 70 million Euros per year. ${ }^{134}$ Obviously, it is not an economically struggling company that needs additional revenue streams to upgrade and improve its technological efficiency. On the contrary, large amount of $\mathrm{CO}_{2}$ generated becomes an advantageous factor for Tara Power to make huge profits, which are even bigger than the investment in innovating clean technologies. Consequently, the Tara Power is bound to continue to follow the current production mode.

It can be seen that CDM project, under the current operational rules, has its limitations in promoting effective GHG emissions reduction in India. Stringent measures are expected to ensure additionality of any potential CDM project.

\section{- Capital transfer}

As mentioned previously, the Indian CDM sector is mostly composed of small- to medium-sized efficiency projects requiring low levels of upfront investment. In this

\footnotetext{
${ }^{133}$ Kevin Smith, “'Clean development” supports dirty energy' (2008) <http://www.carbontradewatch .org> at 7 November 2008.

134 Ibid.
} 
case, India fails to adequately attract foreign investors with public financing for large-scale CDM projects.

In addition, the CDM project portfolio is dominated by unilateral projects with the investors being Indian parties. In this circumstance, most of the CDM developers use domestic financial resources rather than foreign investment. Consequently, large capital transfer brought by CDM implementation is not happening in India.

- Technology transfer

As introduced before, the CDM portfolio is dominated by unilateral projects in India. Thus, most of the investors are Indian parties, employing locally available technologies. As a result, although this has provided a significant impetus to local innovation, the CDM has not led to the technology transfer from industrialised countries to developing countries envisaged by the Protocol.

- Poverty alleviation

According to the India Government, the goal of social well-being criterion of sustainable development has been elaborated as alleviation of poverty by generating additional employment, removal of social disparities and provision of basic amenities to people leading to improvement in quality of life of people. Based on that, the three conspicuous factors that reflect the CDM's contribution to poverty alleviation in India may include:

- the employment opportunities provided by the development of CDM projects; 
- $\quad$ supplementation of the poor income, especially agricultural income; and,

- $\quad$ improved availability of electricity as in the studies on infrastructure in dealing with poverty problems, where electrification emerged as an important infrastructure component in dealing with poverty problems ${ }^{.135}$

As mentioned before, renewable energy, particularly renewable biomass power through agricultural wastes, has the dominant share in CDM project portfolio in terms of number of projects in India. This is because first, the biomass energy project has the capacity to generate direct and indirect employment in developing CDM projects, which may include the construction and operation the related plant and collection and transportation of the biomass from fields to the plant site. The biomass energy project also has the capacity to generate additional income to farmers through sale of crop residues and other biomass, which was otherwise being under-utilised or burnt due to its negligible commercial value. ${ }^{136}$ With the aim to sell generate and sell electricity, the biomass energy project also has the capacity to provide more electricity. Therefore, it can be said that the CDM projects may have a certain positive effect on poverty alleviation in India.

Overall, the CDM is not contributing to promoting sustainable development to any notable extent in India. No real reduction of GHG emissions, transfer of technology or transfer of capital has taken place.

\footnotetext{
135 Smita Sirohi, 'CDM: Is it a "win-win” strategy for rural poverty alleviation in India Published' (2007) 84 (1) Climate Change 91, 103.

136 Ibid 94.
} 


\subsubsection{India beyond 2012}

(1) International pressure

Based on the fact that rapid economic growth and a huge population in India mean this country will be contributing more to the growth of emissions than developed countries beyond 2012, most developed countries say that meaningful change cannot happen without the robust participation of India and China. Therefore, India is also under the great international pressure to address climate change and is expected to take on heavy responsibility to reducing anthropogenic GHGs beyond 2012.

\section{(2) Domestic position ${ }^{137}$}

However, on the domestic front, on a per person basis, India still produces far fewer pollutants and gases than developed countries, and thus it argues that this is how its contribution to climate change should be judged. Thus, based on the moral ground that its people have the same right to wealth as anyone, India strongly advocates an equity principle and common but differentiated responsibilities and respective capabilities principle in addressing climate change issues. India insists its long-held stance that the developed countries should affirm their responsibility for accumulated GHG emissions and fulfil their commitments under the UNFCCC to transfer new and additional financial resources and climate friendly technologies to support both adaptation and mitigation in developing countries. Meanwhile, India focuses on poverty eradication and improved standards of living and claims that its per capita GHG emissions will at no point exceed that of the developed countries even as it

\footnotetext{
${ }^{137}$ For more details, see Chapter five 291.
} 
pursues development objectives. Therefore, India should not be expected to take on binding emissions reduction obligations in the post-2012 period.

(3) Current actions for adaptation and mitigation

The current actions for adaptation and mitigation in India are relatively transparent. The India government clearly expresses how much it spends on climate change issues. Current government expenditure in India on adaptation to climate variability exceeds 2.6 per cent of the GDP, with agriculture, water resources, health and sanitation, forests, coastal zone infrastructure and extreme weather events, being specific areas of concern. $^{138}$

\subsection{A Comparative Study}

It can be inferred from the above statement and analysis that, as another major developing country, India has many similarities as well as differences with China with regard to the CDM-related issues.

First of all, India's basic national circumstances are similar to China's. With the large population, India's GDP growth rate has averaged roughly eight per cent in the consecutive five years, which makes India the second fastest big emerging economy after China. Despite the phenomenal rate of economic growth, India is still a poor country. Moreover, wealth distribution in India is fairly uneven and nearly half of the population is still without access to electricity. Therefore, electricity popularity, poverty eradication and living standards improvement are also the priorities in India.

\footnotetext{
138 Above n 18, 17.
} 
Second, India has been identified as one of the global hotspots likely to be worst affected by climate change because the agricultural sector plays an important role in its economy. Furthermore, India's tropical climate is ideal for the deployment of solar generation capacity. Thus, India has the potential to generate power from solar energy.

Third, India is also regarded as another so-called 'major emitter' due to the fact that blistering economic growth and huge population in India and China mean these countries are contributing more to the growth of emissions than developed countries. However, on a per-person or cumulative basis, both nations still produce far fewer pollutants and gases than developed countries, and China and India argue that this is how their contribution to climate change should be judged. What is more, compared to China, India has even lower historical and per capita $\mathrm{CO}_{2}$ emissions. Based on that, India argues that neither the total volume of its $\mathrm{CO}_{2}$ emissions nor its per capita emissions today, would qualify it for the category of 'major emitters'.

Fourth, India was the world's biggest beneficiary of CDM project till 2007, when it was overtaken by China. Compared to China, the CDM projects in India are with the characteristics of the relatively large number of CDM projects, fewer issued and expected CERs, and much more small scale and unilateral CDM projects. Moreover, India lags much behind China with regard to CERs transactions in the global carbon market as a result of high price expectation for CERs in India.

Fifth, the India Government has also created a favorable investment and legal environment for implementing CDM projects. Although there is no CDM specific 
regulation in India, the policy and legal initiatives in India are likely to favor the CDM development. Currently, China and India are the only two developing countries have their own specific policies targeting climate change. After China released its first-ever climate change policy in 2007, India launched it climate change plan in June 2008. As Indian Prime Minister watched China become the largest global producer of solar panels in the last decade, he has realized that India's tropical climate is ideal for the deployment of solar generation capacity. Thus, the NAPCC was released, focusing on solar energy for power generation, which has the potential to become large-scale $\mathrm{CDM}$ projects and attract foreign investment. Besides that, a series of schemes programmes have also been initiated to promote the CDM in India.

Particularly, India has relatively flexible requirements for CDM projects. Compared to China, there are no uniform regulations on the taxation of CER incomes, bottom price requirement for selling CERs or particular requirements for CDM participants in India. But India has clear sustainable development standards. According to the domestic CDM approval procedure, Indian DNA thus far has not seen its role as providing a PDD quality check, but a strongpoint of the Indian CDM is the speedy appraisal of project sustainability. By contrast, the project developers have to fulfill a list of requirements in China. In addition, many enterprises in India are showing their interest and there are a large number of CDM consultants and developers. Accordingly, in light of the CDM awareness, China lags behind India. 
However, there is a problem in India. The CDM developers in India have to pay a success fee to CDM consultants as it is common now in most large CDM host countries $^{139}$ while Chinese DNA has prohibited consultant to take a success fee. The success fee, which is charged when additional consulting services, such as supplementary assistance in validation and registration or searching for prospective emission certificate buyers are needed, is likely to make the project lose reliability and objective in respect to the additionality criterion. This is because if the consultant is paid a success fee, he may have a particular interest in assisting the proposal project in successfully getting the registration. As a consequence, the financial incentive is likely to affect the consultant's objective assessment of the project.

Sixth, with regard to the performance of implementing CDM projects in both countries, India lags behind China in promoting clean technology and attracting financial support because most of the CDM projects in India are small-scale and unilateral. The unilateral project developed by domestic enterprises and without foreign partners cannot bring clean technology transfer and foreign investment. Moreover, the small-scale CDM project does not need so much upfront capital to support its development.

Finally, India is also under the great pressure to reducing emission beyond 2012 which is also the focus of negotiations on mitigating global warming for the post-2012 era. According to its national circumstances, India has its own stance on

\footnotetext{
139 Above n 76, 4.
} 
climate change issues in the post-2012 period. India claims that it should never be considered as a large emitter and is not prepared to accept any limitation on its carbon emissions in post-2012 period. Instead, it is looking for technology as a solution, and not any mandatory cuts. China, with relatively faster economic growth rate, more historical and per capita energy carbon emissions, however, is perceived to be taking the problem more seriously than India. In spite of reluctance of accepting mandatory reduction target, China and India are both concerned with rising emissions, and each country is trying to do something about it. Each country has made a series of rigorous policies, programs and laws and regulations aimed at promoting energy efficiency and renewable energy utilisation.

Generally speaking, China has already surpassed India regarding CDM project development, performance and management. As the major developed countries, both countries have the similar position on climate change issues beyond 2012. China, however, is expected to take on more pressure to reducing emissions.

\subsection{What Can Be Learned From India}

Although China has dominated the CDM regime, it could also critically draw lessons from and draw on the experience of implementing CDM projects and addressing climate change issues in India, due to the similarities regarding CDM and emission reduction between both countries. Therefore, based on the above introduction and analyses of the CDM in India and a comparative study, the aspects that China can learn from India are as follows: 
First, the development of CDM projects in India reflects the fact that the CDM awareness is relatively high in India. Even since the early development phase of CDM, India enterprises began to take part in the CDM projects with great enthusiasm. Moreover, the Indian Government has created a favorable financial environment which may facilitate the implementation of CDM projects. The National bank and other private banks in India can provide financial and advisory services to support the CDM projects. Furthermore, the Indian Government has a streamlined CDM approval process, which saves the project lead time.

Second, the Indian DNA has set up sustainable development criteria for CDM projects approval and is able to appraise the project sustainability speedily. Nevertheless, the $\mathrm{CDM}$ is not contributing to promoting sustainable development to any notable extent in India. This is because the dominance of small-scale and unilateral mode of CDM projects in India could not bring large amount of upfront investment and clean technology transfer. In addition, CDM per se has its own limitations in realizing sustainable development in developing countries. Under this circumstance, it can be seen that government's rational management of the development of CDM projects is essential and indispensable. The government is supposed to provide guide and assistance to attract foreign investment and promote clean technology through optimizing the development of CDM projects. Moreover, in order to minimize the negative aspect of implementing the CDM projects in the long term and address climate change, the government must rely on itself and adopt a series of policies, programs and laws and regulations aimed at raising energy efficiency and promoting 
renewable energy utilisation.

Third, the Indian Government does well in learning other countries' experience and is able to correspondingly adjust its national policy and strategy. For instance, as India saw China make full use of regional natural resources advantages to develop the CDM projects, it realised that India's tropical climate is ideal for the deployment of solar generation capacity. Thus, the India's NAPCC was released focusing on solar energy for power generation, which has the potential to become large-scale CDM projects. In addition, India fails to adequately attract foreign investors with public financing and promote clean technology. Facing this situation, India has studied China's blueprint for drawing foreign investment into clean technology through setting up the Carbon Fund, and the results are encouraging.

Finally, besides legal measures, the Indian Government does well in inspiring public participation in CDM projects and the programs addressing climate change. For example, the Bureau of Energy Efficiency in India has introduced a program under which households may exchange incandescent lamps for energy efficient lamps using CDM credits to as part of the equate purchase price. In addition, India has relatively transparent and clear policies and actions for adaptation and mitigation, making public how much it spends on adaptation to climate change issues. 


\section{Chapter 7 Conclusion and Recommendations: How Provide for Better Implementation of the CDM in China?}

\subsection{Introduction}

Based on the previous chapters, it can be concluded that the CDM is well developed in China, and that China has also benefited from undertaking CDM projects. In spite of this encouraging situation, there are still many barriers as well as risks throughout the implementation of CDM projects in China as a result of its complicated, time-consuming and detailed operational rules and procedures. In addition, due to its inevitable shortcomings as an emerging mechanism, the CDM is criticised for having limited contributions to China's sustainable development in the long term. Moreover, as the expiration of the first Kyoto period is looming, the international climate change legal regime and the CDM are likely to be changed. In this scenario, China, as the major emitter and developing country, is expected to take on more responsibilities to combating global warming in the post-2012 period and thus will be under considerable pressure to reduce carbon emissions without undermining its economic development.

Against this backdrop, China, on the one hand, should continue to further develop the CDM with a view to obtaining the associated benefits of sustainable development that could be obtained through CDM projects. It would be thus necessary for China to focus on reducing the various barriers and risks that are likely to occur throughout the 
project implementation. On the other hand, due to the limitations and shortcomings of the current CDM, it should be considered as a complementary tool for China to realise its sustainable development. Thus, it is necessary for China to have its own strategy towards promoting sustainable development in the long term. Moreover, China must prepare itself for the challenges beyond 2012.

This chapter aims to explore how to provide for better implementation of the CDM in China. Part two discusses how to improve the implementation of CDM projects in China through exploring the possible solutions to overcoming barriers and reducing risks in implementing CDM projects. Part three analyses how to make full use of the CDM in China and cope with the limitations of the CDM on promoting sustainable development in China in the long term. Part four suggests what China should do to meet the challenge of climate change issues beyond 2012. Part five indicates further questions which may arise from the CDM development and climate change issues, suggesting further investigation.

\subsection{Improving the Implementation of CDM Projects in}

\section{China}

In order to ensure the quality of CDM projects, a set of rigid operational rules and procedures are set up by the international community. Consequently, various barriers to the implementation of CDM projects as well as many risks in each CDM development stage might be encountered. The potential barriers and risks as well as influence factors have been identified in the previous parts of 3.5 and 4.6 
respectively. ${ }^{1}$ Some of these barriers and risks are inevitable and are caused by deficiencies of the international operational rules while some of them can be reduced or mitigated by establishing favorable domestic legal and investment environments.

\subsubsection{General Requirements for Improving CDM Projects in China}

The CDM is capable of making a meaningful contribution to sustainable development in China. To achieve this, it is necessary to reduce the complexity and set a basic standard for the ideal CDM project development mode. Based on the above, the ideal CDM project development in China should at least include the following three characteristics:

- Potential eligible CDM projects can be successfully identified.

- CDM projects can obtain registration without delay, rejection or withdrawal.

- The registered CDM projects are able to generate the CERs as expected.

In order to improve the implementation and ensure the smooth operation of CDM projects in China, China needs to create a favorable environment with a view to supporting the implementation of CDM projects. Generally speaking, the domestic environment for CDM includes several components that may be described as follows: a natural resources aspect, an awareness aspect, an institutional aspect, a legal aspect, a financial aspect, and a technical aspect.

First of all, one of the most important factors that may decide the implementation of CDM projects in China is natural resources distribution. Natural resources distribution

\footnotetext{
${ }^{1}$ For more details, see $136-44$ and 247-58.
} 
causes the different development of CDM projects in different regions of China. For example, wind power CDM projects dominate the North-western China because the North-western China abounds with wind resources, while hydropower CDM projects dominate Central China and Northern China because both regions contain many lakes. Local governments should therefore play an important role in assisting in identifying the potential CDM projects according to their resources advantages.

Second, in order to promote the development of CDM projects in China, awareness of the CDM regime and CDM opportunities must be enhanced not only by the Chinese Government, but also the energy-related companies, while service agencies need to promote the CDM and appreciate the range of benefits the CDM would bring to them. Only under this circumstance, can CDM projects be fully developed in China.

Third, the performance of Chinese central and local institutions for the CDM can also influence its implementation. The Chinese DNA functions as a CDM project approval institution. In this regard, its work efficiency of approving a proposed project influences the lead time of that project. Also, review and examination of a proposed project by the DNA are beneficial to guarantee the quality of that project and thus avoid high rejection or withdrawal rates. Moreover, the DNA and provincial CDM service centres' performance on publicising the CDM-related information and promoting the implementation of CDM projects is also considered as an essential factor in improving the CDM development in China.

Fourth, a stable and clear legal environment is needed to attract foreign partners to 
invest in CDM projects. Most of the CDM projects have a long operational cycle and thus, foreign investors prefer to invest in a country with a stable as well as favourable legal environment that could protect their legitimate rights and interests. In this regard, the Chinese Government should make the CDM-related legal framework clear and consistent over the whole project cycle.

Fifth, one of problems existing in implementing CDM projects in China is the lack of upfront investment. Basically, developing a CDM project can involve a large amount of funds. Although potential CDM projects could be readily identified, some of them found it difficult to proceed because the project developers were unable to obtain sufficient funds to support project design and application. Facing this situation, the Chinese Government should create a favourable financial investment environment for CDM project owners. Therefore, a CDM specific funds as well as a carbon trade loan system should be established to encourage and promote CDM investment opportunities.

Finally, the requirements and operational rules of CDM projects are too complicated and technical and hence, the lack of CDM-related expertise has been an essential factor affecting the implementation of CDM projects. Having sufficient technical capacity to implement $\mathrm{CDM}$ projects could reduce project lead time, ensure the quality of projects and reduce rejection and withdrawal rates. This would enable appropriate monitoring plans to be formulated and thus generate the expected CERs.

To conclude, the requirements for improving the implementation of CDM projects in 
China include high CDM awareness and CDM technical capacity, significantly better performance of the Chinese Governments at different levels on managing and promoting CDM projects and more favourable legal and financial environments.

\subsubsection{Managing Risks throughout the Implementation of CDM Projects in China}

The risks that may arise at the different stages in the development of CDM projects in China have been identified and analysed in Part 4.6. This part discusses how to minimise or share these risks among CDM projects participants in China.

(1) Managing the risks at stage one: CDM project preparation and design

The major risks arising at stage one are mainly caused by delay or discontinuation of project design due to the lack of CDM-related information or technical support. In this respect, there are several measures suggested to mitigate the potential risks.

First, energy-related companies in China are the major players in CDM implementation. Thus, their CDM awareness is crucial. The Chinese Government, especially the local governments, should play a positive role in enhancing CDM awareness. It should not only fully publicise the CDM, but also need to create an information platform for CDM participants in order to facilitate the implementation of the CDM projects. In this way, potential CDM projects will be more likely to be identified and successfully implemented.

Second, project owners tend to delay or discontinue project design due to the lack of 
technical support to complete a monitoring plan and PDD as required. In this circumstance, in order to mitigate this risk, it is necessary to enhance the technical capacity of project owners in China; on the other hand, the project owners in China may also share this risk with CDM-related service agencies. Accordingly, aside from enhancing the technical knowledge about CDM implementation in China, project owners could also take the service contract with CDM-related service agencies more seriously. Respective responsibilities and rights of both parties and how disputes arising from CDM services would be resolved should be carefully discussed under the contract.

Third, project owners are expected to take the major risks at stage one. Alternatively, the risks could be shared with foreign partners in cases where the project owner finds appropriate foreign investors. To encourage a sharing of the risks included, the Chinese Government should create a favourable legal and financial environment to attract foreign investors.

(2) Managing the risks at stage two: CDM project application and registration

The risks at stage two are that CDM developers in China will not able to obtain the approval from the Chinese DNA, validation from the DOE or registration from the CDM EB. The major actors involved at stage two include the Chinese DNA, CDM project developers and DOEs. With a view to mitigating these risks, each actor need to take the following responsibilities:

First, the Chinese DNA has two tasks when examining a proposed CDM project. One 
task is checking whether the proposed project meets sustainable development criteria and domestic legal and policy requirements; the other task is ensuring the quality of the proposed project. Thus, the sustainable development criteria and approval procedures and requirements for CDM projects should be clear, standard, transparent and available to project developers. In addition, the CDM approval process should be streamlined in order to shorten the project lead time. The Chinese DNA could also play an important role in examining whether the proposed projects are eligible as CDM projects and thus could reduce project rejection or withdrawal rates. In light of the importance of the Chinese DNA's obligations to ensure the quality of the projects, the technical capacity and expertise of its staff and the experts involved in the approval process need to be improved and guaranteed. Finally, due to the uncertainty surrounding the continuation of the CDM in the post-2012 period, the Chinese DNA must provide timely updates of the CDM-related information for CDM developers and provide relevant and necessary assistance to ensure proper implementation of CDM projects.

Second, in order to successfully obtain the approval from Chinese DNA and the validation from the DOE, CDM developers should understand the domestic legal requirements for implementing $\mathrm{CDM}$ projects in China as well as the necessary international requirements and operational procedures. Moreover, the project developers need to have a contract with a DOE to validate their proposed project before registration. 
However, they are likely to encounter barriers to validation as a result of the shortcomings of DOEs discussed earlier, ${ }^{2}$ language barriers to communication and unfavourable circumstance for Chinese project owners caused by European additionality standard adopted by most of the DOEs. In these circumstances, the best way for $\mathrm{CDM}$ developers to mitigate these risks is to fully understand the international requirements and operational procedures as well as to benefit from the lessons learned from earlier successful CDM projects. In addition, the project owners may make an agreement with their foreign partners to share these risks.

(3) Managing the risks at stage three: CDM project operation

The major risks arising at stage three occur mainly when the registered CDM projects cannot operate as planned, which is mainly caused by unexpected changes happening during project operation. In this circumstance, the measures that could possibly mitigate the risks are as follows:

First, in order to smooth the CDM project operation in China, it is necessary to ensure the financial support. Currently, there are two ways for project owners in China obtaining required capital. One way is through foreign partners' investment in CDM projects and another way is through a financial loan from bank. Thus, contracts are needed to specify each party's rights and obligations and provide legal support for financial assistance.

Second, in order to make CDM projects operate as planned, project developers must

\footnotetext{
${ }^{2}$ For more details, see Chapter two 69-70.
} 
ensure that the necessary technology for a project could be successfully transferred and distributed. In this regard, the contracts between project owners and foreign partners must specify the relevant provisions and respective rights and obligations concerning the transfer of technology and know-how before operating the project.

Finally, as mentioned previously, a typical CDM project could generate up to 30 years worth of credits. ${ }^{3}$ Thus, unexpected changes are likely to happen during the long project cycle. In this circumstance, project owners may share the potential risks as a result of unexpected changes with foreign partners or other project participants such as project constructors through stipulating the items regarding sharing these risks in different types of contracts.

(4) Managing the risks at stage four: CER issuance and transaction

The major risks at stage four are caused by the fact that project owners could not successfully generate or deliver sufficient CERs as planned. As a result, there would be various disputes arising between project owners and their foreign investors. There are several measures below that could be utilised to mitigate and solve the disputes.

First, an unstable social and/or legal environment in China and unexpected changes occurring throughout project implementation are likely to bring about a reduction in CERs generation and delivery failure. Apart from the unforeseeable factors, the main reason might be the inappropriate monitoring plan in PDD, which could make project owners spend considerable time on adjusting the monitoring plan and reporting to

\footnotetext{
${ }^{3}$ For more details, see Chapter two n 71.
} 
CDM EB. In this circumstance, it could be very difficult for project owners to generate the amount of CERs required in the credit period. Facing this situation, project developers along with the CDM-related service agencies should make appropriate monitoring plans according to the specific circumstances.

Furthermore, thoughtfully negotiated and designed EPRA may play a positive role in mitigating the potential risks and distributing the potential risks as well as obligations between project owners and foreign investors. Many key legal issues such as the objectives of contract, legal title to CERs, transfer of legal title to CERs, quantity and purchase price of CERs, liability and indemnities and disputes resolution should be discussed and specifically stipulated in the agreement.

\subsubsection{Overcoming Barriers to the Implementation of CDM Projects in}

\section{China}

It is impossible to accurately figure out the real problems in and barriers to the actual implementation of CDM projects in China only with document review and analysis. For this reason, the author conducted a field work study in China with a view to obtaining first hand information on the CDM implementation by contact with those who involved in the actual implementation of CDM projects. More than $30 \mathrm{CDM}$ participants participated in the written survey and interview. ${ }^{4}$ According to the results of field study, the existing major barriers to implementing the CDM projects in China are identified below.

\footnotetext{
${ }^{4}$ For confidentiality reason, the participants do not want their names and identities to be disclosed.
} 


\subsubsection{Existing Major Barriers to CDM Project Implementation in China}

(1) CDM projects identification

Although CDM awareness in China has been enhanced in recent years and more and more energy-related companies has begun to realize the commercial benefits that could be realised by the $\mathrm{CDM}, \mathrm{CDM}$ project identification remains a major barrier to implementation. The barriers to project identification can be divided into two categories. One category is that potential CDM projects cannot be identified or the project owner does not realise what constitutes an eligible CDM project; the other category is that the project has been identified, but the project owner does not have sufficient information, or technical or financial capacities to further develop the project.

(2) Demonstration of additionality

The demonstration of additionality is a weak point in the implementation of CDM projects in China. There are many reasons for that. One of the reasons for concern is that the current additionality standard adopts European standard, which does not conform to the common practice of project development in China. Another reason for concern is the lack of the high technical capacity needed to fulfill the demonstration of additionality.

(3) DOE's unsatisfactory performance

Problems with the DOE per se also cause barriers to CDM projects in China. First, the current staffing of the DOE is too small to meet the need of rapid processing of CDM 
projects. As a consequence, many proposed $\mathrm{CDM}$ projects in China are delayed waiting for validation from the DOE. Moreover, the performance of the DOE is highly variable and there are questions about the qualification of its staff. Furthermore, there is a language barrier for CDM developers in China in communicating with the DOE as most of them are from Europe and Japan.

(4) An increase in the rejection and withdrawal rates of CDM projects in China An increase in the rejection and withdrawal rates of CDM projects in China has been noted. Basically, there are three major reasons for concern leading to this situation. First, more and more Chinese energy-related companies have begun to realise the commercial benefits that may be realised by the CDM, and thus the total number of the projects in China to be certified under the CDM increases. Second, the CDM EB has strengthened the management and supervision of the $\mathrm{CDM}$ in response to questions about CDM's contribution to addressing climate change and the quality of the registered projects. Finally, with the passage of time of the CDM, its operational rules and procedures become increasingly rigid and complete.

(5) Unexpected changes in project operation

CDM project developers may encounter various difficulties in project operation. The major barrier is unexpected changes which do not conform to the PDD in project operation. It often requests project developers to adjust their project operational plans and report to the $\mathrm{CDM} \mathrm{EB}$, thus prolonging project operational cycle and raising the potential risks. 
This is because in order to obtain the project registration as quickly as possible, some project developers or CDM service agencies who have not fully understood the CDM processes are likely to make inappropriate project operation and monitoring plans that cannot actually conform to the circumstances of project operation. As a consequence, it is very difficult to operate some CDM projects in practice and verify the carbon credits as planned. In addition, the long project development cycle could also lead to unexpected changes in practice.

(6) Low project CERs issuance rate

As mention previously, compared to other major developing countries, CERs issuance rate of CDM projects in China is relatively low. ${ }^{5}$ The noticeable gap between actual CERs and expected CERs may bring about liability caused by delivery failure. The project developers may therefore be in breach of their obligations to the CERs purchasers under the ERPA and may face penalties under that agreement. ${ }^{6}$

There are three reasons for concern leading to the low project CERs issuance rate in China. First, project developers or CDM service agencies may overestimate the amount of CERs that would be actually generated when designing the project in order to attract foreign investors. Second, the project cannot perform as expected and generate CERs due to the inappropriate monitoring plan in PDD. Finally, the DOE's tendency to overestimate the expected CERs is another cause for concern. Project owners present the expected CERs volume, which may be overestimated. DOE is

\footnotetext{
${ }^{5}$ For more details, see Chapter three The CERs of CDM Projects in China 121.

${ }^{6}$ It also varies to the different contracts.
} 
employed and paid by project developers. Under this apparent conflict of interest, the DOE is not willing to object to a project developer and is likely to approve the estimation of CERs in PDD.

Overall, the major existing barriers to $\mathrm{CDM}$ projects in China are caused by unfavourable factors set out above as a result of the international CDM operational rules and procedures per se, insufficient knowledge about CDM and carbon markets and insufficient technical and financial capacities. To mitigate these barriers, there are nevertheless some legal strategies that could be employed.

\subsubsection{Legal Strategies for Barriers Mitigation}

(1) Regulating the CDM-related service industry in China

The major barriers to CDM projects in China are attributed to lack of the expertise of project developers and unregulated CDM-related service industry. As referred to above, the CDM operational rules are extremely detailed and technical. Furthermore, the CDM project developers usually do not have the corresponding technical capacity and practical experience to implement CDM projects in China. Consequently, the project developers tend to leave the processing of CDM project application to the CDM-related consulting service agencies. In this regard, the CDM-related service industry is deemed as a significant part in CDM project implementation in China.

To deal with this situation, the Important Declaration of Standardization of Consulting Service and Appraisal Work for CDM Projects in China (hereinafter 
referred to as the Declaration) was issued by the Office of the National Coordination Committee on Climate Change in February $2006 .{ }^{7}$ The Declaration is mainly aimed at regulating the behaviour of the CDM-related service agencies concluding a contract with project developers for directly sharing CERs or the proceeds of transferred CERs with the project implementation ${ }^{8}$ and the other behaviours that violate the Measures. The CDM is developing rapidly in China and it is an inevitable and long-term trend to reduce carbon emissions through carbon trading. In this scenario, it is necessary to enact a series of comprehensive and compulsory professional standards for the CDM-related service industry. The Declaration has limited binding effect in China (of low legal effect) ${ }^{9}$ and can no longer meet the demand of CDM projects development in China. Therefore, it is urgent and necessary to set up legitimate and legally binding standards for the CDM service industry with a view to regulating and ensuring service quality of CDM service and highly qualified staff.

(2) Regulating financial support for CDM projects in China

Lack of funds for CDM projects implementation is another major factor leading to the barriers to CDM projects. The cost of implementing CDM projects is too high and financial issues are most likely to frustrate the project developers. As a result, it is necessary to ensure the financial support for CDM projects in China.

\footnotetext{
${ }^{7}$ Important Declaration of Standardization of Consulting Service and Appraisal Work for CDM Projects in China 2006 (issued by Office of the National Coordination Committee on Climate Change of the People's Republic of China) <http://cdm.ccchina.gov.cn/UpFile/File630.PDF> at 28 May 2009.

${ }^{8}$ This behaviour is in violation of Article 24 of the Measures. In this circumstance, the service contract must be cancelled within two months of the date of issuing the Declaration.

${ }^{9}$ For details, see Law on Legislation 2000 (the People's Republic of China) art 7. See also Chapter four 245.
} 
The Chinese Government has set up the China CDM Fund aimed to provide long-term financial support for CDM projects and other projects addressing climate change. ${ }^{10}$ Although the nature, purpose, structure and other general issues about the CDM Fund are clear, the detailed rules for implementation and management, the details about the fund are not transparent and public. Therefore, detailed management measures should be formulated in order to ensure financial support for CDM projects. In addition, the Chinese Government must provide various opportunities for eligible CDM developers to access the financial support. The CDM specialized loan needs to be set up by state-owned or private banks in China. Meanwhile, the corresponding management rules should also be established.

\subsection{Dealing with the Limitations of the CDM in Promoting Sustainable Development in China}

It can be concluded from the previous part of Chapter five that, although the CDM has brought and is expected to bring considerable benefits to China, its limited and in some cases negative impacts may affect China's sustainable development in the longer term. ${ }^{11}$ China should therefore, on the one hand, rely on other measures to realize sustainable development, while, at the same time, making full use of positive contribution of properly administrated CDM projects. There are some measures that can be taken to deal with the limitations of the CDM.

\footnotetext{
${ }^{10}$ See China Clean Development Mechanism Fund <http://www.cdmfund.org/\#>.

${ }^{11}$ For more details, see Chapter five, Limitations of the CDM in Promoting Sustainable Development in China Beyond 2012, 299-303.
} 
(1) Setting up clear sustainable development standards

Although China has played a leading role regarding CDM implementation, there are no clear criteria for examining the contribution of proposed CDM projects in China. Mandated in the Kyoto Protocol it is within the prerogative of Designated National Authorities (DNA) for non-Annex I countries to confirm whether a CDM project assists in achieving sustainable development or not. ${ }^{12}$ This means that actual definitions of what constitutes sustainable development vary according to what different countries consider as their development priorities. Therefore, it is of great significance for the Chinese Government to set up clear sustainable development standards when approving the proposed projects in order to ensure the CDM's contribution to sustainable development in China. According to China's national circumstances, sustainable development standards for CDM projects in China contain four factors.

\section{- Economic Indicator}

The principal priority for China at this stage is to alleviate poverty and to further develop its economy. In this sense, CDM projects must be beneficial for China's economic development. In other words, the CDM project activities should bring in additional investment and could promote economic well being in China.

\section{- Environmental Indicator}

Environmental problems are critical in China. Thus, sustainable development in China

\footnotetext{
12 Modalities and procedures for a clean development mechanism as defined in Article 12 of the Kyoto Protocol, Decision 17/CP.7, $8^{\text {th }}$ plen mtg, para 5 (2001).
} 
will not be realised without environmental protection. In this regard, the CDM project activities should promote environmental well being. It should not only bring carbon emission reductions to help address climate change but should also not have any negative impact on the other environmental issues. The project developers must discuss the potential environmental impact of the project activity before applying for government approval of a CDM project.

\section{- Social Indicator}

In spite of rapid economic development, China still faces great social problems, which include widespread economic disparity in different regions as well as significant employment pressure caused by huge population. Therefore, the CDM must be beneficial to assist in addressing these social problems in China by bringing in foreign investment and clean technology in less developed regions, generating additional employment, and improving the quality of life of people.

\section{- Technological Indicator}

Clean technology is no doubt a key factor leading to sustainable development. Thus, the CDM projects are supposed to promote the transfer of environmentally sound technology throughout China.

(2) Effective management of CDM projects

CDM projects inevitably possess economic attributes as the CDM is a market-based mechanism. For this reason, most CDM developers undertake the projects with a view to pursuing maximum commercial benefits rather than focusing on the need to address 
climate change and promote sustainable development in China. Government intervention is therefore needed to adjust the conflict between public interests and private interests. Accordingly, the Chinese Government should play an active role in mitigating the limited or negative impact of the CDM projects on China's sustainable development in the long term through providing effective management and regulation. The effective management and regulation of the CDM projects in China can be realised through regulating participation eligibility of CDM projects, government overseeing of CDM projects and managing CDM projects through financial measures.

\section{- Regulation on project participation eligibility}

According to the relevant regulations of the Measures about participation eligibility of CDM projects in China, foreign companies can only hold a maximum of a 49 per cent ownership stake in CDM projects in China. ${ }^{13}$ Although the regulation is made with a view to maintaining the controlling interest of Chinese CDM developers in implementing the CDM projects, it is not necessarily beneficial in promoting clean technology transfer.

Foreign partners have expressed their concern about this restriction. ${ }^{14}$ European companies are major buyers of China made CERs. The EU is also the largest source of China's technology imports. ${ }^{15}$ However, European companies hope that restriction

\footnotetext{
${ }^{13}$ See Measures for the Operation and Management of CDM projects in China 2005 (the People's Republic of China) art 11.

${ }^{14}$ See, Transnational Review Mechanism Pursuant to Paragraph 8 of the Protocol on the Accession of the People's Republic of China, WTO Doc G/TRIMS/W/60 (2008) (4) (Request to the Delegation of the European Communities - Communication from the European Communities).

15 See, European Communion Trade <http://ec.europa.eu/trade/creating-opportunities/bilateral-relations/countries/china/> at 28 May 2009.
} 
be relaxed. According to Ambassador Serge Abou, Head of a Delegation for the European Commission to China, they would be more willing to bring the most advance technologies to China only when they can participate as the controlling party to protect their intellectual property rights. ${ }^{16}$

Based on the above and given the importance of the clean technology to sustainable development in China, the Chinese Government should extend the requirement for participation eligibility of the specific CDM projects that could bring advanced clean technology to China.

\section{- Government overseeing CDM projects}

The Chinese Government may regulate the development of CDM projects in China and promoting sustainable development in the long term through providing guidance on project scope, scale, operational model and geographic distribution.

As mentioned above, project developers tend to pay attention to the economic benefits that result from CDM projects while ignoring the other aspects that would affect sustainable development in China. For example, projects that reduce end-of-pipe emissions of HFC-23 or $\mathrm{N}_{2} \mathrm{O}$ in industry accounted for large a part of CERs from Chinese registered CDM projects due to their short cycle time, large volumes of credits for a low capital investment and mitigation cost and relatively straightforward additionality assessments. However, this type of project cannot bring long-term benefits to China. Accordingly, the Chinese Government encourages the development

\footnotetext{
${ }^{16} \mathrm{He}$ said this at a press conference in Beijing for the Second EU-China High-level Economic and Trade Dialogue held in Brussels on May 7 and 82009.
} 
of the projects belonging to energy industry. ${ }^{17}$ Thus, the Measures clearly states that 'the priority areas for CDM projects in China are energy efficiency improvement, development and utilisation of new and renewable energy, and methane recovery and utilisation. $^{, 18}$

Besides the project scope, the Chinese Government should also provide guidance on project scale and operational model. Compared to the projects in India, although India had the largest number of CDM projects, it always lags much behind China regarding generated CERs. The main reason for this is the large ratio of small and medium-sized CDM projects in India. Thus, in order to successfully implement CDM projects in China, the Chinese Government should encourage the eligible large-scale energy-related companies to take part in the CDM. Also, a role that small and medium-sized CDM projects play in emission reduction should not be neglected and the Chinese Government may promote the development of these projects by employing sectoral CDM approach and/or programmatic CDM approach.

Moreover, large capital transfer and technology transfer resulting from CDM projects is not happening in India as the CDM project portfolio in India is dominated by unilateral projects with the investors being Indian parties. In this circumstance, most of the CDM developers use domestic financial resources and locally available

\footnotetext{
${ }^{17}$ For example, the Chinese government imposes different ratios of tax to encourage the energy sectors. Article 24 of the Measures stipulates that ' (1) the Government of China takes 65\% CER transfer benefit from HFC and PFC projects; (2) the Government of China takes 30\% CER transfer benefit from $\mathrm{N}_{2} \mathrm{O}$ project; (3) the Government of China takes $2 \%$ CER transfer benefit from CDM projects in priority areas and forestation projects.'

<http://cdm.ccchina.gov.cn/english/NewsInfo.asp?NewsId=905> at 9 October 2009.

${ }^{18}$ See Measures for the Operation and Management of CDM projects in China 2005 (the People's Republic of China) art 4.
} 
technologies rather than foreign investment and transferred technology. Based on that, the Chinese Government should encourage the development of multilateral CDM projects in order to attract foreign investment and clean technology to promote sustainable development.

Finally, CDM projects should be fully utilised to reduce the economic disparity in different regions of China. This is because some impoverished regions in China abound with favourable natural resources conditions that could attract foreign investors to undertake the $\mathrm{CDM}$ projects. In this regard, the Chinese Government should pay attention to the geographic distribution of the CDM projects and encourage the development of the $\mathrm{CDM}$ projects in these regions. The local governments in particular are supposed to assisting in identifying and implementing the CDM projects according to their local circumstances.

- Management of CDM projects through financial measures

In addition to the above measures, the Chinese Government may mitigate the negative impact of implementing CDM projects on sustainable development in the long term through the adoption of financial measures and incentives.

It has intervened in the CDM market through imposing tax on proceeds from the transfer of CERs. ${ }^{19}$ In order to regulate the scope of the CDM projects and promote the development of the CDM projects in energy-related areas, the Government of China takes two per cent CER transfer benefit from CDM projects in those areas

\footnotetext{
${ }^{19}$ See Measures for the Operation and Management of CDM projects in China 2005 (the People's Republic of China) art 24.
} 
while 65 per cent and 30 per cent from HFC project and N2O project respectively.

In addition, the Measures clearly states that ' $\mathrm{CDM}$ project activities should promote the transfer of environmentally sound technology to China. ${ }^{20}$ To this end, the Chinese Government may adopt favourable financial policies for the developers of the CDM projects that could bring the transfer of environmentally sound technology to China. These policies may include preferential imported duty, income tax and loans for this type of the CDM projects.

(3) Legal strategy for CERs

The Chinese Government could also mitigate the limitations of the CDM in promoting sustainable development in China in the long term by creating an appropriate legal framework.

As analysed in Chapter four, the current Chinese legal system has not clearly defined the legal nature or ownership issues of the CERs. ${ }^{21}$ However, in light of efforts to reduce GHGs and the possibility of carbon trading in the future, it is necessary to ensure the legitimate interests and rights of affected parties. In addition, the private ownership of CER is likely to exert certain negative impact on both social and technological benefits in China.

Based on the above reasons, the emission reduction resource should firstly be clearly defined as a natural resource. Second, in order to avoid a negative effect caused by

\footnotetext{
${ }^{20}$ See Measures for the Operation and Management of CDM projects in China 2005 (People's Republic of China) art 10.

${ }^{21}$ For more details, see Chapter four 234-8.
} 
pursuing maximum economic benefit and balance the public and private interests, the public ownership of the CER should be established. Given the paramount legal level of the Constitution ${ }^{22}$, the reduction resource should be owned by the state and meanwhile the Chinese Government should represent the state to provide the management of the emission reduction.

\subsection{Meeting the Challenges in the Post-2012 Period}

Based on the tendencies of international climate change policy in the post-2012 period and the considerable pressure that China will face, it is inevitable for China to accept carbon emissions limit in the future because it has been the largest emitter and major developing country. The CDM, however, even with its shortcomings and limitations, could be regarded as a complementary tool for China to assist it in realising its sustainable development. Therefore, China should have its domestic strategies to deal with climate change in the long term. The only way for China to meet the climate change challenge beyond 2012 is to develop a low carbon economy. Decoupling the growth of carbon emissions from economic development is challenging but achievable in China. ${ }^{23}$ Accordingly, this part discusses the various pathways that would lead to low carbon development in China.

(1) Taking immediate action to address climate change in China

It is necessary for China to attach great importance to and take immediate action to

\footnotetext{
${ }^{22}$ Constitution of the People's Republic of China 1982 (the People's Republic of China), last amended in 2004.

${ }^{23}$ China can Achieve Low Carbon Growth (2009) Economic \& Social Research Council

< http://www.esrc.ac.uk/ESRCInfoCentre/PO/releases/2009/april/china.aspx> at 3 March 2010.
} 
address climate change issues. First, scientific evidence has confirmed that the climate change would have an irreversible adverse impact on China. ${ }^{24}$ Second, China, with surging economic development and therefore a major emitter, has been under the great international pressure to reduce carbon emissions. In addition, China must pay serious attention to the Stern Review Report ${ }^{25}$, which was released in 2006 and is the most comprehensive review ever carried out on the economics of climate change. It states that if countries don't act and spend money on adverting climate change now the world will face a depression worse than that of the $1930 \mathrm{~s} .{ }^{26}$ China is with no exception. Although China's economy is developing at an incomparable rate in the world, this economic advance is at the expenses of environmental interests. In this circumstance, if China does not take immediate action to address climate change, it will spend even more money to compensate for the adverse impacts of climate change in the future.

Therefore, climate change should be put at the top agenda of China and China should take immediate action to address climate change.

The actions of addressing climate change in China may include both minimising its

\footnotetext{
${ }^{24}$ It should be noted that although the IPCC report is supposed to be the world's most authoritative scientific account of the scale of global warming, it has been recently subjected to the criticism that the 2007 report overstates the dangers of climate change as a result of use of unreliable evidence. For example, the panel had based claims about disappearing mountain ice on anecdotal evidence in a student's dissertation and an article in a mountaineering magazine. Consequently, the panel was forced to issue a retraction after it emerged statements about the melting of Himalayan glaciers were inaccurate.

<http://www.telegraph.co.uk/earth/environment/climatechange/7177230/New-errors-in-IPCC-climate-change-repo rt.html> at 5 February 2010.

${ }^{25}$ Nicholas Stern, 'Stern Review on the Economics of Climate Change' (British government, 2006), <http://webarchive.nationalarchives.gov.uk/+/http:/www.hm-treasury.gov.uk/independent_reviews/stern_review_e conomics_climate_change/stern_review_report.cfm>at 13 December 2009.

${ }^{26}$ See Rafael Epstein, 'Stern Report warns of huge costs of climate change', ABC, (London), 30 October 2006 <http://www.abc.net.au/am/content/2006/s1776326.htm> at 2 July 2007.
} 
impact and adapting to its inevitability. In additional, the action should not only be taken by the Chinese Government but also the whole society: The common Chinese people's behaviour and thinking can largely influence climate change mitigation as China is a populous country. In this regard, the climate change issue in China cannot be solved without public commitment. Finally, the human-induced climate change is a complex system, which cannot be settled by an single solution. Therefore, the Chinese Government should take various measures, including technological measure, legal measure as well as financial measure, to combat climate change.

(2) Making appropriate climate change policy

- Proactive climate change policy

Generally speaking, China has played a positive role in addressing climate change and has made a series of climate change-related policies although the government has refused to consider a fixed cap on emissions. However, the problem of the current strategy of China on Climate change is that the strategy is short-term, temporary, and transitional, which is for the period up to 2010. There is no long-term vision and target yet as well as no clear, long-term negotiation plan.

Based on the above and in light of the lasting impact of climate change, China should have its own solutions to climate change, which have to be sustainable in both economic and environmental terms. It is necessary to get a consensus within China of long-term strategy of climate change first and clearly define targets and a roadmap of priority actions. 
- Coordinated climate change policy

In addition, due to the complexity and diversified impact of climate change, the Chinese Government should develop a coordinated strategy for climate change. First, China should coordinate economic development with emission reduction. The maintenance of economic growth is a key to the ability to develop and implement effective policies to minimise the impact of climate change and adapt to its inevitability. To achieve this, China should adhere to industrial development with the basic goal of saving energy and reducing emissions. Meanwhile, technological, environmental and social aspects should also be fully considered when developing these strategies.

Second, China should coordinate and integrate its energy efficiency policy with its climate change policy. It has been confirmed that climate change is prominently caused by increase of human induced carbon emissions. In this regard, the climate change issue is closely related to energy utilisation. Therefore, improving energy efficiency is a key factor in addressing climate change.

Third, the Chinese Government should provide guidance to local governments, the corporate sector as well as individual citizen as to how daily behaviour could be integrated with climate change policy in order to address these issues in a systemic way.

Finally, the climate change policy should also contain both domestic efforts and international negotiation and cooperation. Climate change is a universal problem, 
which can not be solved by any single country. Therefore, China, on the one hand, should make both domestic efforts to reduce carbon emissions, and would also actively participate in international climate change policies regimes and make use of international cooperation. In this regard, both the domestic efforts and international cooperation should be coordinated into its climate change policy.

\section{(3) Setting up clear reduction targets}

In order to effectively implement the climate change policy, the Chinese Government should set up clear carbon emission reduction targets and an appropriate regulatory regime to ensure compliance and accountability.

First, the Chinese Government should make a long-term carbon emission reduction target. The overall long-term target should be divided into several short-term targets at particular stages. Meanwhile, the whole target can also be divided into several targets and distributed to the local governments and related coal power plants.

Second, in order to achieve the reduction targets, a clear responsibility system should be established. The local governments at different levels should assume more local autonomy over climate change issues. China has proposed a new promotion system under which local officials' careers will be judged by their performance in meeting clean development and energy efficiency targets rather than merely by economic performance. Thus, the focal point is ensuring that this system will be strictly enforced. In addition, energy-related companies should also take on reduction responsibility according to their reduction targets and the contracts of responsibility 
should be signed and enforced. The entrepreneurs should integrate climate change into their risk management strategies and manage to achieve their targets through adjusting production; correspondingly, the government should provide supporting policies to reward or punish the companies.

(4) Raising sustainability awareness

In order to effectively combat climate change and ultimately realize sustainable development, sustainability awareness must be raised. Global warming as a result of GHG emissions are resulted from unsustainable production and consumption pattern. The seriousness of emerging climate change issues calls for new thinking and social change. The Chinese population should, over time more fully understand the meaning of sustainable development and harmonious coexistence between man and nature.

In order to raise sustainability awareness, the Chinese people firstly need to know how serious the impact from climate change is likely to be and how drastically it could affect them. The Chinese Government should assume the major responsibly of publicising its seriousness and urgency. Various channels, including media, education and training, could be utilised. Meanwhile, the influence of environment-related NGOs should not be neglected and/or suppressed in China. Furthermore, Chinese people also need to know the important role they may play individually in climate change mitigation and what they should do to address climate change. Individuals should be encouraged to realise a new consumption pattern in order to promote an energy-saving society; companies must begin to assume more environmental 
responsibilities and endeavour to reduce GHG emissions in the most cost-effective way; the whole society should focus systematically on establishing new environmental values, which reflect the thinking of harmonious coexistence between man and nature.

(5) Promoting public participation and freedom of information

Public participation in environmental issues in China is relatively weak compared to developed countries. Accordingly, the Chinese Government should promote public participation in environmental issues and encourage the common people to make their due contributions to addressing the impacts of climate change.

China is used to applying a top-down approach to deal with environmental issues, including climate change. As a consequence, the central government, local governments and public's efforts to combat climate change have not been well coordinated. The Chinese Government has released a national plan for climate change whilst local governments have not provided adequate support for climate change mitigation and the general public have not fully realised the seriousness of climate change issue. Facing this situation and due to the huge population, the bottom-up approach should be strengthened across climate change issue in China. The role that the public may play in addressing climate change in China should be enhanced.

Access to environmental information is one solution to the current dilemma, and could lead to a positive interaction between the government and the public. Meanwhile, openness of climate change-related information is a prerequisite for 
public participation in climate change mitigation. Releasing the relevant information can let the public understand the inherent dangers associated with climate change, and take part in monitoring both the governments and industry's efforts. Companies should therefore be encouraged and to take action to reduce carbon emissions and governments at different levels to take responsibility for dealing with climate change.

Access to climate change-related information could be realised through the following three aspects.

First, the Chinese Government should release and update the relevant information and increase official transparency in a timely manner. The precondition of releasing the information is how to guarantee the quality of information. Thus, the relevant departments should have sufficient funding, equipment and capacity to access to the information. To this end, the Chinese Government should first lay emphasis on and should provide sufficient financial and technological supports for exploring the relevant information. In addition, the Chinese Government should increase official transparency in order to demonstrate that the released information is factual and have statistical backup. In particularly, the Chinese Government's efforts and how the money has been used to address climate change need to be disclosed for public scrutiny.

Second, commercial enterprises need to make public the records of their commercial activities that could impact on the climate and their environmental impact assessment. In order to ensure the reliability of the information given by these enterprises, there 
should be a neutral assessment agency undertaking the job of independently evaluating and supervising the environmental impact of their activities.

Finally, NGO's role in climate change issue should be enhanced in China. Critical information has been collected by NGO. Thus, NGOs and the Chinese governmental organizations should participate in communication to sharing available environmental information. It would be beneficial for promoting official transparency in China and meanwhile ensuring the factual source of information.

(6) Promoting clean technology development

Advanced clean technology, such as renewable energy, energy efficiency, and carbon storage and sequestration, is no doubt one of the key solutions to a low carbon economy. Thus, China should endeavour to promote technical innovations in industry as well as introducing foreign technologies through international assistance and international cooperation. Due to the limitations of technology transfer and diffusion, however, China should focus on self-innovation rather than over-reliance on technology imports to achieve the clean development.

On this basis, self-innovation should be taken as the main and sustainable drive for economic development in the course of importing foreign technologies. However, the inadequate investment in self-innovation in China has held back the country from faster industrialization. The investment in research and development in some industries in China is about 10 per cent of the level in the developed nations. ${ }^{27}$

\footnotetext{
27 This is according to the blue paper issued by the Chinese Academy of Social Sciences (CASS) on 1March 2009.
} 
Therefore, China should, on the one hand, manage to attract foreign clean technologies and know-how through creating favourable legal and financial investment environment, while on the other hand, enhance investment in clean technologies in order to strive for its own breakthrough in a clean development. Furthermore, China should step up efforts to raise the energy utility efficiency and reduce emission through industry restructuring and by update techniques.

(7) Applying various economic measures

The seriousness of the climate challenge will require a profound economic transformation, including in those sectors that carbon market cannot easily reach. ${ }^{28}$ These include making public and private investments in research and development for clean technology development and diffusion, economic and fiscal policy changes, as well as the programmatic approaches to decouple economic growth from emissions development.

- Establishing a domestic carbon trading scheme

Carbon trading has been considered as a cost-effective way to reduce carbon emission. China, as a major player in the global carbon market, has benefited a lot through taking part in the CDM projects. In spite of the uncertainty in the post-2012 period, reducing carbon emissions is the inevitable trend as global warming has been confirmed to be an indisputable fact. Therefore, even if the CDM does no long exist beyond 2012, there must be another more effective emissions trading mechanism or

\footnotetext{
${ }^{28}$ Karan Capoor and Philippe Ambrosi, 'State and Trends of the Carbon Market 2007' (The World Bank 2007) 7.
} 
scheme replacing the current CDM. In this regard, China should establish a nationwide carbon trading scheme in order to make full use of carbon markets to meet the challenge of reducing carbon emissions in the post-2012 period.

The aim of the domestic carbon trading scheme is to provide an economic incentive for reducing emissions. Under the scheme, different provinces and regions would be allocated their reduction targets according to the regional circumstances and contributions to carbon emissions. The provinces that have surplus reductions would be able to earn money from those regions that fail to achieve reduction targets.

Three domestic environment and energy exchanges were launched in Shanghai, Beijing and Tianjin in 2008. ${ }^{29}$ However, designing and implementing the domestic emission trading scheme still involves lots of major work. A local environment exchange could fully play its role as a market platform bringing together domestic and foreign companies, agencies, banks and investment banks in the carbon market. A local exchange could also create a convenient platform for the future domestic carbon trading. Moreover, it could also promote China's participation in the global carbon market by reducing the transaction cost and bringing more transparency to CER pricing.

\section{- Improving a Climate Investment Funds}

Besides the commodities emissions markets, China could also establish climate change funds to promote clean development. China has already set up a Clean

\footnotetext{
${ }^{29}$ See, Shai Oster, 'China Expand Markets for Carbon Trading', The Wall Street Journal (The US), 11 November 2008, A11.
} 
Development Mechanism Fund, which collects carbon credit transaction income and donations from international financial organisations and individuals and is aimed to assist in promoting and supporting climate change-related projects. ${ }^{30}$

In order to meet the challenge of large-scale carbon reductions in the post-2012 period, China should further enhance the investment in research and development for clean technology development and diffusion and the support for other climate change-related activities. The source of funds could be through various channels and be more extensive. International and domestic financial organizations as well as private or public agencies could also be considered as the potential sources of funds. Furthermore, the management of the funds should be improved. More importantly, the transparency of source and utilization of the investment should be strengthened.

\section{- Introducing a carbon tax}

Imposing a pro rata carbon tax on coal and fossil fuels has emerged as an incentive mechanism for curbing emissions in China. The basic proposal of the carbon tax is for China to impose a tax on burning fossil fuels in proportion to the carbon content of the fuels. The effectiveness of the carbon tax would not only rest on promoting carbon reductions, but also on its contribution to addressing climate change as a source of revenue, which is needed by the Chinese Government.

As mention previously, 'made in China' has brought about both a 'lock in effect' and

\footnotetext{
30 The China-U.S. Low Carbon Development Cooperation Program was recently launched by the Washington-based United States National Center for Sustainable Development and representatives from various Chinese government agencies, including the China CDM Fund Management Center with a view to posing financing solutions towards sustainable development. .
} 
'leakage problem' to China. ${ }^{31}$ The products made in China have competitiveness in global trading markets because of cheap prices, which are much cheaper than the real cost as the environmental cost is not included. Thus, it makes foreign investors cheaply utilize raw materials in China and aggravates the problem of GHG emissions. Facing this situation, it is necessary to change from 'made in China' to 'designed in China' and therefore ensure that the prices of the products reflect the real cost. Introducing a resources tax, including carbon tax, is a more effective way to reflect the real cost.

Under the scenario of imposing a carbon tax, given the increased cost resulting from a carbon tax, industry will be encouraged to utilise low carbon-emitting fuels and therefore improve energy efficiency; on the other hand, the governments could apply the revenue from imposing a carbon tax to invest in climate change-related activities.

However, there are two concerns about the introduction of carbon tax to China. One is how to regulate and monitor the implementation of carbon tax and the other is how the revenue from a carbon tax will be used. First, the tax rate should set high enough to effectively reduce carbon emissions. Otherwise, the emitters would rather pay tax than spend money on reducing emissions. Second, it should be noted that the more successful the carbon tax is in reducing carbon emissions, the less revenue will be collected. Thus, the objective of impose a carbon tax in China must be clarified.

- Utilising other incentives

\footnotetext{
${ }^{31}$ For more details, see Chapter five 295-7.
} 
Other economic measures that would promote carbon emissions reduction could also be utilized. First of all, these measures should be able to encourage commercial enterprises and the public to realize the importance of clean development and take part in the emission abatement actives could be implemented. Second, these measures should be able to assist in decoupling economic growth from emissions growth.

(8) Adjusting the current legal system

China could also meet the challenge of global warming in the post-2012 period through adjusting the current legal system. Although China has enacted a series of laws and regulations to deal with climate change, it still lacks a basic energy law to provide long-term and comprehensive legal support for emission reduction activities. Furthermore, the enforcement of climate change and energy-related laws needs to be enhanced in China. This is because some of these laws and regulations are stringent and appear effective, but in reality they are rarely applied and totally ignored in the less developed western and central provinces and municipalities.

- Enacting a basic energy law

China now has four energy laws, covering the coal, electric power, energy conservation and renewable energy sectors. ${ }^{32}$ However, based on both the international and the domestic circumstances, these laws fail to meet the requirement to cope with climate change in the long term. Due to the fact that the complicated

\footnotetext{
${ }^{32}$ For details, see Chapter four Energy-Related Legislation 170-5. These laws are Electricity Law of the People's Republic of China 1996, Energy Conservation Law of the People's Republic of China 1997, Renewable Energy Law of the People's Republic of China 2005, and Law of the People's Republic of China on the Coal Industry 1996.
} 
international climate change regime poses new challenges to China's energy and economic development, China lacks a basic energy law which reflects the energy strategy and policy orientation and coordinates ties between energy and energy-related activities comprehensively. Accordingly, it is of great significance to enact a basic and comprehensive law with a high legal level to deal with the dilemma.

- Enhancing the enforcement of climate change-related legislation

As analysed in the Chapter four, although the Chinese Government has strengthened environmental protection through revising the existing legislation and restructuring environmental management institutions, the enforcement of climate change-related legislation remains a weak point in China.

Facing this situation, the Chinese Government has made a great effort to enhance the enforcement of environmental legislation. In order to further strengthen the enforcement of climate change-related laws and regulation, a new and independent Ministry of Energy should be established to coincide with the introduction of the basic energy law. A unified and independent energy agency is essential to the proper and efficient oversight and administration of the energy sector in China.

In summary, climate change will result in critical and urgent challenges for China. According to its national circumstance, China could meet the climate change challenges through the following steps: taking immediate action to address climate change in China, making appropriate climate change policy, setting up clear reduction targets and a regulatory regime for enforcing these targets, raising sustainability 
awareness, promoting public participation and freedom of information, promoting clean technological development, applying various economic measures and adjusting the current legal system.

\subsection{Further Investigation}

This thesis discussed the legal issues for implementing the CDM in China. In order to obtain a deeper understanding of the issues involved, it will be imperative to conduct further study into the legal issues for domestic carbon trading and voluntary, or verified emission reductions (VERs) markets in China. Whatever the CDM will be beyond 2012, reducing emissions through trading is most likely to remain as the global warming is an indisputable fact and substantial emissions reduction is necessary. Furthermore, it has been proved to be a cost-effective way to reduce emissions. In this case, carbon emission will become a China's new major financial product as China has large potential for carbon emissions and considerable pressure to reduce emissions. Especially, China has already established a carbon emission trading system led by three domestic exchanges. Therefore, carbon emission trading in China will play an important role in reducing emissions in the future. However, China still lacks a corresponding legal system to support the domestic carbon markets.

In addition, as mentioned in Chapter five, China's and the US will play a decisive role in designing a post-2012 framework and addressing global warming. Therefore, the further study may also focus on the cooperation between China and the US in dealing with climate change issues and a comparative study with each country's policies and 
laws on climate change and their respective financial market mechanisms and instruments. 


\section{Appendix One}

\section{Interview Questions for CDM-related Officials}

1. Would you please let me know the current situation of the development of CDM projects in China?

2. What do you think is the most important factor deciding the success of implementing CDM projects in China?

3. Why the developments of CDM projects in different provinces are so different?

4. How come that Hubei Province lags behind other provinces in developing CDM projects?

5. What do you think is the most difficult part in the process of implementing CDM projects in China?

6. Do you think the government has played a positive role in promoting the CDM in China?

7. What aspects do you think the Chinese Government should improve to promote the CDM development?

8. How are the potential CDM projects identified?

9. Are most of the CDM project owners active in participating?

10. What is the major responsibility of CDM Service Centre?

11. What profits have been brought by implementing CDM projects?

12. How many provinces have their own CDM Service Centres?

13. Which province has done best regarding developing CDM projects so far?

14. Can you figure out the reasons

15. Do you think the Chinese Government has created a favourable investment and legal environment for developing CDM projects?

16. What do you think is the major reason leading to the low issuance rate? 
17. How do you think CDM projects will influence the sustainable development in China?

18. What aspects of the CDM do you think should be improved in an international context?

19. What opportunities as well as challenges do you think would be brought by the CDM to China?

20. Do you think the expiration of the first Kyoto Period would affect the development of CDM projects in China?

21. Do you think China should accept fixed emission target in the post-2012 period?

22. Have you ever thought about the tendencies of the CDM in the post-2012 period?

23. What do you think China should do to ultimately achieve clean development?

24. Any other comments about the CDM in China 


\section{Appendix Two}

\section{Written Survey on the Implementation and Development of CDM Projects in China - for CDM Participants}

The purpose of the study is to get the first hand information on CDM implementation in China through contacting CDM projects participants. Based on the results of this study, the current situation of the implementation of the CDM projects in China, including the existing barriers to the development of the CDM projects and the profits having been brought by the CDM projects would be studied and explored.

In order to achieve this aim, the survey is divided into five parts. Part one is about your personal information and experience concerning the CDM. Part two deals with the general questions about developing CDM projects in China. Part three focuses on the specific questions about implementing CDM projects in China. Part four is your opinions on the CDM and climate change issues in China. Part five is supplementary questions.

$\underline{\text { Part One: Personal Information and Experience concerning the CDM }}$

1. Do you belong to the:

A. CDM owner B. CERs buyer C. CDM broke D. CDM service agency

E. CDM related official F. Other, please specify:

2. Have you ever participated in a CDM project:
A. Yes
B. No

3. Are you going to participate or continue to participate in a CDM project:
A. Yes
B. No

4. When did your first hear about the CDM:
A. in 2004
B. in 2005
C. in 2006
D. in 2007
E. in 2008

5. How did you first know the CDM:
A. by government publicity and training
B. in trade conference

C. Others, please specify:

6. Do you quite understand CDM operational rules:
A. Yes
B. No

Part Two: General Questions about Developing CDM Projects in China 
1. How do you usually find the useful information about the CDM:

$\begin{array}{ll}\text { A. through CDM relate websites } & \text { B. through CDM training organized }\end{array}$ $\begin{array}{lll}\text { by local government } & \text { C. through consulting service agency } \quad D \text {. through }\end{array}$ collecting information by yourself $\quad$ E. Other, please specify:

2. How do you find the CDM sellers/buyers:
A. though the CDM-related websites
B. through CDM brokes

C. under government's help

D. Others, please specify:

3. What do you think is the biggest barrier to the implementation of the CDM projects in China:
A. the detailed and complex CDM operational rules
B. insufficient cooperation between CDM sellers and buyers
C. insufficient understanding and publicity of the CDM
D. the incomplete CDM supporting policies and laws
E. the lack of CDM experts
F. language barrier
G. Others, please specify:

4. Do you think the government has played a positive role in promoting the CDM in China:
A. Yes
B. No

5. What aspects do you think the Chinese Government should improve to promote the CDM development:
A. CDM experts training
B. publicity
C. regulating CDM service

industry D. the coordination of local governments E. potential projects identification F. Others, please specify:

6. What phase do you think bears the biggest risks in the process of developing a CDM project in China:
A. Project identification
B. Project preparation (PDD design)
C. Validation
D. Project operation
E. Verification
F. CER issuance
G. Others, please specify:

Part Three: Specific Questions about Implementing CDM Projects in China
A. Project Identification

1. Possible ways to identify the potential projects:
A. Government's guide
B. Project owner's positive participation

C. Involvement of CDM broke and service agencies

D. Others, please specify:

2. Do you think the CDM service industry plays an importance role in 
developing the CDM project in China:
A. Yes
B. No

3. Are you satisfied with the services provided by CDM service agencies:
A. Yes
B. No

4. What needs to be improved if not satisfactory: specify:
A. Lack of CDM specialists
B. Low work efficiency
C. Other, please

5. How is service fee charged:
A. Based on a certain rate of future CER profits
B. An agreed sum

C. Other, please specify:

6. When is the service fee charged:
A. Immediately after the service
B. After receiving the CERs proceeds

C. Other, please specify:

7. Do you need to pay for service if the project fails:
A. Yes
B. No

8. Which factor of implementing the CDM project is most likely to frustrate you to participate in it:
A. Big risks
B. The uncertainty about profits returns
C. Complex operational rules D. Time-consuming developing process E. Others, please specify:

9. What aspect do you think attracts you most to participate in:
A. Considerable investment and economic profit
B. Introduction of clean technology C. Others, please specify:

10. How do you get upfront fund to develop CDM project:
A. Through seller's investment
B. Through loaning from financial

institutions C. Others, please specify:

B. Project Preparation

1. Do you encounter any difficulties in preparing PDD:
A. Yes
B. No

2. How do you solve the difficulties:
A. resort to CDM service agency
B. resort to CDM service centre

C. Others, please specify: 
C. Submission to NDRC

1. How do you think NDRC's work efficiency of dealing with the proposed CDM project:
A. Very efficient
B. Efficient
C. Delays caused by overload

D. Other, please specify:

2. Do you think it is reasonable that the expert review plays a decisive role in the proposed project review:
A. Yes
B. No

D. Validation

1. How do you find the appropriate DOE:
A. through CDM-related websites
B. under the government's help

C. Other, please specify:

2. The major factor influencing you when choosing a DOE:
A. Reputation
B. Price
C. Whether it is convenient to communicate D. Other,s please specify:

3. Usually, how much is charged by DOE:
A. Based on a certain rate of future CER profits
B. An agreed sum

C. Other, please specify:

4. Do you need to pay DOE if the project fails:
A. Yes
B. No

5. Are you satisfied with the equality, work efficiency and quality aspects of the DOE:
A. Yes
B. No

6. What aspect do you think the DOE needs to improve:
A. Biased
B. Difficulty in communication
C. Lack of objective and unified "additionality" standard D. Other, please specify:

E. Project Implementation

1. Do you encounter any difficulties:
A. Yes
B. No

2. What problems are likely to occur:
A. Substantial changes to PDD
B. Force Majeure
D. Others, 
please specify:

F. CER Verification and Issuance

1. Whether the issued CERs are much less than the expected:
A. Yes
B. No

2. What main reason do you think leads to the low issuance rate:

A. Lack of objective and unified "additionality" standard

B. Situation changes in project implementation phase

$\mathrm{C}$ The DOE hired by CDM owner affects the objective of PDD

D. Other, please specify:

G. Contract Issues Involving CDM Implementation

1. Do you know Emission Reduction Purchase Agreement (ERPA) well:
A. Yes
B. No

2. Do you seek legal service when developing CDM projects:
A. Yes
B. No

3. Have you encountered any CDM related contract disputes:
A. Yes
B. No

4. How do you solve these contract disputes if any :
A. Negotiation
B. Arbitration
C. Litigation
D. Other, please specify:

\section{Part Four: Your Opinions on the CDM and Climate Change Policy in China}

1. How do you think the CDM would influence the sustainable development in China?

2. What aspects of the CDM do you think should be improved in an international context?

3. What opportunities as well as challenges do you think would be brought by the CDM to China?

4. Do you think the expiration of the first Kyoto period would affect the development of CDM projects in China?

5. Do you think China should accept a fixed emission target in the post-2012 period? 
6. Have you ever thought about the fate of the CDM in the post-2012 Period?

7. What do you think China should do to ultimately achieve clean development?

8. Any other comments about the CDM in China

Part Five: Supplementary Questions.

1. Do you want to disclose your name in my thesis or paper to be published in the future:
A. Yes
B. No

2. Do you want me to send you the outcome of my investigation via E-mail:
A. Yes
B. No

Thank you for your support and cooperation. For further discussion on the development and implementation of CDM projects in China, please contact me via winglet28@ hotmail.com. 


\section{Bibliography}

\section{Articles/Books/Reports}

Asthana, V, 'Climate Change in Asia' (Asian Development Bank 1995)

Alessandra Barreca, 'Carbon Market and Carbon Contracts for CERs Transactions' in Massimiliano Montini (ed), Developing CDM Projects in the Western Balkans Legal and Technical Compared (2010) 43

Agarwal, S, Pay or Get Paid for GHG (2008) Business \& Economy

<http://www.businessandeconomy.org/20032008/storyd.asp?sid=3098\&pageno=1> at 6 October 2008

Bachner, B, 'Regulating Pollution in the People's Republic of China: An Analysis of the Enforcement of Environmental Law' (1996) 7 Colorado Journal of International Environmental Law and Policy 373

Bodansky, Daniel, The Copenhagen Climate Change Accord (2010) The American Society of International Law Insight <http://www.asil.org/insights100212.cfm> at 3 March 2010

Boyd, E et al, 'The Clean Development: An assessment of current practice and future approach for policy' (Working Paper 114, Tyndall Center for Climate Change Research 2007)

Boyd, Emily et al, 'Reforming the CDM for Sustainable Development: Lessons Learned and Policy Futures' (2009) 12(7) Environmental Science \& Policy 820

Biermann, F, "'Common Concern of Humankind": The Emergence of a New Concept of International Environmental Law' (1996) 34 Archiv des Völkerrechts 426

Brody, J, India Joins the Race for Carbon Credit Investment (2008) Green Beat

$<$ http://green.venturebeat.com/2008/07/23/india-joins-the-race-for-carbon-credit-inves tment/> at 6 October 2008

Baumert K A, Kete, N, and Figueres, C, 'Designing the Clean Development Mechanism to Meet the Needs of a Broad Range of Interests' (World Resources Institute, Climate Notes, 2000)

Beck, Lindsay, 'China Emission-Cutting Fund to Reap up to $\$ 3$ bln', Reuters (Beijing), 9 November 2007 <http://www.reuters.com/article/idUSPEK28505> at 4 March 2008 
Bacon, R.W. and Bhattacharya, S., 'Growth and $\mathrm{CO}_{2}$ Emissions - How do different countries fare?' (World Bank Environment Department 2007)

Bianchi, Stefania, 'Environment-EU: Carbon Trading Scheme Challenged', Inter Press Service News Agency (Brussels), 15 May 2006

$<$ http://ipsnews.net/news.asp?idnews=33233> at 8 August 2008

Baumert, T. Herzog and Pershing, J., 'Navigating the Numbers: Greenhouse Data and International Climate Policy’ (World Resources Institute, Washington DC 2005)

'Backgrounder: Three major stances in Copenhagen climate change negotiations' Xinhua (Beijing), 9 December 2009

<http://www.chinataiwan.org/english/specialreports/sr/Climate/267/43/200912/t20091 209_1168909.htm> at 12 December 2009

Carr, C and Po Environmental Law Jo sembuj Flavia, 'Flexible Mechanisms for Climate Change Compliance: Emission offset purchase under the Clean Development Mechanism' (2008) 16 New York University Environmental Law Journal 44

Cooper, D E, 'The Kyoto Protocol and China: Global Warming's Sleeping Giant' (1999) 11 Georgetown International Environmental Law Review 401

Capoor, K and Ambrosi, P, 'State and Trends of the Carbon Market 2007' (The World Bank 2007)

Capoor, K and Ambrosi, P, 'State and Trends of the Carbon Market 2008' (The World Bank 2008)

Capoor, K and Ambrosi, P, 'State and Trends of the Carbon Market 2009' (The World Bank 2009)

Chertow, M. and D.Esty (ed), Thinking Ecologically: The Next Generation of Environmental Policy (1997).

Cao, Mingde, 'The Current and Future Trends in Chinese Environmental and Energy Law and Policy' (2006) 18(1) Pace International Law Review 253

Castro, $\mathrm{P}$ and Michaelowa, A, 'Opinions of project developers regarding performance of CDM projects ' (Institute of Political Science, University of Zurich, 2007)

Castro, P, 'Empirical Analysis of Performance of CDM Project Case Study China' (Discussion paper CDM-6, Institute of Political Science, 2008)

Cheng, Q, 'A Portrait of China's Climate Policy’ (Discussion paper, German Watch, 
Cotterrell, R, Law as an Instrument of Social Change ( $2^{\text {nd }}$ ed, 1992)

Chandler, $\mathrm{W}$ et al, 'Climate change mitigation in developing countries: Brazil, China, India, Mexico, South Africa, and Turkey' ( Prepared for Pew Centre on Global Climate Change, 2002)

Chen, $\mathrm{Y}$ et al, 'Assessment of Climate and Environment Changes in China (II): Impacts, adaptation and mitigation of climate and environment changes' (2006) 2(1) Advances in Climate Change Research

China's New Five-Year Plan Gives Priority to Environment (2001) China Council for International Cooperation and Environment

<http://www.harbour.sfu.ca/dlam/newsletters/0103.html> at 26 May 2008

'China Human Development Report 2002' (Stockholm Environment Institute and United Nations Development Programme, 2002)

'China to Have 140 Million Cars by 2020', China Daily (Beijing), 5 September 2004

Clean Energy Changes Life of People in Remote Regions (2005) China's Agenda 21 <http://english.acca21.org.cn/acca21/news/news20051125_1.htm> at 11 December 2008

‘CDM-Market Brief- India’ (DEG KFW BANKENGRUPPE, 2006)

China Moves to Tackle Pollution Effects on Health (2007) People <http://scitech.people.com.cn/GB/6605794.html> at 11 November 2008

'China Launches CDM Fund to Address Climate Change', Beijing, 9 November 2007, Xinhua Net <http://news.xinhuanet.com/english/2007-11/09/content_7039202.htm> at 20 December 2008

Chinese Enterprisers' Understanding about the CDM (Trans of [中国企业对 CDM 的 理解]) Clean Development in China

<http://cdm.ccchina.gov.cn/web/NewsInfo.asp?NewsId=41> at 30 July 2009

'China's Parliament Meets to Hear gov't Reshuffle Plan', Xinhua (Beijing), 11 March 2008

<http://english.chinamil.com.cn/site2/special-reports/2008-03/12/content_1160416.ht $\mathrm{m}>$ at 12 March 2008

China can Achieve Low Carbon Growth (2009) Economic \& Social Research Council <http://www.esrc.ac.uk/ESRCInfoCentre/PO/releases/2009/april/china.aspx> at 3 
March 2010

Davidson, O, 'CDM and Technology Transfer: African Perspective' (Point de Vue 2001)

Esty, D C and Ivanova, M, 'Globalization and Environmental Protection-A Global Governance Perspective' (Working Paper No.0402, Yale Center for Environmental Law and Policy, 2004)

Ellis, J and Kamel, S, 'Overcoming Barriers to Clean Development Mechanism Projects' (Organization for Economic Cooperation and Development and UNEP Ris $\varnothing$ Centre, 2007)

Epstein, R, 'Stern Report warns of huge costs of climate change', $A B C$, (London), 30 October 2006 <http://www.abc.net.au/am/content/2006/s1776326.htm> 2 July 2007

Field, B C, Environmental Economics: An Introduction (2 ${ }^{\text {nd }}$ ed, 1997)

Figueres, C, 'Sectoral CDM: Opening the CDM to the yet Unrealized Goal of Sustainable Development' (2006) 2(1) International Journal of Sustainable Development Law \& Policy 5

Fry, C, The Impact of Climate Change: The World's Greatest Challenge in the Twenty-first Century (2009)

Freestone, D, 'Introduction: The UN Framework Convention on Climate Change, the Kyoto Protocol and the Kyoto Mechanisms' in David Freestone and Charlotte Streck (ed), Legal Aspects of Implementing the Kyoto Protocol Mechanisms: Making Kyoto Work (2005)

Freestone, D and Streck, C (ed), Legal Aspects of Implementing the Kyoto Protocol Mechanisms: Making Kyoto Work (2005)

Ferguson, H M, Australia's Energy Security and the Clean Energy Challenge (2008) Minister for Resources and Energy

<http://minister.ret.gov.au/TheHonMartinFergusonMP/Pages/Australia'sEnergySecuri tyandtheCleanEnergyChallenge.aspx.html> at 3 March 2009

Fu, J, 'Energy Law Aims at Power Conservation', China Daily (Beijing), 2 July 2006

Godoy, J, A Development Mechanism: That Cleans Little (2009) Inter Press Service $<$ http://www.climateark.org/shared/reader/welcome.aspx ?linkid=121783\&keybold=K yoto> at 3 March 2009

Guruswamy, L D, 'Sustainable Development and Smart Energy: A New Framework: 
Post Kyoto Energy and Environmental Security' (2005) 16 Colorado Journal of International Environmental Law and Policy 333

Hagen, C and Holtsmark, B, 'Does the Clean Development Have a Viable Future?' (Discussion Papers Number 577, Statistics Norway, Research Development 2009)

Humphreys, S, Sokona, Y and Thomas, J P, Equity in the CDM (1998) Linkages Journal <http://www.iisd.ca/journal/enda.html> at 10 October 2009

'Heavy Polluters to be Restricted from Listing', China Daily (Beijing), 25 February 2008

Huang, Yiqun, Assessing and Managing Regulatory Risk in China's CDM Market (Master of thesis, Oxford University, 2007)

IPCC 1990 Report, Summary for Policymakers

IPCC, 2007: Summary for Policymakers. In: Climate Change 2007: The Physical Science Basis. Contribution of Working Group I to the Fourth Assessment Report of the Intergovernmental Panel on Climate Change, 5

IPCC, 2007: Summary for Policymakers. In: Climate Change 2007: Impacts, Adaptation and Vulnerability. Contribution of Working Group II to the Fourth Assessment Report of the Intergovernmental Panel on Climate Change, 7

International Energy Agency, 'World Energy Outlook 2004' (2004)

International Energy Agency, $\mathrm{CO}_{2}$ Emissions from Fuel Combustion 1971-2002 (2004 Edition)

International Energy Agency, What are the Consequences of India Sustaining Its Rapid Energy Growth over the Next Two-and-a-half Decades? (World Energy Outlook 2007: Fact Sheet India)

Institute for Global Environmental Strategies and Chinese Renewable Energy Industries Association (ed), CDM Country Guide for China ( $1^{\text {st }}$ edition ed, 2005)

International Center for Trade and Sustainable Development, 'Climate Change, Technology Transfer and Intellectual Property Rights' (2008)

'India's Climate Change is Better than China's', The Times of India (New Delhi), 30 July 2008

Kim, $\mathrm{M}$ and Jones, R E., 'China: Climate Change superpower and the Clean 
Technology Revolution' (2008) 22(3) Natural Resources \& Environment 9

Koch, T, 'Proposals for Further Development of Chinese CDM Rules' (International Capacity Building, p.p. InweNT gGmbH 2005)

Kumar, V. S, et al., 'Coastal processes along the Indian coastline' (2006) 91 (4) Current Science 530

Lies, E, Japan Emissions to Rise, Reaching Kyoto Goals Hard (2007) Reuters

< http://www.reuters.com/article/idUST285136> at 15 August 2009

Le Treut, $\mathrm{H}$ et al, 2007: Historical Overview of Climate Change. In: Climate Change 2007: The Physical Science Basis. Contribution of Working Group I to the Fourth Assessment Report of the Intergovernmental Panel on Climate Change, 94

Lay, J, Why the Key to Carbon Trading is to Keep it Simple (2006) Financial Times <http://www.johnkay.com/in_action/441> at 5 February 2010

Li, Taige, China Moves to Tackle Pollution Effects on Health, (26 November 2007) <http://www.scidev.net/en/news/china-moves-to-tackle-pollution-effects-on-health.ht $\mathrm{ml}>$ at 11 November 2008

Lieberthal, K and Sandalow, D, 'Overcoming Obstacles to U.S.-China Cooperation on Climate Change' (John Thornton China Center Monograph Series Number 1, 2009)

Liu, Liguang, Clean Development Mechanism in China: Seeking Synergies to Achieve Sustainable Development (Master Thesis, Roskilde University, 2006)

Li, Ling, 'China Releases First National Report on Climate Change', Worldwatch Institute (Washington DC), 11 January 2007

<http://www.worldwatch.org/node/4848> at 4 March 2008

Lu, X D and Liu, D S, Clean Development Mechanism in China: Taking a Proactive and Sustainable Approach ( $2^{\text {nd }}$ ed, 2004)

'Legislators to Deliberate Draft on Climate Change', China Daily (Beijing), 25 August 2009

<http://www.chinadaily.com.cn/china/2009-08/25/content_8614750.htm> at 12 December 2009

Moore, F C, Carbon Dioxide Emissions Accelerating Rapidly (Earth Policy Institute, 2008)

Murthy, N.S. Panda, $\mathrm{M}$ and Parikh, K, ' $\mathrm{CO}_{2}$ Emissions Reduction Strategies and 
Economic Development of India' (Indira Gandhi Institute of Development Research 2006)

Mishra, R K, India, Home to One Third of the World's Poor (2008) Ground Report <http://www.groundreport.com/World/India-the-home-of-world-s-one-third-poor_1/2 $868168>$ at 9 September 2008

'New Five-Year Plan Gives Priority to Environmental Protection', People's Daily, Beijing, 13 March, 2001

<http://english.people.com.cn/200103/13/eng20010313_64836.html> at 26 May 2008

Netherlands Environmental Assessment Agency, 'Chinese $\mathrm{CO}_{2}$ Emissions in Perspective' (2007)

Olive, Hongyan H. et al, 'China's Fuel Economy Standards for Passenger Vehicles' (Discussion Paper 2009-03, Harvard Kennedy School, 2009)

Oslen, K H, 'The Clean Development Mechanism's Contribution to Sustainable Development: A review of the literature' (Publication, Capacity Development for the Clean Development Mechanism, 2006)

Olmstead, Sheila and Stavins, Robert N., 'A Meaningful Second Commitment Period for the Kyoto Protocol' (2007) 4(3) The Economists'Voice 28

Oster, Shai, 'China Expand Markets for Carbon Trading', The Wall Street Journal (The US), 11 November 2008

Pearson, B, 'Market Failure: Why the Clean Development Mechanism Won't Promote Clean Development' (2007) 15(2) Journal of Cleaner Production 247

Pan, J, 'Roadmap to Post-Kyoto Climate Agreements' (2006) 2 Advances in Climate Change 22

Paterson, M, Global Warming and Global Politics (1 ${ }^{\text {st }}$ ed, 1996)

Pacala, S and Socolow, R, 'Stabilization Wedges: Solving the Climate Problem for the Next 50 Years with Current Technologies’ (2004) 13 Science, 968

Perlot, W, 'Post-Kyoto and the Position of the European Union' (Briefing papers, Clingendael International Energy Programme, 2005)

Qin, D et al, 'Assessment of Climate and Environment Changes in China (I): Climate and environment changes in China and their projections' (2006) 2(1) Advances in Climate Change Research 
Richerzhagen, Carmen and Scholz, Imme, 'China's Capacities for Mitigating Climate Change' (Discuss Paper, German Development Institute 2007)

Raupach, M, 'CO2 Emissions Increasing Faster than Expected' (Working Paper No 07/89, CSIRO Marine and Atmospheric Research and the Global Carbon Project, 2007)

Sari, A P. and Meyers, S, Clean Development Mechanism: Perspective from Developing Countries (1999)

Shui, Bin and Harriss Robert C., 'The Role of $\mathrm{CO}_{2}$ Embodiment in US-China Trade' (2006) 34(18) Energy Policy , 4063

Sunstein, Cass R, 'The World vs. United States and China? The Complex Climate Change Incentives of the Leading Greenhouse Gas Emitters' (2008) 55(6) UCLA Law Review 1675

Smith, K, “Clean development” supports dirty energy' (2008) <http://www.carbontradewatch .org.> at 7 November 2008

Schneider, L, 'Is the CDM fulfilling its environmental and sustainable development objectives? An evaluation of the CDM and options for improvement' (Report prepared for WWF, Öko-Institut, 2007)

Schwartz, J, 'The Impact of State Capacity on Enforcement of Environmental Policies: The Case of China' (2003)12 The Journal of Environment\& Development 50

Sinton, J E. et al 'Evaluation of China's Energy Strategy Options' (The China's Sustainable Energy Program, 2005)

Singhania, J, 'Experiences with the Clean Development Mechanism in India' in David Freestone and Charlotte Streck (ed), Legal Aspects of Implementing the Kyoto Protocol Mechanisms: Making Kyoto Work (2005) 341

Sautter, John A, 'The Clean Development Mechanism in China: assessing the tension between development and curbing anthropogenic climate change' (2009) 27(1) Virginia Environmental Law Journal 91

Sepibus, J.de, 'The Environmental Integrity of the CDM Mechanism - A legal Analysis of its Institutional and Procedural Shortcomings' (Working Paper No 2009/24, Swiss National Centre of Competence in Research, 2009)

Schneidera, Malte, Holzerb, Andreas and Hoffmanna, Volker H, 'Understanding the CDM's Contribution to Technology Transfer' (2008) 36(8) Energy Policy 2930 
Stern, N, 'Stern Review on the Economics of Climate Change' (British government, 2006)

Stewart, $\mathrm{R}$ et al., The Clean Development Mechanism: Building International Public-Private Partnerships under the Kyoto Protocol, UNCTAD/GDS/GFSB/Misc.7/ 21 (1999)

Seres, S and Haites, E, ‘Analysis of Technology Transfer in CDM Projects' (Prepared for the UNFCCC Registration \& Issuance Unit CDM/SDM 2007)

Solomon, S et al (ed), Climate Change 2007: The Physical Science Basis (2007)

Sirohi, S, "CDM: Is it a "win-win" strategy for rural poverty alleviation in India Published' (2007) 84 (1) Climate Change 91

Saran, S, Climate Change - From Back Room to Board Room - What Indian Business Needs to Know about India's Approach to Multilateral Negotiations on Climate Change (2008)

Szymanski, T, 'The Clean Development Mechanism in China' (2002) November-December The China Business Review 26

Sugiyama, T, Yamaguchi, K and Yamagata Hiroshi, 'CDM in the Post Kyoto Regime: Incentive mechanism for developing countries to promote energy conservation and renewable energies' (Workshop Paper, 2005)

Stern, T and Antholis, W, 'A Changing Climate: The Road Ahead for the United States' (2008)Winter 2007-2008 The Washington Quarterly, 175

Sanusi, Z A, 'Technology Transfer under Multilateral Environmental Agreements: Analyzing the Synergies' (Working Paper No. 134, UNU-IAS, 2005)

The 30 Years' Development of Environmental Protection in China (2008) People <http://politics.people.com.cn/GB/1026/6978808.html> at 10 October 2008

Tianjin Climate Exchange Launch Carbon Contract (2009) China Tells <http://blog.chinatells.com/2009/09/1976> at 12 December 2009

Unnikrishnan, A.S. and Shankar, D., 'Area Sea Level trends along the North India Ocean Coasts Consistent with global estimates?' (2007) 57, 301 Global and Planetary Change 5

UNCTAD, World Investment Report 1999: Foreign Direct Investment and the 
Challenge of Development (1999), Annex Table A.I.I

Unep Ris $\varnothing$ Centre on Energy, Climate and Sustainable Development and Ris $\varnothing$ National Laboratory, 'Legal Issues Guidebook to the Clean Development Mechanism' (The UNEP project CD4CDM, 2004)

United Nation, United Nations UN Breakthrough on Climate Change Reached in Bali (2007), press release.

Vennemo, H, et al, 'Domestic Environmental Benefits of China's Energy-related CDM Potential' (2006) 75(1-2) Climate Change 215

Vandenbergh, Michael P, 'Climate change: the China Problem' (2008) 81(5) Southern California Law 905

Xin, Z, ' Green Fund to Help Cut Emissions', China Daily (Beijing), 10 November 200710.

Wiener, A, India steps up and pledges emissions targets (2009) UN Dispatch <http://www.undispatch.com/india-steps-and-pledges-emissions-targets> at 12 December 2009

Werksman, J, 'The Clean Development Mechanism: Unwrapping the "Kyoto Surprise", (1998) 7(2) Review of European Community and International Environmental Law 147

Wiener, Jonathan B, 'Climate Change Policy and the Policy Change in China' (2008) 55(6) UCLA Law 1805

Watkins, K et al, Human Development Report of 2007/08: Fighting climate change: Human solidarity in a divided world, United Nations Development Programme (UNDP) Report (2007)

Wara, M W. and Victor, D G, 'A Realistic Policy on International Carbon Offset' (Program on Energy and Sustainable Development Working Paper No 74, Stanford University, 2008)

Wara, Michael, 'Measuring the Clean Development Mechanism's Performance and Potential' (2008) 55 UCLA Law Review 1759

Wang, M, 'Supervision of Clean Development Projects in China-Illusory Rules of Law and Real Government Intervention'(2008) 11 (1\&2) Asia Pacific Journal of Environmental Law 121

Wolpert, S, A New History of India $\left(6^{\text {th }}\right.$ ed, 2000) 
Weart, S, The discovery of Global Warming (2009) American Institute of Physics <http://www.aip.org/history/climate/co2.htm> at 10 October 2009

Wu, Z, Analysis on the Administrative Legal Relationships Involved in the CDM (2007) [ trans of : 清洁发展机制中的行政法律关系评析]

Xin, Zhiming, 'Green Fund to Help Cut Emissions', China Daily (Beijing), 10 November 2007

Yamin, F, 'Operational and Institutional Challenges' in Jose Goldemberg (ed) Issues and Options: The Clean Development Mechanism (1998) 53

Yang, V, 'Punishing for environmental protection?-Enforcement Issues in China' (1995) 44(3) International \& Comparative Law Quarterly 671

Zasloff, Jonathan, 'The Judicial Carbon Tax: Reconstructing Public Nuisance and Climate Change' (2008) 55 UCLA Law Review 1827

Zhang, Jianyu, ‘Approaching Circular Economy', China Daily (Beijing), 1 October 2004 <http://www.chinadaily.com.cn/english/doc/2004-10/01/content_379348.htm>

Zhang, Z, 'Towards an Effective Implementation of Clean Development Mechanism Projects in China' (Working Paper No 61, East-West Centre, 2004)

\section{Legislation and Domestic Documents}

\section{The People's Republic of China}

Law of the People's Republic of China on Chinese-Foreign Equity Joint Ventures 1979 (amended in 2001)

Constitution of the People's Republic of China 1982 (last amended in 2004)

Law of the People's Republic of China on Foreign-Funded Enterprises 1986 (amended in 2000)

Law of the People's Republic of China on Chinese-Foreign Contractual Joint Ventures 1988 (amended in 2000)

Environmental Protection Law of the People's Republic of China 1989

Electricity Law of the People's Republic of China 1996 
Law of the People's Republic of China on the Coal Industry 1996

Energy Conservation Law of the People's Republic of China 1997 (amended in 2007)

Cleaner Production Promotion Law of the People's Republic of China 2002

Measures for the Operation and Management of CDM projects in China 2005

Renewable Energy Law of the People's Republic of China 2005

Circular Economy Law of the People's Republic of China 2008

Property Law of the People's Republic of China 2007

Emission Standard of Coalbed Methane/Coal Mine Gas (on trial) 2008

Law of the People's Republic of China on Enterprise Income Tax 2008

Implementing Regulations of Law of the People's Republic of China on Enterprise Income Tax 2008

China’s Agenda 211994

Circular of the State Council on Adjustment of Imported Equipment Taxation Policies 1997

Medium- and Long- Term Energy Conservation Plan 2004

National Assessment Report on Climate Change 2006

Important Declaration of Standardization of Consulting Service and Appraisal Work for CDM Projects in China 2006

China Environmental Quality Communiques - Air Quality 2006

China’s Eleventh-Five Year Plan (2006-2010)

China's National Climate Change Programme 2007

Initial National Communication on Climate Change of the People's Republic of China 2007

China's Scientific and Technological Actions on Climate Change 2007 
China's Energy Conditions and Policies 2007

Medium- and Long- Term Plan on the Development of Renewable Energy 2007

National Technology Transfer Promotion Regulations 2007

Policies and Actions on Addressing Climate Change (White Paper) 2008

Blue paper issued by the Chinese Academy of Social Sciences (CASS) on 1 March 2009

Climate Change Resolution 2009

\section{The United State of America}

American Clean Energy and Security Act 2009 (ACES)

\section{$\underline{\text { The European Union }}$}

'Winning the battle against global climate change' (European Commission, 2005)

\section{India}

Water (Prevention \& Control of Pollution) Act 1974 (Act No 6 of 1974)

Forest Conservation Act 1980

Air (Prevention \& Control of Pollution) Act 1981 (Act No 14 of 1981)

Energy Conservation Act 2001

Electricity Act 2003

Petroleum \& Natural Gas Regulatory Board Act 2006

Energy Conservation Building Code 2007

Tariff Policy 2003

New and Renewable Energy Policy 2005

National Environment Policy 2006

Notification on Environment Impact Assessment 2006 
Integrated Energy Policy 2006

National Action Plan on Climate Change 2008

Eleventh Five-Year Plan (2007-2012)

\section{Treaties and International Documents}

Agreement on Trade-Related Aspects of Intellectual Property Rights, Annex 1C of the Marrakesh Agreement Establishing the World Trade Organization, signed on 15 April 1994

Adaptation Fund Draft, Decision -/CMP.3 (2007)

$<$ http://unfccc.int/files/meetings/cop_13/application/pdf/cmp_af.pdf> at 11 March 2008

Declaration on the Right to Development, $97^{\text {th }}$ plen $\mathrm{mtg}$, UN Doc A/Res/41/128 (1986)

Further Guidance Relating to the Clean Development Mechanism, UN Doc FCCC/KP/CMP/2005/8/Add.1 (2005)

Decision -/CMP.3, Further Guidance relating to the Clean Development Mechanism, UN Doc FCCC/KP/CMP/2007/3 (2007)

Further Guidance Relating to the Clean Development Mechanism, UN Doc FCCC/KP/CMP/2009/16 (2009)

Kyoto Protocol, opened for signature 11 December 1997 (entered into force 16 February 2005)

Marrakesh Accords, UN Doc FCCC/CP/2001/13/Add.2 (2002)

The Marrakesh Accords and the Marrakesh Declaration

<unfccc.int/cop7/documents/accords_draft.pdf> at 9 November 2008

Decision 17/CP.7, Modalities and Procedures for a Clean Development Mechanism as defined in Article 12 of the Kyoto Protocol

$<151.1 .187 .213 /$ Assets/8/20040506100129_10-3-36-111.pdf $>$ at 8 July 2008

The negotiating text by the Chairman (NTC) (FCCC/AGBM/1997/3/Add.1 and Corr.1), dated 21 April 1997 
Paris Convention for the Protection of Industrial Property, signed on 20 March 1883 (last amended on September 28 1979)

Protection of the Global Climate for Present and Future Generations of Mankind, GA Res 43/53, $70^{\text {th }}$ plen mtg, UN Doc A/Re/42/53 (1988)

Rio Declaration on Environment and Development (Report of the United Nations Conference on the Human Environment, Stockholm, 5-16 June 1972)

Reducing Emissions from Deforestation in Developing Countries: Approaches to Stimulate Action, Decision -/CP.13 (2007)

<http://unfccc.int/files/meetings/cop_13/application/pdf/cp_redd.pdf> at 11 March 2008

Report of the Conference of the Parties on its First Session, FCCC/CP/1995/7/Add.1 (1995) <http://www.inecc.net/policy-issues/international/Berlin\%20Mandate.pdf> at 7 July 2007

Report of the Conference of the Parties serving as the meeting of the Parties to the Kyoto Protocol, $1^{\text {st }}$ sess, 7-8, UN Doc FCCC/KP/CMP/2005/8/Add.1 (2005)

$<$ http://cdm.unfccc.int/Reference/COPMOP/08a01.pdf\#page=15> at 10 October, 2009

Sydney APEC Leader's Declaration on Climate Change, Energy Security and Clean Development (2007)

Transnational Review Mechanism Pursuant to Paragraph 8 of the Protocol on the Accession of the People's Republic of China, WTO Doc G/TRIMS/W/60 (2008) (Request to the Delegation of the European Communities - Communication from the European Communities)

United Nations Framework Convention on Climate Change, opened for signature 12 June 1992 (entered into force 21 March 1994)

Convention and the Treaty on Intellectual Property in Respect of Integrated Circuits, opened for signature 26 May 1989

Patent Cooperation Treaty, opened for signature 19 June 1970

Funding Adaptation in Developing Countries, UN Doc FCCC/TP/2008/6 (2008) <unfccc.int/resource/docs/2008/tp/06.pdf> at 11 July 2008

Decision -/CP.15, Copenhagen Accord (2009)

<unfccc.int/resource/docs/2009/cop15/eng/107.pdf> at 3 March 2010

Modalities and procedures for a clean development mechanism as defined in Article 
Transnational Review Mechanism Pursuant to Paragraph 8 of the Protocol on the Accession of the People's Republic of China, WTO Doc G/TRIMS/W/60 (2008) (4) (Request to the Delegation of the European Communities - Communication from the European Communities)

Report of the World Commission on Environment and Development: Our Common Future (1987)

\section{Other Sources}

\section{Internet Resources}

United Nations Framework Convention on Climate Change

$<$ http://unfccc.int/2860.php>

American Institute of Physics

<http://www.aip.org/history/climate/co2.htm>

Nature Conservancy

Climate Change Impacts: Rising Seas

<http://www.nature.org/initiatives/climatechange/issues/art19621.html>

Central Intelligence Agency

The World Factbook

<https://www.cia.gov/library/publications/the-world-factbook/geos/ch.html>

A China Information Base

$<$ http://www.chinatoday.com>

China's National Statistics Bureau

< http://www.stats.gov.cn/english/>

Chinabilty

<http://www.chinability.com>

International Energy Agency

$<$ http://www.iea.org >

Clean Development Mechanism in China

<http://cdm.ccchina.gov.cn/english/ItemList.asp> 
National Development and Reform Commission

$<$ http://en.ndrc.gov.cn>

G8 Summit 2007

<http://www.g-8.de/Webs/G8/EN/G8Summit/g8-summit.html>

Asia-pacific Economic Cooperation

$<$ http://www.apec.org/>

Asia-Pacific Partnership on Clean Development and Climate

$<$ http://www.asiapacificpartnership.org/english/default.aspx >

Global Economic Research

$<$ http://www.tradingeconomics.com/>

Ministry of Commerce People's Republic of China

$<$ http://english.mofcom.gov.cn>

Official India Government Website

$<$ http://india.gov.in>

Wikipedia

$<$ http://en.wikipedia.org>

Ministry of Home Affairs of Government of India

$<$ http://www.censusindia.net/>

India National CDM Authority

$<$ http://cdmindia.nic.in/>

The World Bank

<http://web.worldbank.org/ >

European Commission Trade

$<$ http://ec.europa.eu/trade/>

Telegraph

<http://www.telegraph.co.uk>

Nord Pool

<http://www.nordpoolspot.com/>

United Nations

<http://www.un.org/geninfo/bp/envirp2.html> 
China.org

<http://www.china.org.cn>

Cleaner Product in China

$<$ http://www.chinacp.org.cn/eng/>

\section{Speeches and Conferences}

Estrada-Oyuela, R, 'Remarks on From Kyoto to Buenos Aires: Technology Transfer and Emissions Trading' (Speech delivered at a conference held at Columbia University, New York, 24 April 1998)

David Victor, 'Life after Kyoto' (Speech delivered at the UCLA International Institute, Los Angeles, 1 February 2001)

A news conference held by the Information Office of Shanghai Municipal Government on February 72007

China State Council Press Conference about the release of the Medium- and LongTerm Plan on the Development of Renewable Energy, Beijing, September 42007

Yukio Hatoyama, 'Statement by H.E. DR. Yukio Hatoyama Prime Minister of Japan at the United Nations Summit on Climate Change' (New York, 22 September 2009) 